University of San Diego

Digital USD

2004-08-01

\title{
Finding Meaning by Participating in Decisions Affecting Us, Our Work and Our Lives: Lessons Learned at Mondragón
}

David Herrera EdD

University of San Diego

Follow this and additional works at: https://digital.sandiego.edu/dissertations

Part of the Leadership Studies Commons

\section{Digital USD Citation}

Herrera, David EdD, "Finding Meaning by Participating in Decisions Affecting Us, Our Work and Our Lives: Lessons Learned at Mondragón" (2004). Dissertations. 731.

https://digital.sandiego.edu/dissertations/731

This Dissertation: Open Access is brought to you for free and open access by the Theses and Dissertations at Digital USD. It has been accepted for inclusion in Dissertations by an authorized administrator of Digital USD. For more information, please contact digital@sandiego.edu. 


\title{
FINDING MEANING BY PARTICIPATING IN DECISIONS AFFECTING US, OUR WORK AND OUR LIVES: LESSONS LEARNED AT MONDRAGON
}

by

\section{DAVID HERRERA}

\author{
A dissertation submitted in partial fulfillment \\ of the requirements for the degree of \\ Doctor of Education \\ University of San Diego
}

\author{
August 2004 \\ Dissertation Committee \\ Paula A. Cordeiro, Ed.D., Chair \\ Kathleen M. Collins, Ph.D. \\ Cheryl Getz, Ed.D.
}


- Copyright by David Herrera 2004

All Rights Reserved 


\begin{abstract}
There has been a growing interest in exploring participatory organizational models for the last fifty years, accentuated by the recent corporate scandals that revealed the inadequacies of non-participatory organizational systems. Research studies have focused on organizational structures, policies and practices that make participation possible but it is persons who make participation happen. The purpose of this study was therefore to explore the significance of participation by examining the question: What does the experience of partaking in decision making mean to persons who engage in it.

This research is a phenomenological-heuristic study. Phenomenology explores the lived experience of participating in decision making. Heuristic inquiry includes the researcher's experience in the study. Data collection consisted mostly of two in-depth dialogic interviews with each of eight respondents from the Mondragón Corporación Cooperativa (Spain), selected because of their extensive experience as protagonists in an organization that promotes broad participation.

Research data were analyzed by identifying the meanings respondents attributed to the experience of participating in decision making and by using narrative analysis for their work and life experiences. Three feedback cycles from respondents were included in writing the final text. Since this research is intended for the general reader, its contents were represented as dialogic narratives throughout and tools from the "narrative nonfiction" genre were used to express meanings and personal experiences.

The study describes fifteen interdependent outcomes: nine personal stories and six common themes. It also includes a synthesis, as well as personal and leadership implications.
\end{abstract}


This research work intends to enhance the knowledge of participation in decision making by exploring the potential to deepen the meaning of partaking in decisions affecting each person in his or her work and life. It also aims to explore a methodology that facilitates the expression of meanings and lived experiences and makes research studies more accessible to the general reader. 
To my beloved wife Cherie 


\section{ACKNOWLEDGEMENTS}

This work became a reality with the support of many people. I am deeply grateful to my collaborators in Mondragón who opened their minds and hearts to reveal personal details of their lives and experiences, reviewed this research study at three different stages, and corroborated that my interpretation of the study had resonance with their experience.

I express my gratitude to my committee members, Dr. Paula Cordeiro, Dr Kathleen Collins and Dr. Cheryl Getz, who provided me with enthusiastic support and constructive criticism at different stages of this project. I am particularly indebted to Dr. Cordeiro, who guided and encouraged me through the circuitous paths of writing this dissertation as a book. Along with her sensitivity, attentive listening and reading and re-reading sections of my project, she often suggested creative ways to express what I needed to write. Her continuous enthusiasm and flexibility were crucial to accomplishing what I set out to do: write a research study accessible to the general reader.

I am deeply grateful for the fervent support from my family, who found ways to make my dissertation writing process into a participatory affair. Our children Cristina, Daniel, his fiancée Franki, and my parents-in-law helped me with their commentaries, critiques, proofreading of the texts, preparation of my presentation charts and a continued interest in discussing my often-unorthodox approaches to write my dissertation project. I am most profoundly grateful to my wife Cherie, who participated in most aspects of my dissertation, discussing my evolving ideas, offering new insights, proofreading the final text, and especially providing space and time for almost two years to write my dissertation uninterrupted by our usually busy lives. In addition, her patience with my physical and mental absence during long writing bouts, days and nights, weeks on end, was invaluable to complete my dissertation.

I thank all my friends and teachers who shared their warmth, interest and expertise with me. Likewise, I appreciate the wisdom and knowledge that people from so many walks of life, spiritual traditions, cultures and countries have shared with me throughout my life journey, either personally or through their writings. I could not have integrated so many diverse pieces of my life into this dissertation without the inspiration drawn from them. I know I could not be who I am today if they had not touched and influenced me along the way.

Most importantly, I thank God, who has blessed me abundantly with His/Her gifts that make everything possible. 
ACKNOWLEDGMENTS ........................................................................ vii

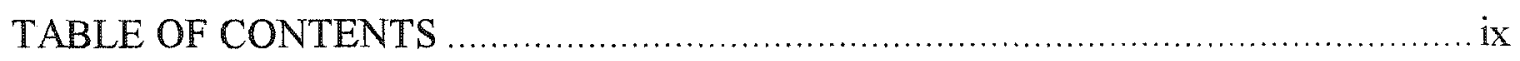

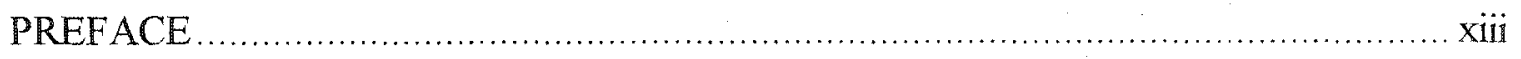

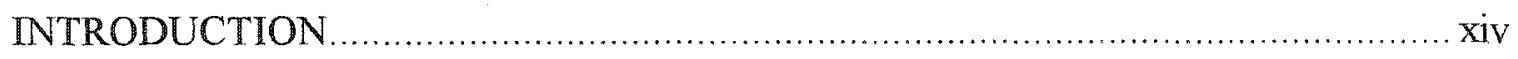

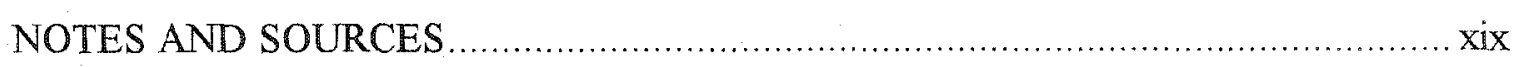

\section{PART I}

THE EXPERIENCE OF PARTICIPATING IN DECISION MAKING ...................... 1

CHAPTER 1

WHY IS OUR PARTICIPATION IN DECISION MAKING IMPORTANT? .............. 2

Rationale for the Study of Participation................................................. 3

Why Study Participation at Mondragón? ............................................... 7

A Meeting with Damian and Kurtis Two Weeks Before My Trip ................... 10

CHAPTER 2

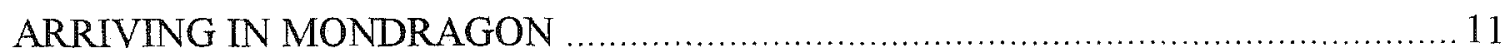

CHAPTER 3

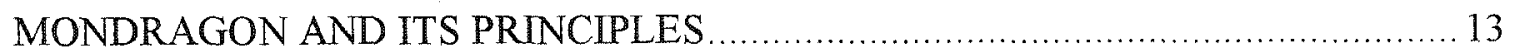

CHAPTER 4

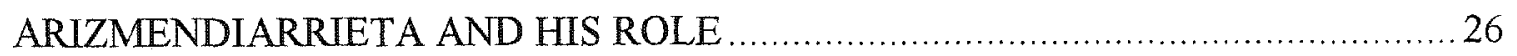

CHAPTER 5

VOICES FROM MONDRAGON - A POETIC TRANSCRIPTION ...................... 44

CHAPTER 6

THE CHIQUITEO GROUP ENCOUNTERS WITH PARTICIPATION $\ldots \ldots \ldots \ldots \ldots \ldots \ldots . . \ldots 2$

Who Are My Collaborators? ............................................................. 53

Introducing the Study about Participation ........................................... 55

Participation and Young People ........................................................ 58

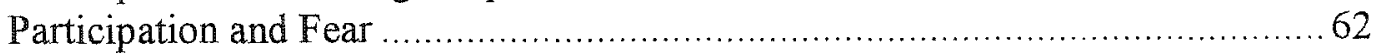

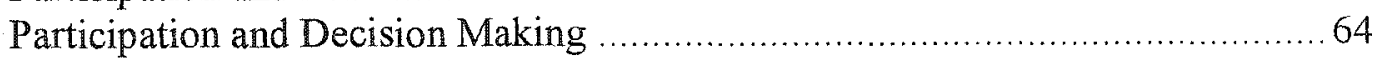

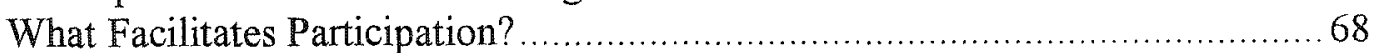

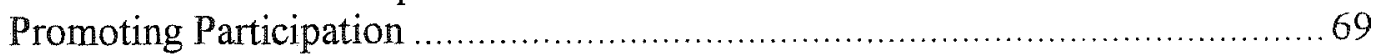

Can We Learn to Participate? .......................................................... 72

ix 
CHAPTER 7

PERSONAL ENCOUNTERS WITH PARTICIPATION ……...............................78

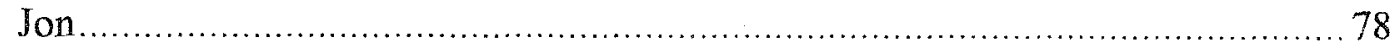

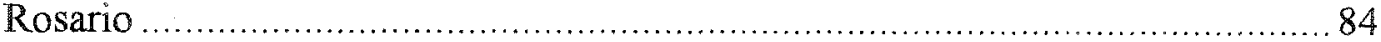

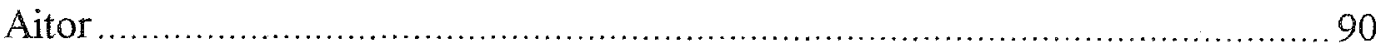

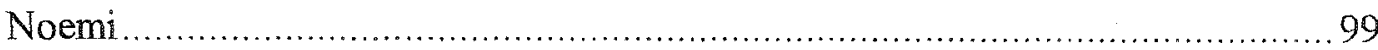

CHAPTER 8

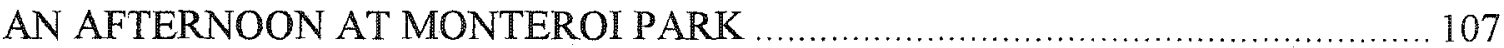

CHAPTER 9

MORE PERSONAL ENCOUNTERS WITH PARTICIPATION …........................ 112

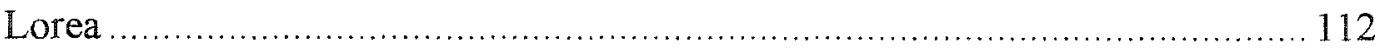

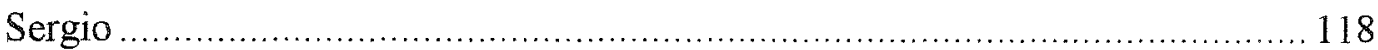

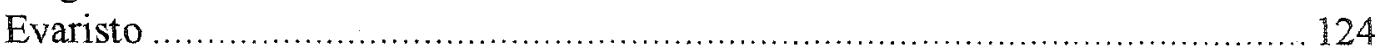

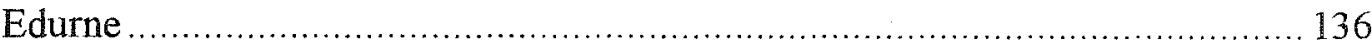

CHAPTER 10

FAREWELL LUNCHEON AT THE OTALORA TRANING CENTER .................... 144

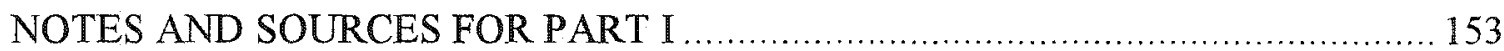

PART II

INTERPRETING THE EXPERIENCE OF PARTICIPATING IN DECISION

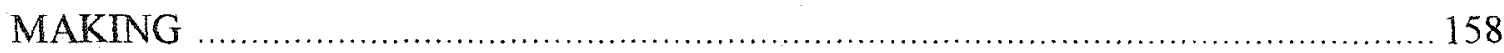

CHAPTER 11

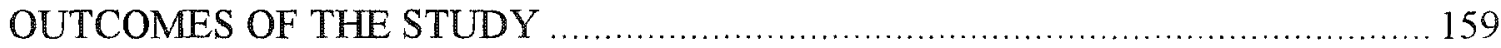

Major Outcomes of the Study ............................................................. 160

Other Outcomes -- Common Responses of Collaborators .............................. 160

Sharing a Broader View of Participation ................................................... 164

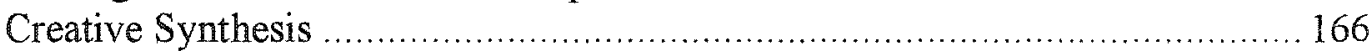

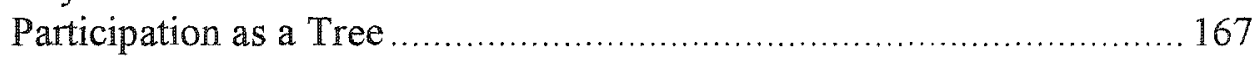

Participation as a Tree Diagram ....................................................168

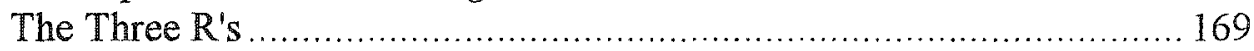

Expanding Consciousness …...................................................... 170

Action-Oriented Meanings …....................................................... 172

Value-Oriented Meanings.......................................................... 176

Transcendental Meanings ........................................................... 178

CHAPTER 12

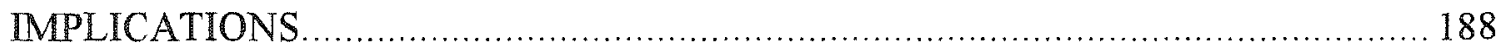

Participation and Abuse in Organizations............................................ 188 
Personal

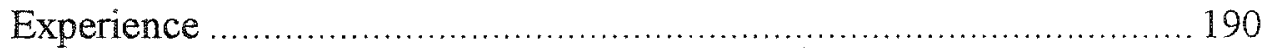

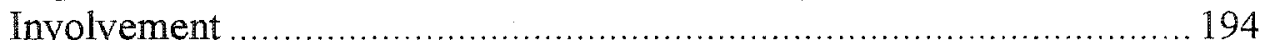

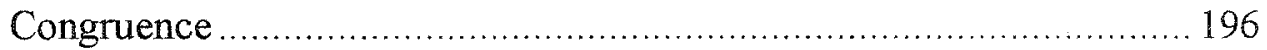

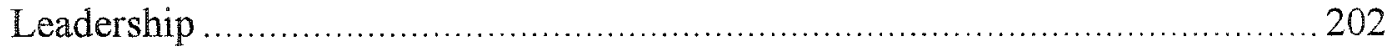

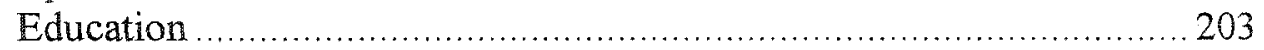

A Nurturing Environment for "Transformation" ...........................206

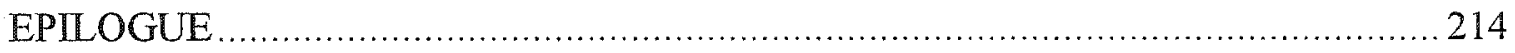

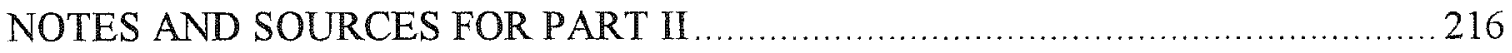

PART III

RESEARCH DESIGN AND METHODOLOGY

CHAPTER 13

RESEARCH METHOD AND DATA COLLECTION ................................... 220

Purpose of the Study ...................................................................... 220

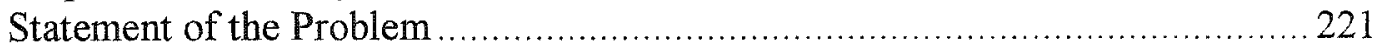

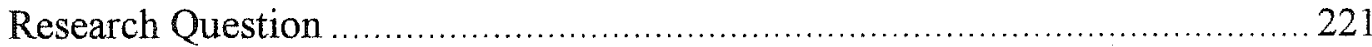

Phenomenological Inquiry .......................................................... 221

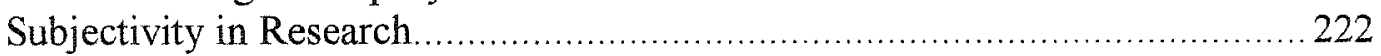

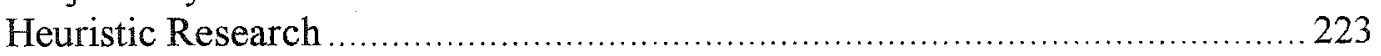

Sampling Strategy and Selection of Collaborators............................... 223

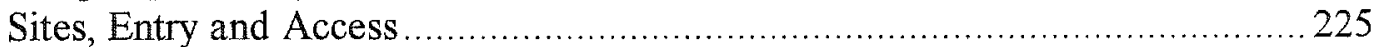

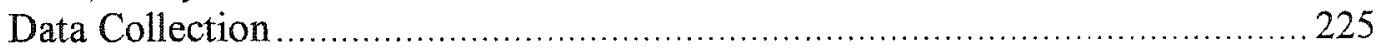

Dialogic Interviews.................................................................. 226

CHAPTER 14

REPRESENTATION AND ANALYSIS OF THE DATA AND CONTEXT ............. 229

Data Representation in Narrative Form ….......................................... 230

Stories and Plots.................................................................... 231

"Narrative Non-fiction" Tools to Represent Data............................. 233

Socratic Dialogues ........................................................... 234

Creation of Characters and Recreation of Locations ..........................236

Narrative Analysis and Other Data Analysis Tools ......................... 237

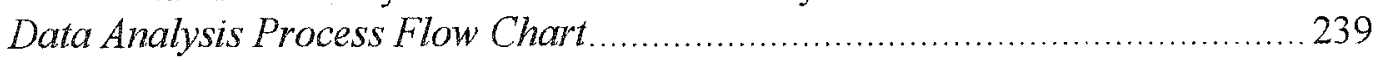

Data Analysis Process ..................................................................... 240

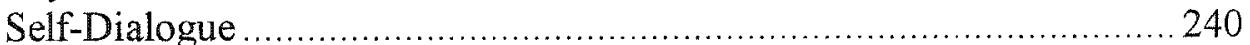

From Interviews to First Cycle of Feedback ................................. 240

Verifying Research Objectives and Methodology ........................... 241

Writing Personal Stories .......................................................... 242

Avoiding Interpretation of the Texts ...................................... 242

xi 
Personal Stories Become Group Conversations and Personal Dialogues 243

Recreating Group Conversations................................ 244

Rewriting Personal Stories as Personal Dialogues ........................... 245

"Ownership" of the Research Texts ................................................ 248

Sharing My "Peak" Participatory Experience ................................... 248

Outcomes Based on Dialogues with My Collaborators ...................... 249

Context of the Story as a Contributor to the Final Outcomes............... 249

Other Outcomes and Sharing Final Outcomes with My Collaborators ... 251

CHAPTER 15

SIGNIFICANCE OF THE STUDY, DOCUMENTING SOURCES, LIMITATIONS

AND DELIMITATIONS AND TRUSTWORTHINESS …................................. 253

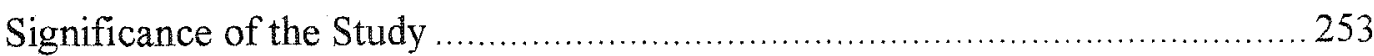

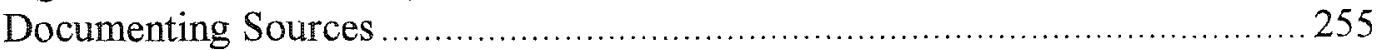

Delimitations and Limitations of the Study .......................................... 256

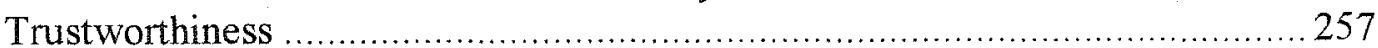

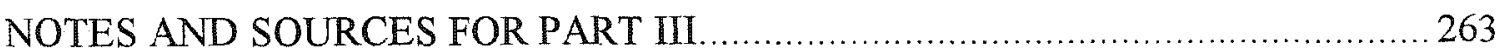

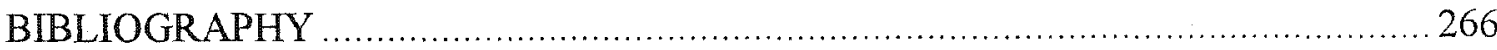

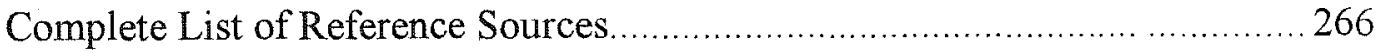

Reference Sources for Representation of Data as Narratives ....................... 276

Reference Models to List Notes and Sources............................................. 278

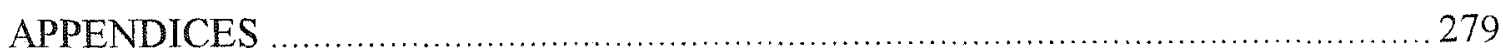

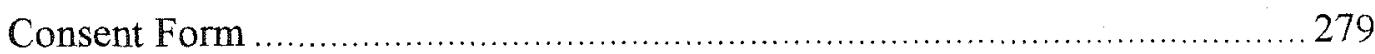

Questionnaire for Interviews ................................................... 280 


\section{PREFACE}

This is a book about the personal experience of participating in decision making. It intends to explore participation, its meaning and implications for us, as persons or leaders, at work and in life.

Accordingly, I have infused this book with broad participation, primarily from my collaborators and me, who provided most of its contents but, as importantly, from you, the reader. I conceived this book as a series of dialogues and conversations in which you were present, listening to our thoughts and feelings, and my reflections afterwards. Knowing I could speak to and share my doubts with you brought reflections afloat that I could not have elicited by myself.

Furthermore, interacting with my collaborators during these conversations provided rich insights about my own work and life. They put me in touch with personal moments of transformation and memories of people, places and events that have had influence on who I am today, unveiling profound meanings embedded in the participation experience.

There have been numerous books written in the last few decades about the virtues of participation in decision making at the workplace. Most of these books address participation as part of larger concepts such as empowerment, high-involvement, networking, high tech/high touch, total-quality systems, team and group work, corporate culture and other schemes that continue to appear on the bookshelves.

I think that these books are a great contribution to understanding participation in decision making for there is merit in providing schemes to support participation. I propose, however, that there is a large missing piece: the experience of the person that participates. This book intends to bring the person to the center of the topic of participation. What does participating in decision making mean to you, to me, to others? Do we need to adapt our organizations to enable you and me to participate? Does becoming aware of the potential meaning of our participation at work have larger personal implications for us as persons or leaders? The purpose of this book is to explore questions such as these. I invite you to join me on this journey of discovery. 


\section{INTRODUCTION}

The topic of participation has been of great interest to me for a long time and I chose the topic to write this book as a doctoral dissertation accordingly. I have mentioned in the Preface that I would like to invite you, the reader, to be an active participant in this book. I would therefore like to begin by sharing with you some of my personal experience, the reasons I am writing this book, its objectives and how this book is organized. I would also like to tell you why I chose the style I used to write the book, how I wrote it, and how I used reference sources and language.

I intended for several years to write a book about participation, after my almost three decades of experience in international business, my studies about management and leadership, and my exposure since 1995 to the Mondragón Corporación Cooperativa (MCC) in the Basque region of Spain.

I retired from my business career in 1993 with a mixture of frustration regarding "traditional" organizational systems and a growing sense of meaninglessness in my job as vice-president of international operations in an American transnational company. At that time, I was 50 years old and my family and I lived in Belgium.

I formed my perspectives about work and how it is organized through living, working and studying in several countries. I had profit-and-loss management responsibility for widespread operations in Europe, Asia, Australia and Latin America for 13 years. I have studied mostly in the U.S. (B.S. degree in Engineering from the University of Illinois, Senior Management Program from Harvard University, doctorate in Leadership Studies from the University of San Diego). I also studied management in Mexico (Master of Business Administration from "Monterrey TEC") and ethics, humanities and social sciences in Europe (M.A in Applied Ethics and M.A. in European Studies from the University of Louvain in Belgium).

My acquaintance with the Mondragón Corporación Cooperativa (MCC) substantially enriched my perspective about the way we organize and perform work. I first visited MCC in the fall of 1995 and was profoundly impressed with the "Mondragón experience," which is grounded on collaborative principles radically different from those in traditional organizations. Learning about and sharing the "Mondragón experience" with others have become major activities in my life. Taking student and faculty groups from the University of San Diego to an annual study-abroad seminar at the MCC Otalora Training Center has allowed me to have continuous exposure to Mondragón and giving talks about Mondragón to college students and community groups have contributed to disseminating the collaborative Mondragón model.

This book, however, is not about Mondragón but about the experience of participating. Yet my main collaborators are seasoned participators in the Mondragón cooperatives, a 
fitting scenario for my topic. I will therefore provide a context about Mondragón and will refer to it when appropriate but it will be mostly to provide a setting in which participation happens.

\section{Reasons for Writing this Book}

I will expand on my motivations to write this book in Chapter 1 . In brief, my experience and frustration with participation in decision making during my professional career, the growing interest in the topic in professional and academic circles, and the recent wave of corporate scandals led me to select this topic as the focus of this book.

\section{Objectives}

This dissertation aims at meeting several objectives. First, it is a research work that fulfills the requirements of a doctoral dissertation. Next, the texts intend to keep the voices of my collaborators at the center of the research, including also my contribution based on my experience with participation in decision making. Finally, the dissertation is written as a book in an attempt to make research work such as this interesting to the general reader as well as to facilitate his or her involvement.

I intend to meet these objectives by using an appropriate research design and a narrative style throughout the research work. To fulfill the requirements of a doctoral dissertation while highlighting the voices of my collaborators and mine, I have used a phenomenological-heuristic research design, which facilitates the expression of personal experiences. To meet the objective of making the texts accessible to the general reader and encouraging his or her involvement, I have written the book as a series of narratives. This approach to write the dissertation is described later in this introduction.

\section{Organization of this Book}

This book is organized in three parts: a research study written as a story, its interpretation, and the method used to write it. Part I introduces the story, provides a context, and explores participation in decision making as experienced in Mondragón. Part II contains my synthesis of the study and some of its implications. Part III describes the methodology used to write this book as a research study.

\section{Writing about the Experience of Participation for the General Reader}

I wrote this book following a simple premise, as stated by Polkinghorne for a phenomenological study:

I want to produce a [book] that gives an accurate, clear and articulate description of an experience. The reader of the [book] should come away with the feeling: "I understand better what it is like for someone to experience that." 
In order to provide a better understanding of the experience in an accurate, accessible manner, I relied on a writing style called "narrative non-fiction." Peter Rubie describes this style as the writing of facts that read like a good novel, using tools that enhance the narratives.

\section{Dialogues and Their Power}

The main narrative non-fiction tool used in this book is the dialogue. Practically the entire book is written as interactive dialogues and conversations because I consider them most appropriate to express the sharing of experiences, thoughts and feelings. I decided to use a dialogic format after I wrote parts of this book in prose style but found it too confining. How could I express what I needed to say to you, the reader? As I experimented with dialogues and conversations, I learned about their power to present, affirm, contrast, challenge, enhance and/or contradict different points of view. I became convinced that you would be more motivated to become involved if you "heard" more than one voice addressing the issues of participation in decision making. Therefore, I decided to transform prose to stories presented as dialogues and conversations throughout the entire book, including the research work, its interpretation and its research design and methodology.

\section{Using narrative non-fiction tools}

Once I was convinced that dialogues were more appropriate than prose to meet my objectives, I needed to find a way to write everything in a dialogic format. I used the tools available to write narrative non-fiction described below.

Personal Dialogues. Interactive dialogues were used but they did not require much adaptation because they were based on the individual responses during interviews with my collaborators. The objective of these dialogues was to highlight the uniqueness of each collaborator as expressed in our interviews.

Recreated Groups for Simulated Conversations. These were used to simulate group gatherings in which my collaborators and I could talk to each other about common themes extracted from the individual responses during the interviews. The objective of these recreated group conversations was to provide a way for you to contrast diverse responses to common themes. Six common themes in two group settings and the sharing of my own experience with participation at a luncheon were in this category.

Created Characters for Simulated Dialogues and Conversations. Various characters were created, as actors in a play, to make dialogues and conversations possible. Although these characters were fictitious, the contents of all dialogues and 
conversations were based on existing research and other publications and their corresponding references are documented in the Notes and Sources sections of the book. The objective of creating these characters was to provide a way for you to examine various perspectives about the research work, as they questioned, challenged and/or helped to explore mostly what I said or wanted to do. The most salient characters were Kurtis and Damian, colleagues from San Diego who appeared at the beginning of Part I and throughout Parts II and III of the book. Also, in Part I, Billy, Sarah and Padre Antonio interacted with me in the Context, and Stewart engaged in a dialogue with two of my collaborators and me in a Recreated Group for a Simulated Conversation.

Personal Reflections. I wrote reflections throughout the text related to my experiences as I dialogued with my collaborators, texts, culture, and past events in my life. I also occasionally indulged and shared with you reflections that are not directly related to participation in decision making but that revealed not so much what I do but who I am as a person--my thoughts, feelings, observations...

Interaction with the Reader. This book invites you to become involved in the journey of discovery of the experiences and meanings of participation in decision making. Therefore, I often posed the same questions to you that I wrestled with myself.

Descriptions. One of the most effective narrative tools to ground the action, make the text come alive, and give it texture and depth is to describe the surroundings of the site where the research is being conducted. For this reason, I described cultural traits, places, bars, meals and related aspects of the setting for the story.

\section{Reference Sources and Usage of Terms}

This book is intended to be read with a minimum use of reference sources.

Accordingly, I have attempted to include as much description as possible in the body of the text, and have omitted footnotes, citations or references in it. Readers interested in consulting references will find them in the Notes and Sources sections at the end of each Part, organized with a system modeled by other narrative non-fiction authors. References about these authors appear in the Bibliography at the end of the book.

In addition, with the exception of Part III that describes the methodology, I have endeavored to avoid "research terms," substituting them with more general expressions as much as possible. I often refer to the research work, as "the study", "the book", "the text" or "the story" to simplify the language and avoid repetition.

A special note about the terms "participation" and "Mondragón": I use the terms "participation," "participation in decision making" and "participation in decision making at the workplace" interchangeably because my collaborators do not make a 
distinction between them and because the last is a cumbersome term to use repeatedly. I have also avoided frequent references to "MCC" or "Mondragón" because my collaborators rarely refer to the place where they work by name, preferring terms such as "the cooperatives" or "the company." Using such substitutes for MCC also helps to read the narratives as belonging to the persons as persons, not as persons who behave as they do exclusively because they happen to work in Mondragón.

\section{A Final Word to You, Reader}

I consider you as a friend whom I can just call Reader, just as I could call you Rebecca or Robert. Often I will address you simply as "you." I will be talking to you often and I appreciate in advance your listening to me. I have heard that a book is written when the story itself is ready to be told, and the writer only facilitates the process. I sense that my incubation period to write this book is ending. I feel I will be able to delve more deeply into the realm of experiences and meanings if you join my collaborators and me. I sense I am ready to embark on this journey, sharing our experiences, reflecting on the issues, asking the hard questions. I earnestly hope you will come along with us. 


\section{NOTES AND SOURCES}

\section{Preface}

Books about participation in the workplace: Bennis, Parikh \& Lessem; Burns; Chrislip \& Larson; Gates; Helgesen; Janis; O’Toole; Ouchi; Senge (1990), Rost.

Participation as part of larger schemes: Pierce J. L. \& Newstrom, p. 4.

\section{Introduction}

Write clear description: Polkinghorne (1989), p. 46 as cited in Creswell p. 177.

Narrative analysis and representation of data: Clandinin \& Connelly, Polkinghorne

(1988, 1995)

Narrative non-fiction: Rubie, p. 7.

The reference sources I used to create narratives, characters, descriptions and dialogues are Franklin, pp. 133-166; Gutkind, pp. 17-66; King, pp. 163-195; Kohan, pp. 47-141; Kubis and Howland, pp. 1-136; Stein, pp. 49-156, 223-248; Stewart (1998), pp. 148252; Rubie, pp. 101-134; and Wood, pp. 18-84, 134-146.

The specific reference sources I used to write the story as dialogues are Chiarella, pp. 19-94 and Turco, pp. 15-75. Both of these books are fully focused on techniques to write effective dialogues. 


\section{PART I}

\section{THE EXPERIENCE OF PARTICIPATING IN DECISION MAKING}

The story in Part I begins with an exploration of the topic of participation in decision making in San Diego, California, continues with a 10-week study about the topic in Mondragón, Spain, and ends with a final luncheon at Mondragón's Otalora Training Center.

Chapter 1 initiates the story by setting the introductory scene to the reasons to study participation in decision making and establishes Mondragón as an "ideal" site to explore how participation in decision making is experienced. Chapter 2 describes how the Mondragón collaborators were selected.

Chapters 3 to 5 provide a research-based context to the story with a description of the tenets of Mondragón; the life and philosophy of Arizmendiarrieta, its spiritual guide; and a poem composed echoing the voices of the people of Mondragón. Three fictitious characters are created as my dialogue partners to tell some of these stories: Bill and Sarah talk with me about Mondragón and Arizmendiarrieta; Padre Antonio and I engage in conversation and provide some glimpses of Arizmendiarrieta's personal life.

Chapters 6 through 11 continue with the story, describing participation in decision making, as experienced by eight Mondragón collaborators. This part of the story is the core of the study about participation in decision making. It is grounded on interviews with my collaborators and derived from a collection of their partial life stories evolving from the joys and pains of childhood, to the early years at work, along their paths of personal and professional growth. Two recreated settings are used to simulate gatherings in which all collaborators talk with each other and me about their experiences, based on material from the interviews. Another recreated setting is used to simulate a final luncheon in which my collaborators listen and react to my recollection of an intense experience with participation in decision making at the workplace. Stewart is a fictitious character created to present an opposing view to participatory decision making. Although with recreated words, the conversation with Stewart is based on a true story, told by one of my collaborators in an interview, about a visitor from Great Britain who challenged her about Mondragón decision- making practices.

This story is self-contained and there are choices after reading it: to stop reading it and interpreting the story with what you have learned, or continue reading Part II that contains my interpretation of the story. 


\section{CHAPTER 1}

\section{WHY IS OUR PARTICIPATION IN DECISION MAKING IMPORTANT?}

Enron discloses $\$ 1$ billion dollar in losses! The media headlines reverberated across the country. It was 6:15 a.m. on October 16,2001. The day was otherwise like any other. It was a clear, crisp autumn morning on the Southern California coast. I was calmly going through my morning routine: early morning meditation, a cup of herbal tea, a quick look at the New York Times daily news website. These headlines were a jolt to my senses. How could the sixth largest company in the United States, a paragon of corporate businesses, whose CEO was glorified in Fortune magazine, surprise the world with such monumental losses? This was scandalous news. A multitude of images went through my mind. What did this mean to Enron's employees? To its stockholders? To other stakeholders-its customers, vendors, contractors, consultants...? To its community?

Reality set in slowly as news worsened throughout the next six months. Enron was not an isolated case. By the spring of 2002, in addition to Enron, there were substantial corporate irregularities in WorldCom, ImClone, Qwest, Tyco, Adelphia... How could these irregularities have been prevented?"

These events dramatized the importance of the topic I had been considering for my book. I called Kurtis Bevins and Damian Kayne, two classmates from our doctoral program, to share my thoughts with them. We have developed a comfortable relationship and I consider Kurtis and Damian not just as colleagues but also as friends. They have broad professional experience in leadership, engineering, teaching and managing people and projects, and are sensitive to the human aspects of work as well. We took turns critiquing Kurtis and Damian's dissertations during several meetings the last three years until they graduated from the USD doctorate program. I called them to have my incipient book critiqued in the same manner.

We had extended summer trips planned and Kurtis and Damian had business meetings overseas during September and October. Therefore, we agreed to meet on Saturday, November 23, 2002 at noon at the usual place, Mimi's Café in San Diego's Miramesa shopping area. I arrived early and sat in the familiar waiting room, surrounded by a New Orleans motif. The aroma of French onion soup permeated the room. The main dining area was crowded and noisy. There were several families eating at long tables with checkered tablecloths. I asked for a booth at the far end of the restaurant, where we could talk comfortably. I noticed new pictures of revered jazz musicians on the walls and the larger semi-concealed loudspeakers. Louis Armstrong sang and blew his horn, Ella Fitzgerald scatted a tune and the old timers of the Preservation Hall group played a blues piece as I waited. 
Kurtis and Damian arrived on time. Every time we had reached a milestone with their dissertations, we had celebrated by having a special meal. This day could also be called a significant event: the beginning of the process of writing my book. Mimi's Café had seasonal fall menus, including Thanksgiving favorites. This was a perfect opportunity (some would call it excuse!) to sample some of its special dishes. Kurtis and Damian had a turkey dinner with all the trimmings: dark gravy, turkey stuffing, cranberry sauce, whipped potatoes and an assortment of green vegetables. I had pumpkin pancakes, a mountain of fluffy, perfectly rounded cakes flavored with cinnamon and other spices I could not identify. For dessert, Kurtis and Damian ordered the delicious pumpkin pudding, a moist combination of bread, raisins and nutmeg topped with whipped cream. I had an apple pie, with an incredibly thin and crunchy crust, sprinkled with cinnamon.

I have observed with interest how people that get together regularly, like us, often develop rituals for their interactions. Today we are a relaxed group of friends. It is Saturday, we are in no hurry to finish lunch or leave afterwards. We catch up with each other's activities while we eat our main dish. We discuss the news headlines over dessert and coffee. We ask the waitress to clear the dishes and refill our coffee cups as we place our papers on the table and then we talk for hours.

\section{Rationale for the Study of Participation}

I had explained briefly in an e-mail message to Kurtis and Damian that I wanted to talk about my book project. "The corporate scandals are a timely subject," I said. "New cases come up daily on the media headlines, as we mentioned over coffee. These scandals are somewhat related to my book and I'd like to discuss them with you. Perhaps you can help me focus my topic. I'd like to start by asking a question: What makes these scandals possible?"

"A bunch of greedy managers that got away with it," said Kurtis immediately, beginning our conversation in a brainstorming mode, that is, reacting to each other's comments with the first words that came to our minds

"Yes, but why could they get away with it?" I asked quickly after.

"Because they made decisions that were favorable to them at the expense of shareholders and employees, and nobody could stop them," Damian replied.

"That's right. Now my second question: What can be done to prevent these arbitrary decisions from being made?" I continued without waiting for a reply. "This recent wave of scandals shows the problem with organizations that concentrate decision-making power at the top. There are not enough checks and balances to prevent the potential damage not only to shareholders and employees but to many other stakeholders, including customers and local communities."

"Yes, but these crooks have been caught and it won't be so easy to do it again," said Damian. 
"I have a different view," I replied immediately. "We continue 'tweaking' the system, adding watchdogs, controls and regulations. But, as history proves, these are not enough. The basic structure, the way organizations function has to be revamped from the foundation up."

"What do you mean by 'as history proves'?" asked Damian.

The conversation was already moving so I waited a few moments before responding. "Irregularities, abuses, excesses, scandals," I enunciated slowly, "have existed throughout the history of organizations in the United States. 'Self-dealing', a term used to describe organizational leaders who enrich themselves at the expense of stakeholders, has been a part of capitalism from the beginning."

"Oh, yeah?" he said. "Give me some examples."

"Okay," I replied. "A well-publicized example from the early $20^{\text {th }}$ century is the 'robber barons', specially the 'Big Four' (Leland Stanford, Colin Huntington, Jay Gould, and James J. Hill), who built the Central Pacific Railroad with other people's money and pocketed all profits through setting up a construction company to build the tracks." I was surprised I remembered the names but I had been interested in this scandal, especially because I had linked Leland Stanford to Stanford University.

"But that was a century ago!" exclaimed Damian.

"There have been many others more recently," I replied. "I'll tell you about a very highprofile case from the 1980s: The Savings and Loans scandal. There were exaggerated salaries paid by their executives to themselves and suspicious transactions with real estate sold back and forth. Of course, these irregularities were at the expense of everyone, except the executives involved. Why were they the exception? Because these executives made all decisions unsupervised and became rich in the process."

I paused, waiting for comments but there were none. "But we have short memories, and, if substantial measures are not taken now to prevent these irregularities, we will forget that Enron, Tyco, WorldCom and the rest ever happened. Some of their executives will go to jail and we will consider the problem solved... until the next time."

"So, what do you propose?" asked Kurtis.

"I propose that if Damian, you or I may be directly affected by a decision, we should be able to participate in making it. I propose that we don't know much about participation in decision making, that we don't know how to participate, and, based on my experience, that many of us don't even want to participate." I sensed an irritated tone in my voice so I stopped talking. 
"So the topic for your book will be about the corporate scandals and how to prevent them?" asked Damian, reaching for his notebook.

I breathed deeply. "Not exactly, my topic is not focused on the corporate scandals, but they demonstrate that major changes have to be made in our organizations. The terrible loss of lifelong investments, pension plans and jobs for thousands of people dramatically illustrate we have to find better ways to do our work. I question: Can we continue to accept a few people at the top of our organizations making decisions that affect us, without our participation?"

"So the topic is 'changing the way we work so we participate more'?" he continued, crossing out what he had written.

"Your questions are helping me to focus on what I am really after," I said, "but we need to talk more before we write it down. I don't think that we should have more participation at the workplace just to prevent corporate irregularities."

"Let us look at your topic from another perspective," said Kurtis. "In our doctoral program we were exposed to leadership authors that emphasized the need to create organizations that promote broader participation to align the investors, managers and employees' personal and organizational objectives."

"You mean like Peter Senge's book, the Fifth Discipline?" asked Damian.

"I am glad you mentioned Senge," I said. "I plan to use his concepts in my book."

"Yes," added Kurtis, "I remember he also emphasized the need for constructive dialogues."

I wrote Senge et al on my notes. "As we can see, I am not alone in thinking that broader participation at the workplace is needed. Because of my interest in the topic, I kept a close watch on other authors we read during the program."

"Such as?" asked Damian.

"There are many. A few that we read in class are Burns, Bennis, Janis, Chrislip and Larson..."

"Okay, okay, I remember," he replied. "So your topic is the need to have more participation because it aligns several stakeholders, that is, investors, employees and managers?" This time he placed his pencil on the table and just looked at me.

"Yes, in a way. But I have another motivation based on my own experience." I leaned forward and placed my elbows on the table. "One of my biggest frustrations in the many years I worked in transnational organizations was the lack of participation in decision making. I saw its absence from the bottom, when I was a departmental factory manager, 
all the way to the top of the organization, when I was the VP for international operations."

"So your interest arises from not being able to participate yourself," said Damian.

"It's one of the reasons, but not the only one, because I personally was able to participate in decision making in the last 15 years or so, when l was in executive positions. But nonexecutive employees could not participate, and I observed certain things in the last few years that piqued my interest in the topic."

"I know what you are going to say," said Kurtis, "executives don't care much to have participation."

"That may be true," I replied. "But my biggest frustration was that, when I was at the top of the organization, I promoted participation among my peers and my collaborators but was puzzled to find that many were not willing to engage in it. I wondered why this happened."

"Are you interested then in the positive and negative experiences of participation?" asked Kurtis.

"I first would like to explore the positive, so we can learn what it is like."

"Have you had any positive experiences of participation yourself?" he continued.

"Oh yes, I had some intense, rewarding participating experiences with my collaborators along the way, but this happened only at certain stages of my career and on certain occasions..."

"So you would like to study rewarding experiences of people who participate when they are given the opportunity?" asked Damian.

"I think we are getting closer to it," I replied. "I have been reflecting on the meaning of the things we do, including participation."

"I think this shows your age," he quickly replied with a smile. "You are going reflective on us."

"You are probably right, maybe when you get to be my age..."

"We are your age," added Kurtis, staring at me.

I laughed. "Okay, let me share my thoughts with you. There are many things we do because we have been 'programmed' to believe we should do them or because someone or something from the outside (our boss, company rules, community, society...) pushes us to do them. We will, however, do things that we do not have to do only if they make 
sense to us, if they have some significance for us. We do these things only if we feel they are meaningful."

"You are getting off the subject," said Damian.

"Not really. We have not been taught or encouraged to participate in decision making. In fact we are generally encouraged not to participate in decision making at the workplace. So, if and when we have the opportunity, we will only participate if we find a reason to do it. I say we need to find meaning in doing it."

"How do I know if my participation is meaningful?" asked Kurtis

"This is what I'd like to write my book about: The meaning of participation. What does participation mean to Damian, to you, to me, to the reader?

"And then?" asked Damian.

"If we find it meaningful to participate, we may muster the energy and courage to make the changes needed in our organizations, whether we are leaders, managers or employees."

Why Study Participation at Mondragón?

"And how are you going to find out about the meaning of participation?" continued Damian.

"This is where my experience with Mondragón comes in," I replied.

"I knew Mondragón had to be somewhere in your book!" exclaimed Kurtis.

"Yes, you have been to Mondragón and know of my interest in its experience-- I plan to find about the meaning of participation there," I said, reserving details for later.

"Mondragón could be a good model..." said he said.

"Mondragón is a living, growing organization," I said enthusiastically, "that has practiced participation and succeeded economically and socially for fifty years. My nine-years experience studying Mondragón has given me hope that participation at the workplace can become personally and professionally meaningful."

"I know you have mentioned Mondragón often," said Damian, looking at me. "But can you describe it again? Just a capsule version."

"Of course. The Mondragón Cooperative Corporation, also called MCC, the 'Mondragón experience' or simply 'Mondragón', is located in the Basque region of Spain. It is a $\$ 9$ billion dollar for-profit organization that promotes participation by sharing decision- 
making power throughout the organization. It is characterized by cooperation, democratic ownership, participation in decision making, and solidarity among workers and with the community."

"Fine David, this is good to start," he said, raising his hands, palms out in front of him, as indicating I had said enough. And he added: "So you'll write about participation in Mondragón."

"Participation as practiced in Mondragón, but hopefully as also experienced by others elsewhere," I clarified. "It's not a case study about Mondragón, it's about learning from my collaborators who have extensive experience in participation."

"A lot has been written about Mondragón, as I recall," said Kurtis. "Hasn't anyone written about participation?"

"A lot has been written about the Mondragón experience from different perspectives. A few authors have included the MCC's systems and processes that facilitate participation. I did a pilot study in year 2000 that highlighted participation in decision making as the most important value at MCC, and described some of the participation processes. But the meaning of participating has not been explored."

"So you will expand your pilot study to a full-fledged project, including meanings," he said.

I smiled, remembering I had the temptation to do that exactly. "In year 2000, expanding my pilot study was my idea for a book project. But in the last three years, I've become more aware of the distinct roles of the support systems and our role, as persons, in the process of participation. Paraphrasing my high-school physics teacher, the support systems are 'a necessary but not sufficient condition' for participation to occur."

"You can take a horse to water but can't make it drink, huh?" said Damian in a joking tone

I identified with Damian's comment, nodded and looked at him. "Systems may be in place to support my participation but I will participate only if I find it meaningful. That's why I will write about persons and meanings."

"But what about the systems? Aren't they important?" asked Kurtis.

"Yes, they are, and they are clearly institutionalized at MCC. But the fact remains that participating is a voluntary act and ultimately it's a personal decision to participate or not. This is why I am focusing on the person that participates."

"Okay David, where are we?" asked Damian. 
"What I experienced about participation at work is the main motivator to write my dissertation about participation and I have written several papers about it throughout the doctorate program," I said, realizing we were in brainstorming mode again.

Kurtis looked at his notes. "Academic writings about organizational models that promote participation show its importance ---this is a good reason to study participation..."

"The terrible consequences of the recent corporate irregularities," added Damian, "could be prevented if more of us, managers or employees, participate in decision making."

"Indeed, my experience at work with participation made me realize that some people participate and some don't, even if they are able to do so." I said.

We paused and I paged through my notes. I broke the silence. "I think the focus on meaning will shift the emphasis from the design of the systems to the experience of the persons."

"And how are you going to focus your study on the experience of the person?" asked Damian, tilting his head back and looking directly at me under his glasses

"I have no answer yet. You helped me to articulate my topic and I appreciate it, but I was hoping you'd help me think about the way to do it too!" I said, half-jokingly. "Why don't we leave this question for next time we meet? I will do my homework. I know I need to find potential ways of focusing on the experience of the persons that participate and articulating what they say. It may take me a few months but for sure I'll have something by the next time we meet."

"Sounds good to me. We'll also think of some ways to do it," said Damian. Kurtis nodded in approval.

We walked to the parking lot together. We checked our calendars and agreed to meet on May 17, 2003, before I left on my trip to Mondragón. We shook hands and left.

On the way home I pondered what had transpired in our gathering. Why not do what Kurtis suggested, an expanded version of the pilot study on Mondragón's support systems for participation? Mondragón has well-established structures and systems in place. I have some basic information already. Why not, you may be wondering? Because it has become clear to me that providing support is not enough. It has been ten years since I retired. As Damian said, perhaps because of my age, and with a perspective probably gained by time and distance, I have concluded that finding meaning in what we do gives a sense of purpose and direction to our lives. Work is a prime example. Having "a job" to make a living is not enough, it is necessary to have meaningful work. But what makes 
work meaningful? Participating in decisions that affect you and me, as I contend? If so, what makes participation in decision making meaningful?

\begin{abstract}
A Meeting with Damian and Kurtis Two Weeks Before My Trip
Damian, Kurtis and I met at Mimi's, as we had agreed, on May 17, 2003. We reviewed what we had talked about last November, that is, the reasons I wanted to study participation in decision making and why I believed that Mondragón was an "ideal" site to explore how participation in decision making is experienced.

During this meeting in May, a couple of weeks before I left on my trip to Mondragón, we talked almost exclusively about the methodology, that is, the methods I was planning to use to conduct a research study that focused on the person that participates and to articulate what they told me about their experience. We also discussed whom I would talk to and how I would gather information. Our conversations during this meeting are shown in Chapter 13 of Part III, which describes the Research Design and Methodology.
\end{abstract}

For the next two weeks after our meeting, I read as much as I could about the details of my upcoming study and got ready to leave. My flight was scheduled to arrive in Bilbao, Spain on June 3, 2003, from where I would take a taxi to Mondragón. I was prepared for a ten-week stay. I learned I could get along with much less than I was used to packing for long trips, since I needed space in my baggage for a laptop, a heavy pedal-driven transcribing machine, voltage converters, and several books. I was ready to start my work at Mondragón... 


\section{CHAPTER 2}

\section{ARRIVING IN MONDRAGON}

The flight to Europe was uneventful and I arrived at the Bilbao airport on time on Tuesday, June 3, 2003. I took a taxi to the Arrasate Hotel in Mondragón, an hour and a half away. I met Esteban and Rosi, the hotel owners, who were waiting for me at the hotel lounge. They showed me up to my room right away because I was very tired, but I was so jet-lagged that I could not go to sleep immediately. I woke up at about nine in the morning, excited about my appointment at 11 a.m. I took a taxi to meet my friend Jokin at the Otalora Training Center, usually called just Otalora. As I rode up the hill on the steep and narrow road, I thought about how many times I have been there. I visited it for the first time in October of 1995 and have been back nine times since. It felt like I was going home.

My friend Jokin was waiting for me at the lobby. We hugged and caught up with each other's news about the family, mutual friends, work, activities, trips... I had contacted him previously and described my book project. I had also told him about the desired profile of the eight collaborators: four men and four women with extensive and intensive experience in at least two jobs, who had been members of at least one cooperative council and were willing to share their experience. I had also identified two collaborators from my last research project in year 2000 and had requested him to suggest six more. He said he had identified two and wanted to talk to me about them. If I thought they fit the profile for the collaborators for the book, he preferred they were involved in selecting the other four. I knew both of his suggested collaborators but had little previous contact with them. I trusted Jokin's judgment but still went through his notes with him. I thought they fit the profile very well.

When we were finished, Jokin said: "I've set up a meeting for the four of us this afternoon in my office."

"Great, Jokin," I said enthusiastically.

Jokin stood up. "How about lunch?"

"I am ready," I replied. "Nothing like the delicious, wholesome food from your dining room."

We had lunch with the Otalora manager and others from the Otalora staff, giving me an opportunity to greet those I knew but had not seen for a year and to meet newly transferred group members. As usual, Otalora had rotated some of their people to get new perspectives from experienced managers involved in the training aspect of Otalora. I thanked the Otalora manager for his letter of acceptance to my request to contact people from Mondragón to write my book. He was quite helpful also assigning a space in the Otalora building to hold the meetings with my collaborators. 
Lunch was a typical Basque meal: large portions of fresh ingredients, including a variety of vegetables, fish and meat, and bread baguettes, wine, bottled water, dessert and coffee. I had green salad with lettuce, tomato, asparagus, sweet onions, black olives and large chunks of bonito (tuna fish). As a main course I tried the bacalao a la vizcaina (codfish in a delicate sauce), a specialty of the Basque province of Vizcaya. We had light, young red wine from the Rioja vineyards in the southern part of the Basque region. I settled for homemade flan, a caramel laced custard, for dessert. I finished the meal with a small cup of freshly brewed, strong black coffee.

Jokin, the two selected collaborators and I gathered at his office right after we finished lunch. He had explained my book project to them but they had some questions. I answered them and asked them if they were willing to commit to help me with my book project as I had described it. They both agreed with a contagious enthusiasm.

I looked out Jokin's office window and saw the evergreen mountains. "Now that we are five collaborators, and seeing that you are happy to participate in this project, I'd like to ask for your help to find the other three members of the group that would fulfill the criteria Jokin shared with you earlier."

Jokin pulled out a list of names and read them aloud, with the other two collaborators comparing them with the established criteria. After mentioning six names, they agreed on three potential collaborators who seemed the most appropriate, and listed the rest in order of preference. They decided who would contact each of them before we met to verify their interest and commitment. Jokin asked me about my availability, so he could set the appointments. I had prepared an information package that introduced my study to my collaborators and asked my three colleagues if they could mail it to those on the list that accepted to be part of the study. I planned to review its contents again, perhaps over the weekend, before we met for the first time.

We got up, shook hands and our two new collaborators left. I stayed behind with Jokin in his office to discuss the details of the upcoming activities. We left the office and walked together to the parking lot. I thanked Jokin for his generous help and said goodbye. 


\section{CHAPTER 3}

\section{MONDRAGON AND ITS PRINCIPLES}

After exchanging a few comments about the meeting and the activities of the next few weeks, I thanked Jokin for the meeting and left him in his office. I was very pleased having already eight potential collaborators for my book. I was smiling as I walked down the stairway to the Otalora lobby and I saw a young couple standing by the ancient wooden doors. She looked up and smiled at me. I smiled back. "Hello. How are you? My name is David...David Herrera," I said, looking at both of them.

"Nice to meet you," he replied as he shook hands with me. "My name is Bill O'Connor."

"And mine is Sarah Goldman." She extended her hand to meet mine.

I had heard at lunchtime that an American couple would be visiting MCC that afternoon but did not expect to meet them on my way out. I also did not imagine them to be so young--they must have been on their mid-twenties. "I hear you are interested in learning more about MCC and have an appointment this afternoon."

"Yes," Sarah said. "I just finished a degree in Anthropology and will be starting graduate school this fall. We studied a case last year about the anthropology of work that referred to the "Mondragón experience" and how it's all about placing the person at the center. I'd like to know more about it, so here we are!

"I see. And you Bill?"

"Well, you could say that I just came along for the ride. I'll be starting my second year of my MBA this fall. Sarah and I had planned to come to Europe this summer and she convinced me I could learn something different about business if we came to Mondragón together."

"It looks like we are all interested in similar things," I said. "I am at the University of San Diego and teach a course to student groups here in the summer."

"Really? And where is your group?" Sarah asked me.

"Oh, this year is an exception. I didn't bring a group. I came here for ten weeks because I'm also finishing a doctor's degree in Leadership Studies at the same school and I am conducting some interviews for a dissertation/book I am writing.

"Wow," Sarah said. "Perhaps we can talk with you about Mondragón during our stay here?"

"I thought we'd be leaving tomorrow morning," Bill said, glaring at Sarah. 
"Of course Bill. Perhaps Professor Herrera can talk with us some time between now and then?" She looked at me questioningly.

"Please call me David," I said, smiling at both of them. "I hope we can get together. I can give you a short version of the course I teach in a couple of hours," I said. "I am staying at the Hotel Arrasate at Mondragón. And you?"

"We are at a small hotel in Mondragón too!" exclaimed Sarah. "Can we meet tonight?"

"I am sure we can find a way to do it," I replied. "I have a commitment for dinner at ten, right at the botel's dining room. Perhaps we can meet at about eight tonight?"

"Yes, we can!" said Sarah enthusiastically. "We should be finished here at about 5:30. Where can we meet?"

"My hotel has a large lobby area for guests. I will arrange to have a table ready for us to talk,"

"Great!" exclaimed Sarah.

"Well, see you then." I looked at both of them as I turned towards the Otalora doors. Sarah had a wide smile in her face. Bill did not seem pleased.

Sarah and Bill arrived right at 8 p.m. Sarah was a petite woman with outgoing ways, long black hair and eyes, and a girlish smile. Bill was medium-height, a bit heavy, had red hair and blue eyes, and seemed shy. They both had changed clothes for the evening. At Otalora, Sarah had a summer dress and shoes and Bill had khakis, a polo shirt and loafers. Now she had low-riding jeans, sandals, a tank top, and a ring on her navel. She also had a tattoo of an angel playing a trumpet on the left side of her bare midriff. Bill had jeans, sandals and a Basque Kukuxumusu T-shirt with a peace motif in the front. Sarah could have passed for a Basque girl but Bill's red hair gave him immediately away as a tourist.

"Buenas tardes," said Sarah to Esteban and Rosi, the hotel owners and hosts, as they entered the guestroom. "Buenas tardes," they replied almost at unison, as Esteban invited them with a gesture to the opposite end of the room. Bill nodded as a response to the greeting and followed Sarah to our table at the far end.

"Hola, David," Sarah said, setting an informal tone for our talk. Bill half-smiled, looking at me.

I looked up. "Hola Sarah, hola Bill. You pronounced my name perfectly in Spanish, you must speak the language," I said looking at Sarah. 
"Un poquito, David. I've studied it for several years but need to practice." Bill mocked a heavy accent: "Yo no hablo el español."

I smiled. "Please sit down. Would you like some red wine or water? I placed my hands lightly over both bottles on the table. Sarah looked at me and touched the water bottle, Bill, the wine bottle. I served them and poured some wine in my glass.

We exchanged a few comments about their trip, their plans to go around Spain and my previous experiences at Mondragón. Sarah and Bill also talked about watching the introductory MCC video and visiting the FAGOR cooperative.

We paused and I reached for my notebook. "I know we don't have much time. I have prepared some notes for our meeting but would like to know first how acquainted you are with Mondragón and what you would like to talk about."

"I know that there are 68,000 people working in Mondragón and that a priest and five young engineers founded it in 1956" said Sarah immediately. "What was the name of the priest? "

"Don Jose María Arizmendiarrieta, called Don Jose María here and Arizmendiarrieta or Arizmendi in books written in English," I replied.

"A-riz-men-di-a-rrie-ta!" Sarah repeated slowly, with only a trace of an accent.

"I know that annual sales are about 9 billion euros, "added Bill, apparently unimpressed with Sarah's correct pronunciation.

"And how much would that be in U.S. dollars, Bill?" I asked.

"The euro is now the strongest it has been against the dollar," Bill replied, "at about 1.2 dollars to one euro, so sales must be around 10.8 billion dollars."

"I was surprised to see in the video the diversity of Mondragón businesses. I understand they have 165 different cooperatives..." said Sarah

Bill leaned forward. "I can't believe that the same company has such large manufacturing, retail and financial businesses at the same time. And some of them look so high-tech!" added Bill, showing some enthusiasm.

"I learned in class that there are some principles all cooperatives follow," added Sarah. "This is what I would like to talk about. I remember one of them was that workers are also owners but we didn't talk much about the rest of them. Can you help us here?"

I looked at her and then Bill. She had placed her arms on the table, he had backed away and had locked his fingers behind his head. "Yes. We can start at the beginning," I said, "the only condition of admission to $\mathrm{MCC}$, aside from being qualified to do the job, is to agree to adhere to the ten principles you mention." 
"Can you tell us more about the others?" asked Sarah with apparent anticipation.

"The ten principles are all interrelated and are not easily explained individually. I will divide them in three groups. You mentioned placing the person at the center, Sarah, and that's the first group: giving primacy to the dignity of persons and their work. The second group refers to the equality of persons, and that includes worker ownership that you also mentioned Sarah. The third group is related to solidarity with each other inside and outside of work and with the community. All of them are permeated with the principle of participation of the workers."

Sarah leaned forward on the table and looked at me. "Can we talk about ownership first?"

"Sure. MCC has a principle of Democratic Organization, which means that all workers are members on an equal basis by investing equal amounts to own one share and have one vote--'One member/one vote', as this principle is referred to. Whether they are managers or employees, all workers are called "worker-members" or "worker-owners" in English. They call themselves socios, which of course means 'associates', in Spanish."

"I know, this is like an ESOP," said Bill, still sitting away from the table.

"What is that?" asked Sarah.

"ESOP stands for Employee Stock Ownership Plans," said Bill, looking at Sarah as if she were supposed to know the term.

Sarah was unfazed. "And why are they similar to Mondragón?"

"In these organizations, all workers own a share of the business," said Bill, "just like in MCC."

"Some ESOPs can resemble MCC," I said, "but there is one very important question to ask when talking about worker ownership: "Who has the ultimate power to make decisions?' If workers can not participate in decision making, ownership in an ESOP is limited to helping finance the organization and sharing in the profits equal to the one share each worker owns. AT MCC, the difference is that worker-owners have the ultimate power in decision making."

Bill did not pursue the subject further. "So are there any companies like MCC in the U.S.?"

"I have not found one yet, but I keep looking!" I replied.

I reached for the wine and refilled Bill's glass. "The Democratic Organization principle gives the worker-owner the right to be, to possess and to know." 
"Can you elaborate?" askedSarah.

"Yes. This means that worker-owners are able to speak their minds, have ownership of the company and be informed about the affairs of the organization. Therefore, they are able to find out what is going on with the company and have the authority, and responsibility, to participate openly in decision making."

"And how much does a share cost?" asked Bill.

"One year's minimum salary, or about 15,000 euros."

"Really?" said Bill. "I can't imagine everyone who applies for a job at MCC has that kind of money available up front."

"This is not necessary, Bill. The principle of Open Admission states that if a qualified applicant doesn't have the initial capital to invest, an MCC bank loan is available, payable in three years as a payroll deduction."

"And can you tell us now about solidarity?" asked Sarah enthusiastically.

"I will soon," I said smiling. "But first I'd like to tell you about other principles that are closely related to those I've mentioned. One is called the Subordinate Character of Capital. This principle states that worker-owners have ultimate control in decision making through their participation and vote because capital is subordinated to those who do the work."

I looked at Bill. "This principle in effect reverses the relationship between capital and labor we use in our organizations, in which capital, or capital investors, have ultimate control in decision making and workers are subordinated to capital, being used as 'instruments of production'."

"People are more important than money," said Sarah.

I nodded and smiled. "A closely related principle is the Sovereignty of Employee's Work over Capital. This principle means that since work is more important than capital, profits are distributed among worker-owners according to the work they have performed instead of according to what they have invested."

"And what about pay?" asked Bill.

"Jobs are evaluated and rated as they are in traditional organizations and pay is tied up to these evaluations."

"How much does a CEO in a cooperative make?" continued Bill. 
"The pay for a general manager, or CEO, is eight times as much as the lowest paid worker-owner, it can be more or less depending on the type of business, this is an average."

"Eight times!" exclaimed Bill. "You said that the annual minimum salary was about 12,000 euros. Does this mean that the CEO makes only about 100,000 euros... let's see... about 120,000 U.S. dollars a year?"

"That's right, Bill," I said as I turned to Sarah. "Now we can start talking about solidarity. The principle of Payment Solidarity states that the ratio between the highest and lowest paid worker-owner must be kept at a determined ratio. At the same time, a comparison with similar jobs outside of MCC is maintained, and the ratio can be increased if the difference grows too far out of proportion."

Bill leaned forward on the table. "And who decides when to change pay ratios?"

"Like all important decisions made at MCC," I said, "it's the worker-owners who decide by voting, after reviewing the pay comparisons, if the CEO's pay is to be increased in their own cooperative. This is why the participation of worker-owners is so important at MCC."

"As in any democracy," said Sarah.

"Indeed," I replied. "If people don't participate in the debate, if they don't vote, the power of the people in a democracy is diluted."

Bill looked at me intently. "So worker-owners participate in all decisions?"

"Not exactly Bill. Worker-owners compose the General Assembly, and they participate in electing a Governing Council. This council selects a CEO who makes day-to-day decisions, but all major decisions have to be discussed with all worker-owners."

I paused to allow Bill and Sarah to think about what I was saying. "It's precisely the participation of worker-owners that created and continues re-creating MCC, because they make all major decisions."

"Because they vote?" asked Sarah.

"Voting in general assemblies is the ultimate confirmation of a decision but it's only part of the participation process. Previously, worker-owners participate by analyzing information, discussing issues in small groups, and naming peers to represent them in corporate level meetings and congresses."

I paused and looked at both. Sarah continued looking at me eagerly and Bill looked at his drink, but I could sense he was now listening as intently. "And worker-owners also participate in self-managed teams and in the design of their own jobs." 
"What is a self-managed team?" asked Bill.

"In jobs that require teamwork, worker-owners decide how to organize tasks, how often to rotate jobs, how long rest breaks will be, and so on. This does not only give more freedom to the worker-owners but is also less costly because it reduces the number of supervisors."

"Cooool," said Sarah looking at Bill.

I smiled and wondered why older adults can never quite imitate the way young people utter that word. "But participating does not only mean having rights. There are also responsibilities to be educated about the issues, to stay informed, debate, compromise, stay involved throughout the process, discern, and vote on the issues."

"Again, like in any democracy," emphasized Sarah.

"Yes, like in any democracy, or actually like in any participatory organization." I replied. "Individual responsibility, not paternalism is what prevails in a democratic workplace such as MCC."

"But there is individual responsibility in all organizations," protested Bill

"This is true when you talk about your own job," I replied. "As far as doing it right, for example, that is our individual responsibility. But making the major decisions about the organization in which we work is a paternalistic process in most cases. Why? In my view, it's because the people at the top of the organization behave as parents who think they know best, and consider employees as children who need to be told what is best for them."

I knew I was provoking Bill and Sarah so I stopped. "What else can you tell us about solidarity?" asked Sarah.

I smiled. "I can see that you are really interested in solidarity. Tell me, what is solidarity to you, Sarah?"

"I'm not sure. I see it as sharing. Being interested not only in your own good but in the good of others also. Helping those who have less."

"Like charity?"

"Yes," replied Sarah.

"I see it more as being related to justice than to charity," I said, "but it's only an opinion. Let me tell you what MCC does and you can judge for yourself." 
"Excellent," said Sarah.

"I've already told you about payment solidarity but we can find that solidarity, as participation, permeates practically all of MCC principles. I will be specific now. MCC has a stated objective to create cooperative quality jobs. This is part of the Social Transformation principle.

"And how are jobs created without affecting productivity? This is one of the most important economic problems back home," Bill said, showing interest again.

"Jobs are created at MCC primarily through growth, not loss of productivity," I said, "since MCC products compete in open markets around the world. Growth happens mainly through increasing market volume or share, mergers and acquisitions and, lately, globalization. The growth I have seen since I became acquainted with MCC in 1995 is from 28,000 to 66,000 jobs."

"And how do they finance such growth?" Bill asked, apparently surprised at the numbers.

"Through solidarity."

Bill looked at me intently.

"Mondragón," I continued, "finances this growth with its profits."

"But the profits belong to the workers," replied Bill immediately.

"Exactly, Bill," I said, "this is why I said that growth is financed through solidarity. As all other major decisions, it was the worker-owners who voted to use their profits to create jobs."

"How?" asked Sarah, reentering the conversation.

"Bear with me and I'll give you some details. Worker-owners have increased the collective reserve fund, financed with their profits, from $20 \%$ required by law to $45 \%$. They also have increased the fund by keeping an additional $45 \%$ deposited in their individual accounts at the Caja Laboral bank. The profit sharing invested in the collective reserve fund is given up totally and the deposits in the individual accounts are claimed at retirement. This means that almost all profits are available to finance growth and job creation."

"Awesome!" exclaimed Sarah, opening her eyes wide while looking at Bill.

I looked at both and emphasized. "Worker-owners decided to participate in job creation by investing their profits."

"And the other 10\%?" asked Sarah. 
I could see Sarah was following my words closely. "The other $10 \%$ of profit sharing goes to an educational and promotional fund for community projects and to the dissemination of the Basque language and culture. This $10 \%$ contribution is mandatory by Basque cooperative law."

We stayed silent for a moment. "This is why I consider that MCC's solidarity is oriented mostly to social and economic justice," I said. "Ninety percent of the profits are dedicated to job creation, one of the most effective ways to promote justice, and ten percent are dedicated to the community, which can be identified more closely with charity."

"It's about teaching someone how to fish instead of giving them a fish to eat today," said Sarah smiling. "Justice not charity, we all deserve to earn the means to survive."

"I think so," I replied. "MCC considers that a job is a right that should be extended to all. And once a person has a job, it is protected. I see it like at MCC everyone's job is 'sacred'."

"What do you mean?" reacted Bill immediately. "It's impossible to expect organizations to keep people employed in good and bad times if they want to improve profits."

"We have been led to believe it is the only way to improve profits, Bill, but it is worthwhile to question if it is true," I replied. "Perhaps firing people is a convenient and fast way to improve profits in the short term and this is why I think it's the first costreduction measure taken in our organizations. At MCC, this is the last resort and MCC is still very profitable. No worker-owner has ever been fired from MCC in its almost 50 years of history."

"Really?" asked Sarah, enunciating slowly. "And how they do that?"

"Since they believe in creating and protecting jobs, there are policies to manage diverse situations. For example, worker-owners who are displaced because of a market slump are relocated to other cooperatives. If necessary, these worker-owners are retrained for new jobs. This is established in the principle of Intercooperation."

"And who pays for this?" asked Bill.

"There is a collective fund to finance these processes."

"And how is the worker-owner paid?" continued Sarah.

"The worker-owner earns $80 \%$ of his last pay if a job can not be found immediately, but this is rare. If a job is found in a farther location, the worker-owner is compensated accordingly. Also, the worker-owner keeps his previous pay while he is doing the new job if the new job is rated at a lower level." 
"Wow!" exclaimed Sarah.

"Sarah," I added, "let me tell you how I see solidarity as practiced in Mondragón. To me, it is like concentric circles," I said, making a circle with my hands in front of me. "The closest one to the center is solidarity among peers at work. This is attained with policies based on solidarity, that is, helping each other instead of competing with each other."

"That sounds good," said Sarah

"Yes, but as Arizmendiarrieta used to say, keeping it at this level still remained a selfcentered approach, not at the individual level but at the small group level. So, solidarity moves to a larger second circle," I again placed my hands in front of me simulating a larger circle, "with solidarity with the community. This consists of job creation and community projects that I have mentioned."

"So solidarity in its more developed form extends beyond the organization," said Sarah.

"Yes," I replied immediately. "In 1999, MCC worker-owners decided that they wanted to extend solidarity also to others beyond their community. This would be part of the Universal Nature principle that addresses solidarity with those who promote economic justice around the world."

"Whoa, whoa," said Sarah pushing her chair back as she spoke. "And how do they do that?"

I smiled broadly. "MCC has entered into a joint venture with the Basque government to help people in the so-called developing countries to share the cooperative model, help finance basic institutions, and educate the people involved. This is done through an organization called Mundukide."

"And what countries are involved?" asked Sarah, still somewhat incredulous.

"Well," I replied, "at this time there are projects in Mozambique, Colombia and Ecuador, and there are idea-exchange sessions held at the Otalora Training Center annually with people from African and Latin American countries."

Sarah and Bill just looked at me. The grandfather clock in the room indicated it was 9:30. "What else can you tell us before we end our session?" asked Sarah.

"There are still two principles I haven't talked about," I replied. "One has been implied all along but I have not mentioned it explicitly. It's called Participatory Management. I will not elaborate, since I am sure you already saw the role of participation throughout all principles."

Sarah nodded. Bill shifted positions on his chair. 
"And there is one more principle," I added, "this is written at the end because it encompasses all others. It's Education. Arizmendiarrieta said from the beginning that without education, the ability to participate, the willingness to share, the quality of the decisions made would suffer. To him, this was the most important principle."

"David, we have not talked about A-riz-men-di-a-rrie-ta! - Sarah pronounced the name slowly and correctly.

"That's right, I am sorry we have run out of time."

Sarah leaned forward, opened her eyes wide and looked at me intently. "Can we meet tomorrow? She leaned back and breathed in noticeably. "Oh, I hope it's not an imposition..."

"No Sarah, it'll be fine if we can find a way to do it." I took my calendar out of my briefcase. "I have a meeting at 10:30 tomorrow morning but we could meet afterwards."

Bill looked at Sarah. "We agreed to tour the Rioja region tomorrow and get some red wine, don't you remember?"

"Yes, I know, but this is the only chance we have to hear about the founder," she said.

"You can call him Don José María, most local people do, it's easier to pronounce," I suggested.

"Right." Sarah looked at Bill. "I'd really like to know more about-Don José María," Sarah turned her head and looked at me, as if seeking approval for her pronunciation.

I smiled. "We can meet before my appointment if you wish so you can still head south in the morning.

"Great," said Sarah. "Should we meet here? And at what time?"

I put my calendar away. "It may work out better if we meet at the Eskola Politeknikoa, the engineering campus of Mondragón University. How about 9:30? Do you know where the university is? You can walk to it from here in 15 minutes."

"We'll find it David," said Sarah.

"How about meeting in the garden? There are benches close to a statue of Don José Maria. He kept an office there, you know."

"Great, see you tomorrow," said Sarah, smiling. Bill nodded his head to say goodbye. He was not smiling. 
Jokin called me that night at the hotel. "David, we have eight names. One preferred not to participate so I called the next one on the list and he accepted. I also made appointments on the dates you told me you were available. The first two are scheduled for next week."

"Thank you so much, I didn't expect such quick response!" I exclaimed.

"I know you need to get this done as soon as possible. You've told me this is only the beginning..." said Jokin.

"Right you are!" I said emphatically.

"You will meet all of them informally first. I have asked them to meet with you some time this week, as you requested. You know Jon and Aitor. They will meet with you at the hotel the day before you meet the rest of the group and will tell you more about your future collaborators. I told them you'd like to meet at least twice as a group. Not everyone can be there for the whole time."

"That's fine, we'll have a chance to talk privately during our personal meetings."

"David, I know you'll enjoy meeting these people. I think they will be willing to help you as much as they can."

"Thanks again, Jokin." I said.

"Goodbye, David."

"Goodbye."

I hung up the phone and smiled. I appreciated even more what we had learned about gaining access to your collaborators. How could I have done this without the help of my friend Jokin? And what about my first two collaborators? The four of us had a one-hour meeting just to decide who would be the best collaborators for my study! One had traveled from another location. Both could certainly have used the time they spent with Jokin and me doing something else. I felt grateful to experience what it is like to be in a culture of participation, in which they were focusing on something that was important to me, not them.

The next step was meeting with my collaborators. I reviewed my self-dialogue and my guiding questions for them. Being the first time we met, I intended to start with general questions. If the conversation progressed as I hoped, and everyone felt comfortable to 
talk about more personal issues, I would ask more probing questions. I, however, had to be prepared for either situation. I felt the excitement of the upcoming days and weeks. I sensed it was going to be an incredible adventure! 


\section{CHAPTER 4}

\section{ARIZMENDIARRIETA AND HIS ROLE}

I arrived early to my appointment with Bill and Sarah and stood in front of Don José Maria's bronze statue in the Eskola garden. His figure elicited an unusual feeling. So many times I have raised my eyes to see oversized statues mounted on tall foundations with an inspiring message, depicting the honored person as an unreachable image, larger than life, dressed elegantly, fearlessly looking forward. Military heroes may also be mounted on powerful horses, sometimes with sword in hand. Don José María's image offers a stark contrast. It is life size, supported on a two-foot platform with the simple inscription "José María Arizmendiarrieta, 1915-1976." It is the image of a man about 50years old, sitting down on a stool, with a priest collar and civilian suit. He is wearing glasses, looking slightly down and to the left. His arms rest one on his right leg, the other on the chair's arm. He is holding a small book in his right hand. I never met Don José María but I look at his image and sense him as an accessible person.

"Buenos días, David," said Sarah, standing behind me. It looked like she had been there for a while, silently waiting, probably not wanting to interrupt my thoughts.

I turned around and smiled. "Buenos días, Sarah... where is Bill?"

"Oh, he decided to leave early to the Rioja region, to buy and drink some wine before coming back tonight, he said."

"Hey, you sound upset," I told Sarah.

"Yeah, we had a fight last night because he didn't want to come today. He said he didn't believe what you told us last night was possible, that there had to be a catch."

"Sarah," I said, in a soft voice. "Don't be too harsh on Bill. Many people feel threatened when they hear about the Mondragón experience. Most of us have been exposed only to one way of organizing work and have been "programmed" to believe it is the best. Becoming aware of the success of Mondragón means changing our way of seeing our work and our life. It takes time and not everyone has the courage to embrace another way of doing things."

"Right, David." Said Sarah, looking at Arizmendiarrieta's statue. "I understand Don José María was quite a man."

It was clear she did not want to talk about Bill. "People who knew him say he was extraordinary," I replied.

"Did you know him, David?" 
"I wish I had," I said longingly. "Don José María died when he was 61 years old, almost 20 years before I visited Mondragón for the first time in 1995 . What I will share with you today, I learned from what his disciples and others have written, excerpts from Don José María's journals, and what my Mondragón friends have told me."

"Great!" Sarah said, sitting down on a nearby semi-circular concrete bench partially shaded by a tree and taking out a small notebook and pen from her purse.

"How did he do it, David?"

I sat next to her. "What do you mean, Sarah?"

"Yes, how did he convince his five students to start Mondragón? I read a little bit last night about Don José María and the founders. It would have been easier for these young engineers to get a job at the big company in town."

"You mean Union Cerrajera," I said. "The founders were among Don José María's students who started to work in this company after graduation. He didn't convince them to start Mondragón. What he did was to educate them to a different way of thinking and working."

"Cooperating?" asked Sarah.

"And participating." I said. "Don José María taught his students that they should always be able to speak their mind, get involved in discussions, give their opinions, debate..."

"Was that at school?"

"Don José María created spaces for his students to participate after school."

"Can you tell me more details?"

"He organized 'circles of study', discussion sessions about social and economic themes. Don José María stimulated them to discuss and feel responsible for their solutions from the time they were teenagers. Ormaechea, one of the founders, estimated that Arizmendiarrieta conducted more than 2000 of these circles from the time he arrived in 1941 to 1956 , when the first cooperative was created."

"Wow!" Sarah exclaimed. "So he focused on young people instead of adults."

"Yes, as I mentioned last night, Don José María believed the most important task of society was education. He promoted education in technical and management subjects but also in values and behavior. He envisioned these young men, armed with solid professional knowledge and a firm belief in ethical human values, would transform the social order by participating in the important decisions for the community." 
"Was Don José María trying to transform the Mondragón society from capitalism to socialism?"

"This is a good question, Sarah, and I am going to give you the long answer," I warned her with a smile. "Don José María did not believe in 'isms': Catholicism, capitalism or socialism to him were equally worthy of study. He believed in the dignity of persons, justice and solidarity, which have been Christian values throughout the ages and are the foundation of the ten principles. He also thought that capitalism had something to offer, such as the proclivity to work and the quest for efficiency and productivity.

"And what about socialism? asked Sarah.

Socialism, in theory at least, offered the concept of a classless society and collective ownership. These ideas from socialism of course were disregarded in the Soviet Union so Don José María criticized that brand of socialism. He also criticized Catholicism, or rather its institutions, because they were autocratic and capitalism for its deviation from Adam Smith's original idea, pursuing instead selfish interests and neglecting the common good.

"So Mondragón's system is not capitalism or socialism..."

"Mondragón is the prime example of Cooperativism. Don José Maria called it 'the third way', equidistant from individualistic, egoist capitalism and soulless, depersonalizing socialism. Cooperativism, he added, kept the dignity of the human person at the center. He believed in values that prioritized human beings as persons and as members of a community."

Sarah stopped writing. "So he taught these values in the classroom."

"Don José María preferred to talk to students at the study circles after school. He was a great communicator in one-on-one situations and in small groups. His young disciples found in Don José María a source of inspiration when he talked to them in these environments."

"How long did Don José María know these young men to be able to influence them so much? After all, they lived in a Western European society, similar to ours in the United States."

"He knew them since he arrived as a young Catholic priest in Mondragón in 1941, when the founders were teenagers. Don José María walked into a poor society, a demoralized community with high unemployment and few job opportunities. The Mondragón people call this period "the years of hunger." Some of my friends here have told me they remember being poor. Don José María illuminated these people with a new vision. He spoke of solidarity and the dignity of people and their work. He said that work was not a punishment but a way to cooperate with God to transform our world, so job creation was a priority." 
"By what you told us last night this vision was translated into principles that Mondragón lives by even today," said Sarah.

"Yes, but Don José Maria was a practical man. He firmly believed in certain principles but insisted believing was not enough. They had to be put into practice."

"So Don José Maria's role was influencing the young people with certain values early on to apply later at work," said Sarah.

"Not only that. Don José María's influence was felt throughout his life. Yes, he was the spiritual leader behind the young people and community that founded the Mondragón cooperatives in 1956. But he did much more. Don José María stretched the young founders to their limit and was never satisfied with their accomplishments. He was a visionary and was always a step ahead of them. For example, he started this university." I pointed vaguely at the buildings surrounding the garden. "It became a professional school in 1957 , the year after the foundation of the cooperatives."

"Wow." Sarah said, eyes and mouth wide open. "Some vision!"

I smiled. "But this was just the beginning. Don José Maria insisted that the cooperatives needed their own source of financing to grow at the pace required. The founders were not convinced because they knew nothing about banking but, after much insistence from Don José Maria, they reluctantly established the Caja Laboral bank in 1959, only three years after the first cooperative was founded. Without the bank, MCC would not be what it is today. So, you are right, Don José María had 'some vision' "

"I see. I saw the financial division figures in the video yesterday, they are now an important part of the Mondragón operations," said Sarah.

"Yes, and although the original intention was to create the bank to finance the cooperatives' growth, it was open later to the community," I said, as Sarah took notes.

I paused and looked at Sarah. "I'll give you one more example. Don José María proposed that the cooperatives needed their own technology to reduce dependence on foreign research. In 1968, a research department was founded within the university grounds, and ten years later, it was expanded to become the Ikerlan research center. It was established in its own building up the road from where we are," I signaled with my raised hand up the hill, in the general direction of Ikerlan. This new venture was financed completely by the cooperatives and the Caja Laboral bank. The bank's headquarters are higher up on the same road, on the way to MCC headquarters."

Sarah wrote down what I had said, turned the page and placed the tip of her pen on the top of the new page. "Can we talk more specifically about Don José María's values? I'd like to write them down." 
"Yes, of course. Most of them are obvious in the principles that we talked about last night. The dignity of persons and their work, the primacy of work over capital, social and economic justice, democracy, participation in decision making, solidarity, education..."

Sarah scribbled my words quickly. "And the less obvious values?"

"Those values are not always spelled out, they are implied." I said, realizing how closely Sarah was following my words. "Let me highlight some of what I call the Mondragón over-arching principles, which permeate all others."

"Good," said Sarah.

"The first one is 'work'. Don José María saw work as a means to self-realization, not as punishment, as I said earlier. A person that doesn't work misses the opportunity to participate in the transformation of the world. Some of the Mondragon policies reflect this principle. One example is the stated objective to create jobs. Another is the system to transfer displaced workers from one cooperative to another. Instead of having an unemployment fund to support idle workers, Mondragón has a system to get people back to work as soon as possible. This directs people towards gaining in self-realization instead of towards losing in self-esteem."

"Totally awesome!" Sarah said, looking up from her notes.

"Another value is 'freedom'," I said. "Without freedom, we can't seek the truth on our own, having to resort instead to those in authority. Freedom allows us to speak up, participate in decision making, agree or disagree with the boss, and so on. Freedom allows us to become better persons, as we are able to choose our path and forge our future. Democracy at Mondragón exists because there is freedom."

"One-member/one-vote, you said, that is democracy," said Sarah.

I nodded. ' Justice', economically and socially, is another principle. The open admission policy, ability to participate in the management of the enterprise, and solidarity in pay are supported by a quest for justice."

I paused. "This is justice in action, having the right to work whether I am rich or poor, the right to be part of the group that makes decisions that affect me, the right to earn enough money to support you and me and our families." I was surprised I had pointed my finger at Sarah and myself, as I said the last few words, as if I were talking about us. Or perhaps I was...

"Let me see if I wrote what you said," Sarah said, looking at me and then her notes.

"There are those values which are clearly stated in the principles: the dignity of persons and their work, the primacy of work over capital, democracy, participation in decision making, solidarity and education. And then there are the overarching values: work, freedom, economic and social justice." 
"There is one more," I said. "It is called 'equilibrio'."

"Balance," Sarah said, recognizing the word.

"Yes, but those who write about Mondragón in English call it 'equilibrio' because it has a broader dimension than the word 'balance'. It implies taking time to discern who is affected by a decision and making it accordingly, seeking equilibrio. This is important because socios participate in decisions made at their cooperatives often, which implies a big responsibility."

"So the consequences to affected parties are considered when making a decision," Sarab said.

"Yes, Sarah. Equilibrio can be applied to any decision that implies a conflict of interests of worker-owners versus their organization, a cooperative versus others in the

Mondragón system, social versus economic objectives, the cooperative system versus the community..."

"Equilibrio is based on justice," said Sarah.

"That's right. Decisions are not 'either/or' with one winner and one loser, but 'both/and', a win-win situation. This implies not getting all I want at the expense of another. I call it 'enoughness', a word I learned from Charles Handy, an Irish management writer. It refers to my willingness to share whatever good is at stake when I have enough of it. It supports the common good and is opposite to pursuing exclusively my self-interest, which sometimes is taken to the point of accumulating goods I don't need."

"I'm going to have to think this through later," Sarah said, looking down at her notes and paging back through them slowly. "For now, I am still trying to understand the role of Don José María. As I see it, he really was the leader of Mondragón," Sarah asserted.

"If we look at what Don José María did in more than 30 years in Mondragón," I replied, "we would conclude he was the leader. He was behind all important decisions but was very modest about the accomplishments of the cooperatives. Don José María always said he was not a leader or an entrepreneur. 'I just propose ideas,' he once said, 'the young people do everything'."

I leaned forward. "Don José María described himself as a teacher. He was involved in education throughout his life."

"This is why he founded the school first," Sarah said.

"Yes. The only technical apprentice school in Mondragón then was in Unión Cerrajera, the only large company in Mondragón. This school was only open to the sons of its workers while Don José María's objective was to offer education to everyone. One of his 
sayings that is often repeated today is 'it is necessary to socialize knowledge in order to democratize power'. Education should be available to all, education is power."

"And what did Don José María teach?" asked Sarah.

"Several subjects, among them sociology and ethics, but his main teachings were outside the classroom. He firmly believed that the most important learning happened when education and practice were put together. For example, he taught the young people of Mondragón to finance their projects with organized raffles, festivals, and other public events. These activities helped to obtain funds, of course, but also gave the enterprising young men practical experience. In addition, it gave them visibility in the community. These were the men who started the Mondragón cooperatives later.

Sarah moved to the end of the bench, positioning herself so that the sun shined on her bare arms and legs. "You have told me about the men, David. What about the women?"

"Interesting question, Sarah," I said. "Let me tell you what I have learned about your question. Women here assumed the traditional role of women elsewhere at the time. In the fifties, Basque men worked and women took care of the children and stayed home. In the sixties, as in other places, Basque women started to work outside the home but not at the same level as in the United States, where women had become a significant part of the workforce during World War II. Many Basque women had little formal education. Those that worked in the cooperatives in the sixties were in low-paid office support, blue collar or personnel jobs. In the 1970 s more women joined the cooperatives and by the end of the decade, almost one third of cooperative workers were women. This is a brief piece of history and I hope it answers your question."

"Pretty much. But tell me, did Don José María have something to do with this change?" asked Sarah.

"Yes. At first he believed as the rest of society, men work, women take care of the family and home. In the early seventies, however, he began criticizing masculine 'superiority' and called for equal rights for women, saying that half of the total population doesn't have the right to rule the other half. He said that work resulted in economic gain, as well as individual and community self-realization, equally for men or women."

"And did he do something practical to help the situation?"

"Yes," I said. "Arizmendiarrieta supported Auzo Lagun, a catering service cooperative, organized by married women who could work only part time. By 1985 it was producing 4000 meals a day. I know some of these figures because we have hired this cooperative to cater a dinner for next month, for participants at a University of Deusto conference in Bilbao. I am coordinating these arrangements." 
Sarah looked at her watch. "David, it's almost time for your meeting. I wish we had more time. I am going to walk up the road. Can you tell me what I have to look for?" she asked as she put her notebook and pen away.

"Of course. As you will see in the map engraved on the sign at the bottom of the hill, you will first find the headquarters for Lagun-Aro insurance on the left. As you continue climbing up the road you will see Ikerlan research center to your right and ALECOP below it. Then the Caja Laboral bank headquarters on the left and the three-story, coppertinted symmetrical concrete structure housing the $\mathrm{MCC}$ headquarters higher up on the hill. It's a good walk and the view is great. Looking behind you, towards the Mondragon, you will see the six- to eight-story residential apartment buildings perched on the town hills. Looking ahead of you, you will see the pine-covered mountains with some reconstructed 'caserios', the large white-walled and red-roofed buildings where Basque people used to live in past centuries. At this time of the year, you will also see sheep grazing on the green pastures and verdant fields with white and yellow sunflowers."

"Good, David, thank you so much, you have been very helpful," she said extending her hand to say goodbye. "Perhaps we'll meet again."

"It's been a pleasure. You exude great energy, Sarah," I said, while we shook hands. "I was very happy sharing the Mondragón story with you yesterday and today."

I looked at her as she walked away. Then she stopped. She walked back and stood in front of me. "David, I'd like to tell you something before I leave." She looked at me intently. "You talked about the courage to embrace a different way of doing things. I would like to do that. I want to participate to make a difference in our world. I wish I could apply the Mondragón principles to my work in the future. I wonder if I could do it back home."

"Sarah," I said, understanding her concern perfectly. "It's not easy but it's possible, if you find others who think like you and are willing to embark on the same journey. You must keep in mind that you will depart, and often defy, conventional wisdom and traditions about organizations. You may also find people who will try to dissuade you. Seek those who will encourage you and are willing to forge ahead with you. It's possible to take a different path. It's possible to make a difference, as the Mondragón founders did."

Sarah didn't move, her large brown eyes fixed on mine. I said: "I'll leave you with a final thought from Don José María. When asked how he and the early Mondragón socios decided what to do, having no models to follow, he would repeat the words of Antonio Machado, the Spanish poet: "We build the road as we travel..."

"Thank you David." She hugged me and walked away.

I stood in front of Don José María's statue. I almost felt he could hear me. How many people have told me what Sarah did? How many others have asked: what do I have to do 
to change the way we work? I wondered how many times he had heard the same comments and was asked the same questions....

After my meeting at the university, I walked back to the hotel. I was still thinking about Sarah's words. I remembered a visit I made to a cooperative in another part of Spain. The G.E.C.V cooperative group in Valencia, Spain, is modeled after Mondragón. I have a friend there who told me the following story:

The founders of the G.E.C.V. cooperative group visited Don José María at Mondragón and asked him: "What do we have to learn from Mondragón so that we can be successful with our new cooperative group?" Don José María replied: "See everything you can in the Mondragón cooperatives and make sure you do not copy anything you see here. Look at your own situation and adapt only what applies to you. As to the rest, decide it together and do something different but appropriate to your situation.

I wondered if Sarah would find a way to change the world. Young people like her are what keeps me enthused about Mondragón and its potential to change the world of organizations. Some day the change will come, we just have to keep planting seeds..

A few days later, I walked up the cobbled street towards Saint John the Baptist's church. The plazas, the streets, the narrow pathways were all deserted. Two elderly couples and a few women were walking ahead of me. Only those going to Sunday Mass could be seen on the street so early.

I entered the church through the back doors. I have always marveled at Europeans' desire and skill to preserve antique structures, providing the comforts of modern technology without disturbing the exterior facade. These massive buildings could more easily be demolished than rebuilt but there seems to be a reverence of the past that is not seen in other Western countries on this side of the Atlantic Ocean.

I walked in and welcomed the cool temperature from the air-conditioned system. I sat on a pew close to the front of the church, right under the pulpit. I looked up to the four tall, narrow stained windows, depicting the twelve apostles in the middle two and the four evangelists on the other two. Ilooked at the simple statue of St John the Baptist high above the altar, disproportionately small as compared to the six massive columns with high Gothic arches running across and along the church walls. There were mostly gray heads around me in the sparsely attended Mass. Participation in church rituals may have been widespread in the past but this Mass was not the place to find it today. The men wore suits or slacks and plain-colored shirts, the women black or subdued-colored dresses. It reminded me of my childhood years in Mexico, when everyone dressed up and women covered their heads in church. Today, however, there were no children running up and down the aisles, no teenagers attending mass together in small groups, no whispering before mass. This was the main difference: the silence. 
I stayed in my pew after Mass. There was no more silence. I could hear the departing people chatting away, as is customary in Latin countries, except that they seemed to linger in front of the church for a longer time. "Perhaps this is because it is a small town," I thought. I imagined Don José María in the pulpit, the people outside as youngsters listening to his homilies, the difficult times they must have lived. I was deep in my thoughts when I felt a hand gently touching my shoulder from behind. I turned around and sprang to my feet. "Hello," I said smiling to the elderly priest. He smiled back. "I am sorry, I did not mean to disturb you but I could not fail to notice you. You are the only one left in the church. We have not met. My name is Padre Antonio," he added, extending his hand. "I have been staying in Mondragón this summer. I gather you are also a visitor."

"Yes," I said, as I shook his hand. "My name is David Herrera." I realized as I looked at him that he was not the same priest who had officiated Mass.

"Where are you from?" he asked.

"I live in San Diego, California but I was born in Mexico."

"I see, and how long will you be visiting us?"

"I arrived a few days ago and will be here for ten weeks," I replied.

"Ten weeks!" he said, sitting next to me. "I have been here almost as long but must leave tomorrow. Are you here for business with the cooperatives?

"Not exactly. I am writing a book about workers' participation in decision making, as lived in the Mondragón cooperatives."

"Well, then you must be writing something about Arizmendiarrieta!" he exclaimed.

I smiled as I looked at Padre Antonio. He had an alert demeanor and a jovial face, was quite slim and sat very straight. "He must be in his seventies," I thought "Perhaps he was among those who listened to Don José María when he preached..."

He reacted to my smile, and I wondered if he knew what I was thinking.

"Arizmendiarrieta and I went to the seminary together. In fact, we were born in the same town, Markina, in Bizkaia."

"Padre Antonio," I said, "I thought you were one of his disciples!"

He laughed. "How could I be? I am 87 years old! Arizmendiarrieta was two years older than I am." 
"What can you tell me about him?" I asked. "I am not focusing my writing on Arizmendiarrieta but knowing about him will enhance my understanding about participation."

"Well, what would you like to know?" he asked.

"I have read what the founders of the cooperatives and others from this community have written," I said, "and there are a few books in English that refer to him. I have also asked my local friends about Don José María. Perhaps you can tell me more about him as a person, from your perspective as a friend."

"I will call Arizmendiarrieta 'Don José Maria', as you and many others do, so that we can refer to him by the same name," said Padre Antonio. "He and I knew each other since we were young. We joined the military together during the Civil War. As you probably know, the Basque people aligned with the constitutional government and we lost the war with Franco's Fascists."

"Yes, I know about the war. What did you do in the military?"

"I enlisted as a soldier but Don José María enrolled as a journalist because he had lost an eye in a childhood accident."

He paused and looked at me intently. "He was almost killed in the war..."

"Oh, yes," I said. "I saw a list with his name among those to be executed in the Arizmendiarrieta museum in the Otalora training center. Can you tell me what happened?"

"I remember it well," said Padre Antonio. "He and I were in prison with twenty-seven Basque companions for about a month. When Franco's occupying forces questioned Don José María about his livelihood, he said he had been a soldier in the Basque army. This saved his life because he was classified as a prisoner of war. Don José María's colleague said he was a journalist and was executed. We were ordered to join the Civil Guard because the army officials thought we were both soldiers. We spent the rest of the war in Burgos and finished our university studies at the seminary after the end of the war."'

We stayed silent for a moment. "What was he like?" I asked.

"Don José María was an unusual person. He was a driven man with a mission: changing society to make it more humane, focusing on the world of work as a vehicle to achieve his objective. He was a tenacious man with boundless energy, which he applied to his numerous cooperative projects. He was an avid reader and was always well informed about topics related to his goals and knew and used the power of information to justify his projects."

I leaned forward. "How did he use that information?" 
"He constantly made alliances and capitalized on his influence to help cooperative projects come through," replied Padre Antonio. "He often defended his projects with the skills of a politician, as many of them were not popular among some members of the community, the government, the church, or the rich people in Mondragón."

"And what about his personal life?"

"Don José María was very austere in his ways. He had simple tastes with no interest in material comforts for himself. He rode a bicycle to his office at the Eskola Politeknikoa, the engineering campus of Mondragón university today. He never accepted his friends' suggestion to buy a car, although he had a heart condition. He had an open-heart operation and depended on a pacemaker for the last years of his life. His slim figure, with receding hair and sunken cheeks, was a familiar sight in his later years, when he walked in the streets of Mondragón."

"How did he perceive his role in the development of the cooperatives?" I asked.

"If he saw his role as important, he did not show it. He always talked in collective terms, rarely used the pronoun ' $I$ ' when talking about the achievements of the cooperatives, although he usually was instrumental to their success."

"I understand that he never intended to write a book about the Mondragón experience, his life or his work," I said, seeking Padre Antonio's confirmation.

"That is correct. He wrote in his personal journal but not for publication. He constructed very complicated sentences and long paragraphs that contained several themes. But, when he got to the core of his ideas, he explained them in powerful sentences. This is why some of his thoughts have been expressed as maxims and slogans, often quoted today. Have you ever read his writings? Some people at the cooperatives have taken extracts from his journals."

"Yes, I have." I replied. "In fact, five of us in San Diego translated Don José María's writings from his book 'Pensamientos', which has excerpts from his journals. We called it "Reflections" in English. We indeed found it difficult at times to understand what Don José Maria was trying to say."

"I am not surprised."

"I understand he also preferred to participate in one-on-one conversations or small groups,"I continued.

"Yes. People that knew Don José María said that he was not a charismatic speaker in large audiences, in church or in class. He articulated his ideas in very complicated ways and people did not understand him. In his interactions with small groups, though, he talked about subjects in depth instead of engaging in superficial conversations." 
Padre Antonio smiled. "My friend José María was very intelligent and had firm ideas but was not able to articulate them easily. He would move his hands incessantly when he talked, emphasizing what he was trying to say, often to no avail."

I suddenly realized I move my hands the same way when I am excited about what I say and instinctively crossed my arms.

"We used to have long discussions about social and economic theories and possible solutions to local problems when we were students in the seminar," he continued.

"What did you study at the university?" I asked.

"We both studied philosophy and theology as undergraduates in the Seminario Mayor of Vitoria. We were accepted at the graduate school in sociology at the University of Louvain in Belgium..."

"Really? I went to school there!" I exclaimed.

"So did I!" replied Padre Antonio. "I studied a Masters in Sociology, are you a sociologist also?"

"I studied a Masters but in Applied Ethics to Business,"

"Interesting. I graduated in 1945. And you?"

"Padre Antonio, when you were graduating, I was two years old! I graduated ten years ago, after I retired from my business career... but let us continue with Don José María's story. What happened then?"

"I went to Louvain but Don José María was instead sent to Mondragón in 1941, as a diocesan priest. Military forces still occupied the Basque Country. Mondragón was a broken society with low educational levels and high unemployment."

"I understand that education was high on Don José Maria's priority list," I said.

"Don José Maria saw himself as a teacher, with a commitment to social change. He aimed to participate with the people of Mondragón to create a freer, more just social system. Education was to be technical, moral, political, and social in the classical Greek spirit of paideia, that is, the development of a good society."

"And this good society would be created through education," I said.

"Don José María believed education was indispensable," Padre Antonio emphasized. "He believed young people were educated by learning and doing. Practice was important to learn responsibility and commitment and to enhance self-esteem, he used to say." 
"And how did he start with the young people?"

"First, he formed a sports club, then he got financing for a soccer field. At the same time, he formed 'circles of study'..."

"Yes," I intervened, "I have read about them. I also read that he created the technical school one year after the cooperatives, but how was he able to do this in a community with no funds?"

"You are interested in participation," Padre Antonio said, looking at me. "The funding of the school is a good example. I'll tell you the story:

Don José María organized a parents' association to raise funds and disseminate the idea of building a school in Mondragón. The contributors to that fund would be members of the association with the right to vote for the leaders and establish policy. Six hundred people, $15 \%$ of Mondragón population became members of this association. Some people provided cash, others taught at the school as volunteers. The school was opened in 1943 with twenty students. By 1948 the parents association became Hezibide Elkartea, the League for Education and Culture. This participatory structure, with members entitled to vote and with the right to elect leaders, foreshadowed the future organization of the Mondragón cooperatives."

"This is a great story," I said. "I have also wondered how he accomplished what he did while being a priest. How did he manage?"

Padre Antonio looked at the vaulted ceiling, as if trying to concentrate on what I was asking. "José María and I were in close contact throughout his life. I could say his path took him through different stages. At first, when he arrived in Mondragón, he was a priest like we all were, concerned with faith issues and personal problems of the community members. But he was also a pragmatist. He believed that religious ideas had to be converted into something that linked with the real world. At this time he was also dedicated to the formation of young people. A few years later he started focusing on the development of cooperativism based on the 'social question', as understood in Catholic social thought. Do you know what I mean?"

"Now I do," I replied.

"How did you learn about it?" asked Padre Antonio.

"Now I will tell you a short story:

In 2001, I was invited by my former advisor at the University of Louvain to present a paper in the Vatican about Mondragón and the 'social question'. This paper was to be written under a section called: 'Hope for the future', that is, hope of having work organized in a more humane manner. To write this paper, I 
had to learn about Catholic social thought, which I found quite interesting, especially as I connected it to Mondragón. It gave me a new perspective of the Catholic tradition and helped me to understand the consistency of its social thought throughout centuries. My paper addressed the dignity of human work, justice and solidarity, pillars of Catholic social thought, in Mondragón as compared to traditional organizations."

"So there is an interest in the Vatican about Mondragón," said Padre Antonio.

"The Pontifical Council for Justice and Peace published my paper in a book called 'Work as key to the social question'. To me, this shows some interest but I cannot say it has a burning interest in Mondragón."

"But a seed has been planted," said Padre Antonio.

"I hope so," I replied. "But I am digressing... Going back to Don José María, what happened in this second stage of his work as a priest?"

"He became concerned with issues of property ownership and social problems. He read other sources besides the Catholic encyclicals. We used to discuss Catholic social thought and $I$ know he continued using it as a foundation. But we also discussed at length the personalist social philosophers Maritain and Mounier, the classics of cooperativism such as Lambert, and the social utopians Owen, Fourier, Buchez, Blanc."

"That's quite a selection," I said.

"Indeed. We also used to discuss the thought of Paulo Freire and he had the book Pedagogy of the Oppressed in his library. Don Jose Maria agreed with Freire that education must be developed with and not for the student. Education is about participation of professor and student, in an interaction in which both learn from each other. We both also agreed with Freire when he wrote that if human beings can not participate in their own decision making, they are being treated as objects not persons. Full humanity, Freire said, can not be attained through individualism but in solidarity."

"It seems clear that Freire was a source of inspiration to create the Mondragón values," I said.

Padre Antonio nodded slowly. "I think so. He had a wide variety of books in his library, including Chairman Mao's Little Red Book, and he knew Marx's theories well. He was exposed to thinkers from all cultures."

"You said earlier he was an earnest reader," I said.

"That is right. But I would like to clarify that Don José María did not create new theories. His contribution arose from his capacity to combine the thoughts of others, finding 
pragmatic applications while maintaining the values of the human person in the center. In the process, he improved some of these theories too."

"When you speak of the human person, I assume you refer to the 'H-PAC'," I said.

"I do not know that term," said Padre Antonio.

"I am sorry, I thought you had also learned about the H-PAC in Louvain," I said, realizing it was probably a recent term, having such a title. "H-PAC stands for the 'Human Person Adequately Considered'. We are 'human persons' when we are subjects not objects, ends not means. 'Adequately considered', means that it is not enough to have work and earn a living, we need to be accepted in society as full participants in the decision making processes, social interactions and opportunities afforded to others."

"I see."

"Going back to the theories that Don José María improved," I said. "Can you give me an example?"

Padre Antonio paused and looked at me. "Yes. Mounier's idea was that an economy should exist in the service of human persons, or H-PACs if you prefer," he said smiling. "The economy, Mounier added, should promote primacy of work over capital, education and leadership as a vocation to awaken the personality of others. We find some of these concepts in the ten Mondragón principles. Do you know them?"

I nodded and said in a low voice: "Yes, I do."

Padre Antonio leaned forward. "But there is a difference: Mounier believes workers are not educated enough yet to follow his idea. Don José María contributes enormously to advance Mounier's thought with his complete trust in the capacity of workers for selfmanagement. 'The workers are mature enough', Don José María says. 'It is management that is not mature, because of their child-like selfish motives'. Don José María had rocksolid faith in the person and unlimited confidence in the worker. If he had agreed with Mounier, the Mondragón cooperatives would probably still be waiting to be created! Arizmendiarrieta's vision would not have been fulfilled."

I tried to assimilate Padre Antonio's words. I looked at him. His eyes were bright and alert. He transmitted a contagious enthusiasm as he talked about past conversations with his friend. I wondered if others perceived me when I talk about Mondragón as I perceive him. "Can we talk about that vision?" I asked.

Padre Antonio leaned back and paused for a moment. "His ultimate objective was to change society. Education for all, the creation of jobs, lifting the standard of living and raising consciousness were vehicles to transforming society." 
"I have read about this but would like to hear your perspective: Transforming society how?"

"He believed it was possible to start by changing the world of work. Don José María did not believe in transformation through paternalistic social reforms seen in existing organizations. The solution to the social and economic problems, he said, required structural reforms."

"Changing the way they are organized and managed," I said.

"Yes, but he was talking about radical change," said Padre Antonio. "Succinctly expressed, it was necessary to change from the sovereignty of capital to the sovereignty of labor."

"A concept also contained in the ten Mondragón principles."

"Yes," he answered immediately. "And also congruent with Don José Maria's idea of the priority of persons over capital, organizations or institutions. All these are needed but the priority resides with the person that does the work."

"Always the emphasis on the person," I repeated.

"Yes. I perceived his concept of the transformation of persons as a process of learning how to be more human. Don José María moved his ideas about the centrality of the person from his head to his heart, making them part of his own identity to a point that he could not renounce them. I think this is what made him a persuasive teacher."

The church bells rang. Padre Antonio looked at his watch. "I have really enjoyed talking with you. Our conversation helped me reminisce about old times and about my friend José María." He looked at me, "I mean, Don José María."

We stood up slowly. Padre Antonio looked at me. "You told me you are writing a book about participation so I would like to make one more comment before we part: Some people see the Mondragón system as something static. To Don José María, cooperativism was only a tool to transform society that, as we discussed earlier, needs to be adapted to new social realities."

Padre Antonio held me gently by the arm and we started walking towards the back doors. "Part of his legacy is an emphasis on continuous renovation. He insisted that institutions must be adapted to day to day needs. He forewarned his followers, however, that these adaptations would be suitable only if they were made respecting the will of the people who participate in these institutions."

We had reached the doors. "Thank you so much for sharing your stories about Don José María with me," I said, extending my hand. "Your words will help me to write my book. Have a good trip tomorrow." 
Padre Antonio shook my hand warmly and smiled. "It is a pleasure meeting you. I hope we meet again when your book is in the local bookstore. We can talk some more then. God bless you"

"And may God bless you, Father."

I walked down the street, smiling at the groups of people now walking up to St. Michael's.

I reached the plaza in front of my hotel and sat on one of the shaded benches under the trees. The plaza was almost deserted, there was a man reading a newspaper and two elderly women talking. My thoughts were with Don José María and his mission to transform society. Big word: transformation. I thought about his quest for a more humane society, the centrality of the person, work and the creation of jobs, solidarity instead of individualism...they all required a transformation. Institutions, organizations, workplaces had to change. But who can make these changes? People! We have created these institutions, organizations, workplaces... It is we who have to change, or rather, considering the scope of these changes, it is we as persons that have to be transformed! I then thought about participation: on the one hand, we need broad participation from large numbers of people to effect this transformation. On the other hand, Arizmendiarrieta was one person who started a transformation with a group of young people whom he educated to participate. Participation is at the core in either case. Does this mean that our transformation starts with our personal participation? If so, will you and I participate if we do not perceive our participation as meaningful? 


\section{CHAPTER 5}

\section{VOICES FROM MONDRAGON - A POETIC TRANSCRIPTION}

I got up from the shaded bench as the sun was filtering through the verdant leaves. I went up to my room and checked my activities for the next few days. I would be meeting the group twice that week. I needed to review the information package I had sent them to be prepared to answer questions. I pulled my copy from underneath my textbooks, went down the stairs and sat on a shady bench in the park next to the hotel. It was time for lunch on Sunday so the park was a quiet place to read.

The information package thanked the potential collaborators for their participation in the book project, contained the purpose of the book, explained the heuristic-

phenomenological and narrative analysis methodologies, included a flow diagram of the process, and described the intervention of the collaborators at its different stages. It also had an attachment with the abbreviated results of my year 2000 pilot study, including the complete poetic transcription. This study was relevant because it provided a Mondragón context to the book I intended to write so I read what I had written in the packet:

In year 2000, I conducted a pilot study about the Mondragón core values and their relevance to the "Mondragón experience." There were two outcomes from this study that I think are relevant to the topic of this book. The first outcome was the identification of nine core values. Participation in decision making at each worker-owner 's organization was identified as the most important core value. The other eight were democracy, equality, ownership, solidarity, self-management personal responsibility, education, openness and trust. The second outcome was a poetic transcription extracted from the interviews with the eleven collaborators in the study.

This book is in a way a counterpart to the year 2000 study. If the pilot study focused on the Mondragon values and the systems that facilitate participation in decision making in the cooperatives, the book will focus on the persons behind these values and systems. I am including the complete poetic transcription from the pilot study because I believe it foreshadows what I intend to base this book on: the voices of the people that participate in making the decisions that make these values real.

I stopped for a minute before I began reading the poetic transcription. It was written to be read aloud so I moved my lips as I went through it. 


\section{THE SOUL OF MONDRAGON}

"What is the essence of Mondragón?"

"What is the Mondragón 'experience"?"

"What is its soul?"

You ask.

This I am not able to say, not at this time..

But I know I can tell you

what it all means to me.

I'll never be rich,

I'll never be poor

I'll have all I need

and most that I want.

And I'll have enough.

At least I will know

the work that I do

will not just result

in having a few

who already are rich...

get even richer! --0--

We started small:

five men and a priest

(Don José María,

he was called),

plus some others whose names are now lost.

Times were hard, resources few,

but trust, people had, in these men

and their cause

jobs, education, better living for all.

My dad and his friends

borrowed money,

mortgaged their homes,

and worked extra hours

to help with this venture:

a dream of a few, a hope of so many...

The idea was old

the meaning was new: 
Treat your neighbor as yourself.

This now meant:

participation, democracy, equality, solidarity-all contained

in a system of justice that gives all a share. $--0--$

I can have a say about most things.

And this, I like.

Though sometimes

I don't say anything... yet I know that, where I work,

nothing important happens without my vote.

I wish I could, though, have more of a say about me, and my job,

how to make better the place where I work.

I don't always agree with the others and they don't agree among themselves.

We argue, we yell, we get angry...

But in the end

we decide and we do what is best for us all

I know that my vote

a difference makes.

So I vote at the polls,

I vote in my town, and I also vote

where I work all day.

I think I am coherent by acting this way. - - 0 --

One member/one vote

is a rule, we say, that gives us equality.

I know this is true.

But, in my view 
what also makes us equal is that

my boss and I

can talk about anything, we may disagree, we may even fight. And then we part ways, meet on the street, at the square, or at church, have a drink, have a talk.

Friends we still are, nothing has changed.

$$
-0--
$$

I am proud to be owner of something special. It is not what we do

It is that we care for those that we know and those that we don't.

$$
--0--
$$

It is not charisma that makes our leaders.

It is credibility, or rather, it's trust.

I know our leaders, look more to the East and not to the West.

They are not the omnipresent protagonist heroes.

Rather

they set the stage, get out of the way, and trust that people will do what they should.

As I said, it is all about trust.

$$
--0--
$$

And some people say:

"Yes, I understand it all, but who has the power?"

And then I reflect:

We are owners.

We make the decisions.

We elect our leaders.

So I ask:

who has the power?

For you know, 
really,

I am a leader...

and so is she...

and so is he...

and so are they.

Sometimes I lead,

sometimes I follow.

But mostly

we all lead, we all follow, we do both together

$--0--$

I like to participate,

to vote,

to know that we are equal

in life and at work.

But I also know

I must be the one

who makes these decisions:

to be educated,

to keep well informed, develop myself, and keep up with all.

If I don't do this

I'll find that my vote, my participation, won't help us at all. $--0--$

We now have a big name:

Mondragón Corporación Cooperativa, or MCC.

"Sounds better," some say,

"than the quaint:

'Mondragon experience'."

But I still like our old name better,

For we may be a "corporación cooperativa"

but we are still the "experience."

For one thing I know:

what makes us, is not our name--

it's the way we look at a challenge:

We

discuss it,

discuss it,

agree,

disagree.

Discuss it, 


$$
\begin{gathered}
\text { discuss it, } \\
\text { and then } \\
\text { we decide. } \\
\text { We change, } \\
\text { we change, } \\
\text { we evolve, } \\
\text { we evolve } \\
\text { we evolve together. }
\end{gathered}
$$

This is what keeps us alive - this is "the experience."

$$
--0--
$$

And I know this for sure: we need to make money.

But, we need to care too for those who have less...

I know that for sure.

Globalization is a need, I hear.

We must now grow in far away places-too far to go.

You know,

I am beginning to think this is needed, and so

I should let those who know decide what is best for us all.

Or should I?

I'd still like to know how decisions are made since when we lose money in Argentina

it's us that will pay. $--0--$

"Solidarity" you say?

That word I don't use... but let me tell you what I think it means.

It means sacrifice of those at the top so others like me can earn a bit more. 
It means that we all share earnings with all in good and bad times we divide it all up.

It means that we share year in and year out part of our earnings to help those without.

Sometimes it seems

I am like a Siamese twin: the pain of another I feel just as much.

And at times I feel It is like we're all climbing a mountain with only one rope. We know very well if one of us falls down we all go. -.0.-

I think this is true, we care for each other. But I fear for the future because of the ghosts that come with new words like "globalization." --0--

But in spite of my fears, my doubts, my complaints,

I prefer working here and face all these ghosts.

For we have a tradition of solving these things

by working together and finding a way.

Will this time be different?

I don't think so.

We will work through it all

as we always do.

Hard work, change, whatever it takes, I know we'll come through. $--0--$

So, you ask me: 


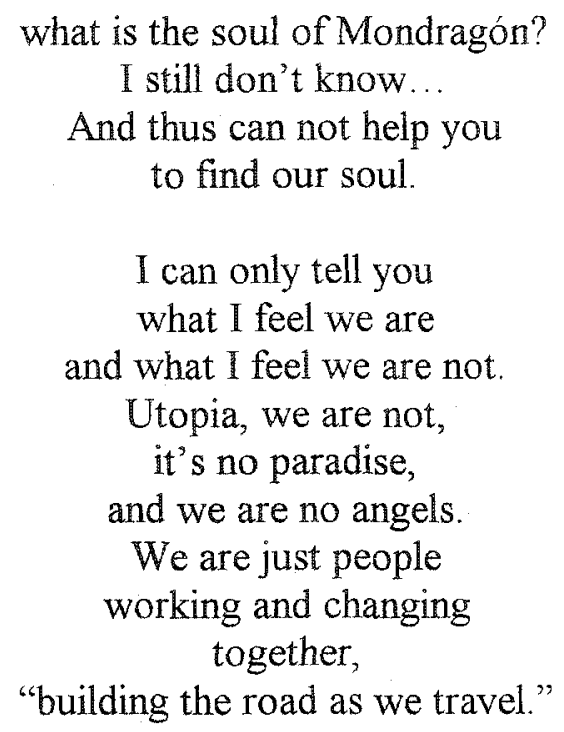

I looked up as I finished, surprised that I had read the poem with different eyes today. It seemed like I was already preparing to write this book grounded on the personal voices of my collaborators when I wrote it. The poem already singled out personal voices even though the study was designed to draw conclusions from the majority of participants. I remembered the poem was created in a spontaneous burst of writing that exploded one day when I woke up. Was I already feeling the need to hear the personal stories when I did the pilot study? I smiled as I thought that perhaps this book was indeed ready to be written ever since then... 


\section{CHAPTER 6}

\section{THE CHIQUITEO GROUP ENCOUNTERS WITH PARTICIPATION}

Jon and Aitor were already waiting for me at the lobby of the Hotel Arrasate, my "home" during the summer in Mondragón, when I arrived from my daily afternoon walk in the Monterroi park. Esteban, the hotel owner and ever-gracious host had served them some fried, moist chorizo de Ubera, an exquisite pork sausage, and a glass of Rioja wine. They were all sitting in the comfortable upholstered couches in the guest room.

"You are early!" I said, as I shook their hands. "I'll be down in a minute."

I hurried up to my third-floor room, changed clothes and returned a moment later. When I sat down, Esteban silently served me a glass of wine, smiled, and left us alone to talk.

"David, we came early to review some of the details about the people we'll meet today," said Jon.

"Great! I certainly appreciate it."

"Let's start for we do not have much time," said Aitor. "There are four women and four men in the group, including us, for a total of nine with you. We have between eight and forty years of experience, have had at least two cooperative jobs in MCC, are between 30 and 65 years old and have belonged to some management councils."

Aitor looked at me. "We hope this fulfills the characteristics you requested."

I nodded enthusiastically.

"Although all but one of the participants are Basque," Aitor continued, "they have diverse backgrounds and different family, educational and working experiences."

"As agreed, we'll meet during the chiquiteo," added Jon, "here in Mondragón. We have organized two sessions, although not everyone will be able to attend both. We have also scheduled personal one-hour conversations with you, as you requested David and have given them your introductory material."

"Excellent!" I exclaimed. "Jon, I'll have to describe the chiquiteo tradition in my book. How would you describe it?"

"The chiquiteo, as you say, is a tradition in the Basque Country. It's a way to get together with friends and patronize local establishments. As you know, it consists of drinking a chiquito or zurito, a small quantity of wine or beer in a large glass, which is often not even consumed. Groups of friends move from one bar to the next, greeting friends from other groups in each." 
"You can also have pintxos, what is called tapas in other parts of Spain," added Aitor. "I suppose you can describe them as snacks in your book."

"But you don't eat too many pintxos, do you? Just a couple, as you say, it's a snack."

"Yes, because we go home for dinner at 9 o'clock. Before that time, everyone in the family is out on the street, talking to friends, catching up on the news."

"Good," I said, "I don't think I have to elaborate much more."

"Fine, so let's get back to the meetings," said Aitor. "We can discuss general themes when we meet as a group, and we can talk about personal experiences during our private conversations."

\section{Who Are My Collaborators?}

"Can you give me some details about the members of the group?" I asked.

"We'll respect what you asked us," said Jon. "We'll give you enough details so you can have a general idea of the profile of the participants but, as you told us, you'll be writing our conversations in your book and you prefer to protect our identity."

"That's right."

"In general," said Aitor, "there are three graduates of Mondragón University in different fields and three, although not the same, live in the town of Mondragón. Three have attended other universities in the Basque region, and two have studied elsewhere. Five of us live in different villages between here and the coast, 50 miles away. As you know, each village has its own traditions and way of life."

"We are nine people in the group, including you," said Jon. "You know Aitor, Evaristo and me. You have talked to two others a few times, and the other three you haven't met.

\section{"Great""}

Jon pulled a list out of his briefcase and gave me a copy. "This list has the order and date in which we'll meet personally with you. We can review them quickly. I am first on the list, as we agreed, I'll tell you about my background along with Aitor's at the end.

Second comes Rosario, who has responsibility for one of the largest cooperative businesses. She has 20 years experience in finance and management."

"You and I will meet next," said Aitor. "Noemi follows me. She has responsibility for total quality in one of our oldest industrial businesses. She has eight-years experience in quality, projects and computer science. 
"Lorea, the next person you'll meet," continued Jon, "has twenty years experience teaching and managing people and programs at Mondragón University."

"The last three people you'll meet, Sergio, Evaristo and Edurne, have around 40 years experience each," added Aitor. "Sergio has been responsible for human resources in large cooperatives and has broad experience as a manager and as a consultant. Evaristo has worked in technical jobs, has managed human resources in several large industrial cooperatives, and has extensive teaching experience. Edurne manages a consulting cooperative and has ample experience managing people and projects. She also has been involved in the creation of new ventures and has worked in the Caja Laboral cooperative bank."

"To complete your list," said Jon, "I have 20 years experience in personnel hiring, evaluation and management in one of the largest cooperatives, as well as in teaching, consulting and communications."

"I also have 20 years experience," added Aitor, "in Industrial Engineering, including project implementation and evaluation as well as design and development of statistical studies within the cooperatives. I also have experience managing people, international relations and teaching."

"This is excellent," I said, looking at Aitor and Jon. "I really appreciate your making these meetings possible and getting just enough details about each one."

Jon looked at his watch. "We should go. We agreed to meet the group at seven at the Monte bar."

We walked down the stairs, past the antique carved mahogany umbrella holder, the smoked mirrors and the glass entrance door and faced the plaza where the Mondragón families had already gathered for their daily stroll. The diverse conversations sounded more like a continuous murmur. There must have been about one hundred people in the plaza, including grandparents, parents and children that walked and stopped in exquisitely timed and perfectly coordinated patterns so that all had a chance to talk to all they wished to. I have observed this joyful afternoon tradition every day from my hotel room's window. In fact, I have attuned my ear so that when the conversation reaches a certain level, I know it is time to stop writing my book draft and join them!

We entered the Monte bar, right next to my hotel, and had the first round of Rioja Crianza chiquitos. Some of the regular customers were playing cards in the airconditioned, smoke-filled room and the bar was congested and noisy as usual. Our guests had not arrived yet. Aitor suggested we sit outdoors to be able to fit all nine of us. This was the hottest summer on record, with temperatures reaching over 100 degrees, and the heat lasted until late afternoon. At this time of the year, it got dark at about ten at night. 
Aitor had selected the Monte bar first because it is in the bottom floor of a three-story building and the sun did not reach the tables in the shaded area at that time of the day.

We pulled together three light-brown wooden tables and nine matching chairs with darkgreen canvas seats and backs. Lorea, Sergio, Rosario and Edurne arrived within the next ten minutes. I greeted Lorea and Sergio and Jon introduced me to Rosario and Edurne. Jon looked at me to indicate we could start because Noemi and Evaristo would be joining us later.

Jon stood up. "Welcome! We're glad you're here today. You have all met David. As you've read in his handouts, he's interested in our personal experiences. He'll explain what he'd like to know in a minute. We've given David our profile. We can tell him more about ourselves when we meet personally." Jon looked at me. "David, the floor is yours."

Introducing the Study about Participation

"Thank you Jon and all of you for coming," I said. "As you read in my introductory material, I'm interested in learning about your experiences with participation in decision making, the core part of the book I am writing. I did a pilot study here in year 2000 about the Mondragón values and I'd like to focus on personal experience this time."

"Could you tell us about the conclusions of your pilot study?" asked Edurne.

"Yes. In brief, I concluded from my conversations with 11 people that all MCC values are important but that participation in decision making was the most significant. Therefore, my paper described the MCC systems that encourage participation."

"The systems are important, David, or we would not be able to participate," said Sergio.

"I totally agree, but I have become more aware in the last three years that there is another important but not usually mentioned factor: what happens with the person who does the participating."

"And how did you come to this awareness David?" asked Lorea.

"First through reading about participation at MCC," I replied. "At that time, I looked through recent issues of the TU Lankide bi-monthly magazine and found many comments, positive and negative, about the personal aspect of participation."

I glanced around the table and saw I had everyone's attention. I looked at Lorea. "I have also reflected about my long experience in transnational companies. Having encouraged participation on many occasions, I thought that allowing and encouraging people to engage in it would make it happen. 
"I've come to the conclusion that setting systems and encouraging people to participate is not enough," I said after a pause. "Not even here at Mondragón. Systems make participation possible but persons make participation happen.

1 looked at each one in the group at a time. "My question now is: What is your experience like at MCC, a place in which you are always able to participate?" I asked, enunciating carefully."

I heard a voice behind me. "Hi, everyone!"

Jon got up and quickly glanced at everyone. "Hello Noemi, I think you know everybody here but David. 'David, I would like to introduce you to Noemi'. He looked at her. "I'll bring you a chiquito."

"Thank you Jon," said Noemi.

I looked at her. "Very happy to meet you and thank you for accepting to participate in this study..."

"Nice to meet you, David, and thank you for including me. I have read the information you sent me and I am most interested in your phenomenology and heuristics descriptions. I like psychology and it seems like your study is a lot about what we think and feel."

"I'll be glad to say more about it" I replied, as Jon gave Noemi her chiquito and sat down. "I've not mentioned phenomenology yet."

"Can you do it in twenty words or less?" joked Aitor.

"I'll try, not in less than twenty words but in less than twenty minutes!" I replied, laughing and realizing that apparently my reputation for giving long explanations had extended to Mondragón.

"Let's say I'll do it in less than five minutes," I added. "Phenomenology studies human phenomena, as the name implies, and participating in decision making is such a phenomenon. As Noemi says, it's about experiences, which are described in terms of feelings, memories or sensations. Phenomenology attempts to 'catch' the experience before we reason it through."

"And heuristics?" asked Noemi.

"Heuristics refers to my role as the main researcher writing the book. In other types of studies, the main researcher attempts to stay 'objective'. In heuristic research, the main researcher is one more collaborator in the study. He or she still has the responsibility for its direction and outcomes but participates openly, co-creating the outcomes with the other collaborators." 
We had finished our chiquitos. I sensed it was time to move on but waited for our hosts. A moment later, Aitor said: "Ok, everybody, let's go to the next bar."

We walked under the semi-circular Roman stone arch with the carved Mondragon seal on it, up the main cobbled-stone Erdiko Kalea (street) towards the center of town. We walked past the Dublin Irish Pub, with its wooden-façade, transllucid windows and the Kilkenny and Guinness draught advertisements on the doors. The pub seemed out of place in the main street amidst the numerous balconies with red geraniums.

We arrived at the main plaza and Aitor and I entered the Bar Kajoi to order chiquitos while the rest of the group gathered chairs and tables under two umbrellas and sat down. There were many people at the shiny, light-colored wooden bar and the two young women behind the bar moved constantly from one end to the other to serve the continuous flow of incoming customers. As we waited, I noticed the geometricallyshaped motifs on the walls and matching colorful chinaware-bright green, orange, yellow and blue-striped dishes, which reminded me of the colors used in Mexico for everything from houses to pottery. I also noticed the variety of liquor bottles on a rack hanging from the ceiling above the bar and on shelves going up to the top of the high ceiling on the wall behind the bar. I estimated there must have been 400 bottles of imported and local hard liquor, in addition to the wines kept in cardboard boxes. I have often wondered how so many bars in Spain have such a variety of liquors and how they manage their inventories. There were at least 10 open bottles of red, rose and white wine in a large metal bowl in the middle of the bar, to serve chiquitos. There were also two draft beer dispensers and two express coffee machines.

The Kajoi has a privileged location, with its outdoor sitting area right on the plaza. To our left, we could see the City Hall, with its ornate classic façade, its five arches and irongrilled gates and wide balconies. I remembered the concert I had attended there the year before, a performance of Basque music with school children playing the chistu, a unique Basque flute-like instrument played with the right hand while the musician pounds a small but sonorous drum with his left hand. To our right, we could see the back wall of St John the Baptist church. The perspective from the bar showed a 100-foot high, narrow, solid-stone gray building with similarly narrow stained windows that looked like mere slits on the massive structure.

As Jon and Aitor brought the chiquitos to the table, Evaristo arrived. He seemed to know everybody, greeted one at a time, the women with kisses on each cheek, the men with a handshake.

He gave me a warm hug. "Welcome back, David, I have not seen you since last year. I received your information saying this gathering is about material for a book you are writing." 
"Actually it's a dissertation that looks like a book. I have to comply with the rigorous requirements of a dissertation while its format will be more like a story or a novel."

"I see. And I understand it is about participation"

"Yes, participation at the workplace, not the systems, not the theory, but the experience of participating."

\section{Participation and Young People}

We are now standing in a close circle and everyone has a chiquito on hand. I sense a warm feeling in the group that moves me to speak. "For you and me to better understand the meaning of participation, I may have to ask you some questions that require personal introspection. This is why I'd like to meet with each of you later, as Jon mentioned. Today I'd like to talk about your initial experiences with participation. Let me start with a more general question: We are already in the second and third generation since the Mondragón experience began. What will it be like for young people today and tomorrow, what will be their experience of participation?" I asked.

"I think we need to understand our young socios better," replied Jon immediately. "Some of the elders say that young people don't commit to the cooperative values the way their parents and grandparents did. We need to see our young people from another perspective. I agree that external influences are growing but I don't think our young socios are getting worse."

Aitor looked at Jon. "I agree. Some elders think that in the past we lived our cooperativism more intensely than we do today. They say 'In the sixties, we were all aware of how many full trucks were shipped out, for example, and we were happier. The young socios join the cooperatives just to have a job, they're not concerned with our values'."

Edurne leaned forward. "I think there are two sources of motivation to seek a job at MCC. One, which may be the most important, as the elders say, is to find a job. It has been this way for many years. But the other reason is that these young people are seeking a certain quality, certain values at the workplace."

"What values, Edurne?" I asked.

"On one hand there are the values we see in society today, such as individualism and consumerism, and these are brought into the cooperatives. On the other hand, even though these values exist, we continue being in solidarity. Our solidarity is institutionalized, inside and outside the cooperatives. The promotion of Euskera, the Basque language, is only one example." 
I turned to look at Edurne. "Solidarity as a value does not exist in traditional corporations. The individualism you mention and the intense personal competition are barriers to achieve solidarity."

"I see young people as being cooperativists in the same degree as I am," Aitor insisted. "I think they see the advantages here because they have seen other enterprises and lived other realities. When young people come here, they see more advantages than disadvantages."

"I agree with Aitor," said Sergio. "Some of our socios, that is, our worker-owners, may not see value in the opportunity to participate, unless they have worked elsewhere. I talk to young professionals (engineers, economists...) who may not have reflected about the opportunity they have to participate, and I ask them: 'Say, would you like to work in another company?' Their reply: 'Not me, I do not even consider it.' Of course! Probably they have not thought it through, but these young people feel welcomed and challenged, and they think: 'I am satisfied. I am staying here'."

"And these young people participate?" I asked.

"I am convinced that they develop their commitment to participate as they mature personally and professionally," replied Sergio, "but only if there is a context of freedom. I don't think the commitment to participate can be developed under coercion."

"I think it's also necessary these young people feel included," said Lorea.

"Do you have any suggestions to make them feel included, Lorea?" I asked.

"An example. Suppose I am heading a meeting, and we have been talking about a topic for some time, and there have been many opinions. At some point, I would say in an informal tone: 'Let us go around the table: Elena... Mikel... Arantxa... What do you think about (this or that) topic?' This way people participate, nobody feels threatened."

Lorea looked at me. "I've also had students from environments in which cooperation is not customary. They feel assailed if I ask them to participate. It's necessary to insist that I care about their opinion. If I proceed this way, they usually are convinced at the end that I am truly interested in what they think."

"I agree with you Lorea," Sergio added. "I was involved for many years in hiring young people and am gratified to see how they have evolved as they were given a space and an opportunity to participate."

Noemi was following the conversation attentively. "I also agree. I give my opinion as the youngest person in this group. I do have the opportunity to participate because I am in the Management Council in my cooperative."

"Great," I exclaimed. 
"But I also realize," Noemi continued, looking intently at me, "that my comments don't carry the same weight as those of the other members of the council. I think the reason is that I am young and have scarce working experience. I want to make clear that I am very serious in working matters and meetings, but I do not have that look of dry seriousness of older peers. I think that if I were 45 or 50 years old, my opinion would be taken more seriously."

"As I understand it, Noemi," I intervened, "you have the opportunity to participate but it's not motivating to you that the comments of your older peers weigh more."

"Not exactly, David. I understand that I am young and my participation is not the most influential but I like to be aware of what is going on and to be heard in the line of fire This satisfies me for now. I would, however, like to talk about other young people at work who are not in the same situation."

"Your peers at the office?" I asked.

"The young people at the factory." Noemi said. "I've found two situations here. First, some of these young people have excellent suggestions. They are self-motivated and do it on their own initiative. I think they have a personal inclination to participate."

"Do you think it's because of their personal inclination or because they are given the opportunity to participate?" I asked.

"I think it's something personal," replied Noemi. "We all work within the same participatory system but these people become more involved than others. Why?" Noemi looked at me. "These socios don't get discouraged if their suggestions are not accepted at the beginning. They insist until they are allowed to act on their suggestions."

"And what is the other situation?" I asked.

Noemi turned her head towards the group. "Others participate once and if they don't feel recognized for their effort, or the system doesn't support them to carry out their initiative, they don't participate again. It's the system, the hierarchy, a lack of humanistic leadership that discourages them. I say to them: 'Let's see how you can participate with this system.' And some turn to their peers and say: 'You can participate if you want to, but leave me alone'."

Noemi inhaled and looked at me. "These are not just the young people, they are also the older, experienced socios, those that are burned out."

"I agree with Noemi," said Rosario. "There are people who are more participatory than others. There are those who do the minimum and others who seek to participate because they believe in it. And there are still others who don't want to participate because being 
involved in decision making implies a responsibility and some prefer not to assume it. They say: 'Let others participate, I will do my own thing."

Jon leaned forward and placed his chin on the palm of his right hand. "I myself would find it difficult to commit to a system due to inertia or because it's an obligation, as I did when I was younger."

"So what is required?" I asked Jon first and then looked to others in the group.

"We have to continue evolving, as we have in other aspects in our 50-year history," said Jon. "We have to make our objectives concrete. I would not feel at ease participating to meet an ethereal objective: What is the common good? What are these things we have for objectives?"

"Going back to David's initial question," said Evaristo looking at the group. "How can we transmit all we have said, especially to young people? How do we make them realize that our participation has a decisive influence in the decisions that affect all of us? That participation implies rights as well as obligations? That we are owners of a part not the whole?"

Evaristo looked at me. "Perhaps one way is to visualize persons with Great Souls that participate or have participated in life, in the world, illuminating it with their example."

"Could you elaborate Evaristo?" I asked.

"Sure David. I'd like to illustrate what I say referring to our personality. According to the experts, we have three personalities: what others think I am, what I want others to believe I am; and what I think I am. But the most important is the personality that I am not, but would like to be. To accomplish the last one, I need orientation more than rules, I need models of real people I can learn from. There are things I do not like about myself but I try to overcome them following the trail of others who have walked the same path and been successful."

"Very interesting," I said. "And how do you relate what you say to the young people?"

"Don José Maria used to say that it's much easier to educate a young person than to reform an adult. I'd like others to see my reasoning process as I see it, that all my loved ones, especially the young, were interested in learning how to participate. I wish they understood that we can participate to build a better world. And I can say the same about all young people."

"I'd think this would also apply to many of us adults," I said.

"David," Evaristo concluded, "to take action, even if it's not enough, the will to participate is required. If I want to participate and I cannot or I am not allowed to, I 
suffer. But if I am allowed to participate and I can participate but I do not, I begin to die..."

Evaristo stopped talking and the rest of us remained silent. After a few moments, Aitor got up and said in a loud voice: "How about going to another bar? The next one has very good pinchos." We got up almost in unison and followed Aitor.

We walked across the plaza and continued up Iturriotz Kalea (street), past the side entrance to the church, to the Joxe Letona Emparantza (square), where the Goiz Alde Kafe is. This café is located in a contemporary five-story building the street and has a terrace. The ambience is different, it feels more like a teahouse, with embroidered curtains, plain wooden windows, brass details on the bar and walls, and a more complete menu. The pintxos on the bar indeed looked delicious. They were pierced with toothpicks, as they usually are. Everyone selected a few. I selected several: red pimento and albacore tuna; large anchovies with green olives; baby eels on toast; sweet red choricero pepper and cheese; salmon on toast. To my collaborators these were just snacks before dinner, while I wondered if I'd be able to have dinner later after this feast

We ordered chiquitos, walked out to the terrace, gathered the dark blue tables and chairs, sat down and I started the conversation. "I'd like to tell you something a bit more personal," I said. "I wrote a reflection about my experiences with participation before I came to Mondragón, in order to get in touch with my lived experience."

\section{Participation and Fear}

"About your experience in the organizations in which you worked?" asked Jon.

"That's right, Jon. I'd like to share part of it now:

I started to work in my first transnational company when I was 24 years old. I had a strong desire to participate in decision making, I wanted to change a lot of things. I had finished my engineering degree and an intensive one-year training program at company's headquarters and had been transferred to a large factory in Mexico City. Because of my degree and training, and in spite of my youth and scant working experience, I started at a middle management position. I attended meetings with the plant manager, senior executives and my peers every morning. I would report in these meetings what I thought was wrong on the factory floor, and I hoped others would do the same. Unfortunately, my comments sometimes were seen as criticisms. Soon I saw that even my own boss, instead of supporting me, would criticize me at the meetings."

"In that aspect," said Noemi, "we have a good system here. Each one of us can participate in any theme that affects us as socios. I can say what I think and there is no problem. 
"And we can say a lot," emphasized Noemi. "Due to our participatory climate, even those who are not socios yet and can't vote on the General Assembly, can say what they want."

"My experience was not so fortunate," I said. "I quickly learned that there was a tacit agreement among the participants in the morning meetings: "you say nothing that makes my department look bad and I will reciprocate'. The plant manager would also let us know subtly that he didn't want disagreements among us in the meetings. This system motivated everyone to keep quiet."

"There have been cases when I've felt it's better to stay quiet," said Jon, "but it's been because I think: 'I don't feel strongly about that issue one way or another so I won't intervene."

"It wasn't like that with my peers or myself," I said. "And, at least in my case, I wouldn't participate at times because I was afraid of the possible negative consequences to my future within the company. Also, I could be fired."

"I can't say I've ever refrained from participating due to fear," said Jon. "When I have to say something, I speak up."

"I understand. And what is your experience?" I asked, looking at the group.

Rosario leaned forward and looked at me. "I think sometimes we are afraid to speak because we feel what we are going to say something stupid. It helps to realize that we have to make mistakes once in a while."

"I had a period of insecurity at the beginning," added Evaristo, "possibly because I didn't feel sure of what I knew. I would then support someone who seemed more certain about what he said. In this period, I had a stage of dogmatism. I followed the person who seemed sure. But I evolved in my way of participating."

"For me it was also difficult at the beginning when I had no experience," Rosario added, "but I learned and matured, feeling freer to participate and make suggestions."

"Let me tell you about my experience," said Sergio, looking slowly at each one's face. "When I was offered a job in Human Resources, I said to myself, reflecting on my capabilities, 'I don't know if this is for me'. But my boss said 'I trust you and have information from others that know your capabilities. We all trust you'."

Sergio was quiet for a moment. "Participation based on trust is something else. That act, that expression of confidence in me, was very important. I was able to leapfrog to a job in which participation in decision making was significant because others trusted me."

As I listened to each one speak, I felt that I rarely had the freedom to be completely myself when I participated. I looked at the group. "I need to think about what you have 
said about freedom, trust, the evolution of participation," I said to conclude. "I have many questions: Is participation something we learn? What does it feel like to participate?"

I paused for a moment. "I know it's late. Should we meet again on Thursday at the same time and place?"

Everyone nodded. We got up and I shook hands with the men and kissed the women on both cheeks to say goodbye, as is customary in Mondragón, thanking every one personally for attending our group session.

\section{Participation and Decision Making}

Everyone walked outside the bar. Lorea, Rosario and I walked out last. We were chatting about participation and management styles. "Hola Lorea!" we heard in a loud accented voice.

"Hola Stewart, qué sorpresa!... replied Lorea, as she shook hands with him. "Let me introduce you to my friends Rosario and David. We are part of a group," she said, vaguely raising her hand towards those walking ahead of us, "who are exploring participation in decision making." Lorea turned her head to us. "Stewart is a college professor from London with long academic experience teaching management courses. $\mathrm{He}$ is studying the cooperatives and their systems."

Stewart nodded slightly towards each of us as a way to greet us. "A pleasure to meet you." Rosario and I nodded silently.

"Stewart," said Lorea, "we were talking about decision making based on the boss's decision or as a result of worker's participation..."

"I will not hold you long, but I am very interested in that subject," said Stewart. How about one more chiquito and we leave?"

We were ordering three chiquitos when Stewart spoke directly to the point. "I have been studying decision making in the cooperatives. I don't understand why bosses have to include subordinates to make a decision. How does this help?"

"Stewart," replied Lorea. "If I am the boss and leave others out when I make a decision, where will they get the enthusiasm and drive to comply with it? If we are not all in from the beginning, we get lost along the way, there is no energy to keep us on track."

"Well, they simply follow the boss's orders. That is why there is a boss, to make decisions, Lorea. Don't you agree?"

"That is not how I see it," replied Lorea. "If you have a person who doesn't agree with my decision, and I don't take him or her into consideration, this person becomes an opposing force to my decision." 
"But it's so inefficient," Stewart protested. "Waiting for everyone to give an opinion takes a long time."

I intervened. "Stewart, what you say is normal in our organizations, what is called sociedades anónimas here, in which participation is not common. I'd like to share something I read a few days ago about what you are saying. I'll paraphrase it:

On one hand, if the boss makes a decision, it's easy: he or she makes the decision and gives orders to obey it. This step doesn't take long, perhaps $10 \%$ of the total time from making the decision to making it happen. The other $90 \%$ is spent on implementing it.

On the other hand, if all involved participate in making a decision, you are right, it takes a longer time, probably $90 \%$ of the total, but it only takes $10 \%$ of the time to implement it because everyone has agreed on it. The most important point though, is that the total time to implement this decision in the former case is much longer than in the latter.

I'll tell you now about my personal experience with the two approaches:

When I was managing the international operations of the last company I worked for, I was frustrated because strategies were only half way implemented even after one year. These operations were all over the world and there were always very good 'reasons' not to have implemented them. When we changed to a collaborative approach, implementation was reduced to just a few months. At least I didn't have to come into the next planning cycle a year later to hear excuses about the incomplete projects from the year before!"

Stewart looked at me and took a deep breath. "You may be right, but the boss is there precisely to make decisions. Besides, the boss is in a better position to make them because he has a more complete vision of what is happening in the enterprise."

"I don't agree," said Rosario. "When everyone participates, people's capacity is utilized to the maximum. It's clear to me that the worker doing the job knows more about it than the boss. Organizations utilize only $20 \%$ of people's capabilities when $100 \%$ is possible. In my cooperative, we want to capture all potential ideas. All of us have intelligence and knowledge, every one of us. Our main problem is not who makes the decision, but how to feel free to express our own ideas."

"I think that bosses who consult others before making decisions," said Stewart, looking at Lorea and half-smiling, "do it because they are afraid to make decisions on their own."

Lorea reacted, apparently thinking that Stewart was trying to provoke her. "Of course I can make a decision by myself, Stewart. But how far am I going to get if I am alone with my opinion?... I need to include others, even though I have to take responsibility for the decisions we make." 
"I agree and would like to elaborate," added Rosario. "Telling a person about a decision that has already been made and expecting him or her to collaborate is very difficult. I need to make sure this person understands why the decision is being made, although 1 will make the decision myself. I don't have to always involve everyone when I make a decision, but I have to explain it. I could say 'let's do this because it's important', but I don't. I take the decision to my teammates so that everyone understands it and assimilates it. It's very different to say 'we are going to do this and let's get together to see how we can accomplish it', than saying "say, we have this situation and if we make a decision like this, we'll be able to accomplish that." In the latter case, my teammates will articulate the pros and cons and the end result is that we all do it together."

"Look Stewart, it may be better if we agree to disagree, what do you think?" I said, realizing that it was getting late and we were in opposite poles with our opinions.

"Right," said Stewart, raising his arms in a conciliatory gesture. "I am very interested in exploring this issue of participation in decision making because I am not convinced. We can continue some other time."

"Good, Stewart," I concluded.

We said goodbye promptly, as it was already past nine and the bar was almost empty. Everyone had gone home for dinner.

The words from our conversation with Stewart were still in my mind. Is the main reason for a leader to exist to make decisions? My experience told me it is easy for a leader to make decisions and give orders, as it is easy for the followers to obey them. The energy invested in this process is not much. But what about the leader in a cooperative? One of the participants in my pilot study, a CEO in a large cooperative, told me once: 'Some outsiders think that my job is easy because I do not make decisions personally, but it is not easy at all. In other organizations, the boss is concerned with what his or her superior will say. I have to respond to my superiors and my subordinates!' Both Lorea and Rosario talked about having everyone involved in decision making, regardless of who made it. What do you think: Is the leader's responsibility to make decisions and give orders or to promote participation in the decision making process?

I walked past the mostly destroyed walls that once surrounded the city, They were built in the XIII and XIV centuries by orders of the King of Castilla, Alfonso VII, who had conquered Arrasate, now called Mondragón. Walking alone in a medieval town certainly helps to see things in perspective. I imagined the soldiers in the King's army. They did not participate in decision making, did they? The leader gave orders, the soldiers obeyed them. Simple. It dawned on me that there was room for leaders who exist mostly to give orders... if they are military officers in the midst of battle!

I stopped in the plaza in front of my hotel and sat down on one of the deserted benches. I tried to put my thoughts in order. I was surprised to hear that those in the group trusted the young socios to become motivated participators as they gained experience. It seemed 
that getting in touch with their own past made some in the group realize they had learned to participate as they matured.

But it was not a unanimous conclusion, as some credited other sources. Sergio spoke of the trust bestowed on him. Lorea referred to making young people feel included. Aitor, Edurne and Sergio felt it was a question of values: solidarity, trust, encouraging participation.

But several factors that could facilitate participation were also mentioned. To Evaristo, it was having inspiring models. To Sergio, freedom. To Jon, clear objectives. To Rosario, sharing decisions and information. To Lorea, caring for young people's opinions. How much of this is provided by the institution, how much by aware persons such as those in the group? What is your opinion? Is it the system or is it the will of the person?

And then there was Noemi. She is living what others only remember: participating as a young person. She participates, she says, because she belongs to the Management Council. Others, young and old, are reluctant to participate. Is there a participatory personality, is it self-esteem, is it the hierarchical system, the boss's personality?

And what happens if people, such as the immature or the disillusioned, do not want to participate? Is a vacuum created in the decision making process and those in authority quickly fill it? Or is it the other way around?

I realized how many parallels there were between the experience of those in the group and my own. I could identify with following other decision-makers when I was young and with not wanting to participate if I didn't know enough of what was being said. I also could understand not wanting to invest energy in something that was not very important to me--I remembered the saying translated from Spanish "do not burn your gunpowder in small hells (battles)." How do you feel about this?

It was hot again on Thursday afternoon. Rosario, Edurne, Noemi, Jon, Aitor and I arrived on time at the Monte bar. Everyone sat at the terrace while Aitor and I went down the few stairs to enter the bar to order chiquitos. The round bar, with its unique alligator-skin design on its walls and wooden counter, was crowded. There was a soccer game on the giant screen with a dozen men watching it, with their chairs aligned as in a theater. There were also two groups of men, one playing cards, the other dominoes, and two women at the pinball machines. Everyone seemed to be oblivious to the high noise level, as those watching the game would yell and argue about each play, looking at the television, gesturing and giving loud advice to the team coach--and then complaining because he did not follow it! Although it was bright and hot outside, it was dark and cool in the bar. The stained glass wooden windows were closed, the air conditioner was operating full blast, although it did not succeed in clearing the air from the strong cigarette smoke. As we waited to be served, I noticed a bartender preparing a carajillo quemado, a concoction of 
flamed anisette with coffee beans on top, poured from one cognac glass to another, and topping it with coffee. We finally got six chiquitos, went up the stairs and sat with the group. We exchanged a few comments about the day and then went silent, as indicating we were all ready to start our conversation.

\section{What Facilitates Participation?}

"Lorea, Evaristo and Sergio called me," I said, "they will join us later, so we can begin. Summarizing, last time we met, we talked about our early experiences, when we started to participate in decision making. Also, we talked about what we thought would happen to young people today, as they mature. I'd like to continue talking about your experience, and mine, as we participate in decision making. Where could we begin?"

"I would start by referring to the means already institutionalized," proposed Aitor immediately. "It's clear that the monthly meetings are the best way to have participation in our cooperatives. These meetings are a formal part of our management model. As we all know, the general managers meet with the functional managers, manufacturing directors with technical people and line supervisor, these with the factory workers and so on with all socios.

"And this works well," I said, in a questioning tone of voice.

"Unfortunately," said Aitor, "not all cooperatives practice this system, not at all levels. Some general managers meet with their functional managers and these meet with their collaborators, but the line supervisors do not meet with the factory workers. Also, some managers still use the authoritarian system of delegation. . but I think we are improving."

"Supplementing what Aitor says," added Jon, "we need to consider also the formal participation in the committees, such as the Governing and Social Councils."

"And what is needed for participation to happen in these committees?" I asked, looking at Jon.

"In my opinion, it is fundamental that participation be well established at a basic level before someone participates in a Council. As Maslow writes, if I have already eaten and I am not hungry, I can dedicate my time to other things and I am able to understand that I have other aspirations, I can participate in other ways."

"Good," I said. "Accepting that institutionalized measures help and that the way we participate varies from the basic to the fullest, what else can we say about other helpful means that exist in the cooperatives?

"There are some things we are doing in my group to facilitate participation," said Rosario. "For example, there are people who are experts in technical matters but are not capable of working as part of a team. These persons can be helped. We are elaborating a 
manual of 'personal competences,' which we use to describe ourselves, evaluating not only our technical skills but also our general skills."

"What are these 'personal competences"?" I asked

"For example, what is my attitude, what type of leadership do I apply to manage change? We are going to evaluate this to see how we can improve and what kind of training we need to accomplish this improvement. I think this is positive for us as persons as well as for the organization."

"In our cooperative," said Edurne, "we are sensitive to this topic and are engaged in an authentic reflection about how we can participate in the strategic and management plans. These plans are structured in the business units but we are trying to elaborate them from the base up so that everyone is committed."

"I have some experience in participatory strategic plans," I said. "What worked for our team was to meet 'halfway,' at the middle management level. We established minimum guidelines at the executive level and generated objectives to meet the plan from the bottom up. As you mention," I said looking at Edurne, "I found that the most positive outcome was that everyone contributed and was committed to the plan."

"We also have tools to set objectives," she added. "These are elaborated with ideas from all socios, not just the managers. And we are also trying to improve the tools for decision making."

\section{Promoting Participation}

"Another way to invite everyone to get involved," said Rosario, "is to encourage everyone to participate even if they make mistakes. We are learning how to manage errors, as I briefly mentioned last time we met."

"Can you elaborate on that?" I asked.

"If we see errors as sources of learning, and we allow some errors to be made, we facilitate the experience of participating. Otherwise, we may prefer not to take the initiative. I think that if errors are seen from the learning perspective, we are stimulated to participate, take the initiative, and be innovative."

"There are also some leadership structures that promote participation," said Edurne. "We need to reflect more on the tools the corporation has."

"Can you explain what you mean?" I asked.

"Yes, David. At the institutional level, I think we have not succeeded in motivating today's socios to be more active participants. In other words, there are tools to facilitate participation but they are used in a somewhat passive way. We officially offer these tools, 
and they are quite appropriate, but we also have to stimulate people to participate. We do it, but we can improve."

"I agree that these tools can improve," said Noemi. "We have established systems to participate in my organization but I perceive that these are not the ones socios prefer. We are establishing these systems with no participation of the socios who are going to use them in their design."

"The established systems promote participation but people do not accept them because they are imposed from the top," I said, seeking corroboration from Noemi.

"That's right. Many think that we managers want to impose participation according to a system we invented to have the type of motivation we prefer to have. I do surveys about this issue but they are not very useful as compared to a conversation at a coffee break. In fact, my surveys are perceived as one more system we are imposing."

Noemi paused. "I have learned that imposing a system does not work. People do not accept it, because, I repeat, they want to participate in its design. Well ... at least those socios that still want to do it, those we have not discouraged yet," said Noemi as she looked at me.

I nodded as I looked at her, trying to transmit that I had understood her disappointment. "Since people do not participate," Noemi continued, "someone could get the impression that I have not asked them to participate, when in fact I have, but with very specific systems. And, in a given moment, people stop participating. They keep their mouth shut, later expressing their disagreement with what has been discussed. This cycle is harmful because people talk about it and get upset, probably as a reaction to our imposition of the way people should participate."

Everyone kept silent. It seemed that Noemi was not finished.

"I recognize, however," she concluded, "that it is easier to impose a system than to involve the socios in the details. I, myself, when I say 'we seek your participation', and ask for opinions, see that it becomes an endless story because everyone wants something different. Indeed I ask, but then I impose. Indeed I try to capture many ideas from the socios, but at the end I decide according to my judgment."

"Undoubtedly, the situation has changed, and this affects participation," said Rosario. "Years ago we were a small organization. Today we realize the difficulties arising from our size, scope and growth rate. So now we capture people's opinions through suggestions."

"The suggestion system, for once, seems to facilitate participation in my organization," said Noemi enthusiastically. "We have a formal suggestion procedure channeled through the Social Council. We used to have about twenty suggestions per year, with this system these have multiplied tremendously. Now people are not timid about making suggestions. 
This is probably because participating this way is well accepted by the socios or because we got it right this time." She looked at me. "I feel satisfied with our accomplishments."

"Another barrier to participation," said Rosario, "is the great number of new socios. I try to explain what a cooperative is and its values, but it is a difficult task. How can I make these new socios live the experience of those who created the cooperatives? They see the cooperatives from a different perspective and it takes time for these socios to become immersed in our cooperative culture."

"Speaking of values," added Edurne. "I think that, as persons who live in a cooperative environment, we lack clarity about today's values."

"What values are you talking about, Edurne?" I asked.

"I think that what is happening in society is also happening in the cooperatives. Moreover, the framework within which we live today is different. On the one hand, we are an organization that has objectives such as generating profits, which is obvious. We all know the complexity of the business world and how difficult it is to stay abreast of competition. On the other hand, we have the complexity of the person who works in our cooperatives and has personal objectives and economic challenges to survive. We are asking this person, at the same time, to also participate intensely. Our corporation has lived through a spiral of growth that in a way damages our social values, such as participation."

Edurne paused for a moment. "And I ask myself: where are we failing? What is our authentic responsibility? What do we have to do within the cooperatives so that participation is more alive in the $21^{\text {st }}$ century?

We stayed silent. There seemed to be no comment to Edurne's rhetorical question. The invisible, yet palpable rhythm of the chiquiteo indicated that it was time to move to another bar. Jon stood up. "How about going to the next one?"

"I agree Jon," I said, standing up along with the rest of the group.

Aitor asked the group: "Do you mind if we go to the Goiz Alde Kafe next? I didn't have lunch today!"

Lorea, Evaristo and Sergio were arriving. Everyone agreed it was a good idea so we walked together towards the Kafe.

We entered the Goiz Alde Kafe and the pintxos looked as good as always but it was too early for me and I knew I would have a big dinner later, so I ordered the chiquitos and waited. 
The bar was almost deserted, although I knew that it would not be long before a group arrived. The bar is air-conditioned but most of the tables are outside. Patrons who stay inside stand up around the bar and talk, we needed to proceed with our meeting.

Some members of the group selected some pintxos, we walked out, joined three tables, gathered nine chairs and sat on the terrace. I felt several in the group looking at me, which I interpreted as their waiting for me to initiate the conversation. And so I did.

\section{Can We Learn to Participate?}

"Perhaps we can continue now," I said. "We have talked about our experiences participating when we were younger, which for Noemi means the way she participates now," I said smiling at her. "We have also mentioned how we felt when we began to participate, what facilitates participation and what we can do to promote it. Perhaps we can now dig more into our personal experience and explore the questions: Do we learn to participate? When, how, where...?"

There was silence for a few moments. "There are people who want to participate from the beginning," began Edurne, "and these can be identified quickly. These people usually end up being elected and serving in the various councils. But I think it is also possible for others who do not have an inclination to participate to learn to do it."

"When I started to work here, I did not know much about cooperativism," added Jon. "Although I was born in the area, the 'Mondragón experience' was not well known. Perhaps my family environment, in which I felt free to participate, influenced my openness to cooperative attitudes. When I started to work in the cooperatives I was asked to participate and I did. If I had not had the inclination to participate, or if it went against my way of thinking, I probably would not have lasted long in the cooperatives."

"I had no problem participating from the beginning either," said Aitor, "because engaging in participation and cooperation is consistent with my personal values. What I realize, however, is that it was difficult, even for people like me who had worked in other cooperatives, to start work here with a true appreciation of the Mondragón cooperative values."

"To me," added Rosario, "participation is part of the identity of the cooperative, as is democracy, solidarity, cooperation or communication. This is because we own the capital and also work here, which obligates us to participate. Participation impregnates the organization and seeking consensus is innate."

"I think that the values we have," said Noemi, "such as participation, are a result of simple humanistic actions. These values are basic and are 'a given' if we work as we should, whether we work in a cooperative or in some other type of organization."

"I consider the values are not the same," I intervened. "My experience has been in noncooperative transnational corporations which do not share the values of democracy and 
participation in decision making, cooperation, or solidarity as in cooperative workplaces. Instead, values are autocracy, willingness to comply with superiors' decisions, personal competition, and pursuing self-interest."

"I think that having the opportunity to participate changes a person," said Jon. “Otherwise, I would just say 'I don't like this,' and I wouldn't do it. You come into an environment in which you can participate and you do it. Yet, I think the way of participating varies."

"Could you elaborate, Jon? How does it vary?" I asked.

"Yes, David. I felt involved from the beginning in decision making in the organization, but my participation was more formal. I did it with a sense of discipline, in the good sense of the word. I participated because I had to do it, but I did not feel as a truly involved participant. It satisfied me but I was less autonomous, I did not feel completely free to participate..."

Aitor seconded what Jon was saying. "I also have participated from the beginning, but like anyone else. I think we all start as innocents and gradually become more participatory. I say that 'a cooperativist is made not born.' And for the cooperativist to be made, he or she needs time, experience and personal maturity."

"I agree," said Rosario. "I don't think we have participation because those of us who work here are participatory by nature or that a bunch of participatory persons coincided here. The way of life of the cooperatives is contagious, this is what makes us participate."

"You may be right, Rosario," said Jon. "But, although we don't arrive here married to the values of the organization, I think we have a very profound feeling in our cooperative culture expressed as a value: 'we have to participate because it is good for the community, to which we have to contribute'. And thus we participate."

"I find your comments interesting," said Noemi, "about experiences that probably you had when you were my age. I work here mainly because I was offered an interesting job. Later, I replaced someone who was in the Management Council, which allowed me to become a member also. But I am dedicated to my work in the organization and its objectives, independently of being in a cooperative or not."

"It is a job well done that fulfills you," I said, "more than the ability to participate or other cooperative values."

"I work and try to participate to progress and because I work in this environment," said Noemi, "but I see my work as giving me personal and professional learning and experience, more than as a quest to defend cooperative principles."

Noemi paused and added: "And for now, I leave issues referring to voting or discussing our rights as worker-owners in the hands of the experts among us." 
There was a pause. Then I broke the silence by asking a more general question on the same subject.

"Where does the interest to participate come from?" I asked. Let me begin by telling you my experience:

I grew up in a culture in which my contribution to the common good was through economic help, not personal involvement. I was attracted to participatory systems since I started to work in a company in my twenties, but I can not say this attraction originated in my family, school or culture.

Where does this inclination towards participation come from?" I asked, not expecting an answer.

"I think that participation can not be taught but can be learned," replied Evaristo, looking directly at me. He turned towards the group. "I am not sure I can explain this from the intellectual point of view, or that I can support it cognitively, but I speak from my own experience. I think that looking into the heart of each person we will always find a power in human nature that obligates us to participate in our world.

Evaristo paused for a moment. "If this power is not fully developed in some people, it is because there is interference caused by fear or a lack of formation to achieve self-esteem and an awareness of our personal dignity. I suppose there are people who have lived in a family or a society in which participation is considered to be negative and in which everything coming from the outside is not only negative but also harmful. In these cases, it is very difficult to become a participatory person.

"Other environments are more open." continued Evaristo. "In them, there is more trust in each person and the human aspect prevails. I would say that to have this kind of environment depends on the type of leadership that each entity has because it has so much influence in personal development. We are fortunate when we have, in key moments of our life, persons who orient us to try to be Great Souls, whom we would like to emulate, who give us a positive message of life and its possibilities. We are fortunate to have these persons as 'lighthouses' who illuminate us at night towards a good port. Persons who affirm us and tell us with their example and recognition that our participation can be and is important."

"I concur with the influence that persons and experiences that one finds along the way can have," said Sergio. "I see participation as a continuous development in my life. Each one of us has stages, some times it is our turn to offer support, others to have been fortunate to find persons who support you. There are so many factors involved, for some, the decisive factor is A, for others it is $\mathrm{B}$, or $\mathrm{C}$. But what is truly decisive is our personal maturity because our participation evolves, along with other aspects of relationships and personal interactions."

Sergio paused for a moment and added: "I feel that when I participate, I do it with a life perspective that I didn't have when I was 18 years old, but I definitely have now that I am much older." 
"Let's explore what we are talking about from another perspective," I said, asking rhetorically: "Do we participate just because we become mature, or is it necessary to learn to participate, independently from our age and seniority?"

"To participate or not participate," said Lorea. "I say that participating is innate, rather than not participating. I believe that we as persons have within us the urge to participate and we will, unless someone prevents us from doing it..."

"Lorea," I interrupted, "I thought we learned to participate as we learn to read or write."

"I have long experience interacting with small children," continued Lorea, "and their inclination to participate is evident. Of course, children, because they are still at an evolving stage, sometimes participate to impose their opinion. But we adults do it too!" emphasized Lorea, with a smile on her face. "We do not always participate to listen or to help build the other person's opinion. Regarding children, it is always better to have this type of participation than giving them no option to participate at all."

I smiled. "I need to assimilate what you are saying. This is new to me." I looked at the group still smiling. "And I have many other things you have told me today to reflect upon."

It was already almost nine o'clock. I didn't want to hold anyone after dinner time so I looked at Jon signaling we could end the gathering. We stayed in silence a bit longer. Jon got up, checked that we had finished our chiquitos and looked at the group. "Well, it looks like David has some material to digest," said Jon, with a smile. "There will be another opportunity to expand on the themes we talked about, when we dialogue with him personally. We will meet again after these personal dialogues to have dinner together at the Otalora dining room. You already have this information."

I got up slowly, as not to rush anyone. "Thank you very much for your comments and insights, I've learned a lot tonight," I said.

Some nodded but nobody spoke. Everyone got up and we said goodbye, one at a time.

I began to walk slowly back to my hotel. There was still some daylight. The streets were empty, a marked contrast to the last few hours, when the sound of voices emerging from the plazas traveled throughout the narrow streets we had walked. I was excited after my second meeting with the group. So many things had been said. There was no need to wait until I talked alone with some of the members of the group, they were so free to talk about their experiences in front of the group. Where to start?

I entered the hotel and had dinner with Esteban and Rosi, the hotel owners and my hosts. Esteban prepared a revuelto de sisas, a kind of seasoned omelette with sisa mushrooms, 
a delicacy. He opened up a bottle of red Rioja wine with a rich ruby color, which I really enjoyed and asked Esteban about it. He showed me the bottle and reminded me it came from a Tempranillo grape. I read the label: Viña Alcorta Reserva 1995. "A four-star wine from a very good year," Esteban added. He insisted I join them in drinking an Orujo, a Galician digestive herb liqueur, so I could sleep better.

I finally went up to my room, feeling grateful for my growing friendship with Esteban and Rosi. I still had turmoil in my mind. I opened the window. Some of the young people were gathering in the plaza downstairs. These youngsters, I thought, are the future of Mondragón. I lied down and stared at the ceiling. I tried sleeping but kept tossing and turning. I finally sat up and looked out the window with the lights off. I could still see the young people walking and talking and I returned to my concerns. I thought again: These are the future socios of Mondragón. But it was not only the young people I had in my mind...

I thought about all that had been said by my collaborators. It was complex to make sense of it all and I had many questions. I thought I may be able to understand some of the issues better if I compared them to my own experience. I began by looking at the role of the established systems and persons in their participation

Aitor, Jon and Edurne said that the MCC structure and systems facilitate participation, but not all managers or socios participate in them. Noemi added that systems imposed from the top do not work but accepted that it is easier to impose than to ask for participation in the system design. This is probably what a manager in a traditional organization would do too: impose not ask for opinions. How many cooperative socios think this way?

And what about encouraging participation? Rosario and Noemi mentioned suggestion systems. Rosario talks about identifying 'competences' such as reflecting upon personal capabilities to accept change, work as a team, etc. Edurne questions if she as a leader is promoting participation enough and talks about involving worker-owners in strategic plans and objectives.

These initiatives are similar to those used in traditional organizations. Speaking of my own experience, I remember using suggestion systems from early on in my career. Also, the performance appraisal system established in my last two jobs included involvement of the employees in their objectives and I have involved them in strategic plans. I have less experience identifying personal competences to accept change or to work as a team, but I can see that they are also tools applicable to traditional organizations.

Rosario also mentioned using errors as a source of learning to encourage people to participate. This approach became popular when The Search of Excellence book first came out but in my experience employees in traditional organizations still fear the consequences of making mistakes, so using errors as a learning tool is not widely used. 
Also, what facilitates participation? Rosario said that not everyone who works in a cooperative has an inclination to participate. Edurne mentioned some workers arrive wanting to participate, others do not, but they can learn. Jon says at the end it is the person who decides to participate or not, based on Maslow's scale of needs. Does a person have a natural proclivity to participate and another doesn't? Does it depend on what we learned as children? Or, as most collaborators seem to think, do we learn to participate at the cooperatives, because the environment propitiates it?

And what about Lorea's perspective? Based on her experience with children, she says that we are born wanting to participate and we will, unless someone prevents us from doing it. Is this what happens to us as adults in our workplace: we are prevented from participating and we just sit back and accept it? We are not children, we can exercise our free will... The prohibition to participate from the bosses of the founders of Mondragón at the company where they previously worked was what motivated them to quit and start the Mondragón cooperatives. But they had been educated to participate when they were younger. What do you think? Is this what we need, education of the young people? Will an adult be able to "learn" to participate (or "unlearn" to not participate)?

Enough to ponder for one day. I lied down still thinking about all that had been said until I fell sleep. 


\section{CHAPTER 7}

\section{PERSONAL ENCOUNTERS WITH PARTICIPATION}

Today I have my first personal interview. I will be meeting my collaborators in three or four different places but I will be with most of them in the Otalora Training Center. The Otalora building is a massive structure dating from the XIV century, when the Counts of Otalora lived in the manor. The façade has a 15 -foot high set of solid wooden doors and three rows of external windows. Although the doors and windows are not equidistant from each other, the façade gives the impression of perfect symmetry. The back of the building has an additional floor and a balcony along the complete wall. The view of the mountains from this balcony is magnificent.

I have been assigned a large room for my meetings with my collaborators. This is the room where we have held six study-abroad summer sessions with professors and students from the University of San Diego. The room has massive walls, four arched doors of solid dark wood, two windows facing the beautiful green mountains, and translucent gold and white stained crystal walls facing the inside hall in the back of the room. There is a high ceiling with wooden beams that match the rich brown color of the doors. This is a meeting room with a capacity for about 20 people sitting in a horseshoe arrangement, with a projection screen, a blackboard and an easel. I have set a desk with chairs on opposite sides, a tape recorder, a notebook, a pitcher with water and two glasses.

Jon

Jon arrives on time. I greet him and we talk about the hot day and the advantage of being in the cool Otalora building, where having a few windows open allows the fresh mountain breeze circulate throughout the floors. He asks me to start with what I want to know.

"Jon," I begin, "I am intrigued about your comments on duty and freedom during the chiquiteo the other day. You mentioned a cultural value: "you participate because it's good for the community to which everyone must contribute'. Is this a value of the Basque culture?"

"No, it is a value of our cooperative culture."

"So you began participating according to that value, with a sense of discipline, because it was your duty. Is this how you learned to participate?"

"I can't be sure," Jon replied. "I think I started to participate much earlier, at home, although I did it indirectly. During my childhood and adolescence I felt free to speak up, 
give my opinion, do things. My family was traditional in the sense that my parents ruled at home but I don't remember them imposing their will on me."

"This topic is of much interest to me," I said, "because it could help us to understand the influence of our early experiences on the way we participate as adults. As you, I did not grow up in an environment of imposition but it was not one of participation either. My parents made decisions and I complied with them. This is very different from what my wife and I have done with our children, whom we have asked since they were quite young what they wanted to do, how they wanted to dress, and even where they would prefer for us as a family to go on vacation."

Jon nodded. "The freedom I felt at home was reinforced when I went away to college, which was not usual in my town. While being away, I learned to do things differently and during summer vacations at home, I would say: 'I am going to do this or that', and I had no problem with my parents."

"So you learned to participate when you were a student..."

"Yes and no. I went to school in the Franco era when there was no student participation at school. Oh, yes, I participated but in the student demonstrations!" he said, smiling. "But it was a way of participating against the school system, not for it. At school there was a relationship of authority between the instructor and the student, and if the instructor was renowned, he placed himself on a pedestal and did not even go to class, sending a substitute instead. It was a very different environment from what we see today at universities."

"When I asked myself the same question," I added, "I realized I started to participate when I went to college in the United States, where the relationship between instructors and students was much more open than in Mexico, and, by what you say, in the Basque country."

We paused for a moment. "My work experience as a student was during the summer, in jobs where my participation was with my muscles, not my mind. We could not see the whip, but we knew it was there. Rigidity was the norm and participating with our opinions was not in the vocabulary of the foremen in the yard."

"Considering your youth experiences, how and when did you learn to participate?" I asked.

"Look David," he replied, "as I see it, one learns to participate...participating! It is a process. My participation has evolved in the several jobs I've done in the cooperatives. I started in the industrial sector and was elected to several councils. This was a rich experience because I needed to be open to belong to these Councils. Later I was in jobs that exposed me to other cultures and ways of working, allowing me to participate with a broader perspective. Now I work as a consultant within the cooperatives, which affords me the opportunity to act with more creativity and freedom." 
"In other words," I said, "can we say that there is a stage in which you participate because it is required of you and another stage, as you are living now, that you participate because you feel free to do so?"

Jon looked at me. "Understanding participation grounded on freedom and not duty is a result of personal maturity. At first, I didn't think if I had the option to participate, I just assumed I had to. I did not analyze why I got involved in a decision. To illustrate, my idea then was: 'I belong to the organization and I defend organizational values'. I didn't look at the person and his or her probable needs."

"And how is that different now?"

"Today, I would not give absolute value to the needs of the organization but would also consider what the person needs. I would look for a way to match the needs of both, the organization and the person. Now I know it can be done and that is what I do. Earlier in my career, I was loyal to the organization and did what I was required to do. I did not analyze if what I did was aligned with what I thought should be done. The process was blind, now it's more open. I feel that my participation today is much more positive, effective and creative. I still defend the interests of the organization but in a different way. It is here that I go back to the maturing process, which is most helpful."

"Agreed," I said. "Can you describe what your participation means to you now?"

"I find meaning in the way I participate because of what I do. Looking back, independently from having participated with a sense of duty at the beginning, or by my own initiative later, I have always participated in decision making in my work group. Now I participate also in the design of my work, in contrast with previous jobs in which my work was circumscribed by a specific job description that limited my field of action. In the past, I tried to fulfill my job the best way possible but the work situations were repetitive and my response was more mechanical."

"My study in year 2000 showed people were satisfied with their participation in decision making but were dissatisfied with the level of participation in the design of their own job. This type of participation obviously depends also on the type of work you do, since, as you mention, in previous jobs there wasn't much latitude to change the job description."

"That's right," said Jon. "And I feel the difference. Now I am freer to act, I participate with two peers in determining the guidelines for my job, and I am free to work according to my judgment. I value greatly my autonomy to decide what, how and when to do what I consider appropriate for each case."

"And what does this freedom and autonomy mean to you?" 
"I'd say that my work now allows me to participate more profoundly, more in line with my personal aspirations. And," he added looking at me, "most importantly, I feel completely identified with my work, I feel my work fulfills my dreams as never before."

"What do you mean when you say your work fulfills your dreams as never before?"

"My work now is consistent with my personal values, it allows me to participate with more autonomy and creativity, and it helps me to develop myself not only professionally but also personally. I am committed to certain values and I do things inside and outside the workplace that are in agreement with these values. I am congruent inside and outside the workplace."

"Oh, yes, congruence. Could we talk more about it?" I asked. "I remember how frequently congruence was mentioned in my Mondragón study in year 2000. I would say that one of the most important problems I had as an executive in traditional organizations was precisely the lack of congruence, between what I did personally and professionally, as if I had two lives with different values."

"I believe that participation can only be meaningful if there is congruence," Jon affirmed. "This means that I act in all aspects of my life in accordance with my values."

"But how do I make sure that my actions are according to my values? And what happens if I act without congruence?"

"This is my view," he said. "If I cannot find enough personal and professional congruence, I can act in several ways. First, if my values are not aligned with those of the organization, my work becomes merely a means to have a good salary and my activity is limited exclusively to doing my job according to my skills. Some people find this is enough, as was mentioned in the chiquiteo sessions."

"Second," Jon added after a pause, "I may find it difficult to participate based on my reasoning, commitment or freedom because I have always participated out of duty. In this case, I can make an effort to participate and also encourage others to do it, trying to align my objectives with those of the organization."

He paused again and added: "And there is a third way to participate, which I think gives the most personal satisfaction. This is to accept the commitment to participate, understood not as something imposed upon me but as a voluntary act that fulfills me. In this case I indeed make a fundamental commitment. This commitment is different from responding superficially: 'A commitment to do that? Yes, it sounds good, let's see, we can talk about it later...". This fundamental commitment, of course, can only be made if there is a concordance, at least at a minimum level, between my personal objectives and those of the organization."

"And if there is no concordance at all?" I insisted. 
"I can't see how I could develop professionally and not personally in that case."

"Can you elaborate?"

"Yes. For example, it is not congruent that I, as a consultant, listen actively to my peers at work, trying to understand what is behind what they are saying, and not listen just as attentively to a friend or someone in my family. To me, the dividing line between who I am when I work and who I am outside of work is very thin."

"Right. To wrap this up, what does all we have been talking about mean to you? Is this something you have been searching for all along?"

"Yes, I have probably not consciously been looking for the specific work I do now but for some kind of work that helps the organization to meet its objectives while I also feel satisfied professionally and personally. I think that my personal inclinations and my contribution to the organization today allow me to shape my path so that my work activities in the future maintain the same pattern."

"Thank you, Jon, your comments have greatly clarified my perspective about what participation means."

"You are welcome."

Jon left the room and I went upstairs to the balcony. I looked at the green mountains, with their high peaks covered with fog and breathed the fresh air. I tried to put what Jon had told me in context.

I see Jon's experience with participation linking the relationship between participation, duty, maturity and congruence. Perceiving participation as a duty, as a value that benefits the community, seems to have been a solid beginning. How our country would change if our young people felt they participated at least at this level of duty!

His catchy phrase "We learn to participate...participating!" has the tremendous implication that we do not just tell, offer or try to force someone (or ourselves!) to participate. It is a process, it needs practice (we need to remember how Don Jose María started with his young students). Can I grasp the full meaning of this? Will people in Mexico participate in the political process because now they have a democratic government after 70 years of "dictatorial democracy"? Will the people in Irak participate just because we have decided to provide a democratic system for them? Will young people in the U.S. start participating if they don't see it as a meaningful value, a freedom others don't have, if we have not taught them to appreciate it? We do need to be educated to participate.

Jon started participating by defending the values of the organization, as a way to participate while not knowing, or having the courage, to participate according to his own judgment. It's easy to be for or against the organization, it's a comfortable position, no 
gray areas. Just adopt the corporate values and participate accordingly, or quietly subvert them. Not much effort involved here.

More mature participation, however, requires learning to discern. The responsible thing to do is to find alternatives that satisfy both, the organization and the person. The wonderful value of equilibrio which Morrison and Whyte and Whyte emphasize so much, is found once I acquire the capacity to discern.

And then there is congruence. Have we thought enough about congruence? My poetic transcription had already captured this concern in year 2000 . Jon expresses congruence as "realizing his dream."

The question is: do you, do I, do others we know, live congruently? I think the lack of congruence in my life was what finally created enough internal disruption that I needed to leave my business career. Without realizing it, a lack of congruence existed in my job by design. As I went up in the organization, I participated in decisions that were incongruous with my personal values. I was appeased by slogans such as "business is business" or "shareholders come first" to keep worker wages low, raise prices to our customers without justification, squeeze suppliers on their payments, or dump toxic substances in the rivers. There was no congruence between what was the right thing to do as a manager or a worker, a seller or a buyer, an industrialist or a member of the community.

I believe we have been able to live with lack of congruence by fragmenting instead of integrating our lives. For example, at school we teach ethics as a subject, instead of integrating it into the curriculum. This reinforces the idea that ethics is only a part of our lives. That is, it is permissible to act unethically in some cases but not in others, allowing for example accounting schemes to cheat on taxes or artificially inflate the share value in a business. Personally, it allows us to lie to someone who will buy our car or our home ("buyer beware," we conveniently say). We can ask so many questions about congruence in the big and small issues. For example, is it congruous to expect a clean street in front of my house while I throw garbage out the car window on other people's streets?

But I know that "it is easier said than done." I am so used to a lack of congruence that I need to question many things I do to find out how congruent I really am. Can you help me think through the following questions: Am I actively participating to integrate my personal and work objectives? Am I willing to make a commitment to participate fully in the decisions that will allow my work and my life to be integrated?

I went down the staircase to the first floor, walked out to the parking lot and headed back to the hotel. 


\section{Rosario}

I visited Rosario at her office two days later. I asked for her at the lobby, was given a visitor pass and waited for Rosario's assistant to meet me. She smiled as she came through the door from the factory, introduced herself and guided me in. A multitude of images assaulted my senses as I walked with her on the long aisle in the factory.

Everything looked so familiar. The machine operators greeted us by raising their eyes and nodding without interrupting their work. The forklift trucks braking and accelerating in spurts, their back lights flashing, their horns blaring intermittently. The pedestrian aisles with their diagonal yellow lines on the floor. The aroma of the warm lubricating oils on the machines and the smell of the metal being transformed to a thousand shapes. The rhythmic noise of the machines repeating their working cycles, the thumping of the packaging machinery at the end of the manufacturing line. The memories of the first ten years of my working life in factories crowded my mind. Everything seemed to be similar but was different at the same time. The plant layout, the processes, the products, the whole experience could be transferred to the factory I worked at in Mexico City in the decade of the seventies. Even Rosario's office, surrounded by picture windows, was similar to mine when I was the superintendent of manufacturing in a factory with 1500 workers. But the resemblance ended right there. What was different was what I wanted to talk about with her: the invisible human aspect, the relationships and interactions of the people in the shop floor, offices, laboratories...

Rosario greeted me in a friendly manner, exuding serenity in her attitude as well as her gaze, although it was obvious by the papers on her desk that she had a mountain of work awaiting her. We sat down at a small conference table in her office and exchanged news about her work, my book and the weather. I then told her I wanted to start on time so she could go back to her work. She agreed pleasantly, I never noticed a slight sense of rushing.

"Rosario," I said, "I realized in the chiquiteos that you have a very clear idea of what participation means to your people and your organization. I also perceived that you invest a lot of energy to promote it. I felt you had great respect for the persons who participated and their contribution to making better decisions. I'd like to talk more about this..."

"Look," she said, looking into my eyes, "to us, participation is most important. It's not a theory, it is our daily practice. We understand that it's good for a person to participate because he or she feels motivated and involved."

"It's paradoxical, because for executives in traditional organizations what you say is seen exactly backwards: it's a good theory that persons participate in decision making but it does not work in practice."

Rosario paused and looked at the factory through the window. "There are 500 people down there. It's much better to have everyone participate than ten of us in the Management Council making decisions on our own. It doesn't matter how much the ten of us give of ourselves to try to reach the best decision, it will not be as good as if 
everyone participates in making it. And the intention to include everyone in decision making extends to the formal councils. For example, we are very proactive with the Social Council. Anytime we have something to decide, even though we do not have the obligation to consult its members, we talk to them, we share our concerns and tell them why we do what we do."

"I worked in transnational companies for many years. Those of us who were in executive positions, as you are, made decisions in small groups at the top of the organization. Sometimes we consulted others, not to include them in the decision making process but to gain their support and expedite a decision that was already made."

"We see participation here from another perspective," she replied. "We say in our meetings 'if we are ten people here and all of us have the same opinion, we have nine too many'. Everyone perceives a situation from his or her perspective. We are enriched with multiple points of view and there is no other way to know them but for all of us to share ours."

"I understand what you are saying," I added. "When I reflected on this topic I remembered that it's crucial that everyone has the necessary space to participate. I referred to this space as 'sacred space'. When we are in a gathering, the space we share is sacred, if we recognize that each one of us is an equally worthy person. It is not sufficient to say it, we need to make sure that everyone understands that we mean what we say." I paused and clarified: "This is even more important in non-cooperative organizations in which the equality of participants is not commonly accepted."

"I feel very free to participate," Rosario replied, "because I have learned that each one of us is different and has a unique experience. The truth doesn't exist, what exists is 'something' and many ways to see that 'something'. Each one of us has his or her truth and participates according to it. From this perspective, I feel freer to participate because I don't have to think: 'should it be this or that way?' Instead, I say 'this is how I see it', and the way I see it is as valid as the way each one sees it. It is not about someone saying something better than what I have said, but that I am expressing my point of view and the others are presenting theirs.

"I agree," I said. "None us has the absolute truth, we construct our truth with our language and our experience, don't we?"

"Indeed we do."

"Good, we are talking at a more personal level now. Could we focus on you? Could we start at the beginning... when did you begin to participate?"

"I began to participate once I was working at the cooperatives. I do not remember my school promoting my participation. Today my small son and his classmates sit in a circle in class, but in my school we had our desks perfectly lined up facing the teacher. I can 
say the same about my family, my participation was at a normal level, it wasn't emphasized. I don't feel I was educated in a participatory environment."

"Do you think that our early education influences the work we seek when we graduate?" I asked.

"If you have lived in a family and studied in a school in which participation was not promoted, it would not seem strange to work in an organization where five people make all decisions and the rest obey them. It did not happen to me but I can see how those who start to work in traditional organizations would perceive that way of working as being normal."

Rosario paused. "But I am not sure of what I am telling you because my experience has always been within the cooperatives. Let me tell you a story:

Recently I had the opportunity to observe a non-cooperative organization that we were planning to acquire. There were three people who made decisions and the rest obeyed them--nobody would give an opinion, nobody would even say anything. I was very surprised to see this. Once we acquired them, we told the managers and workers about our participatory system of management and asked them to design a new management model showing how they would like to be organized. They developed a model that allowed a lot of participation! We realized then that it was not that they didn't want to participate but that they didn't have that option or didn't know how to participate."

"Very interesting," I said. "Rosario, since you are able to participate and know how, can you tell me what it feels like? What are you like when you participate?

"Participating in decision making, to me, is meaningful because I feel that my opinion is being taken into account and because in some way I am creating something. That is, I don't think that my organization is forging ahead in one direction or another 'in spite of me' or that I have nothing to do with the path it decides to follow. I am collaborating and defining the future of what is most relevant to me professionally, which is my organization. I feel I am determining its future and participating in its successes and its failures. I feel I am integrated, cooperating to achieve the organizational objectives. I feel I am not detached from my organization but instead that I know how it's moving forward and evolving.

"So you always participate in decision making in your organization?"

"Not exactly. I don't stand out because of the way I participate nor do I always raise my hand spontaneously in large groups. I am more comfortable participating in smaller groups in which I can clarify what I say instead of my words being interpreted in a thousand different ways."

"I understand," I said. "And what do you feel when you participate with your team in these small groups?" 
"When we reach a decision as a team that commits us substantially to meet an objective, I feel proud and at ease, even if we don't meet the objective, because all of us participated in making the commitment. Although these important decisions also fill us with respect and make us nervous, we are calm because we recognize that what is important is to attempt to meet our objective as a team."

"And is it relevant that you are a woman? Do you feel different as a leader?"

"As a woman, I don't feel any different in my work," she replied. "I have not felt any additional barriers along my professional career because I am a woman. I have had opportunities and I have capitalized on them, I have not felt hindered at any time. I don't notice a difference when I participate because in our cooperative environment women are not obstructed to participate freely."

"But women in higher management jobs are few..."

"Some people say that numbers tell the story," said Rosario, "that not many women have jobs at the top. I think that in our cooperative we have a lot of participation from women. In the Governing Council we have four women and in the Executive Council we have two. In the Social Council we also had until very recently two women. In the Management Council, which directs our organization, we are three women who participate exactly as men do."

"I worked for many years in an environment with no women in executive jobs," I said. "As I talk with women like you, I am more conscious that the organizational world has missed many opportunities by not including women in executive jobs. Simply listening to the inclusive way you express yourself, it's easy to see how different it is when a voice such as yours is not part of the conversation. How do you perceive what I say? Can you get in contact with your feelings and tell me what it's like? Do you participate in a different way?"

"Yes and no. Indeed people say 'you are a woman, you have other values, you express your emotions in a different way'. It may be. In my professional career I have seen men who express their emotions very well and I have seen women who are dry and cold in their relationships or that are less participatory. I have seen a little of everything. I like to be caring in my relationships with other persons, find out what concerns them, but I don't attribute it to my being a woman. I don't see why I would behave differently because I am a woman, I feel comfortable in my relationships and value their emotional aspect immensely."

"To me," I said, " expressing our feelings to those with whom we have a relationship as peers at work, as friends, or in any other way, whether we are women or men, is important. But I know I am in a minority." 
"We as women have less problem revealing our emotions," replied Rosario. "I think men see crying as a weakness, 'a woman cries, a man doesn't'. We need to be more open because in the professional world I need to understand the emotions of the person I am speaking to and be more conscious of my own emotions at the same time." After a pause, she added: "I accept, however, that I still have some trouble revealing my emotions at work and some times I 'put the brakes on' even if I would prefer to be more open. I still have much to do about this."

"I understand," I said. "When I worked as an executive, I used to read books about this topic, and the standard advice was not to show your emotions at work because it revealed your vulnerability..."

"On the other hand," Rosario continued, "I do feel that as a woman my participation is different in the way I say things. Some people, with their somewhat cold way of speaking in meetings, oblivious to the person who is listening to their words, attain nothing but rejection at the end. I think then 'I would probably have said this or that in some other way, I would have said the same thing but looking more for acceptance than rejection'. At the end, I have persons in front of me with whom I want to collaborate and the way I say things can either push them away or get them closer to me. I indeed notice that I would say things in more inclusive ways."

"I understand," I said. "And what else can influence your experience of participation?"

"We have to consider the topic of leadership. I think that at certain levels we need leaders who facilitate participation. I've worked with my team and we have defined what a leader is. For us, a leader is the one who influences others with his actions so that they work with enthusiasm in the implementation of our management model, which emphasizes participation. In other words, a leader is someone who, indirectly, setting the example, gets other people excited about "pulling the cart" together.

"I remember that Antonio Cancelo, when he was the President of the General Council, once told a journalist that leaders in the cooperatives are different because they encourage persons to use their intelligence and freedom."

"That's right," she replied.

"But my immediate reaction was "what Cancelo says is exactly the opposite to my experience, because it is precisely those human characteristics, intelligence and freedom, that we as executives suppress in traditional organizations, since we don't allow our employees to participate in decisions or tell us what they think'."

"To me, working in a cooperative environment, it is difficult to understand what you are saying," replied Rosario.

"Fine, what can we add to finish our conversation?" 
"I could summarize the way I feel with an image. I think that we can move forward if we all pull the cart together than if two or three of us try to pull it by ourselves. Furthermore, deciding what everyone should do on my own is even worse than pulling the cart by myself...it's actually as if I were pushing the cart from behind!"

I smiled. "Excellent, Rosario. I'll keep your vivid image in my mind. Thank you very much."

"You are welcome."

We said goodbye and Rosario's assistant took me back to the lobby. I was planning to take a taxi but, with characteristic hospitality, Esteban, the Arrasate hotel owner, was waiting for me outside the factory to take me back to the hotel. "It is difficult to find a taxi at this time of the day," he said. I had a cup of coffee with him at the lounge bar in his hotel and went out for a walk and lunch. I went up Ferrerias street and passed the cyber-cafe as I heard the church bells, reminding me it was two o'clock in the afternoon. I arrived at the crossing with Zurgin Cantoya street and turned to the right to walk on its narrow pathway to avoid the hot sun. I remembered the saying "only mad dogs and Englishmen are out at this time of the day" and I thought, "What am I doing out here in the summer time?" It was quiet everywhere, there was no one walking on the streets. I arrived at one of the ancient lateral gates of the walled city, turned to the left to reach the park, went across the bridge and found a bench in the shade.

Rosario had such clear, well-articulated ideas during our conversation. Although I would ask her about her own experience, she talked in terms of others. "We can not accomplish anything without participation," she said. Her language was permeated with terms such as "we," "our team," or "our cooperative." She did not mention the word, but her comments reflected the concept of "equilibrio" or balance: participation is not about focusing on one objective and maximizing it at the expense of all others, but in balancing all needs, she said. I always marvel at the way people in Mondragón talk, rarely mentioning their values but always following them closely.

With a good dose of humility rarely seen in company executives in traditional organizations, Rosario said that having broad participation is a better way to make a decision than relying on a few people at the top of the organization. Her disbelief, almost shock, when she realized that in the company overseas they joint-ventured with, bosses made decisions alone, was refreshing. Such visceral rejection to workplaces where people are not allowed to participate is what is needed to shift to a participatory workplace.

Rosario also had a clear idea of what participation means to her. She expressed herself in terms of creating, being integrated, feeling worthy when her voice was heard and she cooperated with others to determine their personal and collective future. She preferred to participate, she said, when there was close interaction among participants, as happens in small groups. I interpret this as participation being meaningful when she was able to interact in an intense way with others. 
She had great images that reflected her thinking. "If ten people participating on a decision agree too quickly, we have nine too many." Dissent is not only welcomed but encouraged. Quite a contrast with traditional organizations in which the goal is to have everyone agree as soon as possible with what the executive decides.

"I have 'my' truth, you have 'yours'. But no one has a 'better' truth or the whole truth." Everyone has a different life experience and a corresponding perspective. Thus, we can participate knowing our opinion is as worthy as any other. There is such a feeling of equality and mutual respect behind those words. Again, very different from my experience in business organizations.

Her final image was the most graphic: "Participating is like pulling a cart together, deciding myself is like moving the cart on my own--not by pulling it but by pushing it!" This sentence needs no comments...

Aitor

Aitor and I got together in the meeting room in Otalora. He was very open and told me he had no meeting after ours so we could take as much time as we needed. This was welcomed news for me. I put my tape recorder on.

"Aitor," I began, "during the chiquiteo you expressed participation in terms of values and I'd like to explore your comments further. My study in year 2000 was precisely about values and principles, as key to the $\mathrm{MCC}$ cooperatives, so this topic is very interesting to me. Could you tell me more about what these values and especially the value of participation mean to you?"

"Sure," he replied. "I could say that I went through a maturation process. As I continued having new experiences, I deepened my understanding of the wealth of our basic principles and of how, through my participation, I gave them life. I had already internalized cooperative values such as participation in decision making, democracy, egalitarianism and solidarity since I was younger. Later on, I could see how participation was intimately related to democracy, and that, when I participated, I acted according to my responsibility and my right to work in a democratic system."

"That's right," I said. "Participation is possible because democracy is in place."

"This connection between democracy and participation is clear also to cooperativists," said Aitor. "This is why many conclude that democracy, represented by the onemember/one-vote system, is the most important principle."

"I agree. Democracy is the principle that grounds all others," I said, with conviction. 
"I don't see it that way," he replied. "From my point of view, democracy, and therefore participation in decision making, exist as a consequence of a more basic principle: the sovereignty of work over capital. This principle establishes that the person who performs work has ultimate power and that capital is a means, an instrument subordinated to work. And this power is not limited to the freedom to organize one's work but also includes the management of the cooperative."

"That is, democracy, and therefore participation, are not possible unless the worker has the power," I repeated, intending to clarify what Aitor was saying. "The person participates because he or she is sovereign. Otherwise, the person would be just a means, an instrument of production."

"Precisely," he said, indicating with his tone of voice that what I said was obvious to him.

"I had seen democracy as the root," I said. "I had not perceived it as democracy in turn being grounded on the sovereignty of work over capital. Now that you say it, it's evident With this perspective, it's easier to connect the sovereignty of work, or rather of the worker, with my topic, which is based on the concept that any activity, including participation of course, is centered on the person. The person, because he or she has the power, is the engine that has driven the cooperatives to be what they are today. All decisions throughout Mondragón history were driven by persons who participated and decided to create what exists today.

He nodded.

"If tomorrow," I added, as if thinking aloud, "the socios decided not to participate, the cooperatives would be stuck."

"I think so," said Aitor. "The cooperatives were founded by a group of people who are now retired and new socios have taken their place. The cooperatives as organizations have transcended the original group of people and continue being alive because there are new people making decisions."

Aitor paused giving me a moment to assimilate what he was saying. "From a more universal perspective," he added, "the most important principle is social transformation, which promotes a society with more justice, egalitarianism and solidarity. We contribute to this transformation generating employment, a scarce resource."

"You are referring to Don José Maria's vision to transform society by creating employment for all," I said.

"But unfortunately it's not a simple task," he continued, "because, to attain this objective, we have to be productive and make money. We want to help humanity but we can't forget we can't lose money. Although our mission is not to obtain the maximum economic benefit, we need to use capital as a means to fulfill our primordial mission: to 
create wealth in society. To achieve our mission, we need to balance the economic and social aspects, which helps us to maintain the appropriate perspective."

"You are referring now to the principle of equilibrio.

"Right."

"I have reflected on this topic," I said, eager to share my thoughts with Aitor. "I find considerable differences in the way work is perceived from the personal and the organizational perspective. My experience in traditional organizations has been that persons as well as organizations seek to focus on an objective endeavoring to meet it at all costs. Do you see what I mean?" I asked rhetorically, testing if this was an interesting topic for him.

Aitor nodded attentively.

"When the intention is to maximize an objective," I continued, "we dedicate all available resources to meet it, but the cost of the trade off with how many people are affected, or with actions not taken, is not seen until later. We find, for example, organizations that focus exclusively on profits, growth or efficiency in the short term. Worker participation in these cases is limited because it's considered inefficient so decisions that may affect the organization or the community adversely in the long term are made. For example, rash decisions such as firing employees when markets go down temporarily are made without considering the effect on the people fired and the cost of hiring and training new employees when the market goes up again. These decisions also affect the community that nurtures the organization in the short term as well as the workers, the organization and the community in the long term. I'd say that in this case we gain focus but we lose equilibrio.

I paused. Aitor was following my every word but I realized this way of working was far removed from his experience. I didn't expect any comments from him so I changed the subject. "Aitor, could you identify when you began to participate in decision making?"

"My experience with participation in decision making has been part of me since I was young," he said, "starting when some colleagues and I formed a cooperative organization of twenty professors in one of the largest cities of the Basque Country. I was one of three members responsible for its coordination and participated intensely in all topics. I felt quite committed to our cooperative and dedicated a great amount of time to our problemsolving meetings."

"And how did you feel contributing in this cooperative which your peers and you had created, as compared to your experience here?" I asked. "You must have felt you were doing something important, uh?"

"Not really. Although our group was different because we had created a democratic organization with an egalitarian workplace, I didn't feel we were doing something 
important because we had created this cooperative to resolve our economic problems. But when I started to work here, the situation was different. This was an already established group of industrial cooperatives with a professional organization. I became a member of the Governing Council almost from the beginning and was quite active in the social and cultural life."

"Do you remember some of your experiences with participation at that time?"

"Yes. Let me tell you about one of my most vivid experiences of my early years in one of the most important manufacturing operations here.

The objective was to change from the machine-oriented Taylorist system of standardized group work to a person-centered autonomous organizational system based on the freedom of those in the group to make decisions about their own work. This intensive two-year project required extensive worker education, participation in numerous debates and making multiple decisions that affected the involved workers personally in their day-to-day routines. I realized then that my participation would not only help me to have a voice but that it was also a means to help others. I also understood the importance of involving many people in a project of this magnitude. I felt quite satisfied because at the end work was organized in such a way that it was more motivating and satisfactory for all those who participated."

"This project must have been very rewarding to you, huh?" I said.

"Yes, it was then, but now I see it as part of my personal development process. In my next job I acquired a broader perspective of the meaning of work in a participatory environment because it included contact with people from organizational cultures in other parts of the world. I realized that there were many people who wanted to know about our experience, allowing me to see our cooperatives with different eyes. It seemed we were doing something positive, not only for ourselves, but for others, for humanity."

"And how did you feel?"

"I felt proud when I understood we had something special," said Aitor. "I felt it was necessary to preserve the cooperative system and that it behooved me, as well as others at our cooperatives, to abandon personal agendas and do whatever was necessary to perpetuate the cooperative system."

"You saw the cooperative system as something very good..."

"Yes, but although I think that our cooperative system offers more advantages than disadvantages, I'd like to clarify that I don't think we do everything well."

"Aitor," I replied immediately, "having worked in other environments, although the cooperative is certainly not perfect, it works better than the mainstream model in 
traditional organizations. I think no one can take away MCC's merit of creating a workplace with principles that offer flexibility but maintain their essence."

"Possibly. But in reality, as I am more conscious of our values, I am also more aware of our problems. As an example, the principle of sovereignty of labor over capital, which I already mentioned as being very important, does not apply to people we hire with temporary contracts under a wage system. These people work in the cooperatives as I do, but they do not have the right to vote."

"Yes," I said, "it looks like growing so fast has had a cost."

"Another aspect is the internationalization of our cooperatives," he added. "We have focused on the economic aspect in our new ventures, but we could emphasize the social aspect much more. All operations in other countries are organized as traditional organizations. Of course, it's easier to start up an operation as a traditional organization and just hire people who want to work in it, and that's the end of the problem. I think we could do more, we could apply our values and be more participatory instead of going for the quick and easy fix."

"What do you mean when you say you could do much more?"

"Yes, we could start by looking for people who want to be owners and workers, so they can participate."

"I see. But reviewing your history, I think I am being realistic when I say that the socios will overcome these new challenges, as you have in the past," I replied, trying to shed some positive light to Aitor's arguments.

"I certainly hope you are right, David. I haven't lost hope. In the last general congress, held every four years, some resolutions were approved to work more with the expansion of full-fledged socios, considering the whole cooperative gamut: participation in profits, ownership, and decision making."

"It will be interesting to see the results..."

"What I consider important," Aitor concluded, "is that fortunately there is interest in solving problems such as this through day-to-day dialogue and the formal MCC Congresses."

"That's good, I said. "Could you give me an example of participation by the socios that would illustrate its importance?"

Aitor looked out the window and I waited. He then said: "I'd like to tell you a story that I remember well. It's old now but provides a good example:

In 1993, there was a debate about changing the pay system from a range of 1:4.5 between the lowest and highest paid job to fixing the maximum salary within 
$\mathrm{MCC}$ at the level of $70 \%$ of the external market for an equivalent job position. Making this modification, other job positions would change to become aligned with this change, which was proposed because there was too much difference in the salary of some people within the cooperatives and their counterparts in similar external job positions. The meeting to make this decision lasted from 3 p.m. until midnight. $98 \%$ of the worker-owners participated in the general assembly because of the interest it had generated and the nature of the decision, which impacted everyone. To make the story short, the final vote was against this change. Because of this decision, the governing council resigned next day, its members stating they felt they were not aligned with the opinion of the rest of the socios. But this is not the point of my story. What I am trying to illustrate is that it was demonstrated once more that worker-owners have the power to make final decisions in important matters. We allow the general manager to have the power to make decisions on a daily basis, but the right to make the final decision is vested in the general assembly, composed of all worker-owners.

"This is a good story!" I exclaimed.

He smiled slightly and nodded once.

"How do you experience participation now?" I asked.

Aitor paused before answering. "As a fruit of my experience, when I participate today, I do it more conscientiously, analyzing the consequences of my participation much more. I am happy because the cooperative values coincide with mine. I have a leftist ideology and identify with the utopians that preceded the cooperatives."

"And how do you identify with the utopians today? I asked.

"I feel that, by working here, I am the closest possible to fulfill my values in an egalitarian, communitarian society. I have been aware of this congruence for some time and have concluded that cooperativism, as practiced here at MCC, could be the "third way'. Well, perhaps now we could say it would be the 'second way' because the totalitarian path of the now defunct Soviet countries has disappeared."

"You are referring to cooperativism not only as a way of working but as a way of living," I said.

"Indeed. My experiences with participation have not only shaped my way of working but also my personal life."

"Can you give me some examples?"

"Yes. Let me see...I can speak about participation in my family, other organizations and politics. In my family, ever since our children had reasoning ability, they could participate in our decisions. Today they are adolescents and they participate, of course. 
Decisions are made according to everyone's opinions, if we are going some place on vacation, for example, and my wife and children have one opinion and I have another, I accept doing what they prefer."

Aitor paused to organize his thoughts. "I also think that organizations need to maintain an appropriate size to allow participation and promote efficiency. For example, Lagun Aro, the MCC Social Prevention system, functions much better than the Social Security system at the national level. If someone asks me: do you prefer a cooperative with 200 or with 4000 people? The one with 4000 people may have information channels and formal communication systems to facilitate decision making but these will be slower and more impersonal, affecting efficiency. The organization with 200 people, however, even though it doesn't have such systems, is more efficient and participation is as good or better than in the larger organization. Why? Because in general a small organization works better than a larger one due to the personal contact among its members and the resulting swiftness with which agreements will be reached."

"Your comments evoke the 'Small is beautiful' book by Schumacher. As the name implies, the author proposes that a small organization works better," I said, but with no intention to elaborate. Instead, I paused and changed the subject: "Could you tell me what you think about participation in decision making at the national level, a hot subject in this part of the world."

"Yes. I have very clear beliefs about the responsibility and the right to participate in decision making in the political arena. I am a Basque nationalist but not a Spanish one Why? Because just as I believe participation is better in a small than in a large organization, I also believe that the Basque Country, being a group of small communities that are in close relationship, would work more effectively than if they are part of the large country of Spain. Therefore, if someone asks me: Do you think that an independent political system, instead of one within Spain, would work better? I would respond affirmatively."

"And do you envision how such a change could be achieved," I asked.

"Let me explain what I think. If participation is one of the basic values of a democratic political system, we should have the right to decide: do we continue being part of Spain or do we form a country within Europe, becoming the European Basques? I would vote to be a nation within Europe because I feel I am Basque and European. I do not mean by this that I am not in solidarity with other Spanish regions, if Castilla or Andalucia are in a bad situation, we pay more taxes or do what is necessary to help them. However, if most of us Basques want to be independent and we decide this through a vote, I think it would be better."

"And if the majority doesn't agree?"

"It would be fine too. I don't care so much if the majority vote results in a decision to stay within Spain or to become an independent nation within Europe. What I really care 
about is that our right and responsibility to participate in a decision that affects us directly should be respected."

We were silent for a moment before Aitor concluded. "You ask me, what does participation in decision making mean to me? It means having the freedom to participate in such a way that I look not only for my own benefit but also for the benefit of others. I can achieve this with my participation in those areas in which I have access: my work, the work of others whom I affect with my decisions, my family, my community and my political milieu."

"This is very clear, Aitor," I said as I stood up. "I appreciate your comments."

"Great, David, see you soon."

I could hear Aitor's as he went down the stairs. I had shared the personal experience of someone who has been a participant probably for 30 years of his life.

As I listened to him, I had thought about how we all see participation with a different perspective. Some of us see it as something pragmatic, a way to make a better decision, a way to motivate others. And then, there are others, as Aitor, who see participation in terms of values.

Aitor, as others, recognized that experience and maturity changed his feelings about participation. He already knew and liked cooperative principles when he arrived at the cooperatives but the connections, the patterns, appeared with time.

His connection between participation, democracy and the sovereignty of labor over capital gave me a new perspective of the person being at the center at the workplace. Democracy is a concept that embodies freedom and equality among persons but does not in itself give primacy to persons over profits at the workplace, for example. In contrast, sovereignty of labor is closely tied to the dignity of the person as related to things: his or her primacy over money or other material things. Can you help me answer: what is the relationship between human dignity and democracy at work? Can democracy exist without respecting the dignity of the person?

Another comment Aitor made reminded me of the importance of being open to a phrase mentioned once or twice, a casual comment or a few stray words uttered by a collaborator. Listening carefully, it is some times possible to find resonance with what you or I have felt or experienced. I reacted, for example, to his comment about the cooperatives having transcended the founders. We place much emphasis on the positive role of Don José Maria, the five founders, the twenty or thirty people that followed them, and this is as it should be. But there is another aspect of the Mondragón experience. One of the characteristics of MCC, as emphasized by Don José Maria from the beginning, was 
that the cooperatives had to evolve and adapt to new situations. The cooperatives have been in existence for 50 years and over 25 years since he died and many changes have been made. How have these changes occurred? They have happened because the socios, who have replaced the founding group, have continued to participate, making new decisions to adapt to new challenges. Continued participation in making decisions that fit the present and future is the key to the continuity of the Mondragón cooperatives. This fact can be overlooked when reading about Mondragón but it is a valuable insight.

It was also interesting to hear Aitor talk about the ultimate goal of Mondragón: social transformation through wealth creation, pursuing jobs for everyone. There is strong dissonance between the objective to eliminate jobs in traditional organizations to reduce cost and the objective to create jobs in the cooperatives through growth, retraining and relocation. And this is not about keeping people employed as the expense of productivity. Mondragón competes ably in world markets and has healthy profits. Is having a job a right or a privilege? Are we as members of a society responsible for the wellbeing of those who live in it? Or are we responsible only for our own wellbeing, or that of our family or close circle of friends?

Aitor's ambivalence about what MCC is doing, especially overseas, has been a much debated issue in Mondragón for a few years. How to keep all workers as socios with equal rights and responsibilities? This is far from resolved, appearing already in my study in year 2000 as an important issue. I expressed a contrasting optimism to Aitor's comments, not based on my optimistic feelings but on those of MCC participants in year 2000 , who told me confidently that they have overcome numerous barriers throughout their history and expect to overcome this one also. An example frequently mentioned is the devastating drop in MCC business after Spain joined the European Union and opened its markets to French, German and Dutch products, at better prices and often better quality. It reminded me of NAFTA and the numerous Mexican businesses that went bankrupt when American and Canadian products invaded the Mexican markets. People at MCC regrouped, reorganized, took cuts in salaries and forged ahead. In time, MCC became competitive with these products and has now captured markets in those countries.

Aitor's words also resonate with Jon's idea of congruence. To him, participation extends to all parts of life, believing that smaller is better in all milieus because participation is broader and more effective.

Participation, Aitor concludes, is related to freedom. Everyone's freedom to have a voice in all aspects of life in which they are part of a larger group, be it family, work, community or society. Do you feel you have this type of freedom, particularly at the workplace? 


\section{Noemi}

I was waiting for Noemi at the Otalora meeting room. The day was cool and I was glad because I was planning to take the rest of the day off and reflect on the experience so far, now that I was at a midpoint with my dialogues. I had come early and walked along the narrow road in the Otalora area, absorbing the tranquility of the green valley and mountains. I felt energized and ready to start.

Noemi arrived on time, oozing enthusiasm, as she had during the chiquiteos. She was very interested in my book project and it showed. We sat down at the table. She asked me some questions about the methodology for my study and seemed anxious to get started. "I'll be candid in my comments," she said. "I really want to contribute to your book."

I smiled and nodded. "Noemi," I began, "during the chiquiteos you also spoke very candidly of participation as you live it with your colleagues. I wonder if there is something you would like to add."

"David," she said, with a tone of voice that seemed to show frustration, "what I see is that not all of us have the same opportunities to participate in decision making in our factory. There, as in any other enterprise, giving orders from above exists. I, thank God, am in the Management Council and participate quite a bit in matters related to my job. But at the level of the factory floor, participation is low."

Feeling that Noemi wanted to say more, I kept quiet.

"I think that if we managers take the opportunity to talk with the socios in the factory," she added enunciating carefully, "we'll see that they have a lot to say, and that the persons and their work coincide. These conversations would of course not be exclusively about personal problems but more about those that affect them as persons in their work. The socios would be happy to be able to express their ideas and I think the satisfaction of participating would increase in proportion to how much the distance shortens between those in high hierarchical positions and those in the factory floor. And of course this would happen as long as the approved suggestions of these socios are acted upon."

"You have the suggestion system you mentioned in the chiquiteo in place," I said.

"True, but we need to improve it. I think that those of us who evaluate suggestions have to learn to value the participation of everyone according to his or her level of experience in the job. We need to recognize that it's not possible that new socios participate with ideas as clever as those of experienced workers, or that factory workers participate with ideas similar to an engineer's. I still find people in the higher levels of the organization, and I consider myself as one of them, making comments such as 'this person writes a suggestion just for the sake of writing something!' "

"And you also have the established systems to channel information," I said, "indicating that there are formal systems to facilitate participation." 
"I agree, but even with existing official channels such as the Social Council, the paths of communication are usually long and at times distorted. In addition, by the time the information gets to the top, time has gone by and you get cold...then this process becomes frustrating instead of motivating."

"Nothing substitutes personal contact, does it?" I said, not expecting a reply. And I changed the subject.

"Noemi, how about if we now focus more on you and your participation?"

"Okay, David. As I am sure you realize, my experience is not only personal but is influenced by what I do at work, because I am very much involved with the established participation systems in the factory. This is why so far I've spoken mostly about my experience as it relates to others."

I nodded in agreement.

"But speaking about me," continued Noemi, "I like to participate in decision making. In the Management council, I can give opinions, I can say what I want, although, as I mentioned in the chiquiteo, I know I am young and that my participation doesn't determine what is to be done. For now I see my participation as valuable when I give ideas in Council meetings, and, if they are accepted, they are applied. My ideas are not always accepted but at least I dive into the pool with the others."

"Can you give me an example?"

"Yes. Recently a colleague and I prepared a project suggesting a more methodical alternative to accomplish certain results. We presented it to the Council members, and, although not all of them were in agreement, it was accepted. We had prepared our presentation well, we understood what we wanted to do, and there was a lot of participation during the presentation."

"And how did you feel?"

"I like participating in this type of projects because it's a challenge to tackle topics I don't know about, and, as I work on them, I become enriched. I felt good participating, we had an objective, we met it, and I felt valued and recognized."

"You felt accepted by the group..."

"Yes," she said unhesitatingly.

"You also mentioned in the chiquiteo, and again today, that your youth has been a factor to be considered in your participation. Could you explain what you feel about this?" 
"Yes. I want to participate in making the important decisions but I know that I have to learn certain things before I can do it."

"Such as?"

"For example, I am interested in learning to listen to others but I know this is not a mathematical process, it's not an exact science. I don't know exactly what to do or how."

"You feel this way because you have a technical degree, uh?" I said jokingly. "I also studied engineering, and at times I would prefer to reduce everything to a method, a process, I don't like to improvise."

"Yes, you have to invent everything!" she exclaimed. "But, on the other hand, learning to listen will help me to think more about who I am and I will know myself better."

"I remember you told me when we met that you like psychology," I said. "Were you referring to what you just said?"

"That's right. I like to know myself. I am also conscious that I'll have to change other things too," added Noemi. "I need to be less competitive, less individualistic and I hope I can change the way I am. I am very competitive."

"Can you describe what you mean when you say you are very competitive?"

"When I speak about competition, I mean being recognized, not in the sense of being the first and "climbing up" regardless of others. I don't mean that I want to step on others to win the competition. No, I hate that way of acting. I must work as part of a team since I know that better ideas will emerge if I do it without being competitive. However, this competitiveness comes from within me and it's not controllable. Normally, I feel like competing, although my head says this is not correct, my heart burns. This is something I have inside of me and I recognize it's not good."

"Could you tell me how you started to be competitive?"

"Competitiveness and individualism have been part of me from the beginning. I was born and raised outside the Basque Country, in a culture of competition, in which you are one of the best or you are worth nothing. I learned since I was a little girl that you have to always strive to be the best. In my family, if I didn't do what I had to do the best way I could, I would have a problem with my father."

"I understand."

"When I arrived in the Basque Country as a teenager," she continued, "I realized that people here didn't compete. I liked to compete but it was not customary here. I remember that in school, in Calculus class, there was a competition about derivatives, which I really liked because I was among the best, but this competition was not motivating or fun for 
the rest of the students. They would compete only because the professor asked them to do it. I could see that students collaborated with each other, they would share their notes, but I preferred to work by myself."

Noemi paused and I kept looking at her attentively.

"Let me tell you an incident from school," she said, looking out the window.

I have a good friend, whom I have known ever since I first came here. On a certain occasion, she had not studied for a class exam. We sat together and she tried to copy my answers but I realized it and covered my papers. She told me later 'that is no way to behave'. I realized right then that we had different points of view: to her, it was forbidden to compete instead of collaborate. To me, it was the opposite. I thought 'you are evaluating yourself and your merits', and of course so was I. Time has passed and I have softened somewhat my way of looking at things, but I believe my point of view has not changed much. In a similar situation today, I probably would let her copy my answers to keep our friendship, but in the future I would avoid her taking advantage of me in order to "climb up"."

I nodded. "And at work?"

"Here I have tried to implement quality competitions among departments, but people don't accept them. Due to these experiences, I realize that I like competition because I see it as a game, but others obviously don't see it that way."

"I think that some times there is an ambivalence between being collaborative and competitive, between cooperating and standing out," I said.

"That's right. But I have also participated with other colleagues. For example, in the project presented in the Management Council meeting I mentioned earlier, a colleague and I prepared it together, the proposal was from both of us."

"And did you feel you were collaborating or competing with her?"

"In this case, there was no competition between us, it was all participation. Of course, I also recognize that there was no reason to compete, since ours was the only project being presented, and it was presented by both of us."

"I understand."

"There is something else I'd like to change," said Noemi. "My dependence on the recognition of others. I know that being recognized is important to me. For example, I like to participate, not just like one more team member, but because I'd like to belong to another team, formed by those who are recognized by everyone. I realize I'm being selfcentered but to participate just to do it is something I prefer not being a part of." 
"How about participating as a means to help others, the community?"

"I feel the same way," she said. "I like to help others but to be recognized at the same time. This way they win and I win. I am not much interested in remaining anonymous, in the shadows. I realize that giving so much importance to being recognized is not good, it's something I have to fight, it's something to overcome because this way I can't be a better person or a more effective one."

"I see."

"In my case," said Noemi, focusing her look on a fixed point beyond us, "I could say that being less individualistic, less competitive and less subjected to the recognition of others are personal and professional challenges that I have to confront. That is, if I want to develop my aptitude to be the leader I'd like to be."

"You are referring now to the role of leadership," I said.

"That's right. The theme of leadership is most interesting and I've been studying it. As I understand it, there are three types of leaders: those that resolve problems, the ones that 'know everything', and the leaders who help others in the path to self-realization, guiding them and listening to them. In my work, the first type of leaders has recognition because they know how to solve problems. Other leaders are 'bosses', that is, they lead by using their authority. The ones we need the most, those who assume an attitude of listening and understanding the other, are the ones we don't have."

"And how do you perceive yourself as a leader?"

"I'd like to be a leader who sways people," she said, after a pause, "and I'd like others to be interested in my point of view. I'd like to have power and influence to help them. I perceive that I have to use my intuition but also my reasoning ability because I need a rational explanation to understand certain things about leadership. To be able to influence others, I have to demonstrate that I have the type of leadership that helps others in their self-realization, I have to learn to be less self-centered and to acquire the ability to listen."

"The type of leader you describe seems to fit well in the cooperatives," I said, "since here a leader acts by influencing others."

"That's how I see it," said Noemi.

"So you want to participate, but as a leader..."

"I want to participate," she replied, "but I prefer to do it in the power groups. I like to belong to them."

"Could you clarify what you mean by belonging to power groups? In a traditional organization, power is at the top and those at that level can make decisions unilaterally." 
"I am not referring to that type of power," Noemi said with conviction. "And it's not that I prefer to be the general manager," she clarified, "but I'd like to have a position from which I can influence others. This is the reason I'd like to continue in the job I have now, because it has that potential."

Noemi paused for a moment. "When I speak of having power, I refer to being like the advisor to King Arthur, who had influence but was not the king. Similarly, l'd like to be the general manager's advisor and have influence over people. This doesn't mean that I want to manipulate others, but that others need me because they see in me someone who can help them."

"And your participation has influence over others now?"

"The effectiveness of my participation depends on several factors. I work in an industrial environment in which most socios are men and I have an advantage by being a woman because it helps me to gain their consideration and facilitates my asking questions. I can delve into themes not accustomed by them, with an emotional feeling they don't share."

"Go on," I said, "sensing she had more to say."

"Besides," Noemi continued, "not being from the Basque Country, others see me as being somewhat of a foreigner and this is a tool also. For example, if I say 'this is not so bad' about something they thought was bad, they doubt. Or if I say 'I don't understand why...' they think: 'that she should not understand this or that is understandable, she is not from here...' and they answer my questions. Also, I am not embarrassed to say or do anything thanks to the consideration given to me because I am a woman, I am young and I am natural."

"What do you mean when you say you are natural?"

"I am very direct and this is a favorable quality. I am not afraid or anxious when I participate, I see it as a challenge: 'will I be capable of doing this...?'. But this type of fear is nice, it's good," said Noemi smiling, "because the challenge grows. In my case, participating presumes a responsibility that I will be successful, that's how I take it. I am also not afraid to look ridiculous because I capitalize on my reputation of saying things exactly as I see them. I think it's a virtue to recognize that I've made a mistake or said something stupid."

"And being direct helps you to participate when you want to?"

"It helps me when I participate in meetings. For example, if someone interrupts me during my turn to speak, I continue talking. If this person insists, my tactic is to shut up, and wait my turn, not so much to listen but to show some manners. And the first chance I have, I say 'well, you have interrupted me and have prevented me from finishing what I 
had to say, I'll continue now...' making evident to others the lack of manners of the person that interrupted. And of course this also allows me to finish what I was saying."

"Are you talking about when a man interrupts you or anyone?"

"Anyone," she replied. "Although if it's a man who interrupts me, I am not as bothered as if it's a woman, and especially if she is as young as I am. It's not that I think men have the right to interrupt me but that we women have an innate competitiveness among us that makes us less tolerant in these situations."

"As a woman, do you participate differently than a man does?"

"I think that being a woman has given me an advantage in the way I perceive situations in a meeting. I think I read more in between the lines, I pick up more things..."

"Could you give me an example?"

"Yes. I observe a situation and I feel: 'this person doesn't agree with what is being said'. I can't describe what I feel, it's something in the way a person moves or speaks. I think that men, in general, don't perceive these things, they are not aware of the feelings of others, they are colder. I am quite rational also, but not in the same way."

"Well, we have covered several topics today. Considering what we have talked about, how do you see yourself in the future, let's say in 10 or 15 years?"

"Look, at this moment, I think that I have competences and abilities that have not bloomed yet and the cooperative system and my belonging to the Management council offer me the possibility to progress and learn. Looking at the future, if I continue here, I'll have more experience in this type of work but I think I'll be pigeonholed within my concrete role and performance in this organization. Therefore, I don't see myself in a higher position in this cooperative."

"What would hold you back?"

"It's not that the system would not permit it, it's that I would drag my past with me. I have my past path and mistakes, which people already know, and this is a handicap, because people don't forget."

"My experience has not been that way," I said. "I started to be a manager when I was younger than you and I also made many mistakes and had to change many things to be able to progress in my job. I understand what you say about having a history and that people remember, but they also realize that you have grown. I had to leave many friends behind along the way when I ended up being their boss, but at the end, they accepted me." 
"You are possibly right. Probably my growth as a person would be valued but even so, I believe the past overwhelms us and creates prejudices. To break this pattern is not impossible but it's difficult. Therefore, it's very possible that I will not be able to exert the type of influence I'd like here and probably in the future I'll work in another cooperative to accomplish my objectives."

"It'll be interesting to see the path you'll follow. Most probably you'll do something that is fulfilling to you."

"I hope so, David."

"Take care, Noemi."

We walked down together and said goodbye at the lobby. 


\section{CHAPTER 8}

\section{AN AFTERNOON AT MONTEROI PARK}

I was looking forward to spending the rest of the day in the Monteroi park, for I had much to ponder. It was about 2 o'clock. I went to the small grocery store close to the hotel and bought some Idiazábal cheese, pimentos, olives and bread and a bottle of very smooth red wine (Rioja Reserva).

I headed up the path, walking slowly and seeking the shade of the trees for it was another hot day. I arrived at a secluded, shady place at the top of the hill, before the path descended on the other side. I had brought a backpack with my notebook full of notes, the food, the wine and a cork opener. The view was beautiful from the top. I could see the Eskola Politeknikoa campus, the headquarters for Caja Laboral (Mondragón bank) encrusted higher up on the hill, and the MCC headquarters even higher up. I had walked up the hill to $\mathrm{MCC}$ headquarters many times before. It was a steep climb but it afforded great views. The view from my spot was much better, however. I could also see the hills beyond Mondragón and a light blue, transparent sky in such a clear day.

I sat on a bench and pulled my notes out. I had scribbled a bunch of notes on the back pages of my notebook. They were all scattered terms that had surged from the dialogues and reflections in the last couple of weeks. I decided to start with the most recent event: my dialogue with Noemi. I was stirred by her fresh perspective. Most present in my mind were her feelings--they seemed to touch some memories within me. I identified with so many things she said, although I was not sure if these things belonged to my past or my present. I had to think about this, for I thought I could learn something from it.

But I decided to look first at her thoughts in her own context. Although in a more incisive tone of voice, much of what she said corroborated what I had heard from others in the chiquiteos and during my personal dialogues with others. Noemi seemed to be experiencing precisely what others in the group recalled as an earlier stage in their participation experience. Yet, there was an edge in her comments that injected them with more intensity. What was it? Frustration, anger, disbelief? Or was she simply a member of the more assertive new generation?

Noemi's spontaneity, being "natural" as she called it, said a lot to me. I was surprised to see that she was so much in touch with her feelings about herself, about participation, and about the cooperative way of life. She felt so free to speak about her perceived personal shortcomings, as seen from the perspective of a cooperative environment, revealing personal feelings that many people would probably not even admit to themselves, much less to someone else. Likewise, she was very open about what she did not like in the cooperative system. 


\section{Participation and Fear}

What Noemi shared about the cooperatives also told me much about how far the socios can criticize MCC. Her comments demonstrated her determination to have her voice heard and her openness to speak up without the threat of reprisals, a new experience to me. Having worked in an environment in which $I$ did not feel free to criticize my superiors when I was a young engineer, and was later immune from criticism from my subordinates when I was an executive, I was refreshing to hear her unedited critical comments.

One of the sensitive areas Noemi touched within me was the issue of fear. I had written about fear at the workplace in traditional organizations in the paper I presented in the Vatican, highlighting the fear of being fired and the abuse to those that stay behind because they feel "lucky" to have kept their jobs but are perpetually afraid to be fired too. But this type of fear seemed to be alien to the experience of my collaborators. When I heard them talk about their initial experiences at work and what prevented them from participating, they spoke of a myriad reasons, except fear, to participate. That was the big difference in my collaborators' experience and mine: the fear factor. I dare say that in many organizations fear drives a great proportion of our actions, preventing us from complaining about an unfair decision, from criticizing any decision made by a superior, or from going against what the group says. We are fearful to reveal ourselves for who we are. Fear is indeed one of the major oppressing forces at the workplace.

I remembered the words uttered by my collaborators: trust, sharing, being included-- they sound so foreign in other environments. Those who don't know about the Mondragón cooperatives may even conclude that fear at the workplace is universal. I remember I told Sarah and Bill about the freedom to be oneself in Mondragón. I wonder if they grasped the extent of this freedom.

I wonder what you think as you read these paragraphs. Is fear at the job an important issue for you?

\section{De-motivating factors for participation}

Her comments about de-motivating factors to participate sounded quite familiar. The lack of interest to talk to workers, the bureaucracy of suggestion box systems and the imposition of systems from the top are commonplace experiences in traditional organizations. Noemi's comments, already foreshadowed by Aitor in the chiquiteos, show that cooperatives have their share of such behaviors. Are those managers a remnant of a Taylorist era or are they a new breed of managers too focused on performance at the expense of social considerations in the new era of globalization?

\section{Compete or collaborate?}

Noemi's conflict between her competitive upbringing and her need to participate in her cooperative job illustrated the dilemma faced by many of us. She expressed her leaning 
towards rationality, having a technical degree and job, and about her head telling her to participate but her heart calling her to compete. This is different from other members of the group who seemed to feel that participation was something inborn or acquired early in life. Is it nature or nurture? Noemi identifies her upbringing as the reason she prefers to stand out instead of participating. Yet in the chiquiteos she mentioned that some young people will participate from the beginning and will not give up until their proposals are heard. Is this a result of their upbringing?

Noemi's ambivalence about competing and collaborating are relevant to my experience. I, like she, was brought up in an environment of competition, instilled not so much by my family but by my school and society. I thrived on competition when I was young. My Catholic school was keen on academia and sports and I excelled in both. My mother was proud that I often was first in my class and once was called the "steamroller" in the annual graduation ceremony because I got the most awards for academic excellence. I also excelled in athletics. I placed first in high jump, the 10,000 meters race, the 100meter dash, and was on the varsity basketball and soccer teams, et cetera. Regarding hobbies, once I got second place in a citywide chess contest in the 12-18 year old category, when I was barely 12 years old. It was no different in my job. I competed throughout my 27 years for the better jobs and I always got them. No wonder I liked to compete!

I share my experience with you because I think many of us have similar stories, and I think they invite us to reflect. As I listened to Noemi, it dawned on me that I liked competition in those activities in which I was among the best, as did she. But what happens to everyone else, those who are not the best? In a culture that glorifies one winner only, I question: What about the motivation of the rest of the competitors? For every winner in a group there are many losers--one gets the accolades, others are silently or publicly booed. Does competition beget excellence? And if so, at the expense of whom and what? Do we feel more satisfied as persons if we stand out above the others or if we participate with others and share the glory? Are we born to go at it alone or to participate?

I also pondered when I became aware of what I just said: the world is not only about me but also about everyone else. When do we start caring enough for 'the other' to moderate our ambition for their sake? There is a personal story that comes to mind. I think it may have had more impact on me than I realized at the time.

In the early 1990s I had responsibility for operations in the Asia-Pacific area, in which our company had acquired several local competitors. Our company was very interested in improving employee safety and had designed a system of competition by which the department supervisor who had the best safety record would be recognized publicly. He or she was awarded a jacket with a distinctive color, so everyone would know who was the "champion" in safety. My boss insisted that this system had to be implemented all over the world, including new acquisitions. We had recently acquired a small company in Taiwan and had recorded performance for several months so my boss felt it was important to name a champion. On my next trip to Asia I visited the plant and told the 
supervisor who was to receive the award that he would be honored in a public meeting and I asked him to try the jacket for size. He was bewildered and politely told me he could not attend the ceremony or exhibit such shameful behovior, that in the factory everyone participated just as earnestly as he had, and that he would not stand out and embarrass all other supervisors. I used to spend many weekends in Asia during these long trips and I remember how I thought about this incident for a long time, pondering whose behavior was more "normal," his reluctance to receive the award or my insistence that he did.

How can we explain this supervisor's behavior? Is collaboration preferable to competition? Is collaboration innate or acquired?

I looked at my notes. I had made many of the reflections on the previous dialogues after they occurred, but I had a few lingering themes to ponder. I wondered if I had more clarity now. I started with some from the chiquiteo dialogues.

Where is participation learned? What influences are important? Family, school, culture, work? Aitor says a cooperativist is made not born. Jon adds that we learn to participate, participating! My experience was of not being able to participate in decision making in the family, school, culture or workplace. Yet I was attracted to promote participation at the workplace from the time I had enough authority to try it. Where did that preference come from?

Another lingering thought about my behavior brought a story to my mind: self-centered and other-centeredness. When I was at the University of Louvain in 1995, I asked my Ethics professor:

"If I help another person and I feel good when I do it, is it an altruistic or an egotistic act?"

"Why does it have to be one or the other?" my professor replied to my question with a question.

"Because if I feel good, I wonder if I really acted to benefit the other person or to benefit myself."

"Most of our acts contain an intention to benefit ourselves," he said. "If they did not, we probably would not act. So, be careful! You are falling into a dichotomy, assuming being good to another and to yourself are mutually exclusive acts. It is not 'this or that', it is 'this and that'. When the Judeo-Christian tradition talks about loving your neighbor as yourself, it refers precisely to loving the other as much as you love yourself, not more and not less. You act to help another but also to help yourself." 
I am still thinking about Jon's reference to Maslow's hierarchy of needs: safety, belonging, esteem and self-actualization. I had not thought of associating this hierarchy with participation. Could he mean that participating in decision making evolved through the hierarchy, from safety, to belonging, esteem and also self-actualization? Furthermore, when I studied Maslow' original texts in Business School I learned that, in his view, the next step after self-actualization is transcendence. Is participating a way to transcend our hierarchy of needs? Can the act of participating be seen as an integral part of our identity, as our most profound meaning as part of the human family or the cosmos? What do you think? I'll need to come back to ponder this later on in the process...

Regarding values, can we say that participation is a value? Jon and Aitor say participation is a value, as is fulfilling your duty with your organization or your community. Rosario adds that participating is part of a set of values in the cooperatives and people participate because "it is contagious." Noemi believes participation is a value that will exist if work is done well in either cooperative or non-cooperative enterprises. Jon and Aitor say being able to participate changes a person, and participation improves as he or she matures. Furthermore, is it outside influences, the work environment or oneself that determines if participation is a value? And who has the responsibility for participation? Is it the leader, the organization, or is it each one of us that have that personal responsibility?

I crossed out each of the above issues scribbled in my notebook. I realized once more how easy it is to write a one-page list with two or three words on each line and find myself pondering each one of those lines for hours on end, and how difficult it is to answer questions that emerge during these reflective periods.

I had finished my lunch. I felt more clarity just by revisiting some of these issues and sharing them with you. I knew that some of them would raise their restless head, again and again, until I got my arms around them. Stimulated by this thought, I replaced the cork on the wine bottle to take back to Esteban and Rosi, closed the olive bottle and packed them in plastic bags in my backpack. I kept the bread out to feed the birds along the way. I walked slowly on the path going back towards the hotel. I acknowledged the presence of several elderly people who were walking up the path with the help of a cane as I went down. I reached the cobbled-stoned streets of Mondragón, which were beginning to come alive with the young couples pushing baby carriages, the elderly ladies chatting away, the bars placing the platters or pintxos on the bar. I looked at my watch. It was already 5:30 p.m. I realized I had been in the park for several hours. It was time to go out to the bars, as everyone else. 


\section{CHAPTER 9}

\section{MORE PERSONAL ENCOUNTERS WITH PARTICIPATION}

The group having breakfast that Wednesday morning at the Hotel Arrasate was quite diverse. There was José Luis, the accountant from Madrid who spent three days a week at his Mondragón branch; Ian, the English consultant who worked in Mondragón two weeks out of the month; and a French businesswoman, a consultant to the cooperatives, whom I had just met. There were also three young Mexican engineers arriving for an extended training period at FAGOR, the largest Mondragón cooperative, in anticipation to a jointventure with their company in Querétaro; two young Iranian clients and their wives, invited by FAGOR Electrodomésticos, one of the domestic appliance cooperatives; and myself. Not everyone spoke English and Spanish, so we translated for each other, and communicated with those who spoke neither language through sign or body language, but everyone felt connected and at home in Esteban and Rosi's hotel breakfast room.

Earlier that morning I had seen Rosi walking out to buy fresh French bread and croissants for breakfast. I had chatted with her while she squeezed fresh orange juice, before the guests came down for breakfast. She had prepared one cup of decaffeinated coffee, which is not so common in Spain yet, for me, ahead of the individually prepared cups of coffee for other guests.

\section{Lorea}

Lorea and I agreed to meet at the breakfast room at 9 a.m., which served as an extension of the lounge room. I asked Rosi to prepare the same corner table next to the window, where I had met with Bill and Sarah earlier in the month. Lorea knew I was pressed for time to get the transcripts done before we met for the second time next day so she graciously offered to meet me early and at the hotel. She arrived on time, we chatted while Rosi prepared some coffee for us and we sat down at the table.

"Lorea," I said, initiating the conversation. "In the chiquiteos you talked about participation as something that doesn't happen to you personally, but as something that happens to you in relationship with your colleagues. Could we start by elaborating on this?"

"Of course. To me, inviting others to participate is automatic. The meaning of participation in decision making is not only about my own experience but also about the other. The experience of participating as a team is much more intense than my own satisfaction. I find meaning in participation in that I don't decide by myself but with others." 
"Agreed,"I said. "I think anyone who reflects on what you are saying would agree that one person alone can't be the only one that has an opinion when making a decision."

"Indeed."

"And what do you feel when you participate with others?" I asked.

"Participating, above all, is sharing. What we're going to do we decide, enjoy and celebrate together."

"Let me rephrase what you are saying to make sure I understand it," I said. "You don't participate with someone only to arrive at a better decision but also to build a relationship with the other."

"That's right," she asserted. "Probably due to my participatory nature, when I am in a position to do it, I tell the other person things about me. I invite him or her to participate, to come into my life. And then this person also allows me to enter in his or her life."

"And do you open yourself to this experience completely?"

"It depends... sometimes I find myself in spaces in which I can do it, as when I feel I am in a group I can trust. Participating is so important to me that, when I belong to a group, I persevere until I can establish a space that allows me to do it."

"And how do you create and establish this space?"

"I realize," she replied, "that in the first stage, when the group is just getting established, my participation is poorer. I give my opinion with soft suggestions, and once the group has been established, or I become part of an established group if I am new, I feel I can contribute with my opinions. Some times these opinions are elaborate because they are well thought out in order to articulate them well. The point is not to participate just by saying something, it's necessary to reflect first. And of course, I relate to the people in the group outside the meeting, I think that the informal spaces are necessary, especially to hear those who don't feel comfortable expressing their opinions in formal meetings."

"And once I have established my space," said Lorea after a pause, "I participate where I feel I can help to make a better decision. When I perceive that I have a lot to contribute, I give my ideas and participate more than others, hoping that the group will accept my ideas. This doesn't mean, however, that I am not interested in listening to others because doing it generates more ideas and we are all enriched."

"So you always participate in a group..."

"It's not always easy, it's necessary to know how to wait," she said. "And this also depends on how long the group has existed and how long I've been part of the group. If my opinion is not taken into consideration, it may be because of the style of the group, 
the personality of those in charge, the authority that has been assigned to me, there are many factors. So I say to myself: "well, there are spaces in which you have no authority, and your opinion will not be considered right away, you'll have to wait'."

"There are other occasions in which I don't participate actively," she continued. "I participate passively, my participation is alive but inside me. As I listen to others, I shape my opinion, which I will be able to express elsewhere."

"I understand. Could we talk about something more personal? Could you get in contact with what you feel as you participate?"

"When I participate," said Lorea deliberately after a pause, "I do it at an emotional level, because participating has much to do with what I feel. I commit myself and give all of myself to be there. I feel others take my opinion into account and value it. I hope that decisions are made according to what I say, since I say what I say because I think it's important. In any case, simply being listened to makes me feel I belong to the group and this is important too."

"And when did you start to participate?"

"Your question takes me back to my family and friends. I have participated as long as I remember. My parents always allowed my siblings and me to participate and it became a habit. The same has happened with my friends, with whom I feel listened to and very free to participate, to the point that I think we are friends because we share the same inclination to participate."

"And at work?"

"There are factors that can encourage or discourage participation at the workplace. Every organization is different and the level of participation varies. If you are a person who likes to participate but are not allowed to, you'll be frustrated."

"Are you talking about non-cooperative organizations in which many people would like to participate but can't?"

"Not necessarily," she said. "T've worked in another organization, which was also a cooperative, before I joined MCC and was not able to participate with the same intensity and freedom I have here. Getting in touch with my feelings about this difference, I understand how vital it is for me to participate, as I realize that my worst professional experiences have been in spaces in which I have not been allowed to participate..."

"Lorea," I intervened, "you know that most people that work in the Western world are not able to participate." 
"It's really difficult for me to conceive that people tolerate it. When I've been in situations in which I can't participate, I feel I am being suffocated," she said, placing both hands around her throat."

"I suppose this is why you invite others to participate too," I said. "It must be difficult for someone like you who is used to participating, to see others who don't."

"That's right. Fortunately in my work now I can participate in decision making as never before, and I treasure my ability to develop and express my personal values and to influence the institutional ones."

"Right," I said looking at her. "I'd like now to explore another topic. You work in an environment populated mostly by women but also participate in groups in which there are mostly men. As a woman in a still patriarchal world, do you feel limited to participate?"

"I have never felt that being a woman has prevented me from participating in decision making," said Lorea unhesitatingly. "I have enough experience to affirm that, in the first stages in a new group, whether you are a man or a woman, you have to establish your presence and knowledge. This is what gives us the authority to participate, rather than being a man or a woman."

"Being new is what counts," I clarified.

"Precisely. Each one of us, however, has a style. I behave according to circumstances, either giving priority to creating a good relationship with a group or addressing the group's task from the beginning."

"You know that in traditional organizations in the Western world, women have been criticized because, instead of contributing with traits labeled as 'femenine' to the world of work, they have adopted traits perceived as 'masculine'. Do you behave 'like a man' when you are in groups of men?"

"No," asserted Lorea. "I am a woman and have always chosen to behave as such in any environment and have never felt to be at a disadvantage because I don't want to imitate men's behavior."

"When you are starting to establish your authority and participate in a group in which you are new, do you behave the same way with men and with women?"

"It's the same in either case. I'm somewhat more informal at the beginning and then behave more formally. This can be because, if I start by being very structured and rational, I may scare some in the group by giving the impression that $I$ am very strict... I don't know but I think this is the reason that I unconsciously act this way."

"And do you feel you participate differently than a man does?" 
"I don't think there are many differences in the way we participate, once we are established in a group. And if there are any," Lorea added, "it's not because we are men or women but because each participant has a different personality."

"That's clear. A last question: how do you see yourself in the future?"

"It's possible that I'll change jobs soon," she replied, "but it's not something I have in my mind all the time, or something that has influence on what I do now."

"What a contrast!" I exclaimed. "When I worked as a businessperson, I used to make plans...in writing! I would describe where I would be within one and five years, always seeking to have more or do more. Now I see," I said reflectively, "that I was not living and enjoying the moment. I was always living in the future. I think that this is a basic difference with the mentality of a cooperativist."

"In the cooperatives," she said, "we have our strategic plans, management plans...we are impeccable when preparing these. But working on the day-to-day chores can take us to 'doing for the sake of doing' when we strive to rigorously meet what we wrote. This detracts from our being good strategists that know where we are going."

"Where we are going, or where I am going?" I asked.

"Where we are going," affirmed Lorea. "The objectives would determine where the group is going to be, not where each one of us will be personally."

"Great difference," I said, in a low voice.

"What I can tell you," she said to conclude, "is that, whatever I do in the future, I see myself in a participatory space and in a cooperative. And, of course, I see myself... participating!"

"Great, Lorea, thank you for your comments."

"You are welcome, David."

I walked Lorea to her car, parked about two blocks away from the hotel. We talked some more before she got in the car but not for long since she had to get to a meeting at the university. I did not go back to the hotel immediately. I walked around the narrow streets of Mondragón thinking about our conversation before I sat down to transcribe it. I had already sensed that participation at Mondragón is not about me only. But Lorea, was emphatic when she told me participation was about sharing. It is not only about reaching a better decision but also about encouraging 'the other' to participate. It is about "being in 
relationship." She said it beautifully: "We decide, enjoy and celebrate a decision together. It is about opening my life to another and allowing the other to enter it."

But she also spoke about the more pragmatic aspects of participation: To be able to participate meaningfully requires preparation, establishing authority and relationships in a group. It also means not being bashful and participating assertively if she considers she has to play a dominant role in a decision related to her expertise. This, she clarifies, is also her responsibility.

She expressed her feelings about participation with descriptive images and words. Participating, she says, is like breathing--necessary to sustain life. Not being able to participate is frustrating, suffocating, unimaginable.

Reader, I must digress for a minute here. I mentioned the importance of listening closely during my meeting with Aitor because someone may say something casually in the course of a conversation that may not be noticed by anyone, except you or me, because it resonates with our experience. This is why I have endeavored to keep the dialogues as close to the original versions as possible, sometimes even keeping extra words or phrases, apparently unrelated to the main topic. Who knows what pearls of wisdom you or I can find as we read these dialogues slowly and with full attention?

In that vein, Lorea mentioned that participation is not "saying something just to say it." Participation requires reflection and taking responsibility for what I say. It is not an exercise in hearing myself talk, when I have nothing to add to the conversation.

Furthermore, after reflecting on Lorea's words, I connected them to Rosario's when the latter said she did not raise her hand all the time in big groups to give an opinion that could not even be discussed. Can we conclude that participation is more meaningful in small groups because we can't 'say something just to say it', but instead enter into giveand-take discussions that require more preparation, intensity and mutual influence on each other? What do you think?

About participating actively or passively: Before I heard Lorea, I did not consider I was participating if I did not voice my opinion. She said it exquisitely: "my participation is alive but inside me." One can participate and form an opinion to be used later. I suppose it is like reading a book or a newspaper editorial. I read by myself, one can say passively, but form an opinion to be expressed, articulated, reshaped, etc. elsewhere.

Participation is not only about our ideas but our emotions, says Lorea. She refers to her total commitment--she takes participation seriously. It gives meaning to her, it is not just an activity. She wants to be heard and, even if a decision is not made according to her ideas, she feels she has contributed to it. This is not an ego trip, expecting $m y$ opinion to prevail because it is mine but putting all opinions together and finding the best, or the best combination of all. 
And, typically, Lorea talked about the future because I asked her. She did not volunteer, as I would have if someone had interviewed me 20 years ago. She is happy living the present moment, with hope for the future but no anxiety, no fear. She closed our conversation cheerfully by telling me: whatever I do in the future, I will be participating!

\section{Sergio}

I was taking a walk after lunch up the road near the Otalora building as it started to rain. It was a hot afternoon and the rain felt good on my face. I knew it was a spring rain, heavy but not long-lasting so I walked back slowly, remembering the numerous times I have walked in the rain in hot tropical islands and how quickly I dried up afterwards. I arrived at Otalora when the rain had stopped. I stayed outside the building until it was time to meet Sergio upstairs. I dried up standing by the stone ledge close to the stairway that connects the Otalora main building to the modern office building down the hill. The majestic mountains were in front of me and, although I had seen them every day during this trip, I never grew tired of looking at them. They were shrouded with heavy gray clouds that afternoon, which gave them a dramatic and imposing look.

I walked up the stairs to the meeting room about half-an-hour later. I was almost completely dry when Sergio arrived. We stood by the window to watch the intermittent rain and chat. I knew he liked to see the rain fall on the fields because he had grown up in a farm.

We sat down after a while and I started the conversation in my usual way, referring to what he had said in the group meetings. "Sergio," I said, "during the chiquiteos you talked about several themes I'd like to explore further. You mentioned the need for trust, commitment, personal maturity..."

"Yes," he replied, "they are interrelated themes."

"We can start with any of them."

"Fine. I'd like to give you some context. I think we can see participation from its different facets. I can think of effectiveness, freedom, trust and the relationship with 'the other'."

"Let me start with effectiveness," he said, after a pause. "A participating organization is much more powerful than one that is not. In an organization composed of people who see themselves as individuals, personal contributions are independent from each other and thus the total effectiveness is the result of adding them up. In an organization with people who see themselves as participating with each other, personal contributions are interdependent with all others, interacting and influencing each other, and the total effectiveness is the result of multiplying them. This is evident." 
"However," I said, "this fact escapes people who work in traditional organizations. I think we confuse speed with efficacy, since quick decision making is considered to be the same as effective decision making."

He nodded. "Another facet, the relationship between authority and participation, is clear to me. I come from a culture in which I had to obey and do my duty. Later on I realized that this type of authoritarian pressure, even though at a given moment gave me some security, also drowned my capabilities."

"Can you explain what you mean?"

"Yes. It's not that living participation as a duty is bad, but it may engender a certain passivity: 'I do what they want done'. This way of looking at participation affects people who have been educated that way, come to work in our cooperatives with a culture of freedom and trust, but still live participation as a duty."

"So I can live participation as a duty, but it's not enough," I clarified.

"I think it's much better to participate based on a commitment grounded on freedom, not duty," said Sergio. "Commitment as a duty feels heavy. Commitment grounded on freedom, which allows you to come out of yourself and orient yourself to another with generosity, is more pleasant, it's lighter. And this lightness leads to everyone contributing to decision making and to feeling connected with each other."

"I identify with your words," I said. "At the beginning I may feel alone with my opinion, but as I grow to be part of the group, it doesn't matter if someone else gives a helpful opinion that I also had. I don't need to be recognized as having that helpful opinion individually anymore. Having a better decision coming from the group is what is important."

"That's right. And the lighter the burden of the commitment, the more effective the participation, and the better the results."

"Participating freely is more effective than doing it as a duty," I repeated.

"Yes, but there are other ingredients. I mentioned in the chiquiteo how important trust was for me, especially at the beginning. Trust, having personal space and building relationships have been a more important influence in my development as a participator than my previous authoritarian culture."

"I would think that it was the culture of participation that you found here which made you abandon your previous authoritarian culture."

Sergio paused. "It's not so much the sense of the organization or its culture. Yes, they've had an influence but basically it has been more whom $I$ have found along the way, who 
has trusted me. That is, if you've had a culture that facilitated participation, it encourages you to work in a cooperative because you feel this value is important. But, at least in my case, when I saw myself as being free, that others trusted me...to me this was the decisive factor: trust."

"And also duty?" I asked.

"Not exactly. At the beginning I could say it was a duty to participate, but today it is a joy, it is no burden...none whatsoever. And, just be being in contact with others, listening, participating with others, I become enriched."

"You mention listening, what role does listening play in participation?"

"Those who have passion for 'the other' know how to listen. But to have passion for the other, I need to open myself, and this comes with my personal development. I can't participate if I can't consider others as centers of a world equal to mine. You achieve this perspective as you mature. Then you value the other, live your participation while respecting him or her, as well as living the values I have mentioned: trust, freedom and good listening."

"You speak of the respect for the other..."

"By respecting the other," he continued, "you obtain his or her commitment without resorting to authority. Respecting the other means knowing how to ask for something, but asking in such a way that you accept his or her freedom. It's making it easy for the other to say 'yes' or 'no', knowing that nothing bad will happen either way."

We were silent for a moment. I felt Sergio was not finished.

"And there are subtle things that help participation," he added. "For example, it isn't just having space, but feeling esteemed. It is important to feel appreciated, not only for the worth of the work you do, but for your worthiness as a person."

"We are first persons and then workers, it's very clear to me," I said before changing the subject. "You have also mentioned maturity as an important aspect of participation, can you elaborate?"

"I think that the history, the development that guides us to participate is different in each one of us. Being participatory is a result of a personal evolution."

"I understand. The participatory context exists for me, but also for all others, so in the end it's my personal growth that counts..."

"That's right. When we talk about the value of evolved participation at the personal level, it's also possible to arrive late, just a little bit late. It's also possible to never evolve enough to be participatory. It is also possible to evolve to a way of participating that is 
less free. In many ways it's the fruit of a culture but I see participation as something mostly based on personal values - it's about being open, it's something that comes from within you."

"We have not talked much about your own history, your personal development, what can you tell me about it?"

"I come from a rural zone in the Basque Country, from a small town in which there was a culture of collaboration to complete tasks related to agriculture. Our families borrowed each other's workers, harvested our crops together and worked in all major tasks together. We did everything with generosity, it didn't matter who contributed more or less, our objective was to get done what had to be done. I attended preparatory school in a religious center, as was customary at that time. Later I studied philosophy and psychology outside the Basque Country and worked as a high school teacher also elsewhere."

"Did you like it?"

"It was a difficult and lonely life. I wanted to work in another type of organization. I had friends that worked in cooperatives and, when I found a newspaper ad offering work in Mondragón, I decided to work here. This decision was not only because I had friends here but because I was attracted to this type of organization."

"Why?"

"Because it was not only getting a good job but I understood I was entering an organization that was concerned with the human aspect of work."

"I see. And what happened once you were here?

"I worked for some time in one of the largest cooperative organizations. I entered a technical track and worked in management and consulting. Later I was promoted to Human Resources where I found a team of competent collaborators. These were good people, very active and dynamic. Participation in decision making was fundamental to my job, which was a serious challenge at the beginning of my personal and professional development. I matured and evolved internally, and, as I assumed larger responsibilities, I acquired greater confidence and enjoyed participating more."

"It sounds like since then you were attracted to the human aspect that you talk about today."

"That's right," he said. "I also felt good in my job because I had a good relationship with my collaborators and always felt well accepted by them. I participated along with them in organizational change projects, in which our contribution as Human Resources professionals was decisive. I had much contact with Plant Managers, who were at the 
same level I was at the Management Council. I also had intense contact with everyone involved in these changes, whether they were my collaborators or my peers..."

"I imagine it was a very intense time for you," I said.

"Yes. Living this experience with such diverse problems, however, was very satisfactory also, although I was very stressed because there were a thousand problems to resolve and things to do."

"Has your participation been this way throughout your professional career here?"

"It has evolved according to the work I did. I was first in an administrative job and later in jobs related to decision-making groups. I've had highs and lows during my career."

"There are moments when the satisfaction curves are flat and others in which the slope is steep," I echoed, remembering my own experience.

"That's right, David. Now I am in a stage in which my experience is being capitalized by others and at the same time I am participating in quite important projects."

"I think this is great! And," I asked, changing the subject, "tell me, does your participation have a social dimension?"

"I have not been an openly social person, I am neither much out in the street nor have I participated in the political milieus, that is not my cup of tea. I spend my leisure time talking with my friends, reading, working on social projects."

"You've been working in the cooperatives for a long time and I know your retirement is approaching, anything you would like to share about this?"

"It's clear to me that when I retire I'll continue doing volunteer or other type of work related to personal development. I prefer to work with small groups and l'd like to do social projects, but just enough of them to do things well."

"Great! Could you summarize what you feel about participation?"

"I can say," he concluded, "that for me the development of participation at the individual level is a personal story. It's a life experience at the personal and social level grounded on freedom. Not the freedom of a person who is aloof but that of persons who commit themselves because they truly find value in making a commitment and in engaging 'the other'. The organization, education and culture are factors that support participation. They have to be nurtured but I think what is decisive is what is within oneself. I say this based on my own evolution. For me, it has been my professional history and the factors that have been given within it that have helped me. The present stage in my life has been very good for me because I have harvested some of the fruit of my life history. This is my personal story." 
"Thank you for sharing your experiences with me, Sergio."

"You are welcome, David. See you soon."

I said goodbye to Sergio and walked toward the Otalora parking lot. I had just talked to the first of three persons who had more than 40 years experience at the Mondragón cooperatives. What was different about Sergio's comments?

The first thing that struck me was the calm assurance with which he spoke. He said it was obvious that a cooperative organization has an advantage because effectiveness is multiplied instead of simply added up. This seems so clear to him yet so much ignored in our traditional organizations.

Sergio expressed himself as a person that has thought about participation long and hard. I asked him about specific values because he mostly talked in terms of values. Reflecting upon what he said became a set of thoughts and questions about each value.

To begin, it is fine to participate as a duty, he said, but it is much better to do it based on freedom and trust. What happens when we have a system, as voting in democratic societies, in which we have the duty to participate but we do not know or care to know what the issues are, what to decide, whom to vote for?

And participating in any milieu requires us to have trust, an important value according to Sergio. The question is: Can I trust my own judgement to participate in the decision making process? And can I trust someone else enough to share information and decision making with him or her?

When he referred to the importance of "whom you find along the way," I felt he was almost implying there is an element of luck in finding someone who has trusted you or whom you can trust. Is it really luck, or do we attract such trusting people because we trust first?

Considering 'the other', listening to him or her, being respectful, being passionate about his or her dignity, presence, participation... What does it take for me to adopt this focus?

Sergio speaks about support systems influencing our maturity in participation, but concludes that, even if all elements are nurtured, it is a personal decision to participate or not. We have free will and it is expressed here as anywhere else. Meaningful participation related to the person not the support systems is the topic of this book, but Jon, Aitor, Edurne and Sergio mentioned the support systems as an important factor in promoting participation. What is your opinion? Is it the person, the organization? Or both? And if so, how influential is each factor? 
He makes the connection between being in an authoritarian culture and being immature as participators because decisions are made for us. He tells us his story moving from an authoritarian culture to a cooperative one and how he grew as a participator but only after many years. My question: Are we immature workers preferring to be told what to do because we work in authoritarian organizations?

If we prefer it otherwise, what will it take to become part of a collaborative culture in which we can participate in the decision making process?

In brief, I think Sergio is a very appropriate participant for a phenomenological study. He speaks from his personal experience of forty years, not theories or other people's stories. He knows and trusts his own story and is willing to share it with me. I am grateful...

I arrived at the hotel, put on my walking shoes and went for a walk in the town of Mondragón which was just awakening after siesta time for the afternoon promenade.

\section{Evaristo}

I walked from the hotel to the Eskola Politeknikoa, the engineering campus of the Mondragón University, where I had met with Bill and Sarah a few weeks earlier. I arrived early and sat on a bench in the garden, close to Arizmendiarrieta's statue, where we agreed to meet. There were few people around. Students had finished their final exams and it was still early for visitors.

I have always felt energized in university environments. I can almost see the students and professors that have crossed their main gates, as I just did, through multiple generations. I visualize the educators and researchers teaching and writing about their life experiences, their research, their interests. I try to imagine the incalculable energy, thought, study and imagination that has gone into the thousand of volumes in university libraries. Universities are centers of learning, not only about academics but about life. They are incubators for future leaders in all walks of life. They have been one of the most important institutions in our societies for centuries.

"Hello, David," said Evaristo, coming from behind. "Beautiful morning."

"Yes, it is," I said, somewhat surprised not to have seen him approaching me.

Evaristo sat down and I shared my thoughts with him about centers of learning and my perceptions about universities. He talked about traveling, hobbies, adventures and life in general. I had noticed that Evaristo delved into deep conversations easily, so I felt comfortable starting to talk in terms of experiences and meanings. I shifted positions on the bench to look directly at him. 
"Evaristo," I began, "during the chiquiteos you expressed participation in very descriptive terms. I had a very distinct impression that it is vital to you. I remember you said that if you want to participate and can't, or worse, can but will not, you start to die..."

"That's right, David. I've been made the way I am by participating, I am who I am because I participate, I know what I know because of my participation. I participate, I have always participated."

"Is this the reason you work at the cooperatives?"

"Cooperativism to me means that I participate in richer ways, with a broader perspective. I am under the impression that everyone seeks, as I do, to be useful, to participate in the construction of the world, to leave our footprint as a witness to our lives. Participation is something we cannot renounce to, it is necessary for all fulfilled adult persons."

"What do you mean when you say that the cooperatives have helped you to participate in richer ways?"

"From my perspective, cooperativism does not attempt to change a person but the relationship among persons, in order to achieve a multiplication of the fruits of their efforts. Cooperativism intends relationships, participation, education and personal regard for each other to achieve a more mature state."

"How do you live your participation at work?"

"First, I participate physically and mentally in the work I do. But, at another level, I also participate in shaping organizational strategy and policy, including the philosophy that orients us towards the cooperative mission. These activities give me, as a socio, meaning in my work. Our participation should not be limited to the work and social areas but to all aspects of human activity. Cooperation is the work of all, it is a choral work."

"This is most interesting," I said. "You see participation at a primordial level: we participate by the fact that we exist. Then we choose to what extent we want to participate in life and at work. It is up to us to give meaning to our participation."

Evaristo nodded, which I interpreted like I had understood what he was saying. I continued. "But if I want to instill meaning in my participation, I need to do certain things that I wouldn't do if I weren't interested in participating..."

"Indeed," he said. "Participating in decision making obligates me to be responsible, to be daring. I need the capacity to renounce to having to be right, because decisions are uncertain. There are many people who prefer not to participate because they are afraid to be wrong."

"Can you elaborate?" 
"Yes. I have learned from people I have known. Some have taught me what is negative. These people try to lead and give orders while avoiding responsibility for possible errors. This is a way of not growing, of remaining immature as persons. There are others l'd like to emulate. These people dare to participate and take responsibility. The latter are the enterprising leaders, the former the whining followers."

"And who are the people you have learned positive things from?"

"Don José María Arizmendiarrieta," said Evaristo, looking at Don José María's statue in front of us. "He was the spiritual leader of MCC, he was a reactionary, as was my grandfather. My mother and the folks in my village were also a positive example for me. My grandfather did not have much education, having attended school for a short time, but he was a wise man about the human condition. There was dialogue at his home, nobody raised their voices, the sensation of serenity was evident even in difficult moments. This was very different with my father."

"Could you tell me more about your life, your experiences with participation?"

"Yes," said Evaristo. "Let me tell you the story about my early life:

My first participating experiences were with my family, in which I lived contrasting situations. At my grandfather's house I was allowed, in fact I was requested, to participate. I was, and this was very important to me, listened to, recognized. I didn't go unnoticed.

It was very different with my father. He didn't encourage participation and his hierarchy was clearly apparent. I received criticisms and orders but not concrete help or advice about my life. My father worked hard and made sacrifices for our family but his life was focused on his work, the orchard, the hunt and our home. He was not concerned with the education of the children, this being my mother's task.

My mother was a balanced person, very human and with a profound, meaningful religious life. I learned from her about the dignity of being a person. She never ignored another person, never failed to help whoever needed her, she was very rich without ever having any money."

"What about participation at school?"

"At school, I felt very clearly that I belonged to an inferior social class. In my village there were rich and poor families, and I belonged to the poor ones. The priests, monks and nuns had more regard for the children of the rich. We were poor and lived in poor homes in a conflictive neighborhood. 
But we as children created our own group to play, study and live. We did not associate much with the rich kids but we didn't care, we maintained our pride as a group, as a neighborhood. The rich children had toys, we made ours, which were coarser but of our own creation. The older children in our neighborhood treated us with arrogance since being older was more important than having a better social position

I felt good among my friends and classmates. I had an active role in my group in which I was a leader. I played jai-alai and soccer. I was not cunning but was a good player, which was important at that age. My status among my friends forced me to study to reinforce my social leadership. As a consequence, I felt valued personally and socially, but had to demonstrate my worthiness in all my actions.

Being in the street taught me three things: to play, to tell the truth, and to participate with others as a team. This is my story."

"I see," I said. "And what happened when you started to work?"

"I know what it's like to work in organizations that don't provide opportunities to participate because I worked when I was young in a traditional non-cooperative organization. Later, when I joined the cooperatives, my working experience was very different, as I realized what I didn't have in my previous work: being able to participate in the decisions that affected us and the organization."

"What were your first experiences like in the cooperatives?"

"I started as a technician and could confirm quickly that the type of management-worker relationships differed significantly from my previous job. Here I was not only asked for my opinion, I was expected to have one. I used to tell my girlfriend that I felt important, because the boss informed me how the company was doing and because I could participate in the decisions being implemented."

"How did you feel being able to participate?"

"It was more difficult but more motivating," replied Evaristo. "If in the past I didn't intervene, or even thought I should intervene, in decision making at work, now I was also an owner and had to consider myself as such. I had leased my work effort before to others, I was a resource for others' businesses. Now the business was ours, I was not an object anymore, I was a subject in an organization."

He looked at the garden and continued: "This was a fascinating stage, an era of discovery. I was elected to the Social Council, even before I finished my trial period. It was a way to learn to be a businessperson. I was very interested in the discussions and debates, which up to then I thought had nothing to do with me."

Why did you become so interested in these discussions and debates?" 
"In my prior job, there was a manager and a company. I contributed with my work but didn't care what happened in the organization. I was there because I had a job, a wage and professional prestige. This was important to me until I found in my new cooperative job that there is a space, previously unknown to me, in which I was the protagonist, not the disposable extra."

"And what happened then?"

"Later I was elected to the Governing Council. This was very important to me. I learned about the economic and financial aspects of the organization and realized they were not as complex as I feared. We were involved with the management of the operation as a whole but without abandoning the human aspect and values."

"You were involved with the operational and human aspects at the same time?"

"We had to make money, we had to be businesspersons but not just any businesspersons," Evaristo clarified.

"I see," I said. "You were not like other businesspeople because you were owners and workers at the same time but the company had to make money as any other business."

He nodded. "I assumed responsibility for personnel issues at the Governing Council and acquired another way of looking at social problems."

"A more cooperative way?"

"A more balanced way, actually. From being a person who was always on the side of workers' demands, I realized that the company can't satisfy all personal claims, as desirable as they may be from the purely human viewpoint."

Evaristo was quiet for a few moments, as if reflecting. "From that idea of the socialists, which I thought was so beautiful, 'giving to each according to his or her needs and demanding their effort according to their capabilities', I could corroborate that in practice needs have the characteristic of being unlimited while capabilities are limited."

We were silent again for a few moments. I waited.

"Then I was offered the Personnel Director's job in another large MCC cooperative," he continued. "This was very motivating because I thought I could do a good job. I worked with enormous zeal, convinced that I had good and just criteria to make executive decisions."

"And how did it go?" 
"I found conflicts I didn't expect and couldn't understand. I felt that I was misunderstood on many occasions and began to comprehend that I could not make others share my way of looking at things because they have had other experiences, other values, other interests, all different from mine."

"Can you give me an example?"

"Yes. There was the case about the socios working habitually many hours beyond their normal schedules. According to my judgment, it was not correct for management to demand continuously such dedication and to deprive them from their vacation time. Our statutes clearly stated ' ... it is an unquestionable right that the socios enjoy paid vacations'. I found, to my surprise, that the first to oppose the elimination of such practices were precisely the socios because they preferred to work overtime and during vacation time at premium pay rates. My efforts to eliminate such practice resulted in many adversaries, misunderstandings and criticisms."

"It is difficult to know what will satisfy others," I said, as I remembered my own experiences.

Evaristo looked at me. "I realized that it was very difficult to change the way people think with a simple rational argument, regardless of how well structured and honest it is. I thought I was very patient and said very reasonable things, 'look, this is this and that way'. There were peers that got better results with methods that were less participatory and this puzzled me. They would say something firmly, decide what to do and tell the socio how, when, and what had to be done, avoiding any participation or negotiation. The socio would reply: 'Ok, good', and would obey what they had been told, without any comment."

"What a surprise!" I said. "Just like the organizations in which I've worked."

"And so have I, he replied. "I understood then that it was not that I didn't say reasonable things but that many socios didn't want explanations but a firm hand: 'Look, this has to be done this way!' I learned that there are different ways to talk to people and that it's necessary to treat each person differently and according to their educational level. I learned that it's imperative to educate people about new models of human relations before putting them into practice. As Arizmendiarrieta used to say, we need to 'make cooperativists first, and cooperative organizations afterwards'."

"Being a cooperativist allows you to participate but it's difficult to do it."

"Cooperativism," emphasized Evaristo, "is a model for mature persons, accustomed to the commitment of being owners and protagonists. Participation requires dialogue but, in a culture that promotes submissiveness, discipline and hierarchy, dialogue can be seen as a weakness or a manipulation." 
"I understand what you are saying because it has been my experience in traditional organizations. I assume, however, that if anyone is asked to participate in a decision that affects him or her, for sure they will want to do it," I affirmed, convinced this was true.

Evaristo looked directly at me. "I have said that all of us want to participate, that it is a human imperative, but I don't think we all want to participate in the same things, and certainly not in the same ways. And, of course, to participate, we need to fulfill at least three requirements: to know how, to be able to, and to want to participate."

"What if someone wants to participate but can't or doesn't know how?"

"I speak from my own experience. I understood that the change required to participate in the real world is achieved mainly by educating us in values, learning while we practice. Also, it's required to adapt the organization to encourage open, fearless participation."

"Education, practice and a support system that eliminates fear and encourages openness are necessary," I said, seeking corroboration from him.

He nodded.

"Evaristo," I continued, "you've worked for four decades in an environment in which the opportunity to participate has been available. What has been your experience as a person who has participated?"

"I've definitely evolved in my way of participating," he said, after a pause. "As a young man, I participated with certain insecurity, as I commented during the chiquiteo, possibly because I didn't feel firm in my knowledge and convictions. I felt attracted to dissenting ideas or persons, those that I felt were more self-assured, more radical. Now I think it was a stage of dogmatism, surely because it was more attractive for a young, unstable mind to be sheltered under someone or something that left no room for doubt. I felt confident being critical of the establishment, denouncing the hypocrisy of society and expecting a revolution that would wipe out the older eras. I was attracted to pure, extreme ideas although my conduct was orthodox. My way of participating was as a follower of everything that astonished me and attracted me as being different from the commonplace."

He paused again, as if remembering. "Then I had a stage of certainty with more ideological balance, but at the same time with a fear of being wrong. I found refuge in studying, being socially active, organizing theatrical productions, cinema forums and similar activities. I started courting my future wife and my feelings and plans acquired a practically absolute certainty. My participation in projecting my future made me feel hopeful and strong."

"You refer to participation not only at work but in others aspects of your life..." 
"Yes. But at work I was also in another stage. I felt sure of my convictions although I think I didn't become a fundamentalist. I was the manager of my department but I wouldn't say 'this is the way this is' because, although I trusted my judgment, there was always someone who thought differently from me. Yet, I defended my points of view passionately. I think I had little capacity to listen-- my capacity to believe in my own ideas was superior."

"What can you tell me about the capacity to listen?"

"Today, I think that listening is very important, it's vital," he said, embracing the subject without hesitation. "The people I love the most, I admire with their defects, which bother me but I still try to listen to them. I pay attention because I think these are opportunities to improve our relationship as well as myself. It's more difficult to listen to others, I spend more time feeling bothered by them, but I also try to understand them."

"So, knowing how to listen above all?"

"Yes, but that's not everything," Evaristo continued. "The capacity to listen well also has limitations. We cannot listen indefinitely or unilaterally if we are not listened to. We must have a conversation, not allowing only my monologue or that of the other. Dialogue delays decisions but it makes them better and more effective."

"Agreed. So knowing how to listen but also how to be listened to are important parts of knowing how to participate," I repeated. "I think that when this sensitivity is absent, you don't want to spend any time listening to the other."

I paused and continued: "I perceive true listening is something we do with our whole being, feeling the presence of the other completely, thinking: "what you say is different from what I think but I accept it sincerely'. We both accept what each other says and we build something together, getting closer to the truth."

"You speak about the truth," said Evaristo. "Lately, I've learned to be more humble when I participate. I have learned not to be right. At the same time I've learned to maintain my own judgment, not against the others but arriving at the conviction that I only have one part of the truth. I don't renounce my truth, but I also value the truth of the other. That is, I humbly consider, listen and reaffirm the other. But learning not to be right or accepting we have only part of the truth or an interpretation of the truth, is more mature."

"Yes, another collaborator had spoken about "your truth, my truth and the truth, is this what you are talking about?"

"I connect with what you say, although I see it as each one of us having part of the truth," he remarked, "instead of your truth and my truth. I am afraid that sometimes, when we talk about participation, we see it as us being the totality. To me, participation, as the word says it, is being a part, not the totality. I think, however, that we have been educated to think we are the totality." 
"Can you tell me more?"

"I think that seeing participation as a part and not the totality has to do with our values," said Evaristo. "Self-centeredness, so infantile in its behaviors, is contrary to the idea of being a part of something because its focus is on possessing everything, although what we possess is only a part. Likewise, the opposite, massification, or depersonalization and uprooting of persons, is contrary to being co-owners of the totality, because these persons don't feel they are proprietors of their part. I think we should look for participation as intended in the cooperatives, feeling we are protagonists and proprietors."

"Yes," I said. "I know that the distinction between a traditional organization and a cooperative is that in the former, owners and workers are not the same but in the latter you are an owner and a worker with decision-making power: a proprietor and a protagonist, as you call them."

\section{"Correct."}

"Keep going."

"It's like when I soil something, but I clean it because I feel it's my responsibility to do it. Why wait for someone else to clean what I have soiled? I consider myself a "proprietor" of the cleaning activity. Since I desire a cleaner world, I am also the "protagonist" of that activity. I am not the totality, I am a part of the totality (the organization, society, the world). I am the only proprietor of that part, but also the co-proprietor of the totality."

"Proprietor of my part, co-proprietor of all," I repeated to clarify.

"That's right. Mature persons feel the need to see themselves as proprietors of their part and part of the whole as an affirmation of being ' $T$ in a world of ' $I \mathrm{~s}$ ' that make ' $W e$ ' possible."

"It is a world of We," I said, "formed by $I$ s that perceive themselves as co-proprietors of a totality. It is not 'me' in my personal world but 'us' in a world of persons."

Evaristo smiled. "I read a quotation in the Museum of Science in Valencia once, I do not remember by which author, that read: 'I have spent 22 years of my life looking for the missing link between the ape and man, and I have finally found it: it is us'. Our objective is to achieve a humanity of persons not of apes."

I also smiled and nodded.

"And there is something else to consider," he continued. "I am afraid that sometimes when we talk about participation we claim only the right: "I know my rights..., I have the right to...' Rights are a part of participating but it's not all. Another part is the obligation in the same proportion as the right." 
"What obligation are you talking about?"

"I think we have the obligation to leave a footprint of our thoughts, of our words, of our work in life, wherever we are. This is why it's imperative to participate. If I participate soundly and with high quality, my organization will be great. Organizations, nations, peoples are great when their persons are great."

"If all persons as individuals participate with interventions of high quality, the outcomes will be high quality decisions," I rephrased.

"Yes, but individualism may clash with the idea of being part because its premise is being all, the totality."

"So individualism does not contribute to participation..." I rephrased again, having learned that echoing what Evaristo said was an effective way to give him an opportunity to either clarify or elaborate."

"Not exactly. It depends on how we understand individualism. I am in favor of individualism--the problem is not individualism but egotism--but in the correct sense of wanting to develop my 'self', trying to find within us the Great Soul that we all have inside. Nobody can participate if he or she has no formation or does not desire it fervently, and only a few will participate if they are not allowed to do it."

"What kind of formation are you referring to?"

"For true participation to exist, we as persons must first go through the stage of personal growth, ceasing to be dependent on our personal shortcomings and egotistical appetites, as well as winning the battle against ignorance and incompetence. This can be accomplished with education and training."

"We start by being more independent and better educated..." I said.

"Yes. Having won this battle, we can be adventuresome and pursue personal independence, forming our own judgments. Nobody can be in solidarity with another if he or she is not profoundly independent. Only being independent can we understand interdependence. At this level of interdependence we are able to understand that we are nothing without the others, that we need each other to be more human. This is when we understand that 'the other' is another I."

"I see," I said, trying to assimilate the full meaning behind his words. "As we develop as persons we understand that we are independent but not self-sufficient, that we need the participation of others," I added, realizing I was thinking aloud.

Evaristo looked at me and nodded. 
"Well, Evaristo, you have offered me a lot to think about. How could we conclude this conversation?"

"From my personal point of view, what I have told you about my life has been the process, not sought or planned, that I have lived. In my family and village I learned to construct myself as a person and to build my dignity, to be proprietor and protagonist of my own life. In the cooperatives, I have learned, first, to create my own judgment and to be conscious of my own limitations, and second, to collaborate with others, to be part of the organization. Participating comes from being part, not all, but a part that is always there. Society or the organization will not be the same without my participation."

He paused. "I maintain that participation happens because persons want it to happen. We had many discussions about this topic in a recent forum. There were some that insisted that we live in a world of organizations, that it was the organizations that mattered if we wanted to have participation because we lived in a world of organizations. I argued that we were not in a world of organizations but in a world of organized persons and that the participation or lack of it in organizations depended more on persons than on structures."

He concluded this topic saying: "There is an impelling force within us that drives us to participate. We may be a product of a certain culture or situation that impedes us, or at least makes it difficult for us to participate. But in the end, the ultimate commitment to participate is one we make with ourselves."

"I interpret what you say," I said, "like the environment, systems and tools are important but at the end it is each one of us personally who decide to participate."

"There is an anecdote related to this theme," he said with a brief smile and as a way to end our conversation.

Paganini, the great violinist, lost his Stradivarius on a certain occasion and didn't want to play without it in an important concert in Vienna. Kings, prime ministers, and other important personalities were going to attend this concert. He was promised a good violin but he thought he could never reach the perfection that his own violin guaranteed him. So, although he refused at first, the pressure from all around him obligated him, against his will, to play. At the end of the concert he said he had learned the most important lesson in his life: "I have corroborated that the art is not in the violin but in me'. His concert had been the best of his career."

"Excellent, Evaristo. You have given me very rich perspectives about participation. Thank you very much." We stood up from the garden bench and said goodbye warmly.

I walked through the garden towards the university gate and I thought again of Bill and Sarah. I had talked with Sarah in the same spot about Don José María and the Mondragón 
principles and it was amazing how many of them were present in Evaristo's language : cooperation, solidarity, ownership, equilibrio, personal responsibility, education.

My conversation with Evaristo provided new substance to my topic. His words were permeated with images of participation as an integral part of his existence. It was about being not doing. Participation is part of us, comes from within, it's necessary for us to be fulfilled. He is who he is, knows what he knows because he participates, he bad said.

In addition, according to Evaristo, his physical and mental efforts at work and his contributions in the governing council are just two different modes of participating, each experience having different meanings. I find this perspective quite interesting. Can we say that our physical, mental, managerial, strategic interventions are ways to participate, and that meaning varies according to the way we perceive our contributions? His words reminded me of the story of the two construction workers who were building a church wall. A visitor approached the site and asked one of them:

"What are you doing?"

"Placing bricks on this wall," he said, with a look expressing what he thought should be obvious to the visitor.

"And what are you doing?" the visitor asked the second worker.

"I am building a cathedral," he said unhesitatingly.

What do you think, is it you and I who assign meaning to our participation?

Furthermore, Evaristo talked about our legacy, leaving footprints of our participation as witnesses of our lives. He saw co-creating our world with others as a worthwhile endeavor. Is leaving a legacy another source of meaning? A few days ago, someone showed me a small piece of paper with a poem called The Gift by Dan Markova. I copied the following words from it:

$$
\begin{aligned}
& \text { I choose to ... live } \\
& \text { so that which came to me as a seed } \\
& \text { goes to the next as blossom. } \\
& \text { and that which came to me as blossom } \\
& \text { goes on as fruit. }
\end{aligned}
$$

Does leaving a legacy transcend what we have built together? Is this another source of meaning? How do you feel about this?

Also, in order to participate meaningfully we need to come to terms with not being right all the time. We often learn that it is good to know how to force, persuade or manipulate others so they do what we want them to do. The focus is on me, my ideas, always 
assuming they are the best. But meaningful participation is not about others accepting $m y$ ideas but about finding the best outcome of our ideas.

Similarly, just as we are not always right, neither is anyone else. Participation in decision making is neither all about me nor all about "the other." I have the responsibility to keep this balance, as does "the other," so we can listen and build on each other's ideas constructively. We are in a world of "I s" that make a "We." It is not my personal world, it is our world.

\section{Edurne}

Today is my last interview with Edurne, one of the most experienced of my collaborators. I am at the Otalora office thinking about the last few weeks. So many people have collaborated with me for my book. I have learned so much from their words and the reflections they have elicited. As I have reviewed and rewritten the dialogues I have realized how unique everyone is. We are such complex creatures and so paradoxical: How can we have such an extensive web of individual and universal feelings, thoughts and traits within us at the same time?

Edurne came in the door and smiled as she approached me. We talked for a while standing up, for both had been sitting down all day, she in meetings, I in front of my computer. We finally sat down and I began.

"Edurne," I said, "in the chiquiteo you talked about the role that values, leadership and the organization play in participation in decision making. Could we start with these themes before we talk about your personal story?"

"Sure," she replied. "I question many things. I think we have a conflict of priorities between the individual and social aspects at work. The businesses expect selfmanagement but as cooperatives they also expect enormous participation. Socios oriented towards project work, as we as consultants, require high levels of participation with the clients in their projects and this happens at the expense of participating in the social aspect of the cooperatives."

"You refer to self-management. During my study in year 2000 about MCC cooperative values, I found that participation in self-management was not widespread, apparently because jobs were more or less defined. But you refer to your colleagues participating intensely in self-management."

"That's right," she asserted, "because our work consists of self-managed projects. As I mentioned, perhaps we are satisfied knowing that our projects require daily participation with our clients and we see social participation as secondary. But having daily participation at the personal level is positive..." 
Edurne paused, apparently reflecting on her words. "However, I am concerned: 'Are we doing it right? Do we really want to participate in the social aspects? Do we have participation?... well ... it looks like there is participation, if what I understand for participation is what we do on a daily basis. But, is this enough?"

"As you, I think it's good to question everything..."

"At least I can say," emphasized Edurne, "that we are participatory within our department. Our management team is very aware of the need to count on our colleagues because they 'own' their objectives. Therefore, it's necessary to 'sell' these objectives if each person is going to participate in them. There are, however, different personal leadership 'styles', many in need of improvement."

"A good leadership style encourages participation?" I asked.

"Among other factors. The 'I give orders and am in command' style is worthless anywhere, particularly here. New management philosophies take into consideration the humanistic facet. We need to manage responding to this humanism, in addition to considering cooperative values. We don't have to use the same words, as many related to leadership are fads. I prefer to talk about leadership values and management traits than to talk about leadership 'styles'."

"I agree."

"There are other things to consider," she continued. "Reflecting on how we have changed in our interest in participating, I remember I lived much apathy in the first years of the cooperative movement."

"Apathy?" I asked, somewhat surprised.

"Yes, apathy. I was very identified with the cooperative movement but it was a period of economic instability and not everyone was enthusiastic about the cooperatives. Later came times in which circumstances in our environment and progress in the cooperatives resulted in living the cooperative experience more intensely."

"As it is now, when there is economic stability in the cooperatives and the economy?" I asked.

"Not exactly. Today we live more rationally, and there is apathy about participation again, although for different reasons. Regarding my own feelings, perhaps I share some of this apathy, as I am more skeptical about the response of our cooperative group to the desires of the socios."

"The larger and more diverse the organization, the more difficult it'll be to respond to everyone's desires." 
"I agree, and I think we should not expect so much about what can be done by management. We as persons must seek participation and be fully conscious that we can participate independently of the level of our job."

"But you are skeptical."

"That's right. I question if persons are willing to make the effort to participate authentically."

Edurne paused again, apparently to reflect on her words. "From knowing about the cooperatives, being proud to belong to them, and having argued angrily about them in numerous occasions, maybe I have also reached a stage of relativism. Perhaps I've arrived at a certain skepticism about our ability to continue maintaining our principles and values."

"Because of the size of the cooperative group?"

"Because of its complexity. There is for example the difficult globalization environment. One of the most important challenges we have now is the internationalization of the cooperatives."

"And how do you feel about this challenge?"

"As part of the organization, I see that we need to be in the world if we want to keep our jobs, our wealth creation, and our international presence. I am in favor of having an open mind, but I also see others who aren't and, as I've learned in some workshops, I think it's logical to have some reservations. In any case, I think it's inevitable to join the world in a capitalist environment. After all, we are an island that is competing in the same world. Capitalist enterprises sell what we sell, and we can't do many things differently from them."

"So you accept the presence of the cooperative group in the world" I said.

"I do, but also ask: If we are cooperativists with a presence in other parts of the world, why aren't the workers there cooperativists in our enterprises? Why don't we give them the opportunity to participate?"

"This is what you refer to when you question if the organization will be able to maintain its values," I said, returning to the topic.

"That's right. Adapting to this era with the business requirements to survive while updating our values is a pending assignment for us."

"Something admirable of the 'Mondragón experience' is its ability to balance the economic and social aspects. You feel this balance is threatened..." 
"That's right, but I hope we can keep it."

"And where would you start?" I asked.

"I think we have to open ourselves up to an experience as we have lived here. Of course, this experience can't be the same elsewhere but we need to trust that a philosophy of participation will work in other places. Why not transport our experiences of participation? We need to ask ourselves: How are we in the world? What for, what is our objective? There is a lack of consistence: here we participate, away from here we don't-what are we doing? These are my doubts about our situations, which are real but have not been structured."

"Perhaps participation can be implemented in steps," I suggested. "As you just expressed, the Mondragón experience can't be emulated exactly, but trusting that participation will work could be the first step. Workers can participate with increased authority and benefits as they gain experience. Of course, it's imperative that the socios in the cooperatives here first agree to make it work. Looking at this situation as an observer, it gives me the impression that MCC is excessively concerned about being in the world at any cost."

Edurne nodded emphatically.

"But I have much faith in MCC and your ability to solve this dilemma," I added. "My faith is not based on wishful thinking but on your history. I think you'll get to a reasonable decision, as you have so many times in the past."

"I have as much faith as you do, but we have to discuss these issues," she said.

We were silent for a few moments. "Edurne," I said, "I realize that you also see participation as an essential value in the cooperatives, wherever they are. My study in year 2000 also showed that participation was the most important MCC value. Let's see if we can now relate this value to your personal experience. Let's see if we can focus on you, getting in contact with the meaning participation has for you, something we can distill from your 40 years of experience in the cooperatives. Can we talk about your life and how you have evolved in the way of participating?"

"Ok, David. I have endeavored to participate since I remember. My parents were not cooperativists but they let me participate at home since I was a child. I had very open, intelligent parents who were, and still are, part of the modern world. I've been fortunate in that respect. The values I learned in my family influenced me. As a young woman, I participated where I could in Franco's times, that is, in church groups. I also participated in a governing council in a food cooperative and had several political leadership jobs in my village."

"Why did you decide to participate in politics?" 
"Out of personal conviction. Some people think that a person participates because he or she wants to be recognized by others. In my experience, recognition helps but selfsatisfaction comes before recognition."

"Can you explain what you mean by personal conviction?"

"Yes. My inclination to participate responds to my personality and I've always being conscious of it. I like to participate. I've always liked it and a favorable professional environment that encourages participation has made it easy. A symbiosis has occurred between my personality and the characteristics of a cooperative enterprise."

"Have you always worked in the cooperative group?"

"Yes, but with interruptions and doubts. I asked for a sabbatical early on in my career and went outside the Basque Country to study. I thought then: 'I am going to do something else', because I didn't like my job. More than once I have thought, in my quest to improve my situation, that working someplace else would be better. I have looked at the classified ads in the newspapers but I didn't dare leave because of the symbiosis I mentioned earlier. It's always been this way, my professional and personal maturity have convinced me that I wouldn't have been comfortable in an organization with a different style. And I would probably have been fired!" said Edurne, laughing loudly.

"Why?"

"I've always been a critic of my own performance and of our organization. And when I say I am a critic, I refer to constructive criticism, ok?" she added, laughing again.

I laughed with her.

"Continuing with the story, my work in the cooperatives helped me to live values I strongly identified with. I've worked in many industrial but also in service cooperatives."

"Edurne, you are one of the female executive leaders with most experience in the cooperatives. I understand there are more opportunities for women today but it's no secret that you live in an organizational culture perceived by male cooperativists themselves as 'machista'. Can we go back to those first work experiences?'

"Sure, David. First of all, it has not been easy. I found obstacles to progress as a woman in my early years. When I requested a change to a new job, my boss told me not to apply."

"Yes, I've heard from others that being young in a cooperative is an impediment to being noticed. Perhaps your boss made that comment because you were young and inexperienced, and not because you were a woman?" 
"No, David," she replied unhesitatingly, "my boss told me clearly that I should not apply for that job because it was not a job for a woman."

"I see, so it was very clear," I said, echoing her words deliberately.

We both laughed.

"But one of the senior executives believed in me," she said still smiling, "and he encouraged me to apply to another division. He probably thought: 'I am going to give this young kid an opportunity'. The new job was difficult because all my peers were older men when I was 30 years old. I felt hounded!" she said, smiling again.

"I can believe it."

"I acted as an agreeable colleague but my peers would test me continuously. It was a personal battle and these were truly difficult years for me. Later my peers started to accept me. The cooperative group was growing, there were new people...I read, studied and had the opportunity to finish a Master degree offered within the cooperatives. After this period, once I had been accepted, everything changed. For example, I had been in the Social Council in my previous job and my colleagues elected me again as their representative in the new one. Bottom line, there were good things, but I'd like to emphasize, it has been hard!"

"Because you are a woman..."

"I think so. We were very few women then working in the cooperatives and most were secretaries. Even today, professional women are in service jobs. Women that belong to governing councils generally have staff or human resource jobs. We don't have women engineers, we are psychologists, sociologists, lawyers. There can be many explanations, but to me, it's still a 'machista' organization, as you mentioned."

"But I understand the situation has changed for younger women..."

"Yes, it's shifting. Universities are now heavily populated by women who are studying business careers. I hope the situation continues to change gradually."

"I hope so, I said, looking directly at Edurne. "In my opinion, women have much to contribute to executive work. Your intuition, perspective, creativity is most needed. To me, you contribute even with the way you participate..."

"I think you are right. I feel that my way of participating as a woman is quite different from a man's. There is a set of values at play and the masculine and feminine behaviors make it different. However, there are women who replicate male roles and I realize it's difficult not to do it... I probably do it myself." 
"It's possible," I replied, "but we need to consider that women in executive jobs have almost exclusively men as models. I think in time women will develop their own models, once there are enough women in executive jobs."

"I am for having both genders complementing each other," said Edurne. "I think men are more capable of developing partial perspectives, and they can be brilliant doing it. Yet, they don't perceive the whole picture, they don't see the interrelations and interactions of certain important factors related to the situation at hand."

"You are talking about using the left and right hand of the brain."

"I think that's what I mean. Men are more specialized, women are more intuitive, more capable to integrate different aspects of a situation."

I stayed silent to make sure Edurne had finished talking. She looked at me, as waiting for me to speak.

"Edurne," I finally said. "What could you tell me as a summary of your personal experience with participation?"

"I can conclude telling you that I continue critiquing what I do and what the organization does. I've had much satisfaction from my personal participation and from the efforts the cooperatives have made to facilitate an environment in which I can participate. I have grown a lot in the cooperatives. My maturity and experience give me more confidence and now I participate much more actively than I did at the beginning. This is probably because I now have more knowledge and much experience. As a consequence, my participation is more abundant and has more quality."

Edurne stopped talking. I waited.

"All of this satisfies me," she said, "but I think I can grow more, much more."

"You don't seem to have changed your personal expectations Edurne," I said with a smile as I got up.

She smiled and we walked out together.

I walked Edurne to the doors of Otalora and I stood outside to think about our meeting. I found my conversation with her to be different because she sprinkled her conversation with many self-examining questions. With all her experience and intense participation, she questioned what participation means to her now. Has she lost perspective, she wondered? She wavered back and forth, doubting and then finding comfort in thinking 
she and her collaborators at least participate with their clients in their projects. Is it enough, she asks.

Edurne had many questions and I have some of my own. Has participation lost its meaning in her cooperative? Is it apathy of those who think there is no need to worry about the survival of the cooperative system, different from when she was young? Taking apathy to another context it reminds me of a parallel situation in the political realm of countries where I have lived. Why do people prefer not to participate with their voice and/or vote, even though they are affected by the election outcomes? Is it that they find no meaning in participating? Is it cynicism, protest, lack of energy to make informed decisions?

Or is it about leadership? Returning to the workplace, Edurne talks about "selling" the objectives, which I visualize as a dialogue between managers and consultants to agree on their objectives, but still implies decision making at the top. She had already said at the chiquiteo that they were attempting to make objective setting more participatory. I previously thought this was 'a given' in all cooperatives. On the other hand, Edurne also mentioned socios should not expect management to promote participation or make all decisions, since everyone has the opportunity to participate. Does this mean that management is making all decisions now?

She also expresses frustration about the cooperatives and their businesses overseas. How can they espouse the value of broad participation at home but not abroad? Of course, traditional organizations in our culture usually do not care to be coherent in values at home and abroad, but to cooperativists coherence is a firmly ingrained concept.

As with Aitor, I took an optimistic stance about solving the globalization and values dilemma satisfactorily because, from my point of view, some Mondragón people lose perspective when they embark on new initiatives, such as globalization. My words definitely reflected my feelings. How many times has Mondragón surpassed major obstacles throughout its history! Adapting to the oil crisis, joining the European Union, reorganizing completely under the MCC corporate umbrella...

I believe Edurne's continuous questioning of the future of Mondragón is very healthy. It would be a welcomed attitude in our traditional organizations-Why do we do what we do? Are there better ways to do what we do? What changes have to be made? But questions such as these require a broad range of stakeholders participating in answering them. Otherwise, I think our organizations will continue on the same path. Do you agree? 


\section{CHAPTER 10}

\section{FAREWELL LUNCHEON AT THE OTALORA TRANING CENTER}

We had all gathered and a joyful ambience prevailed. But melancholy also floated in the Otalora dining room. At least I felt it. I had read about the disquieting sensation that comes when a project such as ours is finished, as we part from others with whom we have shared meaningful experiences. I found it difficult to visualize this sensation when I read it, but, knowing this was our last reunion, I understood what those authors who had walked this path before were talking about. It was a sweet and wistful feeling. Soon we would cease to share slivers of our existence, experiences perhaps buried in a memory that evoked joy and sadness. There were probably feelings that we may have become aware of for the first time under the light of what others had said. But I was also infused with a sense of joy knowing that the nine of us had co-created fresh insights based on meaningful lived experiences that could illuminate the understanding of the experience of participation.

The meal was scrumptious. We had paella as a first dish, with golden-colored saffron rice, fresh shellfish, roasted chicken and sausage, red and green pimentos, sweet onions and other condiments. This was followed with rape, or monkfish, a white fish whose firm meat resembles the texture of lobster, served in a wine sauce with sizzling fried potatoes on the side. For dessert we had a light macedonia de frutas, a multicolored dish of fresh seasonal fruits. Because it was a special occasion, we had chilled cava before our meal, an exquisitely dry, sparkling white wine, called cava in Spain and champagne in France. After dessert we had cafe cortado, freshly brewed coffee served in small cups with a bit of creamy whole milk. After coffee, we were served small glasses of Pacharan, a liqueur from the Basque region.

The conversation was most lively. The moment to recount my story had arrived. I raised my wineglass, which had contained a Rioja Reserva red wine, and softly tapped the delicate crystal twice with my coffee spoon. The conversation stopped and everyone turned and looked at me.

"Well," I started tentatively, "after sharing with you a delicious meal and great cava and wine, and after enjoying such great company and conversation, I'd like to tell you about participation as I have lived it. We are almost at the end of the journey. We have been sharing until now your meaningful experiences, which have required your openness to my questions. I have reacted to your stories and shared some comments from my experience and you have helped me co-create relevant themes about participation."

"It's time to reverse our roles," I added after a pause. "It's my turn to open up to you and tell you something about my experience with participation. I ask you to intervene, as I've done it with you, guided by two questions: "Does what I hear have resonance with what I've felt? If I didn't know whose story it was, would I think a cooperativist could feel and express what I hear?" 
Some members of the group nodded, others simply kept their eyes on me and continued to listen.

"I'll give you first some context and I'll read what I wrote four months ago," I said. "I've shared with you that I was responsible for the European, Asian and Pacific operations in the last transnational company I worked with in the last stage of my career, which I left ten years ago. Today I would like to talk about a previous stage, when I had a similar responsibility in the Latin American region."

"In this region," I added, "we had diverse products produced in ten manufacturing plants in five countries. The management team would meet every year in different places in the region to elaborate the strategic plan. These gatherings lasted four days and included between 10 and 15 people. We had meetings for example in Cancún and Ixtapan de la Sal in Mexico, San Juan, Puerto Rico and Saint Thomas in the Virgin Islands. It was customary that the executives' wives joined us at these resorts to take a vacation."

"Some members of the planning staff and I, as the vice-president of international operations," I continued, "had traditionally prepared the strategic plan and published it for the rest of the organization afterwards. These strategic plans had very sophisticated strategies but a low level of compliance."

I leaned forward and looked at the group. "After several years elaborating these ineffective plans, we changed the system from the planning staff and I elaborating the strategic plans for everyone to the executives of each company elaborating their own. The planning staff, which had no direct responsibility for sales or profits, became advisors. We also experimented with an "inverted pyramid" system, which I mentioned briefly during the chiquiteo, giving few guidelines from the top and letting people who had to meet the objectives elaborate most of the plan. This change resulted in more realistic strategies and improved compliance with the required objectives."

"It's interesting you should mention broader participation in the plan," said Edurne, "because we are also trying to get everyone involved in ours."

"I see that you take the planning process very seriously in the cooperatives, Edurne. I remember when I did my study in year 2000, I learned that in a cooperative of more than 1000 socios, everyone had the opportunity to get involved through representatives and everyone was informed of the process through the transmission of the planning sessions in the intranet system. I thought it was great."

Edurne nodded.

"And of course," I added, looking at her, "this is in complete agreement with what Don José María said about the socios forging their own destiny by participating. If the strategic plan is going to determine the objectives and budgets for the next few years, what better way to contribute in the future of the enterprise than participating in this process?" 
I shifted my posture on my chair. "Now I will give you an example of a planning session in the Spa of Ixtapan de la Sal in Mexico. The process started when participants arrived at the Spa with the plan they had prepared with their teams. Each executive presented the plan to the group to get feedback and the revised plans became the final plan. One special aspect of the gatherings was our invitation to the executives' wives to critique the plan. I remember well how most of their comments were on target, and how openly we accepted their critiques, which often revealed blind spots or lack of realism in our plans. The best part was that at the end we all agreed with the plan, even our wives!"

"Listen, David, I'm telling you, I wouldn't invite my wife," said Aitor. "She would change the whole plan!"

We laughed heartily and I resumed my story. "I 'd like to read now about my personal experience at one of the annual sessions. I'd like to clarify that I wrote this only four months ago and that I can't describe my experience as I lived it then but rather as I remember it now. I don't think I understood the meaning of this experience while I was living it and I doubt I could have put on paper then. With the perspective that time, distance and reflection affords me, I perceive now that my experience went beyond the mere preparation of a plan by a group and that awareness allows me to articulate now what I believe was happening within me then."

I looked at the painting on the wall beyond the group while I pulled and carefully unfolded my notes from my pocket. As I started to read, I tried to be present to my experience someplace else, at another time...

I am in a room in the conference center of the Ixtapan de la Sal hotel. It is nine in the morning on the first Thursday of May, 1988, the day we initiated our strategic planning session for the years 1989-1993. We hove already shared breakfast and chatted about the trip the night before, a two-hour drive from Mexico City. Our wives are already enjoying thermal or steam baths, mud or fruit facials, reflexology, massages ... they will undoubtedly recount their experiences at dinner tonight.

"It must be difficult to concentrate when your spouses are having fun while you work, huh?" said Jon with a big smile.

"Indeed," I replied also smiling, "but we'll also do what they are doing today the next afternoon. Looking forward to this break sure helps too!" I added, laughing. Some members of the group smiled.

I lowered my eyes to my notes and continued: "Today, I will focus on my feelings during one of those meetings."

These sessions give us the opportunity to participate in decision making freely and informally. The regional directors of marketing and sales, manufacturing, finance and human resources and the general managers of the five Mexican companies are present this year. Also, the country managers of Colombia, 
Venezuela, Argentina and the two general managers of the Puerto Rican operations have joined us. We are fifteen altogether, including me, for a total of thirty in the group, including our wives.

"What is happening, what am I feeling?" I asked aloud and in a reflective tone, raising my eyes for an instant and going back to my notes.

We sat in a circle, an unusual practice in my company since rectangular tables are preferred so the boss can sit at its head. With this simple change, I feel we are all equal. I feel proud to be part of this group of motivated people, of having been a catalyst to create it. I trust the people, the process and the better outcome of this meeting because it will include everyone's opinions. I also trust that what is being said, approved or not at the end, is the fruit of many hours of dedicated work of people who participated to determine our future.

"What you say about trusting everyone in the group is important. If there is no trust, there is no participation," Jon said.

"I agree," I replied, looking at him.

I feel the power of our participation as a group, of our capacity to set aside our diverse personalities and individual objectives to contribute to the plan. When I participate, it is with an intense desire to help, not criticize. Everyone's wellbeing is as important as mine. My self-centeredness gives way to solidarity...My mind is more acute than usual, my words are more eloquent, my smile is broader.

I paused to allow comments but there were none.

I feel a connection with everyone in my thoughts and feelings. I have a profound respect for what each one says. I listen more attentively to what 'the other' is saying and I feel that I judge him less. I feel connected because I am aligned with everyone in the creation of something new. When someone presents an idea, I feel like it somehow is a part of mine and that my ideas are part of theirs. I am moved when someone in the group has a new idea that we have not thought about before, although we have been working with these strategic plans for months. I realize that in the world of ideas, there are no monopolies. I process what is being said at a vertiginous speed and I feel that, just as I listen intensely, others listen to me with as much attention. I feel the spiral of our thoughts springing up..I can trace their movement, from a simple idea to a complex concept, in a process of iteration. I participate openly, articulating my ideas with unusual clarity, refuting arguments in a blend of respect and challenge, always feeling that we will end up with a better conclusion because we all contribute with different ideas according to our personal experience. We are not fifteen persons with fifteen minds, but one cosmic mind with fifteen perspectives.

"I think what you have talked about so far fits perfectly with what a cooperativist would say," said Rosario. "I share the same sensation of wellbeing when I am with my team and 
there is something we have to do and we know how. And everyone expresses their opinion, sharing a different perspective. A space is created that nurtures us..."

"I've felt that connection also," said Noemi, "mostly with persons with whom I've established a participatory relationship and feel comfortable working with."

"I wonder," I said, thinking aloud, "if participation at the most meaningful level is possible if persons involved believe in it, feel at ease and have the opportunity to participate."

"What you say would also include perceiving participation as something that really nurtures all of us," said Rosario. "I feel like you when I'm in a group and we're discovering something, that all of us are at the same level. Being the executive in my company, I'm the first one to see myself as equal to everyone and I think they see me the same way. Everyone speaks with great ease and freedom, we debate and some participants challenge my ideas, as they would challenge those of the other members of the group. Everyone's opinion is important, as it is for everyone to know that they can participate."

"Agreed, Rosario," I said, nodding lightly, "I think what I will read now reflects some of what you are saying."

I have sought equality in other occasions but it is here where I truly see my self on a level field. I feel that it does not matter who has the most hierarchy in the organization, who runs the largest business or the business that is most profitable. Neither does it matter who has more academic education, is most articulate, dresses better, or is better looking, younger, richer or healthier. It reminds me that we are all equal when we are born and when we die, that our differences are due to our diverse experiences, and that we can work together if we have a common objective.

"I agree," said Aitor, "about the equality among all of us, and that the color of our skin or what position I have in my work doesn't matter. The way we treat each other, the way we participate, and those other things you said, all of it describes what I feel too."

I nodded silently in agreement and continued:

I am stimulated by the energy created within the group, which is stronger than my own. As we all perceive this energy, we feel equally motivated. It sharpens my feelings and intensifies my attention. My upright sitting posture reflects my acuity and concentration. I listen and speak, speak and listen, and I do not get tired. The sessions last hours and hours, but I forget everything and would prefer not to even break for lunch. Although participating in these sessions is stressful and difficult, especially for me as the facilitator, I feel that a positive energy overwhelms me. There is so much intensity and emotion in me. When the sessions end at sundown, instead of being tired, I am totally energized. I will not feel tired until it's time to sleep, when I will fall in bed exhausted... but for now, I want to feel everything, every idea, word, movement, emotion..." 
"I identify with what you say about energy," said Jon. "What I say you listen to, and what you say, Il listen to'. With both being open to 'the other', what you call energy is produced. You speak about energy, I would call it 'ilusion', a blend of hope, motivation, excitement and expectation. It's something that moves me to place the best of me on the table."

"I"ve also felt the creation of energy when a colleague and I have worked on something worthwhile," said Noemi.

"I speak of energy," I said looking at Jon and Noemi, "because it is the closest to what I have felt, but I am sure it can be perceived in other ways."

I turned to my notes again.

Our participation in these meetings creates a space for us. The words we say are crystallized in a sacred circle we have created..."

"I feel resonance with what you describe about the sacred circle," said Evaristo. "To me, is like Oteyza, the architect of the Sanctuary of Arántzatzu, used to say, "what is builtthe walls, columns, domes-is not the most important. The space created in the middle is, because it is the place where we can be together. Likewise, persons who form a circle, create a space in the center that makes it possible to co-create. We come into this empty space as equal persons, all as naked as when we were born, and we build together within this space."

"I like your image, Evaristo, of 'a space in which we can co-create'." I said.

After a pause, I continued:

When I go back to the time in which I had these experiences, I realize that the strategic planning sessions were special moments in the most satisfactory stage of my career in transnational organizations. I wonder if this is the reason that I believe that the experience of participation is indispensable to be a whole person. In that environment, I had a strong bond with my colleagues, their wives and their families. We were in a space created in an environment of trust in which we could hold our energy within the group and go back to it again and again. The connection that existed among us, the environment we were in, the feeling of belonging to the group allowed us to relate to each other in a wholesome manner and motivated us to commit ourselves to our objectives. This space lent itself to have creative ideas and optimum results, not only personally but for the organization.

Why is it that we do not seek the creation of spaces such as these in our organizations? Is it because we have not had the experience of participating freely and we do not know what it means? 
"I think," said Sergio after a long pause, "that there are cooperativists who feel what you have described, but these would not be everyday experiences for them."

"Agreed," I replied. "I am the first one to recognize that I've described something I lived only occasionally and in sporadic spaces during 27 years of work in traditional organizations. There is a great difference between what these experiences may mean to you and to me. To me, they were a luxury. On the day-to-day basis, I was the boss, placed in a superior level. But for four days a year, in the space described above, we could say 'here, we are all equal', and I could cease to behave as a superior to my collaborators."

"I agree with Sergio," said Evaristo, looking at me. "It's possible that a cooperativist would say what you read David, but only in the best moments. Day-to-day, there are elements that contaminate the environment and, after feeling good about participating for a certain period, interest is lost. The curve ascends in the first stage and descends in the second. In a third stage, a cooperativist may regain interest, and being convinced to raise the curve again. But this is not always the case."

"It looks like the relationship between a person and his or her participation is like the relationship between two people," I said, frowning. "First, there is enthusiasm, then both take the relationship for granted and lose interest, followed by a revival of the relationship... or not! We need to work at it continuously to maintain it."

We were silent for a few moments.

"What you have read," said Lorea, breaking the silence, "could indeed have been said by a cooperativist. But I think that most of us have not made those reflections, at least not as profoundly as you have. It seems to me that your perspective has more of a spiritual focus. We see participation more pragmatically."

"I hear what you are saying, Lorea," I replied. "I wrote what I read on February 9th of 2003. I found it difficult at first to identify the experience I had written about. That morning, I wrote stories of four diverse experiences I've had with participation and selected the one you heard because it was the most vivid. I think I was able to connect with what I had experienced because I focused for some time on what I felt. But, as I mentioned, I also realized I could not recreate a past experience without influencing it with my actual perspective."

Lorea nodded.

"What I have learned today," I said, "is that for a person that participates all the time, as you do, it's difficult to speak about a particular experience. I wonder, however, if a cooperativist wouldn't write things as I wrote if he or she had the opportunity to reflect on the topic, as I did." 
"I don't know," replied Lorea, "but I think it'd be helpful for us to engage in such a reflection. What we have, we take for granted, we don't appreciate it."

"It' $d$ definitely help us to reflect upon these things," said Edurne, "as well as to learn to articulate them. It'd help us a lot to know ourselves better."

"I agree with both of you," added Sergio. "Generally we do not value the opportunity to participate when we work in the cooperatives, unless we have worked elsewhere."

"As Lorea and others said," continued Edurne, "a cooperativist could probably think what you have read, David, but I don't know if he or she could feel it."

Edurne paused for a moment. "Although it's probable that we think and feel what you said, since I don't believe we are so disconnected between our thoughts and our feelings. But we are not used to expressing ourselves in those terms."

"Edurne," said Aitor, "I believe that we cooperativists think and feel what David said but we are bashful to say we have those feelings. We are more introverted."

"I agree, Aitor," I replied, "and I have noticed it in some of our conversations. Perhaps if I had shared what I read today with you from the beginning, you would have expressed yourselves that way too, but I would have influenced our conversations, taking the initiative and inhibiting our spontaneity. I think it was preferable to have talked as we did since you have told me your personal experiences, emphasizing what is most relevant for you, not for me. And, although you didn't tell me some things directly, I've tried to interpret your comments. This is one of the reasons I sent you the texts at various stages of the process. You have ratified what I have written or rectified my misunderstandings and your modifications have been included in the final text."

"Agreed," said Aitor.

"Fine," I said, "to conclude, I'm very happy that you accepted my invitation today so I could share my experiences and feelings about participation with you. You have helped me tremendously to enrich my perceptions about participation not only today but throughout the entire process. I am very grateful."

With these words, we got up from the table and left the Otalora dining room. I walked with all my collaborators to the Otalora lobby. The voluminous doors were open and the cool air from the inside was mixed with the intense heat from the hot sun outside. It was very difficult to say goodbye. I hugged and shook hands with the men, kissed the women on both cheeks, we agreed to stay in contact. Everyone offered continuous help until the end of the dissertation process. I promised to send them a copy of my finished book. With these words and a flurry of good wishes, everyone left. I stood outside the gates until I had waved goodbye to the last collaborator that left the parking lot. And again, I felt alone, I wondered how many feelings were left unexpressed, how many things were left unsaid, how many thoughts were left incomplete.... After the emotional interactions about my experience and what I perceived was an unveiling of the feelings of my 
collaborators as they heard my story, I was alone with my book, standing on the =sunny terrace outside Otalora. I said goodbye to my Otalora friends who had helped =me to put my study together. I walked slowly to the parking lot, carrying books, notebooks, my laptop, extension chords, diskettes, and miscellaneous items. I loaded the trunk of my car and left.

The next day came very quickly. I said goodbye to Esteban and Rosi that night and left to Bilbao the next morning at 5 a.m. A Mondragón friend, who had not participated in the study, had insisted on taking me to the airport. We talked and talked on the way over and she would not leave the airport until my flight left.

I spent most of my way back from Bilbao to San Diego reviewing my transcriptions, notes and reflections and I scribbled some additional ideas in the margins of the printed pages. I had written a citation from Harold Kushner related to decision making on my book but I had not integrated it with what I had experienced with my Mondragón collaborators. I wrote the following in the last few hours before arriving in San Diego:

I began writing this book with a narrow view of participation in decision making at the workplace. The interaction with my collaborators, however, broadened my horizons as I found that they did not perceive their experience as circumscribed to influencing decisions directly or participating only in far-reaching decisions. It was also in the relationships formed and in the small actions and decisions during their daily work that participation became meaningful. As expressed by Harold Kushner:

We have seen the slow but inexorable progression of human society from having one person, the king, determine the course of people's lives to having people decide things for themselves. But we don't vote only in elections. The small choices and decisions we make a hundred times a day add up to determine the kind of world we live in.

This realization broadened my scope as I understood that every human interaction may influence, consciously or unconsciously, our viewpoints and therefore our decisions. Any interaction is thus imbued with meaning, and, if we are aware of its existence, we may enrich our lives. This may happen in matters large or small, at work and in life. In accordance to this view, although the focus of this book will still be on participation in decision making at the workplace, I will expand the topic to include how our participation at work and in life are interrelated and influence each other.

This broader view encouraged me to explore and integrate my own life experiences and reference sources from diverse realms of knowledge that I have read throughout the years, a challenging but exciting task. I felt I was ready to interpret what I had experienced and its implications in our work and our life. 


\section{NOTES AND SOURCES FOR PART I}

Chapter 1. Why Is Our Participation in Decision Making Important? (Pages 1-10)

Enron discloses losses: Behr \& Witt, p. 219.

Corporate irregularities: These were highlighted in 2002 in numerous articles in daily newspapers and weekly magazines that unveiled serious corporate irregularities in several major corporations. Among the corporations included in these articles were Enron (Behr, P. \& Witt, A., The Washington Post, 2002, July 28); WorldCom (Staples, D., Edmonton Journal, 2002, July 28); ImClone (Peyser, M., Naughton, K., Tyre, P., Lipper, T., Gegax, T. T. \& Bergtraum, L., Newsweek, 2002, July 1); Qwest (Kilser, L., Milstead, D. \& Smith, J., Rocky Mountain News, 2002, August 3); Tyco (Maremont, M. \& Markon, J., The Wall Street Journal, 2002, September 13); and Adelphia (Leonard, D., Fortune, 2002, August 12). These are cited in Surowiecki's book.

Self-dealing: Surowiecki, p. xi.

Robber barons: De Long, Chapter 3 [on-line].

The big four: Surowiecki, p. xi.

Savings and Loans scandals: Potter [on-line].

Senge (1990), p. 240.

Broader participation proposed: Bennis, Parikh \& Lessem; Burns; Chrislip \& Larson; Gates; Helgesen; Janis; O’Toole; Ouchi; Senge (1990); Rost, 1991.

Description of MCC: Authors about Mondragón are Álvarez de Mon; Azurmendi; Larrañaga (1998); Morrison (1991), Ormaechea $(1993,1997)$; Whyte \& Whyte. The mondragon.mcc.es. website is also a good source of information.

Different perspectives about MCC: Adams \& Hansen; Bradley \& Gelb; Cheney, 1995, 1999; Whyte \& Whyte, 1991; Kasmir; MacLeod; Matthews; Morrison, 1991, 1995 ; Vázquez; Whyte \&Whyte.

Participation as a major MCC core value: Herrera (2000).

Institutional MCC guidelines for participation in decision making are described in Politica Empresarial de MCC 2001-2004, (MCC Corporate Policy 2001-2004),

Ormaechea, 1993; Whyte \& Whyte, 1991; Morrison, 1991; MacLeod. 
Chapter 3. Mondragón and Its Principles (Pages 13-26)

MCC statistics and description: mondragon.mcc.es.

The Mondragón principles are briefly expressed in MacLeod, pp. 40-43 and Morrison, pp. 10-12. They are more comprehensively described in Ormaechea (1992). Reference pages for each principle included below are based on Ormaechea's book, unless otherwise indicated.

Democratic organization principle: pp. 144-147.

Gates, p. 20. This author describes ESOPs extensively throughout his book.

Cost of one MCC share: Mondragon seminar, June 2002.

Open admission principle: 141-143.

Subordinate character of capital principle: 153-157.

Sovereignty of Employee's Work over Capital principle: 148-152.

Pay ratio: Mondragón seminar, June 2002.

Payment solidarity principle: 164-168.

Financing new jobs with profits: Mondragón seminar, 2002.

Job protection: MacLeod, pp. 51-52.

General Assembly and Governing Council: MacLeod, p. 29.

Self-managed teams: Whyte, Greenwood and Lazes; Herrera (2000).

Solidarity: Arizmendiarrieta's, MacLeod and Whyte and Whyte's books address solidarity in detail.

Justice vs. charity: Pilarczyk, pp. 57-61.

Social transformation principle: $175-179$.

Intercooperation principle: $169-174$.

Arizmendiarrieta on solidarity and self-centeredness: Whyte and Whyte, p. 243.

Universal nature principle: $180-182$.

Mundukide: Herrera, 2002, p. 12-13, and details in TU Lankide issues: December 2000, p. 34; March, 2001, p. 37; May 2001, p. 35; July, 2001, p. 31; February, 2002, p. 37; May 2002, p. 37.

Participatory management principle: $158-163$.

Education: 183-186.

Arizmendiarrieta on education: Reflections, pp. 79-95. 
Chapter 4. Arizmendiarrieta and His Role (Pages 26-34)

Don José María died in 1976: Forty years of co-operative history.

Circles of study: Azurmendi as cited in Whyte and Whyte.

Belief in education as most important task: Reflections, pp. 77-97.

Don José María did not believe in "isms": Whyte and Whyte, p. 253.

Human dignity at the center: Reflections, pp. 21-42, Azurmendi, p. 786.

As source of inspiration: Ormaechea as cited in Whyte and Whyte, p. 244.

"Years of hunger": Azurmendi, p. 8.

New vision: Whyte \& Whyte, p. 29.

Work not a punishment: Reflections, pp. 113.

A practical man: Gorroñogoitia as cited in Whyte and Whyte, p. 245.

Polytechnic School founded in 1957: Forty years of co-operative history.

Founders not convinced of need for bank: Whyte and Whyte, pp. 50-51.

Caja Laboral bank created in 1959: Forty years of history, p. 16.

Development of Ikerlan research center: Whyte and Whyte, p. 64.

Work: Reflections: pp. 113-120.

Freedom: Reflections: pp. 43-54.

Freedom to decide without resorting to authority: Morrison, p. 45.

Equilibrio: Whyte \& Whyte, pp. 185, 275, 296; Morrison also describes this principle profusely.

"Enoughness": Handy (1997), p. 230.

Don José María just proposes ideas: Whyte and Whyte, p. 243.

Union Cerrajera apprentice school: pp. 29, 260.

Socialize knowledge to democratize power: Whyte and Whyte, p. 242.

Women in cooperatives: Azurmendi, pp. 313-324.

Gain for men or women and Auzo Lagun: Morrison, p. 147.

The G.E.C.V. (Grup Empresarial Cooperatiu Valencia): MacLeod, pp. 99-112. 
(Pages 34-45)

Authors describing Arizmendiarrieta at some length: Azurmendi, Larrañaga, J. (1998), MacLeod, Matthews, Morrison, Ormaetxea, and Whyte \& Whyte. Matthews, pp. 185-197 and Whyte \& Whyte, pp. 241-269 provide interesting details about Arizmendiarrieta and his life.

Personal history: Whyte \& Whyte, p. 27.

War story: Azurmendi, p. 8; Whyte \& Whyte, p. 28.

Don José Maria sought a more humane world: Whyte and Whyte, p. 266.

Work as vehicle to change society: Whyte \& Whyte, p. 266.

A man with a mission, knew power of information: Pérez de Calleja, p. 15.

Don José María was austere, rode bicycle: Whyte \& Whyte, pp. 241-242.

Heart condition: Azurmendi, p. 10.

Spoke on terms of "we" not "I": Whyte \& Whyte, p. 242

Preferred small groups, difficulty articulating ideas: J. Larrañaga and Ormaechea, as cited in Whyte \& Whyte, pp. 28-29, 244.

Mondragón, a broken society: Whyte \& Whyte, p. 242.

Education to develop paideia, a good society: Morrison, pp. 140-141.

Learning by doing: J. Larrañaga cited in Whyte \& Whyte, p. 244.

Forming sports club, discussion circles: Whyte and Whyte, p. 242.

Parents association to raise funds: Matthews, pp. 194-195.

Three different stages: Azurmendi, p. 29; Azurmendi as cited in Whyte \& Whyte, pp.

246-247.

Religious ideas linked to world: Whyte and Whyte, p. 245.

Concern with property and social problems: Whyte \& Whyte, p. 246.

Reading other sources: Azurmendi, pp. 36-37; Whyte \& Whyte, p. 247.

Friere's book in Don José María' library: Whyte \& Whyte, p. 256.

Education with student: Freire, p. 66, Whyte \& Whyte, p. 256.

Books in Don José Maria's library: Whyte and Whyte, p. 247.

Don José María combined others' philosophies: Azurmendi, p. 38.

H-PAC: Hoose (Ed.), The Human Person by Selling, pp. 95-109.

Mounier's idea, workers are mature, managers are not: Azurmendi, p. 39. 
Vision: Reflections, pp. 55-97, 111-140, 155-206.

Sovereignty of labor: Whyte and Whyte, p. 244.

Priority of persons: Rubio, pp. 14-16.

Adapt cooperativism to social realities: Retegui, p. 13.

Make changes according to will of the people: Ormaechea, 1986, p. 25.

\section{Chapter 6. The Chiquiteo Group Encounters with Participation (Pages 56-79)}

Participation as a value: TU magazine is the most widely distributed publication about Mondragón. Some articles about participation appear in the following issues: January, 1999 , p. 10; November 2000, p. 37; May 2001, pp. 34-35.

Phenomenology: Creswell, pp. 51-55, 175-178

Heuristics: Patton, p. 71; Moustakas (1990, 1994).

Mondragón, a walled-city: Ramírez, p. 16-17.

Learning from mistakes: Peters \& Waterman, pp. 134-141.

Chapter 7. Personal Encounters with Participation (Pages 80-108)

Equilibrio: Whyte \& Whyte, pp. 185, 275, 296; Morrison, p. 4.

Sovereignty of work over capital: See ten Mondragón principles in Chapter 3.

Chapter 8. An Afternoon at Monteroi Park (Pages 109-113)

Maslow's hierarchy of needs: Wortman and Loftus, pp. 411-412.

Maslow's transcendence (beyond hierarchy of needs): Maslow, pp.259-286.

Chapter 9. More Personal Encounters with Participation (Pages 114-146)

Fear at work and its consequences: Herrera (2002).

Chapter 10. Farewell luncheon at Otalora (Pages 147-156)

Participation in small acts is important: Kushner, p. 150. 


\section{PART II}

\section{INTERPRETING THE EXPERIENCE OF PARTICIPATING IN DECISION MAKING}

Part Two contains my interpretation of the story I wrote about participation in decision making at work and in life. It is based on what I have learned through interacting with my collaborators, finding common responses, reviewing previous research, as well as reflecting on the poetic transcription and my own experience. It is a result of delving into my "total experience" from the time I decided to do this study in the fall of 2002 to now.

Chapter 11 contains a Creative Synthesis that intends to make sense of the dialogues and conversations with my collaborators and other research data through concepts representing the meanings of participation. They are mostly grounded on the meanings given to participation by nine people: my collaborators and me. My intention in developing these concepts is to present them in such a manner that you are able to explore if you identify with them. Perceiving these meanings as being true for you is what connects these nine people with your personal perception of the meaning of participation in decision making. It moves these meanings from being isolated experiences of a few people in a place called Mondragón to being applicable to you and me in our personal lives here and now. It is for this reason that I ask you to reflect upon these meanings. Do you recognize them, do you find resonance with them, does your intuition tell you they may be true for you or for others?

Chapter 12 includes a set of implications for us as persons and as leaders that intend to serve as a source of reflection and as a starting point of comparison for you. The fictitious characters I created, my friends and colleagues Kurtis and Damian, were very helpful throughout this interpretation of the study, since I had them ask questions which added to the conversation with their knowledge and views and contributed in general to enhance the interpretation of the story with their skepticism and support.

As in the beginning of the story, I placed Kurtis and Damian as if they were meeting with me, at Mimi's Café. It would be a place we all knew well and in which we felt comfortable having a leisurely lunch and staying for hours on end afterwards. We had met several times earlier, before and after my trip, to talk about the research design and methodology for the book, which are described in Part III. We dedicated the last two meetings April 17 and May 15, 2004 to talk about the outcomes of the study. 


\section{CHAPTER 11}

\section{OUTCOMES OF THE STUDY}

Damian, Kurtis and I met for lunch at Mimi's on Saturday, April 17, 2004. We had met twice before to continue discussing my Methodology but this time we me to discuss my interpretation of what I had learned in Mondragón. As usual, we caught up with each other's lives and discussed the news. After lunch, I placed my notes on the table indicating I was ready to start our discussion. As the waiter poured fresh cups of hot coffee for Kurtis and me, and tea for Damian, they pulled out their notes too.

"Well, David," said Damian. "You have finished your story and we understand that you will now share your outcomes with us. Can you tell us now about your final chapters, your synthesis, the implications for your reader and for us?"

"Yes, of course," I replied. "However, I would like to start by sharing with you a few words I wrote for the reader who has finished my story in Part I, before he or she reads this part." I pulled a typewritten page and read:

\section{Dear Reader,}

So far, you have traveled the same path I have. The rest of the book contains what I have learned from my experiences, reflections, conversations, readings, dreams, observations, memories and encounters with friends and strangers along the way. I include some thoughts from other people, based on my readings, and I will give credit where it is due. However, I take full responsibility for what I will write.

The contents of the rest of the book are my interpretation of what I have experienced. Perhaps you would like to reflect on what you have read so far before you continue reading this book. Who knows, some day we may have a chance to exchange notes...

I set my paper aside and looked at Kurtis and Damian.

"Sounds good to me," said Damian. "I hear what you are telling your reader but what will you use specifically to write the final chapters?"

"I will use the group conversations, the personal dialogues, the context, the poetic transcription and previous research and other outcomes plus what I am telling the reader about reflections, observations and so on. In brief, I will reflect upon the total experience."

"That is quite a large assortment of inputs. Can you give us more details about the major outcomes of the study?" asked Kurtis. 
Major Outcomes of the Study

"Yes. There are fifteen major outcomes based on the dialogues and conversations with my collaborators," I said. "There are the six themes from the chiquiteo group conversations: participation and young people, fear and decision making, as well as learning, promoting and facilitating participation. In addition, there are eight personal dialogues with my collaborators and the conversation about my participatory experience at the final luncheon."

\section{Other Outcomes -- Common Responses of Collaborators}

"What can you tell us about the other outcomes?" asked Damian.

"These are outcomes that show common responses among several collaborators," I replied."

"General responses?"

"We can call them that, but we can't talk about generalizability. As a reminder, in a phenomenological study we try to learn from individual experiences, not from what the majority says. We do this by 'horizontalizing' common themes, that is, giving equal value to each experience."

"Fair enough."

"There are two visible groups that showed common responses and require a bit more explanation: 'elders' and women."

\section{"Elders"}

I paused. "Elders were quicker to identify participation as a relationship with 'the other', as if they saw participation and being with the other as inseparable. They seemed to come from a human more than a pragmatic perspective."

"I see," said Kurtis.

"Also, the elders were more conscious of their role as senior cooperativists and were more liable to question their way of participating and modeling behavior, as if they felt the responsibility but were not sure they had fulfilled it."

"Keep going."

"They were more humble, attributing their becoming mature participators to others helping them, listening more to others' opinions, accepting mistakes..."

"That's good, can we talk about the other theme?" asked Kurtis. 


\section{Women}

"There was strong agreement among three of the four women about the wory they participate as compared to men."

"You mean they were able to participate as freely as men?" he asked.

"All four women said that there was no difference as compared to men in the level of participation," I said. "But three of them emphasized that their way of participating is different. This was a reply to my direct question since I thought it was relevant to know their perception, considering that they live in a patriarchal culture."

"And how did women feel they participated as compared to men?" asked Damian

"They said that men in general are task-oriented, focused, rational and sometimes insensitive to other people's needs and behavior. Women, they added, are concerned with relationships, aware of the overall picture, sensitive to other people's feelings, intuitive, and perceptive about other people's behavior."

"I assume many women would say the same in our organizations," said Kurtis.

I reached for one of my books. "Not only women," I replied. "I have a related reference about the role of women in our present world. Let me share with you what Warren Bennis, the contemporary 'leadership guru', writes:

Men see the world as individualistic, linear, competitive, atomistic and mechanical. This view has been replaced now by the understanding that the cosmos is made of relationships, not individual objects. Women seem to be culturally trained for the confusion and chaos that chronic change, democracy and the new sciences espouse. Their needs to control are not as those of men, who like to dominate the environment, which is more attuned to the new worldview.

"Interesting," said Damian. "He even ties leadership to the new science."

"Any other items in which your collaborators agreed?" asked Kurtis.

I shuffled my paper copies of the dialogues. "There are some explicit items. They can be extracted from the chiquiteo group conversations. How about if we agree to list anything that was common to four or more collaborators?"

"Sounds good," said Kurtis.

\section{Maturing Young People}

I looked at my notes. "Although there was disagreement about how much my collaborators as leaders and the cooperatives were doing to encourage young people to 
participate, at least half of them were optimistic that the young people would mature to be enthusiastic participants."

"It looks like experience and an encouraging environment are helpful to grow as a participator," said Kurtis.

\section{Learning to Participate}

I nodded. "This takes us to a related commonality: although it was recognized that some people have the propensity to participate and others don't, it's possible for anyone to learn how to participate. Practically all collaborators agreed that they had to learn to participate, some not having had the experience before joining the cooperatives."

"Learning and environment are crucial," added Damian.

Systems in Place Facilitate Participation

Kurtis nodded and I did too. "Another one: Jon, Aitor, Sergio and Evaristo mentioned the importance of having participatory systems in place. Most collaborators in my year 2000 research study also said that established systems were essential to facilitate participation."

"Go on," said Kurtis.

\section{Not Everyone Wants to Participate}

"Most collaborators agreed that there are some socios that just don't have the desire to participate. Noemi was the most articulate, describing how difficult it was to motivate others to participate."

"Even if they have systems in place that facilitate it?" asked Damian.

"Yes, and this is an ongoing concern of senior managers in Mondragón. There seems to be a continuous effort to find ways for socios to participate. Greenwood and Gonzalez, Kasmir, and Cheney have written extensively about this theme and the TU magazine, the main means of communication within Mondragón, addresses this issue constantly."

“Any others?" asked Damian.

"I think these are the main ones from the chiquiteos."

"And how about the implicit themes?" asked Kurtis.

"The implicit themes can be discerned through observations and a careful reading of the personal dialogues," I said as I looked beyond our table for a minute, "but let me mention a few." 


\section{Willingness and Openness to Participate}

I paused for a moment. "There is the willingness and openness to participate. Most of my collaborators participated throughout the analysis process, reading and modifying the narratives several times. Also, even those I had not met before shared quite personal experiences of their lives."

"That sounds very positive," said Damian, "I wonder if you could get such cooperation elsewhere."

\section{Unafraid to Criticize the Organization}

I raised my shoulders and eyebrows. "I don't know. In addition, at least half of my collaborators were openly critical of MCC's role in promoting participation and were not afraid to share their opinion. I even had to convince one of my collaborators to use a pseudonym--he wanted to speak up using his own name."

"How about that!" exclaimed Kurtis.

\section{Present Leaders Speak of Participation in Terms of Their Collaborators}

"I have a few more," I said. "Every one of my collaborators had managed people throughout their careers. However, those that were managing people today tended to speak about their participation not only as persons but as leaders: 'what is my responsibility with my people' they seemed to ask."

"Okay, any others?"

\section{Lack of Concern about Their Personal Future}

"Unless I questioned my collaborators directly, nobody talked about the future. One who replied to my question said that the future of the group was important not that of the individual."

"I bet you this has to do with not being afraid of the future," said Kurtis. "I'd think less about my future also if I were not always concerned about being fired and stuck with mortgage and car payments."

\section{Fear not a Deterrent to Participate}

"A very good observation," I said, as I paged through the stapled copy of my write-up. "A related item: As a response to my direct question, everyone agreed that the reason it's difficult to participate in decision making at the beginning is not fear, but other factors such as shyness, lack of knowledge, interest or understanding of the impact of their contribution. Lorea pointed out that this applies not only to being young but to being new in a group." 
"That's different from our organizations, that's for sure," Kurtis added. "You don't dare speak up against the boss or the organization... unless you don't care about keeping your job!"

I just looked at him.

"There are probably more but these are the ones I could identify," I said.

Kurtis looked at me. "And how do you intervene at the end of the book?"

"With another outcome, called a creative synthesis by Moustakas..."

"And this is how the book ends, with a synthesis," said Damian.

"No, I plan to also include a final chapter."

"Will I, as a reader, be able to read your conclusions in that end chapter?" asked Damian.

I looked at Damian and Kurtis. "This chapter will not look like those in traditional studies. Grouping my narratives will not yield general conclusions or theories because my purpose is to learn what the experience of participating is like from interactions and reflections."

\section{Sharing a Broader View of Participation}

"So where do we go from here?" asked Kurtis.

"I'd like to tell you about how my thinking has evolved," I said. "I began with an expectation to better understand the meaning of participation in decision making. I had read that writing this book would expand my horizons if I trusted the phenomenological process. I trusted it, with some trepidation, but I felt the subtle way my perceptions about participation broadened. My reflections and dialogues with my collaborators persuaded me to look deeper."

"Deeper how?" he asked.

"I understood that participation in decision making is not limited to the overt engagement in participation."

"You mean it's not necessary to participate directly when a decision is being made to find meaning?"

"It can be direct or subtle, it may even be an unconscious act," I said. "It has to do with influence." 
"Influence?" asked Kurtis.

"Yes. I may hear someone saying something that resonates with me. I'recognize' what he or she says and have a shift in my thinking. This shift will influence my future decisions. This person has changed me."

"How?" asked Damian.

"As my collaborators expressed it: subtly. Lorea mentioned that she sometimes participated silently and formed an opinion she used later, for example. Evaristo spoke of participating passively or actively. I have corroborated these dynamics personally."

"Can you tell us an example?" said Kurtis.

"Yes, I am sure both of you have experienced this too. For example, recently a friend said that something I told her, almost eight years ago, had changed an important decision she had made. Being aware of this, I told other friends of the effect something they said had in my decisions. Neither they nor I remembered what we said. It was not a conscious act to influence each other."

"And the moral of the story is...?" said Damian

I leaned back on my chair and looked at the ceiling for a moment. "How about 'my participation is meaningful because it may influence someone's decisions'?"

"Or," continued Kurtis, " If you know something that can contribute to a decision, you need to say it'." He looked at Damian. "Even if what you say doesn't prevail, it will influence others in their decisions in ways you don't realize."

"Anything else?" Damian said, as expecting us to say more.

"Yes!" I said. "Although my intention when I started to write this book was to limit my topic to the strict and direct participation in decision making at the workplace, I realized during the process that experienced participators do not compartmentalize participation."

"What do you mean?" asked Kurtis.

"My collaborators, whom I selected precisely because of their experience, see participation in a continuum. They helped me understand that we are always participating in decision making as we connect with others."

"Okay, so they agree with what we just discussed," he concluded.

"Good. Now I will try to express the meaning of participation and its implications in a way that I hope the reader will be able to relate to," I continued. "But what follows is of course $m y$ interpretation." 
"Will I, for example, be able to identify with your interpretation?" said Damian.

"You may or may not," I replied. "I accept that there may be alternative interpretations to mine - both the reader and you will have direct contact with the texts. What I found meaningful according to $m y$ experience may not be what you find resonance with. Likewise, there may be experiences shared by my collaborators that I didn't find particularly significant but you will."

"Each reader may have a different perception of the meaning of participation and its implications," clarified Kurtis.

"Yes, and this is as it should be. The purpose of having the reader 'present' throughout the dialogues is for him or her to interpret what is meaningful to them and relate it to their lives. We all have our part of the truth which is relevant to us."

"You said that you have tried to express the meaning of participation so that others can relate to it. Can you tell us more about this?" he asked.

Creative Synthesis

I paused to take a sip of coffee. "As I mentioned, I have followed Moustakas' suggestion: ending my heuristic research with a "creative synthesis'."

"I am sure you are going to tell us what that means," said Damian.

"Why, of course," I replied smiling as I turned my notebook to the back page.

"According to Patton, a creative synthesis brings together all aspects of the study revealing new perspectives and meanings."

"That sounds straightforward," said Kurtis.

I nodded. "Moustakas describes it in more detail: the creative synthesis," I read: taps into imaginative and contemplative sources of knowledge and insights in synthesizing the experience... There is a free reign of thought and feeling that supports the researcher's knowledge, passion and presence... [which] can be expressed through a narrative, story, poem, work of art, metaphor, analogy or tale.

"That's a mouthful. It doesn't sound like a straightforward task anymore," said Damian, looking at Kurtis and me.

"I know," I replied. "As you, I am used to thinking in more concrete terms and it's been a challenge to express myself in a different way. To do this synthesis, I have reread the narratives, my self-dialogue, my own reflections and Moustakas' book." 
"And how are you going to express your synthesis?" asked Kurtis. "A narrative, a story, a poem...?"

\section{Participation as a Tree}

"I am coming to it," I replied. "I've described and extrapolated themes and patterns from my collaborators' and my own experiences." I paused. "And I've come up with... a tree."

"A tree?" exclaimed Damian.

"Yes, the image that emerged within me to represent participation and its meanings was a tree. I'll share this image with you in a minute."

"Fine," said Kurtis.

"Perhaps it would help if we first recall the descriptions of experience and meaning," I said, "since we will be referring to these terms often today."

"Can you actually define them?" asked Damian.

"I prefer to say that I will describe them. There are many descriptions of these terms of course, but I will use Moustakas', since I am following his book to write mine." I said, as I turned to the back pages of my notes.

"Go on," said Kurtis.

"Experience," I read, "is determined by the unique perceptions, feelings, intuitions, beliefs and judgments housed in the internal frame of reference in a person. Meanings are inherent in a particular worldview, an individual life, and the connections between self, other, and world."

"Okay, David, show us the tree," said Damian, "I am sure we'll understand what you mean when we see it."

I pulled two copies of a diagram and handed one to each (shown in next page). "We can start bere."

Kurtis and Damian looked at the diagram. "I can read the words and see the tree but don't know what they represent," said Kurtis.

"Right, I said. "The tree and roots depict what I have gathered from my total experience; from the time I conceived my topic for the book until now. The tree represents our participation, and its roots are the meanings we find in it. When I talk about 'our' and 'we', I mean my collaborators and I, a group of nine people. I will dig the ground with you to look at the roots." 


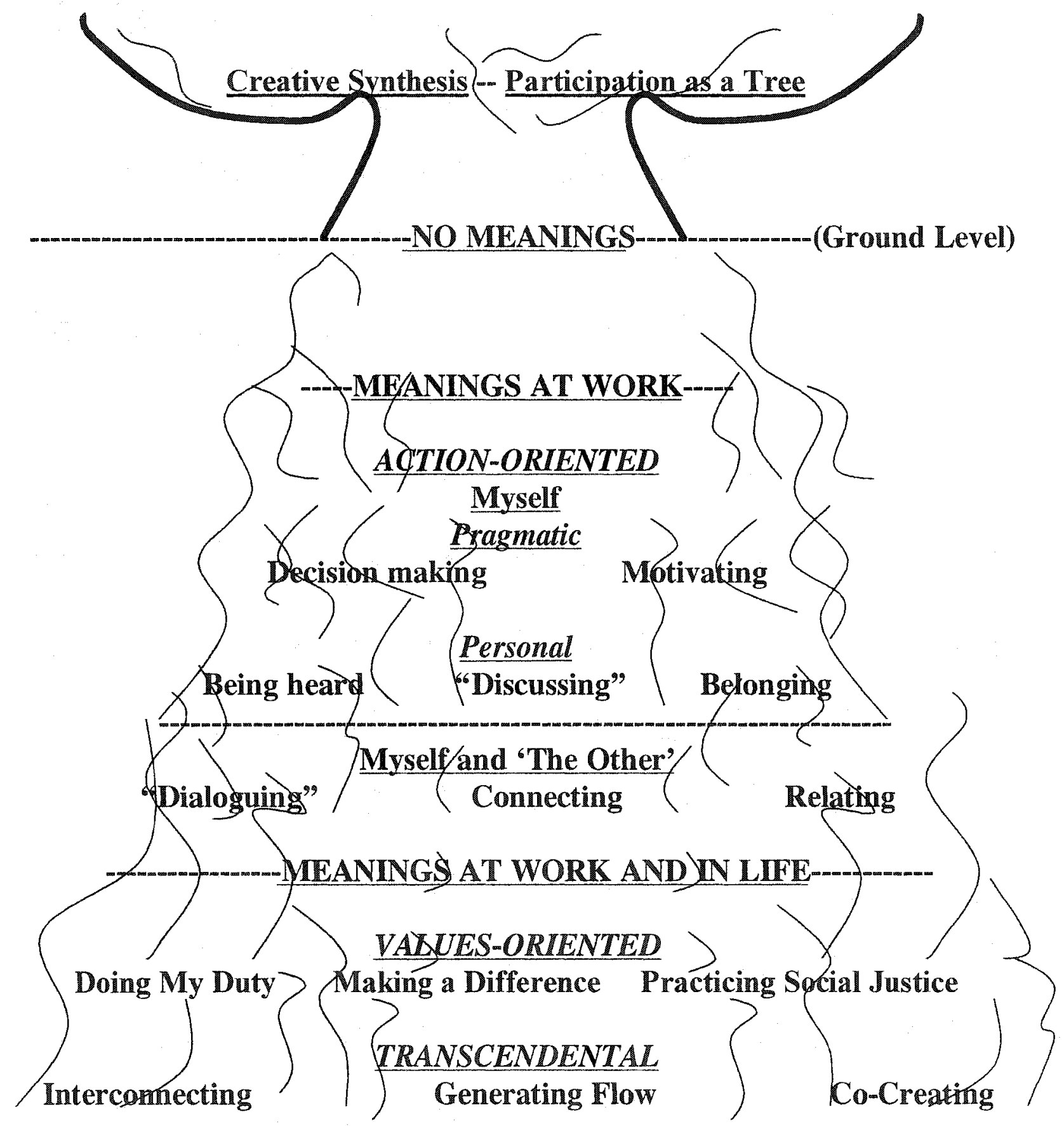


"Good. I like digging in the ground," said Kurtis.

I smiled, knowing he had experience planting fruit trees. "I don't claim to have covered all possible meanings of participation. I see it as a first approximation. Each one of us decides what participation means, it may vary from perceiving it as being meaningless to being very meaningful."

\section{The Three Rs}

I sipped my lukewarm coffee. "You may have three reactions to what I'll say: I call them the 'three Rs'. First is recognition: 'I have had a similar experience'. Second is resonance: 'I have not had that experience but I identify with it'. Third is revelation: 'This is a new experience. I intuitively understand it but don't know if I can have it'.

"Where did you get the three Rs?" asked Kurtis.

"From my interactions with my collaborators and some reflection. This is what happened when I heard some of my collaborators' stories. I would react in one of these three ways."

"And did they identify with yours?" asked Kurtis.

"When I shared my self-dialogue with them, some felt they recognized it, they had lived a similar experience. Others told me they found resonance what something I had read, although they had not articulated it."

"And how is revelation expressed?" asked Damian.

"You are surprised by what you hear-it is a stretch. This happened to me as I discovered depths of meaning of participation I had never felt or thought about before."

"So to you it was a combination of all three reactions," he said.

"Yes, it was. I will describe these 'discoveries' as we dig into the deeper roots."

"Maybe you found these new meanings of participation because you've been immersed in this process for a long time," said Kurtis. "We have not."

"That's a really good point," I replied. "I see the contribution of my book as sharing with the reader, and you, our dialogues and my reflections and experiences. I always imagined the reader was present, seeing and listening to everything we said as we engaged in the dialogues and I reflected upon them. He or she can also become immersed in the process, although probably not as deeply."

"So now you have a tree, your interpretation of your experiences," he said. 
"Yes," I replied. "I see this book as a point of departure for the readers. As they encounter our interactive conversations and dialogues, I hope they will discover their own meanings without immersing themselves in the topic to the extent that I did."

"Is your tree diagram a shortcut to the reflection process then?" asked Damian.

"Not really. I just think that the reader doesn't have to go to Mondragón for ten weeks to explore the meaning of participation."

"But you are presenting your book in a digested form," he insisted.

\section{Expanding Consciousness}

"I don't think so, at least not until now," I said. "My book requires and stimulates thought. The reader will have the opportunity to absorb what he or she reads and hopefully reach higher levels of awareness about the depth of meanings embedded in participation, as I, and I think my collaborators, did."

"You say you included your reflections. Can you tell us more about them? asked Kurtis.

"My reflections made me aware of deeper meanings of participation. I became more conscious of the significance it could have. I wrote them down, hoping to open avenues to expand the reader's consciousness."

"What if I don't identify with what you say?" he asked

"If someone had shown me this tree before I talked with my collaborators," I replied, "I wouldn't have perceived participation as I do now. There is 'stretch' in the tree diagram, as I understand should be in a creative synthesis. This is another way I hope my book contributes to the topic, expanding our horizons of what participation can be."

"You want the reader to be more aware of the meaning of participation," said Damian, "so he or she can identify with your tree."

"Yes, and there is a purpose to it. As you and I become more aware of the meaning of participation, we raise our consciousness level, hopefully to a point where we are willing to make a change, either within ourselves, at work, or in other areas in our life."

"How about if we talk about the roots of the tree?" asked Damian.

"The deeper the roots, the better," said Kurtis.

I smiled as I picked up the diagram from the table and leaned forward. "Indeed. The deeper the roots, the more meaningful participation is. I'd like to start with the levels of meaning we find in the roots of the tree. First," I said pointing to the tree diagram, "we 
can see the tree in terms of the scope of my participation. Meanings can be found at the workplace level or at work and in life."

"You grow from one level to the other?" asked Kurtis.

"Not necessarily. I learned that meanings could be found at several levels at the same time or at different times. Also, not every act of participating has a deep meaning."

"Okay."

"Meanings can also be found according to our orientation," I continued, pointing at the tree diagram again. "I may find meaning in actions I take, values I espouse, or transcendental perceptions I hold."

"Go on."

"And meanings can also be sought according to our personal perspective: Am I trying to find meaning only within myself or do I find enhanced meaning by including others?"

"That's the 'big picture' of your tree, huh?" said Damian.

"Yes, but now we can look at the details. Let's start at the ground level. Some may find no meaning in participation and then there is no tree... or roots."

"And that would be the end of the conversation, huh?" he retorted.

Kurtis smiled. "The first requirement is to want to have a tree."

"Yes," I said. "Many organizations, and some people, don't want to have a tree. I think that many people do not appreciate the significance of participation. This is where we, enlightened people that we are becoming, can help to change the paradigm."

"Ok," he added, smiling. "I feel motivated to do it."

I smiled too. "Let's proceed under the premise that you, Damian and I are willing to plant a tree. We want to explore participation but do not see its significance...yet."

I breathed deeply and pointed to the diagram. "I'll speak as if I am digging the ground myself. I will only elaborate when my interpretation of a 'meaning' is somewhat complex or you want to talk more about it."

"Fine," said Kurtis. 


\section{Action-Oriented Meanings}

"At the Action-Oriented layer, I may find meaning at the pragmatic level by participating, or inviting others to participate to get what I need or want. This could be an improved decision or motivating others to accept something I want to do. My dialogues with Noemi, Edurne and Rosario included some comments about this level of meanings."

"Sounds good to me!" said Damian.

I smiled. "I agree. But if we dig deeper, we may also find personal meaning when others listen to my opinion or I 'discuss' an issue with someone else to influence a decision."

“You mean 'discussion' as Senge interpreted it?" he asked.

"Can you tell us how he interpreted?" asked Kurtis, looking at Damian.

"A 'discussion' is a win-lose situation," he replied, "in which either my view or the other person's prevails. A 'dialogue' is a win-win situation--we build on each other's ideas and come up with something new."

"Got it," said Kurtis.

"Sometimes I might find meaning when I participate because I feel I belong to a group of people who also do," I added. "Rosario, Aitor and Evaristo talked about this."

"But it sounds like you are focusing on what is good for the other person (or me!) individually," he added.

"Indeed. I am assuming that I participate and have a reward. I think it's difficult to do anything if we don't expect to also benefit ourselves. I adhere to what I learned from Anthony de Mello ten years ago: everything I do freely benefits me at some level, or I won't do it. Thinking otherwise is an illusion."

"So it is all about me," said Damian. "What is in it for me, then?"

"It depends on my intention," I replied, ignoring his sarcasm. "Am I considering others as a means to an end, or do I understand their participation as an end in itself?"

"Means and ends?" asked Kurtis.

"Yes. I propose that we find meaning when I see persons as ends not means. I see participation as everyone's right, not only mine. More meaningful yet is if I listen to the other, as an equal to me, and dialogue in equal terms. Or if we consider he or she is not an opponent but that we belong to the same group. And, most of all, if I accept that his or her opinions may be at least as good as mine--and possibly better!" 
"Sounds good," he said. "Do you have an example?"

"Let's say that I'm a manager who wants to have a motivated team. I meet with an employee to listen to a personal complaint, not necessarily to make it go away but because I consider she has the right to be heard. I listen carefully, we discuss the issue, I agree her complaint is legitimate, and correct the problem. In this case, participation is an end: respecting her right to voice her complaint, and, if she is right, taking responsibility to correct what caused it. This improves the morale of my team."

"But I am still using her as a means," said Damian, "to have a motivated team."

"But also as an end--this is also my intention," I said. "Not 'either/or' but 'both/and'.

"But why is intention so important?" asked Kurtis.

"Because my intention, which only I know, determines if my action is ethical or not. Acting ethically deepens the meaning of my participation."

"Can you explain?" asked Damian.

"We can have the intention to benefit another person, 'the other', but also to benefit myself. In my example, I helped the employee with my corrective action to solve her problem and I helped myself by keeping a motivated team. We are both satisfied. This makes our joint participation more meaningful."

"You are talking about the next layer: 'Benefiting myself and the other'" said Kurtis.

"Yes, not discussing but dialoguing with 'the other'," I said.

"Right," said Damian, "we just talked about the difference between discussion and dialogue. No need to elaborate."

"You are probably right," I replied. "But, as you know, Senge is going into a deeper meaning of dialoguing. I'd like to talk about it."

"Okay, go on."

"According to Senge, 'dialogue' moves us from individual thought to collective action," I said as I picked up a book from my pile. "He cites Bohm, the scientist: 'If we participate in a pool of common thought, we will fall more into alignment when we act. It is not a linear process such as the traditional planning, organizing and controlling actions but a simultaneous process, participating and acting together in a non-linear way, as a jazz band does'."

"Okay, I know," said Damian, "dialogue is conducive to reaching insights not attainable 
individually."

"Right," I replied. "But listen to the rest: we fall in alignment when we act together simultaneously. I interpret this means that if we participate together we can come up with actions that contribute not only to what resonates with the participants in our group but with many others that are also tapping into the common pool of thought."

"As a jazz band does," added Kurtis.

"Well, yes," I said. "Jazz musicians play together respecting--and celebrating-- each other's 'voice', holding their place when it's their turn, dialoguing with each other, playing together at times. Just listen to Satchmo and Ella over the loudspeakers," I said, as Mimi's sound system was repeating St Louis Blues. "But jazz musicians can also dialogue with others musicians they have never met, having no music to read, and at times not knowing the melody being played. They are aligned according to a more universal rhythm."

"I don't know..." said Damian.

"Have you read a book called The Cultural Creatives?" I asked. "It talks about something similar."

"Tell us about it," said Kurtis.

"The authors surveyed 100,000 Americans in 13 years and found that there is a sizeable group of people who care deeply about ecology, relationships, peace, social justice, spirituality, and other 'counter-cultural' values. They write that many of the interviewees were surprised to find there were so many others that had the same values."

"How big is this group?" asked Damian.

"They estimated about 50 million," I replied. "But more than the size of the group, my point is that they seem to be tapping into this pool of collective thought that, according to the authors, is raising our consciousness to a level that will change the world."

There was no reaction to my comment. We paused for a moment. "What about connecting?" asked Kurtis, pointing to the diagram.

"Many times we are interested in participating with others because we want a connection," I said, pulling another book from my pile. "I have to refer to another reading." I opened the book up and paraphrased: "according to Fukuyama, "intimate talking' can only happen between human beings ... we often talk not to exchange information but to establish a connection with another."

"It's clear to me," he said, looking at Damian.. "And relating?" 
"Relating has a longer-term perspective", I replied. "The other and I might participate in some issues to build a relationship and find mutual support to dialogue about our ideas, not only now but in the future. We enter into a reciprocal relationship. Do you remember Martin Buber from the Ethics course?"

"I don't remember much about Buber's work," said Damian.

"Neither do I," added Kurtis. "Who was he?"

"A German philosopher," I replied. "Buber's book $I$ and Thou, as its name implies, is about relationships. His book clarified my perception of participation as relationship," I said, turning to the last pages in my notes and preparing to paraphrase Buber.

"Sometimes his language is hard to understand."

"Okay, tell us about Buber," said Damian.

I read in my notes: "The world of experience belongs to the I-It but the basic world I-You establishes the world of relation." Also: "I do not experience you, I am in relation with you." And "The purpose of relation is the relation itself-touching the You. If I stand in relation, I participate in a being that is neither a part of me or outside me. The more directly I touch You, the more perfect is my participation."

"I get the drift...more or less," he said, frowning.

"My relationship with you is a being, an entity in itself, it exists aside from you and me," said Kurtis.

I nodded and smiled. "Buber's words are translated of course and sound abstract but if we read them slowly, they make sense. We'll discuss other people that talk about living in a world of networks and relationships," I said. "Their language will be more concrete."

"It's still about my benefit but I include 'the other' who also benefits," insisted Damian. "It's still about 'what's in it for me'."

"Yes and no," I replied. "As I move my focus beyond myself and the other to the point that I cannot distinguish where I end and the other begins, I find meaning beyond either one of us. I think that's what Buber is referring to. At this level, it is not necessary to keep tabs on how much each participates in a decision, it is the act of being in relationship and deciding something together that counts."

"Is that what you found with your collaborators?" asked Kurtis.

"Not explicitly, but I sensed it in their language. All collaborators have had authority over others at work. To them, participating is not personal; it is something done in relationship. The sense of 'we' prevailed over the sense of ' $I$ '." 


\section{Value-Oriented Meanings}

"Great, so what is next?" asked Damian.

"If we dig deeper, we can find that meaningful participation can enhance meaning at work and in our life. We get into the Value-Oriented layer."

"Can you give us some examples?" asked Kurtis.

"Yes," I said. "Participation can be based on Kant's principle of duty.

"Oh, yes, I remember Kant from our Ethics class," said Damian. "We are good persons if we act according to what we perceive as our duty, just because we believe this is what we should do. The categorical imperative." He breathed in and raised his chest, as children do when they brag.

"Right on!" said Kurtis. I nodded emphatically.

"Here we go again," I said. "First we talked about intention, now about duty, both have ethical implications--and I think both contribute to meaningfulness. Jon spoke of the duty to participate as a commitment with the community. Aitor referred to the duty to participate because that is what is done when you belong to an organization based on participation. Both of them did what they thought they should do."

"Sounds good to me," said Damian. "And what about 'making a difference'?"

"We participate not only to benefit ourselves, "the other' or our group," I replied, "but also to leave a legacy, to make a mark of our passing through this world, to feel our life has a purpose. Evaristo expressed it as 'leaving our footprint'."

"That's a coincidence," said Kurtis. "I read in the Tribune last week that there is a group of businesspeople having breakfast together at the University of San Diego to talk about spirituality at work."

"Yes, I know about them."

He continued: "One of the guest speakers said that we gain a deeper perspective of the meaning of our work if we think about what we've done to improve our world for the next generation. I think he used the word legacy precisely."

"Yes, I read it too," I said. "I think he was in touch with the same feeling Evaristo was. I can leave a legacy when I participate to make the decisions that affect our work and/or our world. We don't do it alone though, we need to do it with others."

Damian looked at the tree diagram. "And what about practicing social justice? How is it related to participation?" 
"There is a branch of social justice called contributive justice," I said. "Human beings, just because they exist, have the right (and obligation!) to participate in all aspects of the society in which they live.

\section{"Examples?"}

"I'll give you a personal example. I was born and raised in Mexico, a country in which poverty is common. Sadly, I see that poverty is becoming more common in the United States too..."

"That's right, David," Kurtis said. "Shameful but true."

"... so contributive justice is relevant to us also," I finished my sentence as I looked at him. "It's easy to forget that the poor have needs beyond economics but are powerless to change their situation. As we become aware of contributive justice, we realize that it's not enough to give charity or find a job for powerless people to appease our conscience. They are whole persons, not different from us, that need to participate in the political, social and cultural aspects of society."

"So if we are "contributively' just," Kurtis grimaced as he tried to pronounce his made-up word, "with others less powerful than ourselves, we will find a deeper meaning in our life? Or is it them who will find meaning?"

I took a deep breath. "Let us take this argument closer to home and see what you think. This may surprise you, but according to contributive justice, we as employees in an organization are the powerless. We need contributive justice applied to us. Can I say I am treated justly in my work just because I have 'a job', a way to make a living? Contributive justice demands that we also have the opportunity to participate in other ways--in the decision making process, for example."

"You can't compare not being able to participate with being poor," said Damian.

"I know. Being powerless is usually seen as being low in the economic or organizational totem pole. But there are other ways of being powerless, although we don't want to recognize it. Charles Handy points out that when I feel I can't make a contribution, when I feel used, I will downgrade the importance of making that contribution as a way to justify that I am powerless to do it. Otherwise, I will feel cognitive dissonance. Thus, my powerlessness is perpetuated." I paused. "I think this is a great insight."

"Wait, wait," he intervened, "define cognitive dissonance for me."

"Cognitive dissonance is the disturbing tension that develops when I am aware of holding two inconsistent thoughts simultaneously," said Kurtis.

"How do you interpret this?" asked Damian. 
. "How about," I replied, " 'I know I have the right to participate in making decisions that affect me, but I pretend I don't care to participate in them because I also know I am not allowed to do it'. I avoid cognitive dissonance this way: 'I don't participate in making decisions but I don't really care to anyway', I say to myself."

"It makes sense," said Damian. "Do you think the readers will identify with that?"

"I don't know, but I hope so," I said, as I leaned forward and placed my elbows on the table. "My book explores the depths of meaning our participation can reach. I am proposing that participating in decision making can enhance meaning not only in our work but also in our life. I think it could, but the choice is always ours as managers, employees, owners or shareholders. You, I, and the readers can choose our future."

"Fair enough," said Kurtis.

\section{Transcendental Meanings}

We were silent for a moment. "I can see you have one more layer: transcendental meanings," Damian said. "What do you mean by transcendental?"

"I think it just means 'above and beyond'," said Kurtis.

"Yes, above or beyond common experience or thought," I echoed.

"And what is it about?" asked Damian.

"We are getting to the deepest ground," I said, "the more profound meanings. According to our tree metaphor, we are closer to the wellspring."

"Hey, I like that," said Kurtis.

I smiled. I knew he would like the analogy, having an orchard at his home.

"And where does your interpretation of these 'roots' come from?" asked Damian.

"From several sources: our dialogues, reactions to my self-dialogue, meditations, conversations with Padre Antonio (which you have not read), reflections, intuition, reading unrelated books... and then some."

"I've felt resonance with most things you have said so far but when you talked about 'stretch' earlier, I think you meant this level." Damian paused and smiled. "I am beginning to feel it as I look at your terms at the deepest level."

Kurtis smiled too. I joined them. "I know what you mean. As my collaborators said when I shared my self-dialogue, we're not used to expressing ourselves this way. Yet, this 
doesn't mean we don't have these deep feelings and thoughts. I've found that as we talk about transcendence, it is not as foreign to our experience as we think."

"Tell us more about it, but don't expect much feedback from me," said Damian.

I smiled again. "It's about becoming more aware of how meaningful participation can become in our work and our lives. This layer provides a vocabulary to express it."

"Go on."

I'll cover the concepts in the transcendental layer in general," I said. "I only intend to share with the reader an extrapolation of my experience and that of my collaborators, hoping to open an avenue for further exploration."

\section{Interconnecting}

"Okay," said Damian, looking at the diagram and then at me. "What can you tell us about interconnecting."

"I'll talk in greater lenght about this concept because it is closely related to the other two transcendental meanings. I'll go back to my study of year 2000 when I first had a glimpse of this way of looking at participation. My poetic transcription, using words from one of my collaborators in that study, expressed it this way:

Sometimes it seems

I am like a Siamese twin:

the pain of another

I feel just as much.

And at times I feel

It is like we're all

climbing a mountain

with only one rope.

We know very well

if one of us falls

down we all go.

These words spoke to me of connectedness, interdependence, solidarity... Later on I learned about Mundukide, the Mondragón-Basque government joint non-profit venture created to support projects in the poorer parts of the world, mainly Africa and South America. This, to me, is agape, or unconditional love, helping those we don't know, tapping into the interconnectedness of everyone and everything."

"I know what you mean," said Damian. "Are you familiar with the "non-locality" principle from quantum theory?" 
"Once an engineer always an engineer," said Kurtis.

"Hey, let me impress you for a while," said Damian in a joking tone of voice. "According to the physicist Fritjof Capra, whom we mentioned briefly in an earlier session, the nonlocality principle establishes that not only people but the whole universe is an interconnected web of relationships."

"What happened to Newtonian physics?" Kurtis asked. "We learned the universe was about 'things' not 'relationships'."

"Sorry Kurtis," he replied with a smile. "The non-locality principle has been proven experimentally with subatomic particles. By physicists Niels Bohr and John Bell, in fact."

"I am impressed," Kurtis replied. "You even know the names of the scientists."

"I like to read that stuff..." Damian said sheepishly.

"I come from a different perspective but also involving Capra," I said. "In The Tao of Physics, he relates modern physics to mystical traditions. Meditation, a pillar of mysticism, he writes, is now being taken more seriously, making it easier to understand the connection between science and spirituality."

"So what are the implications?" asked Kurtis.

I looked at him. "If we can conceive this interconnection in the universe of the physical and the metaphysical, we can appreciate our participation as affecting everybody and everything, whether we know it or not."

"Tell us more."

"Surely you have heard the saying: "A flutter of the wings of a butterfly in Tibet can create a hurricane in Hawaii'. If we sense this connection with others, we understand we participate with others too."

"We need each other, we are interdependent," said Kurtis.

"Right, it would be as Stephen Covey conceives it. Being interdependent means that I am independent as a person, that is, self-reliant and capable, but also aware that if 'the other' and I participate together, we can achieve more than I could alone."

"Yes, I remember Covey's words," he added. "I am dependent when I see the world in terms of you-you take care of me, it was your fault. I am independent when I am capable and I can make choices. I am interdependent when we can do things together, when we can create something greater together."

"And I am sure we can see the implications here," I added. "We need to be able to make 
our own choices before we can create together. Evaristo referred to the evolving process in participation, from following others' opinions when we are young, to thinking we are always right, to understanding we need each other."

"That's clear. Any other implications?" asked Damian.

"Yes. It follows that, if we are interconnected, it is also possible to have shared knowledge."

"Can you explain this?" asked Kurtis.

"Let me give you as an example my approach to writing this book. I selected the phenomenological-heuristic orientation because it focuses on individual experiences. Each one of my collaborators has extensive, unique participatory experiences, which we could not detect if we drew conclusions by grouping the majority of their experiences together."

"But that is shared knowledge, what you just told us," said Damian.

"Yes, to an extent, if you or I also shared the experience of the majority. But by exposing each individual voice to the reader, he or she may find resonance with any of the voices-not necessarily the majority or the collective voice of the group. This multiplies the possibility of tapping into shared knowledge."

"Good point," said Kurtis. "But can we learn from single experiences?"

"That is what Capra's statements imply, I think. We are tapping into a pool of collective knowledge that we are not aware of yet. We will unveil this knowledge according to our own experience. You and I could read the same book and understand it differently or I may read the same book now and a few years from now and understand it differently."

"Is this what you found?" asked Damian.

"Yes, but only after I looked for the meaning behind the words," I replied. "I realized I had lived some experiences I heard, I discovered some inner experiences I had lived but had not identified, and I became aware of others that were obvious only after I reflected on the words of my collaborators. I think this is where the three Rs I mentioned earlier came from."

"So you don't see your reflection process as one of finding something new?"

"I see it as a consciousness-raising process. I am re-living, recognizing or discovering meanings - I am becoming aware of meanings in my participatory experiences."

"And how does this relate to our conversation?" asked Kurtis. 
"I propose that I become aware of these experiences because they already exist in our collective experience. And my sharing this story and interpretation with the readers is because I believe they will find many of them to be true for them also."

"1 have to think about this," said Damian. "You have had some experience with participation. I have not had as much, so I can't say I find resonance with a lot of it."

"Okay,"I replied. "I see it like this: you may have lived fewer participation experiences and have more to become aware of than I have. That is, we have the same knowledge at the collective level, although not the same exposure to these experiences. As you or I experience participation more, we can find more resonance with the deeper meanings."

"But you have also have had more transcendental-type experiences with participation, as your self-dialogue proves it," he insisted.

"My daughter read my self-dialogue and pointed out that perhaps now I felt what I wrote but she questioned if I had felt it at the time I lived the experience. I think she was right. Today I am overlapping a spiritual perspective with a previous experience."

"What do you mean by a spiritual perspective?" asked Kurtis.

"I've been exposed to interconnectedness through Christian meditation."

"Can you elaborate?" he asked.

"I'll give you a capsule description," I said. "Thomas Keating, founder of Centering Prayer is one of the 'rescuers' of Christian meditation from the ancient tradition. He is a psychologist and a Trappist monk."

"Centering Prayer or Christian meditation?" asked Kurtis.

"Centering Prayer is the modern term, which is based on Christian meditation," I said. "Keating speaks of consciousness levels being raised as humanity evolves. Now most of us are at the 'mythic membership' level-over-identifying with our social group from which we derive security, pleasure and power. It is a world in which authoritarianism is accepted because we prefer to belong to and preserve our loyalty to the group, with its economic and social rules and regulations."

"And there are other levels?"

"Yes. Through meditation, it's possible to raise consciousness to the next level, the 'mental egoic'. At this state, there is a basic change of attitudes and worldview."

"What worldview?" asked Damian.

"Being one with others. Belonging to the universe and living by values congruent with it: 
a feeling of equality with other humans, preservation of the earth, harmony, respect for others, cooperation instead of competition, peace instead of war..."

"We are interconnected and thus are in harmony with others and the earth?" said Kurtis.

"It doesn't sound so esoteric, does it?" I asked, looking at Damian. "Is this such a 'stretch'? This is just common sense. And, as we learned from Capra, Bohr, Bell and the other quantum physicists, it is all about relationships and sharing a pool of knowledge. This view favors participation instead of isolation as the natural human state. There is resonance among the scientific, the spiritual and the practical realms."

"I still have my doubts that I will find that resonance," said Damian wistfully.

\section{Generating Flow}

We kept silent for a while. Kurtis looked at the diagram and said. "Okay, how about talking about the next one: What can you tell us about generating flow?"

"We mentioned it earlier but only briefly," said Damian, perking up. "Have you read the book about 'flow'? I have it here," he added, pointing to it.

"Yes, I have," said Kurtis, "and this is one abstract concept I find resonance with..."

"I bet you can't spell or pronounce the name of the author," said Damian, writing it on a piece of paper: Csikszentmihalyi. "It's pronounced CHICK-sent-mee-high-ee."

"I am impressed!" I exclaimed.

Kurtis looked at Damian. "Yeah, me too."

"Well, I refer to him by his first name, Mihaly," said Damian. "It's easier. It's pronounced almost as the end of his last name: mee-high-lee."

"Okay Damian, now tell us about flow," said Kurtis.

"Well, Mihaly's concept of flow is not expressed in terms of participation, but I think the way he refers to it is." Damian picked his book out of the pile. "Flow is 'a state of consciousness that keeps a person deeply involved in an activity that makes an experience enjoyable'. Your description of a meaningful experience of participation surely fits here."

"I remember he also speaks of 'flow' in terms of contentment and happiness," he added.

"And Mihaly also talked about a feeling of transcendence," I said.

"So you read it too?" said Damian, looking at me. 
"Yes," I said. "I became interested in this book after I did my self-dialogue. Mihaly spoke of experiencing 'flow' when we had a peak experience. He referred to being alert, acute, clever, aware, or something to that effect. When I did my self-dialogue, I was surprised of the feelings that came afloat. The sense of 'flow' overcame me, although I did not identify it at first. Three of my Mondragón collaborators confirmed that, in their opinion, my self-dialogue reflected a peak experience and then I confirmed my sense of flow."

"Mihaly also says that 'flow' enhances the quality of the experience," said Damian.

"I certainly feel that way," I said.

"The first time I heard about 'flow' was from Capra," he added. "According to him, Heraclitus, who lived in ancient Greece," he clarified as he looked up to us over his glasses, "said 'everything flows', meaning that the whole universe is in a state of flux."

"Was he way ahead of his times or are we behind?" asked Kurtis.

I shrugged. Although I felt we had fallen behind when we adopted the Cartesian way of perceiving persons as thinking beings only, and the world as a great machine, I preferred not to interrupt the 'flow' of the conversation.

Damian read from his book: "Systems thinking is always process thinking. It is the interactions not the structures that are processes in an open system. And open systems are in a state of flow"." He looked at us. "Capra said it."

I waited until I was sure he was finished. Then I said: "I mentioned earlier that spirituality and science are interconnected. I recently attended a conference by Richard Rohr, a Franciscan priest, founder of the Center for Action and Contemplation. I 'd like to read from the notes I took:

When there is communion, intimacy and connectedness, flow is created. Without them, there is no flow. We just have to allow the flow; we do not have to do much. This requires us to be vulnerable, though.

Participating in the flow is being in the dance, not doing but allowing. When we say 'yes', we allow the flow. When we say 'no', we stop it. It is hard to say yes... do not stop the flow!

What would happen if we, as leaders, allow ourselves to be the flow? Some of this flow will trickle down to others.

The ability to love is not my own doing; we need to allow the flow within us to love.

"They all sound like they are related to what we are saying," said Kurtis, "but with a spiritual perspective." 
"Yes, but what is the connection with participation and its meaning," asked Damian.

"Let's look at the vocabulary," I said. "Intimacy, connectedness, allowing, being the flow, trickling down to others. If we are all connected, I think it make sense to believe that participating together can create flow."

Damian did not reply. Kurtis broke the silence. "David, co-creating is also in your list."

\section{Co-Creating}

"Yes," I said. "Co-creating is either mentioned or implied in many of the dialogues I had with my collaborators. It is closely related to interconnected and flow so I will not repeat what we have already talked about. A few words will suffice. We can start with what we are doing now." I grinned and added, "I believe we are co-creating a new way of looking at participation in decision making."

"You and us?" asked Damian.

"Yes, my collaborators, the authors of the books you and I read, the readers of this book, you and me," I replied. "We are all connecting, participating and co-creating new perspectives of the meanings of participation."

"Is this what you mean when you mention it here?" he asked again.

"As long as we act with a good intention, I think that we co-create something good," I replied. "If my worldview, or should I say 'universe-view' includes any kind of larger entity than myself, I can find transcendent meaning in participating to co-create something better, in all aspects of life."

"Are you talking about God?" asked Kurtis

"It could be the cosmos, the natural world, the human race, my community, my clan, my family or any other concept I may have of something larger than myself. If I believe in God, and I do, I perceive my participation as a means to fulfill my purpose in life."

I paused. "Briefly stated," I added, "this is where I find the deepest meaning of participating: creating a better world with and for others for the common good."

"I can identify with that," he said.

We were silent for a moment. Damian looked at his watch and we reflexively did too. It was time to go. I said: "I appreciate your sharing this part of the book with me. I know you've told me we'll meet until I am finished but I don't want to overdo it. How about if we stop now and wait until the next session to wrap it up? It should not take long." 
Kurtis looked at me and said: "Fine, but I have one more question: you have described the tree and its roots, what else is needed for the tree to grow and bear fruit?"

I looked back at him. He had a mischievous look in his eyes. "Kurtis," I said, "you are asking this because you have thought of something already, what is it?"

"Of course!" he replied, laughing. "You will have no tree if you have not prepared the ground. You need the correct amount of fertilizer, chemicals, water..."

"And if you give the soil continuous care," added Damian, "the roots will grow deeper."

"This is great!" I exclaimed. "Either you are good farmers or you are humoring me to no end," I added facetiously.

"My point is," said Kurtis, suddenly turning serious, "that we need to talk more about implications related to preparing the ground for the tree to grow."

"Hey," I protested. "My topic is the meanings of participation, that is, the roots, what are you talking about?"

"What if I read your book, I agree with you that there are significant meanings in participation that I'd like to experience but I don't know what where to start or how to go about it?" he insisted.

"So what do you suggest?"

"I think we could explore the personal implications for your reader, or for Damian, or for me, for example." Kurtis looked at me and then at Damian.

"Hey," added Damian, "I think you have a good point. And how about something practical too?"

"Such as?" I asked somewhat bewildered.

"Well, let's talk about my situation. It's not all about me. I may want to become more participatory personally but what about 'the others', my people? I am a leader in my company. Let's say I read your book and want to change to a participatory organization. What do I do? You said you need to have support systems, as the people you interviewed in Mondragón."

"I think I would be getting off my topic," I said.

"David, look," said Kurtis, "I know you believe in participation at the workplace. You need to help the reader. At least you can talk about first steps."

"Yes," Damian said, "the reader can consult other books later." 
I paused for a moment to think.

Kurtis did not give me much of a chance. He said: "I agree that you could write your book about experiences and meanings. But I think you will help practitioners if you at least discuss some of the issues of implementation. It would be a more comprehensive book."

"David," Damian added, "we have not talked about this before, yet Kurtis and I are thinking the same thing. I am sure you'll agree that we have tapped into the common pool of knowledge," he stopped and looked at me, smiling, "and have concluded your book should include implications related to the meanings of participation."

I laughed and they laughed after me. "Okay," I said, in a resigned tone of voice, as indicating I was giving up but actually realizing they had a point. "Next time we will talk about implications for persons and leaders. This will be a long session then. I hope that, just as you are helping me to extend my topic (by a lot!), you'll help me to develop it."

Kurtis nodded as he picked up his books and notes. Damian said: "I will bring my books and my questions, you know how much I like to challenge you."

I looked at him. He had a Machiavellian smile. I replied: "Yes, I know, and I welcome your challenges!"

We stood up and walked towards the exit, amidst a cluster of early diners. We agreed to meet again on May $15^{\text {th }}$ and said goodbye at the parking lot.

I got into the car and drove away. I pondered: How did this gradual discernment process to write a creative synthesis in the form of a tree come about? I entered this study with a clear objective--to gain a better grasp of the significance of participation at the workplace. As I completed my self-dialogue, I began to understand that the experience of participation was more complex and multi-layered than I had originally envisioned. I realized that by allowing my mind, emotions and spirit to come into my study, I was able to reframe participation beyond finding a concrete meaning, perceiving it instead as a multidimensional experience. I "saw" the diverse depths of meaning and conceived the tree and the roots that I was just talking about with Kurtis and Damian. I "saw" the possibility to plunge into these depths and realized that the meanings of participation could not be reduced to a static set of defined terms. Instead, they were a dynamic, complex set of interrelated expressions of the experience that were described in multiple ways by my collaborators and me. These were helpful insights.

But for now, I had to start thinking about the implications of what I had learned... 


\section{CHAPTER 12}

\section{IMPLICATIONS}

On Saturday, May $15^{\text {th }}$, Damian, Kurtis and I met at Mimi's Café again. Being at the same table, with a pile of books and notebooks on the side, coffee, tea, and even the same waiter, was a surrealistic experience. I felt I had not left the restaurant since last time we were here. I was eager to share what I had written so far

Kurtis seemed to sense my restlessness, looked at his notes and then at me. "You have told us about the outcomes from the data analysis process, the context, the creative synthesis, and other outcomes. I suppose now you are ready to share your thoughts about the implications of participation, as we agreed last time we met."

"You miss no opportunity to challenge me, do you?"

"Yes, it reminds me of you when I was doing my dissertation," he said.

"I had forgotten that," I said, laughing. "But I'm telling you, if I had known you would be so well prepared to ask me the hard questions, I'd have probably been less inquisitive."

We all laughed.

\section{Participation and Abuse in Organizations}

Damian shifted position on his chair. "How about if we talk about the implications of your study as they relate to the still very timely news that triggered the beginning of your book? How do you see participation and the corporate scandals now?"

I looked at Damian. "You really want to talk about the scandals, huh?"

He nodded. "You bet."

"Fine, let's recap what we discussed a few months ago," I said. "The consequences are clear: Because broad participation of those affected by the decisions made was absent in the organizations that have shown irregularities, thousands of stakeholders--that is, employees, investors and many others in their communities-- have been severely harmed."

"But we already know that this is being corrected," said Damian. "Look at how many of the big shots are on trial or jail now."

"That's not the point," I replied. "The risk to continue having these abuses in organizations is high if we insist on merely changing a few systems and controls but essentially doing the same things. Daniel Quinn's phrase is quite appropriate here: 'If it didn't work last year, let's do more of it this year!" 
"Seems like the best we can do," he insisted.

"Look, checks and balances from government regulations, accounting firms, and Wall Street analysts failed to prevent abuse."

"But the rash of scandals seems to be over," Damian retorted.

"Not really. More major irregularities have been found, now in European organizations. Parlamat's apparent fraud and Shell's overstatement of oil reserves are being investigated. How many big shots have to go on trial to prevent abuses?"

"I think the right question is: Why do we have abuses?" asked Kurtis.

"The opportunity to cheat is embedded in the organizational structures that prevent stakeholder participation in decision making," I said. "This time it was greed, lying to keep stocks rising, or using funds for personal loans. These incentives are not going away and there may be new ones in the future."

Damian leaned back on his chair, interlocking his fingers behind his head. "I still think that the corrective measures will take care of the problem."

"I don't agree," I replied, leaning forward. "Let's face it. These measures may provide a palliative but we need to examine, and if necessary disassemble and rebuild our organizational structures."

"Why?"

"There is a common denominator in these irregularities: people in positions of power made unilateral decisions. There is consequently a need for broader participation of those who are affected by the decisions made--employees and other shareholders for example..."

"How would this help?"

"Managers would have to share relevant information for stakeholders to participate in the decision making process," I replied. "Available information and stakeholders' involvement could have prevented irregularities."

"I can see your point," said Kurtis. "You are saying broader participation is desirable."

"The discussion about broader participation in decision making to prevent abuses could be expanded considerably," I said, looking at Damian. "However, although closely related to my book, my main topic is the meaning we find in participating."

"You are talking about meaning... What do you mean?" said Damian, obviously enjoying 
his pun.

I laughed. "Let me relate it to what we are talking about," I said as I leaned forward and looked at both of them. "In my view, unhealthy organizations require participation to correct existing abuse, healthy organizations to prevent future abuse, but all organizations need it to help people find meaning in their work now and in the future."

"Is there a connection between the need to change the way organizations make decisions and the implications we'll be talking about?" asked Kurtis.

"Yes, I think so," I replied. "To effect this change, we need to look at two roles we play at our workplaces: being persons and being leaders."

"Fine, so where can we get started?"

\section{Personal}

"We could begin with personal implications," I replied.

"What do you mean by 'personal'?" asked Damian.

"These are things we should be aware of and actions we can take personally if we want to experience participation in ever deeper ways. I see them as continuums from the ground surface to the deepest roots," I said, staying with the tree metaphor.

"Okay, let's hear it," said Kurtis.

"I'd like to talk about three of these personal implications..."

"Where are these implications coming from?" Damian asked

"From patterns in the dialogues, reflections, context, readings, everywhere. They are not explicitly identified anywhere but can be discerned if we read the dialogues carefully.

Some are more obvious than others."

"And they are...?" he asked again.

"Experience, involvement and congruence," I replied. "We can begin with experience."

\section{Experience}

"We dig deeper as we have more experience," said Kurtis

"Yes, the appreciation of the significance of participation evolves," I added.

"Seems pretty logical," said Damian. 
"Right, but I don't see it as a straight-line evolution towards experiencing deeper meanings."

"How is it then?" asked Kurtis.

"As I interpret the comments from my collaborators, experience is not only related to age or seniority, and this is why I singled it out."

"Tell us more," said Damian.

"We need to look at the quality of our experience too. It's not only years of practice but also personal growth."

"Okay," said Damian. "Where do we start?"

"Let's talk about the relationship between experience and personal growth," I replied. "My collaborators talked about learning to participate according to the work they've done, the councils they've worked in, whom they encountered along the way, support from mentors, and, most importantly, the desire to participate. All these experiences promoted personal growth."

"So what are the implications of "experience'?" asked Kurtis.

"You are ready to jump in, huh?" I said, smiling. "Experience at an early age seems to favor finding meaning in participating earlier in life. Four of my collaborators, two men and two women, had this type of experience. If this experience is not available, the cooperatives are a fertile ground to learn, as happened with the other four. But in all cases they had to grow to be mature participators."

"I see," said Kurtis.

"Meaningful participation seems to require a process of evolution," I continued. "The awareness of the significance of participation may be gradual, or it may strike us as lightning -- as could happen by reading a book like this and having an 'aha moment'. This would be a solid step that can accelerate the process."

"But you say it's only a step," said Damian.

"Knowing how to participate meaningfully does not happen at once, even if I desire to engage in it," I replied. "I heard it from my collaborators-Sergio mentioned learning to listen, Evaristo talked about balancing the other's participation with yours, Lorea designed strategies to participate."

"More implications for education and training," said Damian. 
"Yes," I replied, "but also for making a conscious personal decision to participate as often and as fully as possible, in order to mature as a participator."

"So finding the depth of meaning that participation is capable of giving our work and our lives depends on personal growth, education and practice," said Kurtis.

"Precisely. It's a growth process."

"Participating meaningfully is not a 'quick fix'," Kurtis continued. "I hear you say that it can't be learned or taught in an intensive course.".

"Probably not," I said, "but I think the seed can be planted in such a course. Becoming aware of the depth of meaning that can be attained is very important. This is the lesson I learned. I became aware of depths I had not conceived before. I think this realization brought the tree image to my mind."

"Can we talk about specific examples?" asked Damian.

"My collaborators invariably spoke of the first stages as being at a shallow level: seeking better decisions, participating because others did, supporting policies from the organization or ideas of more experienced members of the group, and so on. Noemi, who is the youngest collaborator, confirmed some of these ways of participating by expressing her behavior in the management council in these terms."

"But what about those who had previous experience with participation?" asked Kurtis.

"It did not seem to make a difference. The beginning stage of participating in a group was equally awkward to all."

"This is a lesson to learn in itself," he added.

Damian leaned forward. "And what happened later in the process?"

"Most identified participation with personal needs and values: having their voices heard, influencing decisions, including 'the other'. Also terms such as 'trust', 'relationships' and 'balanced decision making' appeared."

"And the most experienced?" he asked again.

"Those with 40 years experience or more added humility to other values. They also had more questions about their role as models, teachers or leaders in participation. They talked not only about the right but the responsibility to participate, not always being right, the need to listen..."

"Any other insights?" continued Damian. 
"They also used terms pointing more towards transcendent meanings such as "considering the other as worthy as yourself", "creating sacred spaces for all to participate', 'co-creating'..."

"So everyone matured at the same pace," he said.

"Yes and no. If you read the dialogues carefully, you'll find that there are differences in the appreciation of the meaning of participating even among those of the same age. The language each one uses is different. Not everyone matures at the same rate or to the same level."

"No hope for me then," joked Damian.

We all laughed.

"But if I am experienced and mature, I can find more meaning as I participate," said Kurtis.

"It depends. We can carry our experience from one group to another but still have to learn to participate in each. Group dynamics vary. Trust, credibility and relationships need to be built to participate meaningfully. This was Lorea's point, everyone is a beginner in a new group."

"It looks like you never finish learning to participate," said Damian.

"Right," I replied. "It's a process not a project."

"Implications?" asked Kurtis

"We can learn precisely from knowing it's a process. We can reflect upon the meanings we find in participation, we can strive to gain experience with humility."

“Any other helpful tidbits?" asked Damian.

"We need equilibrio, or balance," I said. "As we learn that there is a middle path, as Plato, Buddha or Arizmendiarrieta would say with different words..."

"... in which balance is achieved among the interests of all parties," added Kurtis.

"Exactly," I replied. "Also, we need to trust others. To participate in decision making, I need to assume that others have intentions as honorable as mine to reach a decision that is best for everyone. And I need the capacity to listen with my whole being, because the other is as worthy as myself..." 


\section{$\underline{\text { Involvement }}$}

"I think that gives us a pretty good idea," said Damian, nodding at Kurtis, who tacitly agreed. "What can you tell us about involvement? Do you have any examples?"

"I'll give you a comparison based on the dialogues with my collaborators. When I participate by listening intently to form my own opinion, speak up in a large group, or vote, I am involved at a low level."

"What do you mean low level? Is that what they said?" asked Damian.

"These are my words, not theirs. At this level, I participate by myself, the effort involved is relatively low."

"As compared to what? You are participating," he protested.

"True, and this is better than not doing it at all. However, there are other ways to participate. My involvement is at a higher level when I participate with others."

"What makes it a higher level?"

"Our involvement is more intense when we are in groups in which all voices are heard, there is influence flowing in all directions, and a decision we do not necessarily agree with but we all accept is attained. This is participation at a higher level," I replied.

"You are making decisions with 'the other"," said Kurtis.

"Yes," I said, "and my commitment is higher because this process requires preparing, articulating and debating my point of view, listening, negotiating and perhaps capitulating. This is a more meaningful experience."

"We are also building a relationship," he added, "the other and I."

"Right," I said "and your comment brings us to another aspect of the intensity of involvement: frequency. There is a difference between occasional and continuous participation. We can participate in a random event occasionally with the other..."

"This is still good, you are participating," insisted Damian, "and it could be at a high level."

"I agree it is good," I replied, thinking he understood what I was saying but wanted to challenge me. "But, as mentioned by Kurtis, the experience is more meaningful when it promotes a relationship with others in a group, be it a family, a team or a community. These relationships are common among my collaborators because they participate together often." 
"And I guess we could do the same," said Damian. "Her, his, your and my participation can construct meaning together."

"Like laying bricks for a building, one at a time, slowly but steadily," said Kurtis. He looked at Damian and me and said: "I love metaphors."

Damian seemed unimpressed. "And does my desire to get involved increase as I gain experience?"

"Hopefully," I replied.

"But not for sure?" asked Kurtis. "The more you have experienced participation, the better you'd feel about getting involved."

"Yes, I agree, but unfortunately it does not always work that way," I said. "Surely you have heard of the difference between a person that has twenty years of experience and the one that has one-year experience twenty times over."

"I get it. That image is quite graphic, I had not heard it before," he said.

"If I don't find meaning when I participate," I said, "I may not engage in it at deeper levels. I may stay at the passive or pragmatic level, the shallow roots in my tree, probably throughout my whole life."

"Okay, that's clear," continued Kurtis. "I suppose involvement affects everything we do..."

"I think so," I said. "Let's look at an example from politics. We've said there is a difference between participating alone or with others. The difference is also in the impact on the final decision. For example, I participate alone when I vote..."

Damian intervened: "David, voting is good."

"Yes, I don't mean to say it isn't," I replied. "But my and the other's involvement, commitment and impact on the final decision is much lower than if we participate, for example, in a political debate at the local town-hall meeting. In this case, I can influence or be influenced on a decision. Involvement, commitment, influence-these terms are related to enhanced meaning."

Kurtis looked at me and frowned. "I suppose this is why people like Ross Perot and Ralph Nader have appeared as candidates to be President of the United States."

"Maybe," said Damian. "I remember the hoopla when Perot appeared on TV in the presidential debate." 
"Yes," Kurtis said as he looked at Damian. "He and Nader knew they weren't going to win, but they had a chance to voice their opinions in the media. Perot had the chance to participate in a televised debate on an equal basis with the candidates that would win. His influence increased, his participation became more meaningful."

I just smiled. I didn't want to talk any more about politics at this time.

\section{Congruence}

We were silent for a moment. Damian and Kurtis checked their notes. "Can we talk about congruence now?" asked Kurtis.

Congruence?" asked Damian. "How do you describe it?"

"I see it as resonance or harmony," I said.

"Being concordant or agreeable." said Kurtis.

"Consistency," added Damian.

"Good, shall we move on?" I asked, pretending to be impatient, as Damian usually did.

He just looked at me...

I continued: "Congruence probably has the most implications for us. It's related to many of the meanings I have identified in the roots of the tree. I know you will recognize them."

"It looks like it connects many of them," said Kurtis, looking at the diagram.

"Not only that," I replied. "It's also interesting because it has implications that connect participation, work and life."

"Okay, David," said Damian. "Tell us what you mean."

"We already talked about Jon, Lorea, Aitor, Edurne and Evaristo participating in their professional and personal life, in their organizations and their communities. Participation was more a way to be than a selective activity to do."

"Yes, but I still find it difficult to see participation as a way to be," said Kurtis.

"I know," I replied, "but my collaborators convinced me it can be a way to be. If I see myself as a participant in life, everything I do I perceive in those terms. I have what I'd call internal congruence."

"Examples?" he continued. 
"My collaborators participate with colleagues at work, members of the family, or friends. It would be incongruent to participate at work but not allow family members to participate at home or not participate in decisions about raising the children. Similarly, dominating others or staying aloof in other relationships or life activities is not congruent with participating at work."

"Congruence can also be applied to being consistent in what I say and what I do," said Damian.

" 'Walk the talk', as the phrase goes," added Kurtis.

"That's right. There's also what I call external congruence. I think that when we have a sense of congruence in our life, we become sensitive to what is incongruous around us. Edurne and Aitor talked about the lack of organizational congruence between participatory Mondragón workplaces at home and non-participatory ones abroad."

"I get your point," said Damian. "What are the implications for me? I don't work in Mondragón."

"In our free society, I can choose to participate in many aspects of my life: within my family; my church, synagogue, temple or mosque; my local neighborhood association; charitable organizations or political groups."

"Yes, I am free to participate or not," he said. "This is good."

"It's quite clear. I think we seek congruence intuitively," added Kurtis.

"My perspective is different," I said. "I think we are 'programmed' to live compartmentalized lives. How can I be congruent in the way I participate if I live a disconnected life?"

"What do you mean?" asked Damian, leaning forward and looking directly at me.

I shuffled my books and found The Turning Point by Capra. "You like Capra's work and so do I. Let me read what he says about this topic. I opened the book on a marked page and read:

We need a fundamental change of our worldview, a cultural transformation. The mechanistic worldview described in the seventeenth century is fragmented, separating the mind from the body and dividing the world into separate building blocks. The new view is holistic, emphasizing the interdependence of all phenomena and the dynamic, everchanging nature of reality. The organization of the future will face a crisis if it can not adapt to a systems view, as part of a large context of society and the world.

"Do you have any examples?" asked Kurtis. 
"Let me tell you a personal story," I said, glancing at Kurtis and Damian.

"I grew up in a family with a stay-at-home mom and a work-all-day dad. When I misbehaved, my mother would say: "I will tell your father what you did when he comes home and he will punish you." There was a disconnection between my mom who saw my behavior and my dad who punished me. When I went to school and I did something the teacher did not like, he said: "I am sending you to the principal, he will decide what to do with you." Same story, same disconnection.

"When I started to work in the 1960s, I was told: "You are responsible for manufacturing, you make sure the scheduled goods are produced. Quality control inspectors are responsible for quality, not you. If you have a problem with a worker, send him to the Personnel manager, he will punish him..." I lived a compartmentalized life and so did everyone else.

"I had been 'programmed' my whole life to live a fragmented life- -at home, school and work. It took me a decade to understand that if I wanted employees to live whole lives, it was necessary to help them to integrate what they did. This is obvious to me now, but then it was not.

"When I became Vice President of Operations in the 1970s, I changed the system: the supervisor responsible for manufacturing became also responsible for product quality and for handling personnel issues. Authority, responsibility and accountability were integrated.

"By the time I was an international VP in the 1980s, I had colleagues with congruent authority, responsibility and accountability. It was with these people that I was able to have the most meaningful experiences of participation. They are the ones I mentioned when I wrote my self-dialogue."

"Interesting story," said Kurtis, "and it illustrates your point. We need to integrate activities at work if we want to have congruence. I suppose this integration includes participating in making decisions?"

"Yes, of course, but my collaborators stretched me further. Their stories showed me that to participate meaningfully, I need congruence at work and in life. If not, I will suffer the consequences, sometimes not even knowing why..."

"So," interrupted Damian, "is it about balance or congruence?"

"That's such an interesting question," I said. "I wrestle with living a balanced life myself." I pulled a magazine from my pile of books. "I just received the Spring 2004 copy of The Journal of Leadership from Harvard with an article about balance. It's from Charles Handy."

"Oh, yes, Charles Handy," said Kurtis. "One of your favorites." 
I smiled. "The article is appropriately titled: How business squeezes the meaning out of work." I opened the magazine and read a caption in big letters: "Work-life balance: a sad phrase that implies that work and life are separate things." I turned the magazine around and placed the article on the table for Kurtis and Damian to see.

Kurtis leaned over to read it. 'I see words such as 'dislocation', 'disconnection', 'isolation', 'alienation' to describe the way we work and live today," he said after a while.

"We wear different clothes, behave differently, are almost different people once we enter our workplace," read Damian.

Kurtis looked up. "Cognitive dissonance."

"Precisely," I replied.

"Can you give us an example?" asked Damian.

"I am glad you asked," I replied, smiling. "The most blatant example is the fragmentation between the way we live, according to strong values of freedom and democracy, and the way we work..."

"Can you elaborate?" he asked again.

"We say that democracy is the best way to live, and condemn totalitarianism, fascism and others 'isms' because they are oppressive, undemocratic systems."

Damian intervened: "I am sure you agree this is true."

"Very much indeed!" I exclaimed. "In a democracy, we live as free persons, have the right to speak up, dissent, we vote for our leaders. We can make our leaders accountable for their decisions."

"I know where you are going," said Kurtis.

"It's obvious, huh?" I said, as I looked at him and then Damian. "Democracy is a wonderful system. But what happens at work? We are expected to behave as if we lived, in an authoritarian regime. We do not participate in decision making and are not free to disagree with the boss, at least not publicly. If we do, we risk adverse consequences."

"What is the difference between authoritarianism and totalitarianism?" asked Damian.

"It's a matter of degree. Authoritarianism favors subjection to authority as opposed to individual freedom. Totalitarianism controls the freedom, will and thought of others -- it refers mostly to governments." 
"Sometimes I feel I am in a totalitarian regime," said Kurtis.

I smiled wryly. Damian said: "Yes, company executives often exert their authority with a heavy hand but at least they are accountable for their decisions. We have shareholders..."

"Shareholders?" I interrupted. "They can't do much and neither can we. As Enron and others attest, we as employees are very important stakeholders but we do not have the power to hold our leaders accountable."

"Okay, granted," said Damian, "but this is being corrected now."

I did not want to get into this argument again. I said: "The deeper question is: does democracy outside of work and authoritarianism at work reflect congruence in my life?"

"Okay, David," he said lifting his hands in front of him apparently agreeing tacitly and indicating he did not want to talk about this issue anymore.

Kurtis intervened: "Let me give you another example of lack of congruence: How about saying you will govern as a compassionate conservative and then eliminating programs to help the poor, cutting veteran's benefits..."

"Hey, it's probably better if we leave politics out of our discussion," I said, realizing I had opened Pandora's box when I mentioned freedom and democracy.

"Okay then," he continued, "let's talk about examples from business. What about top managers with an income one thousand times higher than those of the lowest paid worker? Is that congruous?"

"Or going to church on Sunday, and verbally abusing your employees if they don't agree with you on Monday?" I added.

"Or heading charity drives and negotiating a labor contract that keeps workers at below living wage levels?" retorted Damian, entering into the brainstorming dynamic.

I nodded. "We can see examples everywhere, once we realize the inconsistencies of who we are and what we do," I said. "Now let's look a bit deeper. I think many of us have not reflected on the consequences of being incongruous."

"I know you have something earth-shaking to tell us," he said mockingly.

"You are right!" I said grinning and looking at him and Kurtis, who was also smiling.

I paused and adopted a serious tone. "Let me try to connect the dots. I suggest that a lack of participation deprives us from the opportunity to instill meaning in decision making at work. This in turn contributes to our loss of meaning in our work, as we feel used and 
with no say in decisions that affect us. Since most of our lives, and often our identities, revolve around work, this in turn results in loss of meaning in our lives. This is a chain reaction: our sense of meaninglessness grows until it permeates all areas of our life."

"Whoa, whoa, whoa!" Damian said, leaning back on his chair dramatically and uncharacteristically raising his hands above his head, as if I had said something outrageous. Kurtis stayed quiet but seemed perplexed.

"Yes," I said. "There is more concern nowadays about the loss of meaning. I just showed you Handy's article fresh out of the Harvard press. It is the rage. Showing concern now may be new but feeling like there is no meaning at our work and our life has been with us for some time."

"Can we go back to your definition of 'meaning'?" said Kurtis calmly.

"Yes," I said as I paged through my notes. "Meanings are inherent in a particular worldview, an individual life, and the connections between self, other, and the world."

"What do you think about that definition?" he asked Damian, but I felt he was asking both of us.

"I have to think about it," he replied.

"David?"

"If we accept this definition as appropriate, I'd say that this is what we are talking about here. We seem to have a particular world view, based on a fragmented life, and we have no strong 'connections between self, other and the world'. I read that we need to be connected and congruent."

"I have to think about it some more too," replied Kurtis.

"Fair enough," I said. "You are the readers of my book. I only have part of the truth, you have yours."

Damian looked at his watch and said: "I need to make a phone call," can we take a break?

"Sure," I said. "We all need a stretch." Damian and Kurtis walked out of the restaurant. I stayed inside to recollect my thoughts. I could hear some voices far away but there was practically nobody close to our table. It was that time between lunch and dinner when the coming-and-going of the servers and the clatter of the dishes stop. I got up and walked to the window. 
Could we really separate these implications neatly? There were patterns, similarities, contradictions, overlaps--it was difficult to speak of one without including the others: experience, intensity, congruence, they all were closely related. Yet, I concluded it was possible to conceive these complex interrelations as separate but joined at the trunk, by representing them as the tree and its roots. It looked like it was clear enough to Damian and Kurtis as they seemed to agree there were distinct meanings at different depths hidden below the surface of the experience of participation. Thinking through the implications to cultivate the ground for the tree has helped me to gain new insights. I wondered if it would be as clear to my readers, and especially if they would be willing to make a change in their lives to join me in the quest for meaning through participating in making decisions relevant to them...

\section{Leadership}

"Okay," said Damian, pretending to be serious. "Time for my questions."

Kurtis and I smiled. Damian continued: "David," he said, looking at his notes. "We've talked about the tree and personal implications connected with experience, involvement and congruence. Now let's assume that $I$, as a leader, have accepted the need to change to a participatory organization."

"Good!" I said.

"We'll go from having no tree to having a wonderfully grown and healthy tree that will provide shade for everyone," said Kurtis. "And fruit," he added, "once it's mature."

"Okay, okay," said Damian. "Let's go back to my being a leader who wants to change things. What are the implications for leadership?"”

"Fine, translating what you just said to the metaphor of the tree, the change would be from participation being perceived as meaningless (at the ground level) to understanding how meaningful it can be (with a strong tree and deep roots)."

"Fine, I have accepted the change to 'meaningful participation'," he said, modulating the last two words very carefully. "How can $I$, as a leader, promote participation in my organization?" he insisted.

"Let us begin," I replied, "with implications for leadership. From now on, I'11 talk about what I would suggest, based on what I've learned from writing this book and from my own experience. Kurtis, you and other readers may disagree."

"Okay," said Damian. "Let's assume you are the teacher, I am the student."

I looked at my notes. "Okay student," I replied. "You need to prepare yourself and your 
people to experience meaningful participation, and you need to create an environment that is conducive to this experience."

"Agreed. What do I need to do specifically?" he said, simulating an obedient tone.

"There are two major factors that require your attention: education and providing a suitable environment to effect change."

\section{Education}

"Fine, teacher," said Kurtis, humoring Damian. "What about education?"

"Welcome to the class," I said, smiling. "What I learned from my collaborators is that education, or rather formation, needs to include three elements: being informed about the issues, holding participatory values, and developing participatory skills."

"And the opportunity to practice?" asked Kurtis.

"Yes, that would also be very helpful."

"In a classroom?" asked Damian. "Like doing group work?"

"If we listen to my collaborators, we hear that all three elements can be learned when we are children, in a family environment. We first teach our children to participate (or not!) when we interact with them as adults. Lorea talked about her experience with children and her conviction that wanting to participate is innate, a desire often taken away as we educate our children."

"Children are to be seen not heard?" asked Damian rhetorically.

"It'd be difficult to get either values, skills or practice if you think participating is not good," said Kurtis.

"Right. Evaristo talked about his grandfather and father modeling participation and nonparticipation. Edurne and Lorea said their parents encouraged them to participate. And so on."

"What about at school?" he asked.

"Most of my collaborators attended schools in which participation was not customary. Rosario and Lorea talked about progressive schools today that teach children that their participation is important and ask them to learn in groups."

"So schools can teach values and help develop skills," he said.

"Yes," I said. "Children, as much as adults, need to know enough about the decisions 
they participate in to feel competent when they do it. And schools can provide a safe environment to practice."

"And what happens to those who didn't learn to participate in the family or school?" asked Damian.

"Most collaborators agreed that we can learn to participate. Of course, especially in our culture, we can also learn to not participate. Jon, Sergio and Rosario said they learned to participate at work, once they were in a favorable environment in the cooperatives."

"Can we also talk about values," said Kurtis. "What kind of values support participation?"

"Those that you and your team agree will promote it," I said. "It depends on organizational culture and history, commitment at the top, and, most importantly, getting those who will be affected involved in the decision making process. The question is:

'what values does everyone think are important'? And you, Damian and me, as leaders, have to be the first ones to accept these values and model them for everyone else."

"In understand," said Kurtis. "Can you give us some examples?"

"How about starting with the Mondragón people? What I've just said so far is what they have done for almost 50 years: having clear values, knowing the issues, acquiring skills to participate and providing a supporting environment."

"Will their values apply to my organization?" asked Damian.

"I think their values are applicable to any organization that promotes participation. The Mondragón people, however, would be the first ones to say that what has worked for them may not work for us, at least not if we just attempt to copy their model. We have to look at our own cultural, social and economic environment."

"Okay, David, what are these values?" he continued, pencil in hand.

"I'll mention a few." I took my notebook and scribbled a few words. "Democracy, the one-member/one-vote system gives each person equal rights and responsibilities when they participate. Equality refers to considering 'the other' as an equal, even if I am more experienced, educated or clever-and expecting the same from others. Solidarity is related to voting and engaging in dialogue with others because everyone deserves my involvement, as I deserve theirs. Solidarity also includes accepting decisions favored by the majority even if I don't agree with them."

"Some of these values overlap," said Kurtis.

"They are all interrelated and support each other," I said. "And they are given life precisely through participation. Another value is equilibrio or balance-understood here 
as discerning if a decision is fair to all involved."

"Is learning values more important than learning skills?" asked Damian.

"I think that learning and living by the values we accept is the most important. I take a big-picture approach to education, especially if it is going to be a cornerstone of my strategy to promote a participatory organization," I said, reaching for a book from my pile.

"Hey," he protested, "You said you would only use your dialogues and your experience!"

"I agree, but my experience also includes reading books," I replied with a smile, knowing I was changing what I had said at the beginning of the conversation.

Damian followed my game: "Okay, as long as you explain everything in practical terms. Remember I am a student but also a leader who wants to implement some of the things you've said."

I nodded. "That should motivate me, huh? I'll start with Schumacher, who wrote the book Small Is Beautiful. Going back to your question, know-how is important, he writes, but to apply it we need to understand how it helps our world make sense."

"That makes sense," said Kurtis, with a look that seemed to indicate he felt clever.

"You think so?" I said, as I smiled and opened the book. "I like his vision about the role of education, values and meanings. It goes much beyond the practical aspects," Kurtis took a pen out of his pocket to take notes. I continued: "Let me read a couple of paragraphs:

The essence of education is the transmission of values but they do not help much if we do not make them our own, if they do not become part of our mental make-up. These values become such a part of ourselves that we think and feel with them, that they are the very means with which we see, interpret and experience the world.

Education can help us only if it produces a 'whole person'. He will not doubt his basic values, or his view on the meaning and purpose of life. These values will be at his center, the place he has created about self and the world.

"No wonder you found resonance with this author," said Kurtis looking at his notes. "His vocabulary: internalizing values, being congruent between learning and living by our values, educating the whole person, these are terms we have been using."

"Hey, you took good notes..." I said.

Damian interrupted us: "David, that's an inspiring vision, but in practice, how do we teach a person who has always followed the boss's decisions to now participate in them?" 
I thought for a moment. "They have to realize things can be done differently," I said. "Have you seen the movie Dead Poets Society?"

"I have," he replied. Kurtis shook his head negatively.

I continued: "You may remember this scene:

The professor, played by Robin Williams, tells the students, who seem to just accept his opinion about a literary piece: 'If you want to develop your own way of thinking, 'he says, 'you have to look at the world from a different perspective.' He realizes by the look on the students' faces that they have not understood. So he stands on top of his desk and asks students to do the same. Surprised, the students climb on their desks, one at a time. 'When you read a book, ' the professor says, looking at the students on top of their desks, 'don't just listen to what the author thinks, but to what you think. Look at it from the desktop. You must strive to find your own voice'."

"Interesting, but I don't find the connection," said Damian.

"The world will be the same but our worldview will change," I replied. "The same nonparticipatory workplace will become participatory. Everyone in the organization will perceive your workplace differently since all will have a voice in decision making."

"Got it," he said. "So, where do we start?"

"At the beginning: changing the people's perspective to the one they will see from their desktops."

"Right, from the desktops," said Damian, smiling.

I smiled too

\section{A Nurturing Environment for "Transformation"}

"Do I hear an implication for effecting change?" asked Kurtis.

"Right you are," I replied. "That is the second implication I'd like to talk about."

"How do you make such a drastic change?" asked Damian.

I leaned forward and spoke slowly: "The corporate scandals in the United States and Europe provide a window of opportunity."

"Do you think such a change can be made now?" asked Kurtis.

"I think we have to go back to the person. He or she has to accept a change is needed. If leaders try to impose a major change that is not accepted by those who have to live with 
it, it will be sabotaged subtly or otherwise."

"How will this change come about then?"

"From increased awareness that a change is needed. This awareness will facilitate everyone to understand the need for change. Without this understanding, change will probably not happen."

"What do you mean by awareness and understanding? I think everyone is aware that things are not right in organizations," said Damian, "We all understand."

"Okay, I'll digress for a minute and talk about the kind of awareness and understanding I am referring to," I said. "These words are very meaningful to me. I credit them with my change of mindset and eventual retirement from my work 10 years ago."

"Really?" said Kurtis. "Tell us more."

"I learned about awareness and understanding from Anthony de Mello's book, appropriately called Awareness. We grow in awareness as we sense that what we perceive as 'reality' is filled with illusions 'programmed' by our parents, teachers and others in our early lives. We are further 'programmed' later by peer pressure, popular culture, advertising and the media."

"If we are 'programmed'," he said, "how do we 'delete' these programs?"

I smiled at Kurtis' clever turn of words of my metaphor. "Through self-observation. We 'wake up' and see that reality is different than what we have allowed others to make us believe. We understand that 'our reality' is filled with fantasy. This process leads us to question established patterns and to accept change."

"You are suggesting that a change will be easier because everyone will understand decision making does not need to happen at the top," said Damian. "We are programmed to believe it has to be this way, but it's not true."

"Yes, and once most of your people understand it - and accept it! --it'll be easier to make a change."

"Okay," he said. "Let's say we all understand and accept participation is better. I am the leader. What do I do now?"

I leaned forward. "Assuming your employees already accept the need for change, the next step is to facilitate it."

"Am I expected to do this by myself?" asked Damian. "I may be the boss but I am only one person convinced we need to change." 
"You'll need help from at least a small group of committed people," I replied. "And there may be other helpful change agents: new government regulations, shareholders" demands, or pressure from an employee group or labor union."

"I think we are talking about major change here," said Kurtis, "Most organizations today follow Taylorism, 'great-man' or other non-participatory leadership models, right? Managers make decisions, others obey them."

"I agree," I added. "To move from a non-participatory to a participatory mindset requires substantial change."

"What do we need to make this change? asked Damian.

"An acceptance of a role change, not only by leaders but also by employees. Authority and responsibility will shift downwards, as your organization becomes more participatory."

"Delegating more?" asked Kurtis.

"In a way, but not just a couple of levels down. It'd have to be all the way down."

"What do you mean?"

When I lived in Europe I learned a term that is central to the structure of the European Union and has become part of business vocabulary. It is called subsidiarity."

"Translation?" asked Damian.

I smiled, realizing I could count on Damian not to let us forget all terms have to be described. I picked up Charles Handy's book from the table and opened it at a marked page. "Handy has a simple definition: It is the principle that moves decisions and responsibilities to solve an issue to the lowest level possible down the organization."

"But people may not be ready to make these decisions," said Kurtis.

"Precisely the point... and the challenge," I said. "Those people at the "lowest level possible' have to be educated to participate, stressing the need to be informed and the authority and responsibility involved in making decisions."

"It sounds like an impossible task," he added.

"It may take time and dedication, but it is far from being impossible," I said. "Not everyone in Mondragón participates but by and large employees have grown from being non-participants to becoming active participants."

"Yes," said Damian, "but you are talking about an organization that is participatory." 
"But they started with nothing," I retorted. "They had to learn how to participate at the beginning, whether they were employees or managers."

"But managers are better educated, it's easier to delegate to them," said Kurtis.

"Managers usually are better educated academically but we don't need graduate degrees to participate. We need to be know the issues, believe in certain values, learn skills, and be willing to share power and responsibility. Arizmendiarrieta believed employees were better prepared to change to a participatory organization than management."

"Really?"

“ 'Employees' lack of education can be conquered', he'd say, 'but how can management's pursuit of power and status be overcome'?"

"He probably had a point," said Kurtis.

I leaned forward. "I wouldn't go as far as assuming all workers are prepared to make all decisions," I said, "but I'd certainly provide the means to educate them to participate. And I'd provide an environment in which they can participate."

"Okay, going back to me and my problem, I am the leader. What do I do?" asked Damian.

"It's a chicken and egg situation." I replied. "It's not possible for leaders to ask uneducated employees to make decisions, but these employees will not be able to make decisions if they are not educated."

"The cycle has to start somewhere," said Kurtis.

"And we leaders have to want to change first, through awareness and understanding," Damian said, half-mockingly repeating my words.

I smiled, ignoring his pun. "As you know, I like to consider the 'big picture'. Let me introduce some stretch here: We can change together as we transcend the way we perceive ourselves and our relationship with others."

He tilted his head back and looked at me sideways. "What are you talking about?"

I pulled another book from the pile. "This book, called Insights on Leadership, has a chapter by John Gardiner, professor of educational leadership at Seattle University. It's called 'Quiet Presence. The Holy Ground of Leadership'. He refers to the need to develop our human consciousness to a higher level, just as we have been discussing."

"And how does that help us make changes?" asked Damian. 
I opened the book to a marked page. "Listen to this:

Our state of being determines our ability to influence others. Yet, our collective state of being, human consciousness, is not developed to the extent necessary to cope with the problems of today's world. A revolution in human consciousness is needed to face them. A revolution is needed in how to relate with each other. Our natural state is wholeness. Thus, unrelated separateness is an illusion. Transforming the sense of separation to one of unity is needed to transform the personal, corporate and global world.

Kurtis put his elbows on the table. "So you are talking about raising consciousness to make a change. Are we talking about a change or a transformation?

"I think you are right," added Damian, "it is a transformation. We are talking about a drastic change of mindset, organizational structures, way of working..."

"Agreed," I said, "but notice the parallels. Schumacher's suggestion to adopt firm values that give meaning and purpose to our life. De Mello's writings about 'awakening' our awareness and understanding. Gardiner referring to raising our consciousness and making us more "whole'..."

"... and from wholeness comes unity, and unity is needed for transformation," added Kurtis, completing Gardiner's statement.

"Education and leadership triumph together!" proclaimed Damian.

We laughed. I looked at Damian's pile of books. "I recognize one of your books," I added, pointing at it. "What can you tell us about transformation?"

"Oh, yes, this is Schein's book The corporate culture survival guide. Sense and nonsense about cultural change," he said, pulling it out. "He describes transformative change in detail. He suggests a number of steps to get it."

"Can you tell us more about it?" asked Kurtis.

Damian opened the book at a dog-eared page. "Here it is," he said, as he scanned through the page: "Steps to be taken include a positive vision. . a system of reward or punishment to sustain it... and support groups..."

"Doesn't he talk also about psychological safety?" he asked again.

"Yes, Schein refers to it as a means to reduce the anxiety of unlearning old ways and learning new ones."

"I interrupted you," said Kurtis, "is there more?"

"Yes," said Damian, scanning the page again. "Other steps emphasize education: formal 
training to adopt new attitudes and skills... informal training and practice in groups ...coaching and feedback...positive role models... and involvement of the learner."

"Some terms sound familiar: skills, training, practice, role models, involvement of the learner," read Kurtis from his notes. "Do I hear Mondragón people speaking?"

"It sounds like them." I replied. "My collaborators used similar terms,"

"I have been reading about psychological safety too," he added. "It's such a big issue in the 'real world'." He looked at me. "The Hungry Spirit book you recommended David, includes a similar concept. Charles Handy calls it unconditional positive regard."

Damian looked up from his book. "What does that mean?"

"In order to learn new ways of doing things," said Kurtis, "we have to be in an environment in which we can experiment, make mistakes without fear of being punished, and have feedback from someone we respect." And he added after a pause: "It doesn't seem like a difficult way to provide a safety net."

"Except that mistakes are not easily accepted in organizations," said Damian.

"I remember Rosario, one of my Mondragón collaborators," I replied, "telling the rest of the group that her team was learning to see mistakes as learning tools. If not, she added, people would not participate for fear of ridicule."

"Okay, I get it," said Damian. "Bottom line is that, on top of educating myself and others to participate, I have to provide a safe environment for transformative change."

"Well said!" I remarked. "You have Schein's book, you just have to follow it!"

"Easier said than done," said Kurtis, smiling. "I suppose it would take some time."

We were silent for a moment. "I assume we are not finished yet," said Damian. "What comes next?"

"There are other steps to be taken but I think they would be the topic of another book," I replied. "I propose that, once the transformative change is accepted and everyone is involved in the learning process, the psychological safety net is in place..."

“... and the ground is well prepared...," added Kurtis.

"...the next step as a leader is to provide a structure that sustains participation," I finished.

"Can you give me some tips about this structure," said Damian. 
"Maybe a few," I said. "My collaborators mentioned some: voting rights, group discussions and governing councils. Others are described in my year 2000 study and the literature about Mondragón."

"Will I be able to ask you about these tools once I am in the midst of my transformative change?" he asked, grinning broadly.

"Why, of course!" I replied.

Kurtis looked at his watch. "Time flies when we are having fun," he said. "I've got to run."

"I know," I said, "we've been here for a long time."

"Is there anything else leaders can do to support participation?" asked Kurtis, as he and Damian gathered their books and notes.

"Oh, yes," I replied immediately, as I gathered mine. "Leaders play an essential role in the day-to-day life of the organization. You know, congruence, "walk the talk'."

"And then?" said Damian.

"I don't know yet," I said. "Perhaps then you can write a book. Surely we'll be able to learn from your experiences."

We stood up and walked to the parking lot together and talked for a few minutes. I thanked Damian and Kurtis profusely. We shook hands and said goodbye.

It was difficult to say goodbye after so many sessions together. I think we all felt the same way and that is why we did not make a fuss about it. Surely we would continue to meet but not to review my book. Kurtis and Damian had mentioned they were happy to have shared my book-writing process. "It was a way to keep up with our friendship while staying in contact with leadership studies," they had said. I told them I felt the same way. We agreed to get together again as soon as I had my book ready. I promised to give them a copy since they had seen the book only through my eyes. They probably knew the book better than anybody else yet had not read any of it. Explaining to them what I had written became a clarifying filter for me too, as I had to answer their questions all along. They had helped me so much with their well-prepared readings and challenging comments!

I drove out of the parking lot thinking about what we had talked about today. The implications were calls for action and I wondered if Kurtis and Damian, and you, were motivated enough by what we talked about to take some action to promote participation in decision making at our workplaces and in our lives. 
But somehow my mind took me back to the consequences of the recent corporate abuses that were so devastating to so many people. Damian and Kurtis had challenged me to talk about them at more length than I had planned in my book, so they were quite present in my mind. I thought about you reader and wondered: After you have read this book, how do you feel about putting your lifelong savings, investments and pension plans in the hands of a few people in the organization where you work? Do you think there is a way to prevent future abuses in your organization? Is it possible to prevent decisions that damage our communities and environment? How? Are you willing to take responsibility for decision making at work? 


\section{EPILOGUE}

I woke up that night thinking about my book. I had ended it referring to the corporate scandals, but that was only a piece of the total picture. I reviewed the purpose of my book and thought about the larger issues.

I believe my book enhances the understanding of the meanings of participation, as I set out to do. I think that being aware of the hidden potential of participation in decision making as a meaning-making experience and the depth it can reach contributes to the knowledge about participation and stimulates personal exploration of these meanings. I also wrote in Part III about the research design and methodology I had used, hoping it would help others who venture to write research work that is accessible to the general reader.

There are, though, some remaining questions: As persons, what else influences us in our participation, or lack of it? Why don't we pursue changes at work that will allow us to participate, and don't participate even when we have a chance? Is it because we feel we are "rugged individualists"? If we think so, is that what we are, or are we puppets on a string with no voice in decisions that affect us? Is it because we feel we are self-sufficient and fulfilled with our lives, or are we just plain lazy? Or are we alienated individuals who feel life is meaningless because we are disconnected from our fellow humans who do participate in solving problems that affect us? Can reflecting on these questions help us understand unexplained vacuums in our work and in our life?

And then I thought about us as persons who work. It seems that we go to work for a number of reasons: as a means to make a living, as a duty, or as a means to acquire money, power or status, for example. Apparently none of these reasons satisfy our quest for meaning. We end up trying to find consolation in doing what has meaning for us when we are not working. But it is difficult to find time for ourselves, as we progressively work longer hours, voluntarily or to avoid being the next person to be fired. It makes sense, I think, to search for meaning at work, where we spend most of our waking hours.

Reader, you have been my companion in this journey. I would like to thank you wholeheartedly for listening to my stories, my doubts, my discombobulated reflections, my interpretations, and, especially, my often bold challenges. Without your company, I would not have been able to bring forth many of the feelings, thoughts, ideas, experiences and memories buried within me. Thank you again for being such a loyal friend.

I have a last batch of questions for you. I hope this book has exposed you to enough experiences, reflections and interpretations to persuade you that participation can become a meaningful experience as you become more aware of its potential depths. I have proposed that finding meaning in participation can enhance other aspects of your life but I know only you can make that judgment. There are two questions that still trouble me as I finish this book. Perhaps you also find them disquieting: Is there a relationship between 
finding meaning when participating in making decisions at work and enhancing the meaning of work itself? Furthermore, considering that we spend most of our waking hours at work or in work-related activities, could this enhanced meaning at work be connected to living a more whole, meaningful life? 


\section{NOTES AND SOURCES FOR PART II}

Chapter 11. Outcomes of the study (Pages 163-183)

Women more attuned to new worldview: Bennis, p. 69.

Participatory systems in place are important: Herrera (2000).

Participation at MCC: Greenwood \& Gonzalez, Cheney (1999); Kasmir. Also TU articles from Jan 1999, Feb 2000, July 2000, Nov 2000, May 2001 and Jan 2002.

Creative synthesis: Patton, p. 73; Moustakas (1990) pp. 31, 52, 85-90.

Description of experience and meaning: Moustakas (1990), pp. 31-32.

I benefit from what I want to do: De Mello, pp. 20-26.

Means and ends: Herrera (2002), pp. 235-238. Human beings are not objects but subjects.

Intention, ethical acts benefit others and me: Sternberg, pp. 95-96.

From individual thought to collective action: Senge (1995), p. 232.

Tapping into collective thought: Ray and Anderson, pp. 7-42.

Connection: John L. Locke, a neuropsychologist and not the 17 th century philosopher, as cited in Fukuyama, p. 179.

I and Thou: Buber, pp. 56, 59-60, 112-113.

Kant on duty: Hospers, pp. 178-180.

Dolbee in San Diego Union Tribune, April 23, 2004. Breakfast meetings at the University of San Diego with Sister Barbara Quinn to discuss spirituality and work.

Contributive justice: Pilarczyk, pp. 52-56.

Avoiding cognitive dissonance: Handy (2004), p. 32.

Cognitive dissonance defined: Worman and Loftus, p. 564.

'Transcendental' defined: McInerney, p. 180; Webster dictionary. Abraham Maslow defines transcendence as "the very highest and most inclusive or holistic levels of human consciousness, behaving and relating, as ends rather than means, to one self, to significant others, to human beings in general, to other species, to nature and the cosmos." (Maslow, p. 269) This definition is also relevant to this study. Mundukide: Herrera (2004), p. 65. 
Agape defined: The love of Christians for other persons, corresponding to the love of

God for humankind. Webster dictionary.

Non-locality principle and web of relationships: Capra (1982), pp. 75-97.

Connection between science and spirituality: Capra (1982), p. 78.

Interdependence: Covey, pp. 49-51.

Christian meditation: Keating, pp. 32-43.

Flow: Csikszentmihalyi (1990), pp. 71-93; (2003), pp. 167-188.

Flow as expressed by Heraclitus: Capra (1996), p. 43.

Flow as spiritual connection: Rohr (Religious Education Congress, 2004).

Cartesian: Descartes philosophy emphasizing logical analysis and the mechanistic interpretation of physical nature, as defined in Webster dictionary.

Systems thinking is process thinking: Capra (1996), p. 42.

Open systems are in a state of flow: Capra (1996), p.48.

Congruence described: Webster Dictionary and Thesaurus.

Need fundamental change of worldview: Capra as cited in Bennet, pp. 77-78.

Chapter 12. Implications (Pages 193-214)

If it does not work, do more of the same: Quinn, p. 9.

Parlamat fraud: Milking lessons in The Economist, January 3, 2004, pp. 45-46; Parma splat, The Economist, Jan 17, 2004, pp. 59-62.

Shell's oil reserves: Callus in San Diego Union Tribune, Mar 19, 2004, pp. G1, G4.

Corporate abuses: McClam in San Diego Union Tribune, Dec 28, 2003, p. G6

Work-life balance, a sad term: Handy (2004), pp. 30-31.

Mondragón values: Ormaechea (1993).

Equilibrio: Morrison, p. 4.

The meaning of education: Schumacher, pp. 82-84, 95.

Dead Poets Society: 1989 film directed by Peter Weir.

Awareness and understanding: De Mello, pp. 20-26

Taylorism/non-participatory models: Ray and Rinzler, pp. 32-34; Bass, p. 416.

Subsidiarity described: Handy (1997), pp. 248-249.

Raising consciousness: Gardiner, pp. 116-117. 
From wholeness to unity: Gardiner, pp.116-117.

Transformative change: Schein, p. 124-125.

Unconditional positive regard: Handy, pp. 135-136.

Structures to support participation: Herrera (2000). 


\section{PART III}

\section{RESEARCH DESIGN AND METHODOLOGY}

I hope the writing style for this part of the book will make it interesting for the general reader. Although the subject matter and the language are of a somewhat more technical nature, the contents are written as dialogues and conversations, as the rest of the book. I have again recurred to our familiar characters, my fictitious San Diego friends Damian and Kurtis, to help me engage in dialogues throughout this part of the story, challenging my research design and methodology during our three after-lunch meetings.

This book began in Chapter 1 with a conversation with Kurtis and Damian that included the first steps to conduct a research study. These are the rationale to study participation in decision making, my motivations to explore this topic, and the reasons I selected Mondragón as an appropriate place to study it. This part of the book describes the remaining steps of the research design and methodology for this study.

Chapter 13 describes our meeting on Saturday, May 17, 2003, two weeks before I traveled to Mondragon. Kurtis, Damian and I reviewed the basis to conduct the study and discussed approaches to do the research work in Mondragón. We also talked about the characteristics of the people that would be involved and how they would be selected, the ways I would gather information, and the context I was planning to provide as background to the study.

Chapter 14 portrays our meeting on Saturday, August 23, 2003, a week after I came back from my trip. At that time we discussed mostly the ways to analyze and present the contents of the interviews, describing in some detail the narrative approach and its use of writing tools from the "narrative non-fiction" genre, which allows stating facts in story form. We also discussed the steps of the process to analyze the research data, represented in a flow chart.

Chapter 15 depicts our last meeting about the research design and methodology on Saturday, February 7, 2004. We talked about the remaining items: documenting sources, and the significance, delimitations and limitations, and trustworthiness of the study.

Kurtis, Damian and I met twice more before I finished my book, but we shifted our attention during those meetings to my interpretation of the study of participation in decision making. The dialogues and conversations during those meetings are the contents of Part II of this book. 


\section{CHAPTER 13}

\section{RESEARCH METHOD AND DATA COLLECTION}

I met with Kurtis and Damian once before and twice after my trip, to discuss the research design and methodology for the study. The meeting before my trip was on Saturday, May $17,2003$.

As I waited at Mimi's Cafe, I thought about how I have enjoyed our meals and conversations with Kurtis and Damian. Today was the first time we would talk in some detail about the way I was planning to conduct the study.

Damian and Kurtis arrived on time, as usual. We had lunch and placed our notes on the table, ready to discuss the details of the study. Damian made his customary remarks, warning me about expecting his frequent challenges to what I said. Kurtis joined him this time letting me know he would be asking a lot of questions because he was puzzled about my research design and methodology.

"I found a good way to write my book!" I said enthusiastically as I opened my notebook.

"Wait, wait!" exclaimed Kurtis. "Before we talk about how to write your book, let me see if we are together on where we are." He looked at his notes. "Let me see...you're writing this book mostly because of your frustration with the lack of opportunity and/or desire to participate in the companies where you worked and you want to understand this better by looking into what people experience as they participate."

"Right."

"And you also know, as well as we do, that there is an increased interest in employee participation from practitioners and academics," added Damian.

"That's also right," I said.

"Okay," he continued, "but the trigger to begin writing the book was the corporate scandals in the last two years."

"Yes."

\section{Purpose of the Study}

Kurtis turned the page and continued. "Can you tell us again the purpose of your study? You have told us you will not write about the organizational systems that make participation possible but about the persons that make it happen."

"The purpose of my study is to gain a more thorough understanding of participation in 
decision making by exploring the personal experience of my collaborators and the meaning they find in participating, supplemented with my own experience."

"Persons not systems," repeated Kurtis.

Statement of the Problem

"That's right," I said. "In terms of the statement of the problem for a research study, the literature about participation, in and outside of Mondragón, addresses the organizational systems-structures, policies, processes and practices-that make participation possible."

"These systems are necessary, though," Damian said.

"Yes, they are, and describing the systems that support participation is an important contribution to the topic." I paused and leaned forward, looking at Damian. "This is very important to know but it is not enough. It is persons, not systems, that make participation happen as they engage in the voluntary act or participating."

\section{Research Question}

"So you are going to write about the person who participates," said Damian.

"I'd like to explore what the experience of participating means to this person so we can have a better understanding of participation in decision making."

"What do you really want to know?"

"To answer your question, I imagined myself in Mondragón sitting with a collaborator across the table. What would I want him or her to share with me? What I'd like is a reply, in his or her own words, to the question: 'What does the experience of participating in decision making mean to you?" "

"Good," he said. "I wanted to be sure you had a clear research question."

I nodded. "I guess I am anxious to discuss the way I am planning to write my book and I forgot to start at the beginning. I know you have some suggestions, how about starting with those?"

\section{Phenomenological Inquiry}

"Fine, I'll go first," said Kurtis, looking at his notes. "As you both know, my dissertation was an ethnography, which is "a description and interpretation of a cultural or social group or system"," he read. "I thought perhaps you could do something similar since you are looking at something in the Mondragón culture and social group."

I looked at him. "My pilot study in year 2000 was an ethnography focused on the group. 
This time I'd like to focus on each individual person in that group. I'd like to learn from them as persons with unique experiences, in ways that can not be tabulated, summarized or studied at the general level."

"You recall my dissertation," added Damian. "I did a grounded theory study. I focused on my co-workers' reactions to a major change we had in one of our factories. As a result, I generated a theory, based on interviews, visits to the factory, and people's interactions and coping mechanisms. I was studying individual people, like you would like to."

"Your approach is closer to what I would like to do," I responded, "but still ends up with a theory based on group behaviors. I intend to keep the person at the center of the study."

"And did you find a way to do it?" asked Kurtis.

"Yes, I did. It's called phenomenology."

"I remember it from class," said Damian. "Phenomenological inquiry studies personal experiences, as with terminally ill patients who have been in a war."

"Can you apply it to your book?" asked Kurtis.

"Phenomenology started as a philosophical concept," I explained. "It was later transferred to psychotherapy and the social sciences, and lately has been applied to research. As implied in its name, phenomenology refers to any phenomenon experienced by human beings. Participation is such a phenomenon."

"Can you describe it some more?" asked Damian. "You are losing me."

"I know what you mean. This has not been an easy stage in the study, trying to grasp the concept of phenomenology." I paused to organize mentally what I wanted to say.

"Phenomenology is not about thinking in order to understand an experience but about reaching understanding from within us. It's about being in touch with an experience as it happens, before we conceptualize it or categorize it." I looked at Kurtis and Damian. "But I agree that in the world of leadership and management it is an unusual term."

"This is why you emphasized the word experience when I asked you about your objective for the book," said Kurtis.

"Yes, this is why I will focus on the experience of participating, not its consequences, mechanisms or motivations behind it. These parts of the process may influence a person's experience, and they contribute to it, but they are not the experience of participating."

\section{Subjectivity in Research}

Damian frowned and consulted his notes. "How are you going to stay objective?" He assumed a familiar posture, leaning back and looking under his glasses. 
I laughed out loud. "I think you are asking me a trick question. All three of us have learned that objectivity is a relative term and that we are always subjective in our research: when we design a questionnaire, when we decide what variables or responses to consider, or when we write results. Yet, we claim we are objective researchers."

"Just checking," he said, with a smile.

"Have you heard of the Heisenberg Principle?" I asked, looking at Damian.

" A watched particle is different than one that is not watched'?" he replied quickly. "Persons also behave differently when observed."

"Right!" added Kurtis. "This is why objectivity is not possible, because the moment I am in contact with a subject, the situation changes. I provoke the change."

"Okay, just checking," I said, smiling. "I know you are both fond of systems thinking."

“Are you impressed?" asked Damian.

\section{Heuristic Research}

I nodded emphatically and looked down at my notes. "Among the several types of phenomenological approaches, there is one called heuristic." I turned my notes to the last page. "As you can see I am prepared to talk about this."

"It looks like it," said Kurtis.

"According to Patton," I read, heuristic inquiry asks 'what is my experience of this phenomenon and the essential experience of others who also experience this phenomenon intensely? The researcher comes to understand the essence of the phenomenon Ibeing studied] through reflection and inquiry with co-researchers'."

"We are going to need a roadmap to follow what you are saying," he added.

I smiled again. 'Patton's definition has two implications. The first answers Damian's question: I do not intend to stay objective in my study but instead I am openly subjective. The second is the choice of participants."

\section{Sampling Strategy and Selection of Collaborators}

"That was my next question," said Damian. "Will you use a purposeful sample?"

"Yes. I have concluded that my experiences and my access to some people in Mondragón provide a purposeful sample, that is, an "information-rich" source of knowledge about participation in decision making." 
"You certainly will need that type of sample, if you plan to talk about personal experiences," said Kurtis.

"Right. I will talk to my collaborators about themselves as persons who participate actively in a workplace that facilitates it. I believe I can learn a lot about participation, not only as it happens in Mondragón, but as it happens in general to persons that participate."

"What will be the profile of your collaborators? asked Kurtis.

"Since phenomenological studies are about personal experience, participants need to have extensive experience in the phenomenon to be studied so we can talk about their experiences in depth. If the study is about feelings when being sick, the selected participants must have been sick, for example, so they can provide ample information about what being sick is like."

"Well, I've been sick, does that mean I could be in a book?" asked Damian

"Yes, you could," I said as I laughed. "But the quality of the data will also depend on how sick and how many times you have been sick. The more frequent and intense your experience, the richer will be the information you can provide."

"And will your collaborators have had different experiences?" asked Kurtis

"It's hard to predict. My interest is to talk with people who have lived multiple experiences of participating extensively, intensely and continuously. So I have set some criteria: a minimum of ten years experience; having had at least two different jobs, or the same job in two different Mondragón cooperatives, and having belonged to any of the councils."

"What are the councils?" asked Damian.

"There are three councils that MCC worker-owners can belong to: the governing, the management, and the social council. They are the leading bodies of the organization."

"You are looking for top managers then?" asked Kurtis.

"Not necessarily," I replied. "At Mondragón, people who belong to these councils are from any hierarchical level, although I will probably have access mostly to managers and staff persons at the middle and higher levels. Yet, regardless of their job level, I believe these people are most appropriate for my study because belonging to a council implies a desire to participate more intensely and ensures more involvement in decision making. This is especially true if we consider that there is no additional pay attached for these council members and that meetings are often held after working hours."

"And what else are you looking for?" asked Damian. 
"My collaborators must be able and willing to share their stories. Phenomenological studies require a lot of personal investment and involvement. This is a critical part of the profile because my methodology asks for several feedback cycles and the desire to engage with me in the process of 'discovery' about participation."

"I assume you know enough people in Mondragón that fit your profile," said Kurtis.

"Not everyone I know fulfills my profile. I will have to interview people I don't know."

"And how many people will you interview?" he continued.

"Phenomenological, as qualitative studies in general, are focused on few participants. Some have been done with one person only, if he or she has intense experience in what is being researched. I plan to interview eight: four men and four women."

Sites, Entry and Access

"And what is the strategy for your entry to Mondragón?"

"I will contact people I have known for a few years and write a letter to the Otalora Training Center manager for authorization to have a place to work there."

"The site for your interviews with your collaborators will be in Otalora?" asked Kurtis.

"I will offer to hold our interviews in my collaborators' offices but will also offer my assigned space in Otalora."

"And how will you access your collaborators?"

"I will ask two people at Otalora to help me find additional collaborators by using the snowball method."

"Yes, I know," said Damian. "This method is about asking the first two or three collaborators that qualify to find collaborators who have similar profiles."

I nodded.

\section{Data Collection}

"And how are you going to collect data for the book? Interviews with the participants? Document analysis? Observations?" asked Kurtis.

I smiled and looked at him. "I can see you remember well the main sources of research data. I will use mostly interviews..." 
Damian interrupted me. "I assume you'll still follow what we have learned about doing interviews."

"Yes. The first dialogue will last about one hour and be audio-taped. I will have prepared questions as a general interview guide to insure our conversation revolves around lived experience. I will use these questions sparingly though, favoring an informal conversational approach to allow my collaborators to talk about what they think is important regarding their experience of participation."

I looked at Damian smiling. "Before you ask me, I will also transcribe our dialogues within 24 hours, as the traditional method suggests, and e-mail them back to my collaborators immediately for their review, ."

He nodded approvingly. "And they will return their comments by e-mail?"

"Actually, I'll ask my collaborators from the beginning to meet at least twice. The second time will be to review the transcriptions personally."

"And what about observations in the field?" asked Damian.

"I am intervening in the dialogues with observations from the past, based on previous studies, conversations and visits to Mondragón, as well as other observations based on my pre-Mondragón experience. But this is a secondary source of data."

We paused. "So you'll have eight collaborators and 16 interviews at least," said Kurtis.

"Yes, I am seeking depth more than breadth."

"It looks pretty straightforward," said Damian.

"Yes," I said. "But there is one characteristic of our interviews that we have not talked about. Since heuristic phenomenology seeks shared lived experience, I will rely mainly on dialogues between my collaborators and me. As you have noticed, I speak of 'dialogues' and 'collaborators' instead of 'interviews' and 'participants' because I see our interactions as two persons sharing equally the exploration of the meaning of participation."

"Yeah," said Damian, "but you are still the researcher interviewing them."

\section{Dialogic Interviews}

"Not exactly," I replied. "Our interactions will not be question and answer conversations, they have been called dialogic introspections in which cooperative sharing prevails. I'll still give priority to my collaborators' voices but will intervene to refocus, probe a theme, or refer to my experience, if I think it's relevant to the conversation." 
"David, you know what Senge has to say about dialogues," said Kurtis.

"Tell me."

"He says that dialogues are very effective to learn something new, as was practiced by the Greeks and by many so-called primitive societies, such as the First Americans."

"And you have heard about the physicist David Bohm," Damian continued, "developing a theory and model of dialogue, when several people participating together can open "to the flow of a larger intelligence'."

"Senge also talked about 'collaborative learning' in science, and about the IQ of a group being much greater than that of any individual," I added.

"I don't feel we tap into a larger intelligence in our discussions at work," said Damian wryly. "They seem like a contest."

Kurtis looked at him. "Senge distinguishes discussion and dialogue. In a 'discussion', each person attempts to win by having his or her ideas accepted by the group. In a 'dialogue', the idea is to go beyond anyone's understanding, to gain insights that can not be reached by any member of the group individually."

I leaned back, elated by our conversation. "You know, you are helping me to decide how to present my material in the book. I will dialogue interactively with my collaborators, but instead of converting these into prose, as I did in my year 2000 study, I can present the material as a series of dialogues."

Kurtis intervened: "Well, data is collected in dialogues during your interviews, you could present them like that..."

"I wonder," I said, interrupting him, "if I can write everything in the book in a dialogic format? Dialogues may lead to more insights than prose. I have to think about this..."

"And what about the analysis and representation of the data?" asked Kurtis.

I breathed deeply. "I am not there yet. I am still reading and thinking about it. According to Gadamer and Rorty, there is no set of investigative procedures to analyze the experiences shared in the dialogues. In other words, in phenomenology, there is no specific method to analyze or present data."

"This sounds pretty complicated. You mean you have to design your own method?" asked Damian.

"Not really design it from scratch," I replied. "My methodology will be firmly grounded on Moustakas' guiding principles and Merriam's examples for the analysis of data, two of the authors I am following closely. I foresee, though, that I'll have to adapt it to the 
needs of the study. Sometimes I wonder if having this flexibility is better or not. It certainly would be easier to follow a prescribed method to the letter, but by what I have read, other research methods would not help me explore my topic adequately."

"Will we have a chance to challenge the rest of your methodology?" asked Kurtis with a smile.

I smiled too. "I am glad you are willing to go over my ideas for the book; I know it's not a simple project. The next meeting will have to be after I come back from Mondragón this summer. I'll tell you about my methodology and how the trip went then."

"How long will you be there," asked Kurtis.

"About ten weeks. I plan to do the interviews and have some time to read about the methodology and to write part of the dissertation."

"Great," he said, as we got up from the table. "We'll look forward to talking to you after your trip."

We walked out to the parking lot. "Have a good trip David," said Kurtis, extending his hand to shake mine. "Yeah, have a good one!" Damian added, also shaking my hand.

"Thanks for your help, see you after I come back," I said, waving as I walked to my car.

I suddenly felt quite alone with my book project. On the way home I thought about how I was going to design the method to analyze my research material. Falling back on the group analysis was the safest. Even Moustakas suggested it. But what about the diversity of responses? I wanted to give each person a place in the book. I had to find another way. I decided to take some of my seminal books about research and writing on my trip. Perhaps I could read them in my spare time? I smiled. Would I have any spare time? 


\section{CHAPTER 14}

\section{REPRESENTATION AND ANALYSIS OF THE RESEARCH DATA}

Today is August 23, 2003, two weeks after I returned from my trip and about three months since last time Kurtis, Damian and I met. I arrived early as usual, as I enjoy settling down and listening to the music before I meet my friends. I sat in the lobby with anticipation. I heard Louis Armstrong and Ella Fitzgerald over the loudspeakers again, but this time "Satchmo" was not playing his horn and Ella was not scatting her song. They were singing "Autumn in New York" as a duet, Satchmo with his characteristic raspy voice, Ella with her engaging responses.

Kurtis and Damian arrived at the same time. We greeted each other warmly, after such a long time. We sat on the same booth at the back of the Café. It was such a déjà vu. We had lunch and talked about my trip and their summer vacations. We caught up with family, work and personal news.

I am happy to be here. I feel comfortable and am eager to share and be challenged about my study. The waitress has served some fresh tea with extra lemon for Damian and coffee for Kurtis and I. "David, we are anxious to hear how your book is coming," said Kurtis.

"Yes, I have my questions prepared," added Damian, looking at me sideways and pulling a small notebook and a pen from his shirt pocket.

"Last time we met, you were going to design a process to analyze and present your research data," continued Kurtis.

"Yes, indeed. I appreciate your wanting to continue participating in my 'adventure'. It's a long process, but I'll try to make my explanations as short as I can." I glanced at both of them, who looked intently at me. "It will help if you don't ask any questions," I joked.

"No way, Joseee," said Damian. "I've done my homework, I have plenty of them."

"And so do I!" added Kurtis, grinning.

"Okay, I'll start where we left it last time we met. Our conversation about dialogues was most helpful. It further encouraged me to explore ways to invite the reader as a participant in my book and to make it easier to understand."

"Can you elaborate?" asked Kurtis.

"I learned about some tools to analyze and represent data in a narrative form. I'd like to tell you first about the representation of data as it illustrates what narratives, which I used throughout the data analysis process, are about. I also want to share with you some of the tools I will be using to write my narratives." 
"Go ahead," said Kurtis.

Data Representation in Narrative Form

"I learned about representing texts as narratives..."

Kurtis interrupted me: "Could you tell us why you want to represent your texts as narratives instead of just writing out you data analysis and conclusions?"

"Narratives, according to Merriam, intend to make sense of experience. My book is about making sense, exploring meanings in lived experience, which include feelings, thoughts, dreams, memories, and other human experiences. These can be best expressed as narratives. Many human fields are now recurring to narratives to gain a better understanding of aspects of life that cannot be explained in simple prose."

"For example?" asked Damian.

"According to Durrance, narratives are used in organizations to transmit their culture and to motivate and educate employees. A story may also be constructed to share the culture, beliefs or history of a group. It is a way to experience our lives."

I paused for a moment. "Another example: in medicine, narratives are being used to enhance understanding and explore meanings. Bruner, in a book called Making Stories, writes about a Narrative Medicine program in Columbia University that is concerned with narrative ethics."

"Narrative medicine?" asked Damian.

"Yes. Bruner writes that doctors in the program realize that patients' suffering, and even death, are often caused because doctors were 'sticking to the facts' instead of listening to the patients' stories. A similar program in the University of Southern California is concerned with having a narrative, that is, a story describing a possible recovery to supplement therapy for children recovering from disabling illnesses."

"Impressive!" said Kurtis. "It supports your point that research is not only about facts. I can see now that many human aspects need a form of expression such as narratives."

"Narratives are described as being meaning-making," I replied.

"Very appropriate," he added.

I turned the page in my notes. "Fortunately I was able to read Narrative configuration, Analysis and Representation by Polkinghorne before I met with my collaborators. This is new to me too so I will consult my notes as we talk about them." 
"Did you have to change your methodology then?" asked Kurtis.

"In some ways. I mostly changed my approach to interact with my collaborators."

"How so?"

"I became less structured and controlling. According to Polkinghorne, if I allow my collaborators to answer questions the way they wish, they will most probably tell stories. He suggests not to intervene when a collaborator goes 'off-track' from your specific questions."

"I see,".

"I also found much resonance among Polkinghorne's language, that of my collaborators, and my book. It moved the center of our dialogues from what I want to know to what we can learn together. It echoed the heuristic phenomenological orientation and Mondragón's people's way of being."

"Examples?" asked Damian.

"For instance," I continued, "he spoke about collaborators, not interviewees, subjects, participants or co-researchers. If I want to hear my collaborators' stories, he added, I need to establish solidarity with them, share control of the meetings, and build a context in which both of us try to understand important aspects in our lives."

"It sounds like he is writing about Mondragón," said Kurtis.

I nodded. "Merriam does too, We construct the story and its meaning," he says, "the story is always co-authored. This language is very appropriate for my book."

Stories and Plots

Damian looked at me and said: "So are narratives the same as stories?"

"Yes, I am using the term 'narratives' to represent stories," I said, "although narratives are interpreted in many ways by researchers. In any case, I'd like to clarify that these are not fictional tales, as the word 'story' implies."

"So what are they? If I read a story, I expect it to be fictional," said Damian.

"Merriam describes narratives as first-person accounts of experiences, expressed as stories, which provide a source of understanding of the human condition. Polkinghorne refers to narratives describing life events as 'stories', to avoid using more technical terms. Ricoeur adds that stories are an excellent form to express lived human experience."

"And how do you describe a story?" asked Damian. 
"I base my description on Polkinghorne's interpretation." I paused to look at my notes "A story is a group of events and actions drawn together into an organized whole. A story, according to Merriam, has a beginning, a middle and an end."

"And how do you put a story together?" asked Kurtis.

"Stories are drawn together by means of a plot."

"Like in a movie?"

"Movies have plots, and so do stories," I said as I looked at my notes again. "Merriam describes plot as 'the theme or point of a story'. Polkinghorne defines it as 'a conceptual scheme by which a contextual meaning of individual events can be displayed'."

"And that means in English...?" asked Damian.

I laughed. "I know what you mean. Let me illustrate it with a simple story, paraphrased from Polkinghorne: "Everybody agreed that participating is important. I was happy." I looked at Damian and Kurtis, indicating I was finished.

Damian leaned back on his chair. "This is a story? And which is the plot?"

I smiled and nodded. "Let us look at it carefully. It's not the independent events, which can stand on their own, that make the story. It is the relationship created between them that matters, this is the plot that makes meaning. If you read both propositions together, you understand the conceptual scheme: I was happy as a response to everyone believing participating was important. Putting them together provides a context to understand why I am happy. This happiness then becomes meaningful, that is, it makes meaning."

"And what will be your story?" asked Kurtis.

"My book has several concurrent stories," I replied. "The core story is the quest for a better understanding and higher awareness of the importance of participating in decision making. It has a beginning, my motivation to write it; a middle, the quest to understand meaning in the experience of participating; and an end, a better understanding and increased awareness of the reader--and myself!--about the topic. I, however, plan to take my book a step further that will leave us with some questions about the meaning of participation."

"I see," he said, "but you have not done that yet."

I shook my head from side to side, signaling I had not.

"Can you tell us about other concurrent stories?" asked Damian. 
"The methodology to write this dissertation as a book for the general reader, which we are talking about now, is written as an independent story. Other stories are the personal dialogues with my collaborators. Each one is a short story that includes a main theme related to the meaning of participation as well as personal excerpts of their lives."

"And your plot?"

"Again, there are several plots embedded in the stories, the main one is exploring the meaning of participation, others are embedded in the uniqueness of the personal stories."

"I see," said Damian. "So, what will your main story look like?"

"Narrative Non-fiction" Tools to Represent Data

"I needed to learn how to write a story so I read a few books about ways to express meanings, experiences, thoughts and feelings. I learned about some narrative tools used in non-fiction and fiction books."

"Tell us more," said Damian.

"I read Rubie's description of narrative non-fiction: a factual writing that reads like a good novel. Root and Steinberg call it creative non-fiction, a 'fourth genre', along with poetry, drama and fiction."

"Sounds interesting," said Kurtis. "I'd like to know more about this new genre."

"I'll include a list of these sources at the end of my book as reference."

"Good."

I looked at him and Damian and then at my notes. "I am subscribing to Eisner's view that promotes alternative ways to represent data: 'research is a reflective effort to study the world and find vemies to share what we have learned about it', he writes."

I glanced at my notes again. "Richardson proposes poetry as a way to represent data because it 'can touch us where we live, in our bodies' and invites us to 'vicariously experience the self-reflexive and transformational process of self-creation'."

"How are you planning to present your texts then?" asked Damian.

"I plan to present them as a story with a series of dialogues, as if I were writing a novel or a script for a documentary movie. I also read some books about writing styles, and how to write dialogues, descriptions, introductions, transitions and other tools novelists use to make the text come alive and to give it texture and variety."

"Really?" he asked, arching his eyebrows. 
"Yes. I also read Doing Documentary Work by Robert Coles. I got the idea from his book to use dialogues from a movie whose interaction among three people impressed me. It is called Mindwalk, and is based on Fritjop Capra's The Turning Point."

"The movie sounds familiar," said Damian, "but I don't think I've seen it. I know about Capra and his work, though."

"Great."

"How will you present your texts then?" he asked.

"I will use many of these narrative non-fiction tools in different parts of the book. In fact, I decided to write the whole book in a dialogic format."

"Can you elaborate?" asked Kurtis.

\section{Socratic Dialogues}

"Once I saw the power of expression in the dialogues with my collaborators, I decided to learn how to write other parts of the book in a dialogic format too. I read a book, for example, about 'Socratic dialogues'--I was motivated then to use the dialogic format for the whole book."

"I remember we read about these dialogues in our Ethics and Leadership class," said Kurtis. "The author was Plato."

"Right," I said. "Turco, the author of the book I read, appropriately called Dialogue, reminded us that the 'Socratic dialogue' is an excellent teaching technique."

"Why?" asked Damian.

"Because it is an interactive exchange of thoughts, feelings and experiences that build on each other," I replied. "It coincides with what Senge writes, as we discussed when we met last time."

"I see."

"Plato's dialogues read as if he had written them immediately after he had talked with Socrates," I continued, "as we would after we audio-tape an interview. It was not so, he wrote them much later."

"Really?" asked Damian.

"Yes. Plato's Dialogues contain elements of fiction to tell a story grounded on non-fiction conversations with Socrates. Plato wrote stories as dialogues to discuss the nature of 
truth. This is a difficult subject but the dialogue format made it easier to understand. This is why it's a good teaching technique."

"So you are going to write a story to discuss 'the nature of participation'?" asked Damian, looking at me and smiling.

"Hey, I am not Plato," I said laughing. "I'm just saying that his approach can apply to my book. What if I create stories as dialogues situated in Mondragón, including suitable descriptions to enhance the story? What if I dialogue with the reader to explore what participation means to him, her, you or me?"

"Got it."

"The dialogic format," I insisted, "as illustrated by Socrates, has worked well for my book. It has been a great learning tool."

"Teaching or learning tool?" asked Kurtis.

"From my point of view," I added, "it's a good learning tool for me also."

"What do you mean?" asked Damian.

"Have you ever played chess?" I asked.

"I have," he replied. Kurtis shook his head to indicate he had not.

"Well, let me tell you a story. I played a lot of chess when I was a child. I used to compete in local tournaments but didn't have anyone to practice with. So I learned to play the game for both opponents alternately. First, I'd play the white pieces, looking for the best possible move while anticipating my opponent's. Then, I would turn the chessboard around and play the black pieces, to find its corresponding best move. It was quite a mental exercise."

"A dialogue is the same then," said Damian.

"I think the learning process is the same," I replied. "If my purpose is to illustrate to the reader what I am trying to communicate, converting my mental or written stories into dialogues allows me to anticipate questions, and stimulates me to find answers."

"Is that how you felt during your conversations with your collaborators?" asked Kurtis.

"It varied," I replied. "Groing back to Socrates, sometimes the interaction seemed to be one-sided as he talked more than his disciples, but the questions posed by them prompted his insightful replies. I used a similar approach. Some of my collaborators, as Socrates, would tell a story practically without my intervention, others preferred me to take the 
initiative. So I asked questions or intervened accordingly. I learned from both, stories and replies to direct questions."

"Interesting," said Kurtis.

\section{Creation of Characters and Recreation of Locations}

"Since the book is going to be in a dialogic format throughout," I added, "I learned about other tools 1 could use, such as creating characters to dialogue with and recreating settings to facilitate comparisons with conversations among my collaborators and me."

"But then you will be writing a fiction book!" protested Damian.

"No, not really," I replied. "The characters I have created may be fictional but the contents of our conversations are strictly based on existing literature, and their sources are documented in detail at the end of the book. Any time a created character says something beyond asking questions or clarifying answers to move the dialogue along, his words are documented. When these characters help me express my final outcomes and interpretation of the story at the end of the book, their responses are also documented."

"And what about the recreated settings," added Kurtis. "What happens there?"

"The recreated settings or locations situate my collaborators in a space in which they can interact but again the contents of those conversations are based on our original interviews and have been approved by my collaborators."

"And what other tools will you use?"

"Expressing the data as narratives also gave me the opportunity to include descriptions of the culture, place, meals and other details of Mondragón and the sites for the interviews. I could also add anecdotes and tales and my reflections, which I started to record in my journal but then continued writing directly as part of the story."

"I see."

"Hey, how about a break? I need to stretch a little," said Damian.

I agreed. We all needed a break. We got up from the table and Kurtis and Damian walked out. I stayed behind and told the waiter we would be back shortly. He nodded and smiled politely, looking at the papers and books on the table. I figured he was wondering what kind of work we were doing and why sometimes our conversations were so intense.

There were few people at Mimi's, probably because it was 3 p.m. already. I looked out the window and pondered. As I explained my methodology, which seemed so well structured, I wondered: Is it really helping me to make sense of what I have been writing? I had trusted the process and was gratified I had found ways to express what my 
collaborators and I had experienced. But how was I going to distill the information to create the outcomes of the study? I had a growing awareness of the potential of participation as a meaning-making experience, using Patton's words. My concept of participation was becoming broader, adding a new dimension. My book was being transformed into a study of the phenomenon of participation and its significance at different levels of our experience. I began to see new patterns of meanings at and beyond the workplace...

Kurtis and Damian came back and we all sat down while the waiter refilled our cups with coffee and tea.

\section{Narrative Analysis and Other Data Analysis Tools}

"David and Kurtis," says Damian, "I wonder if it wouldn't be better to quit now and go out to the place across the street and have a cerveiza y nachous. He grinned. "Hey, how do you like my Spanish pronunciation?"

"Great!" I said, laughing. "Let's go."

"No, I am just kidding. It's just that I went out to walk a little and it is such a nice day. We'd better continue here." Kurtis and I smiled.

"What else do we need to know about your data analysis?" Damian asked.

I paused before we got into the conversation again. "Just as I learned to use some tools to represent narrative data, I also learned others to analyze narrative data."

Can you give us some examples of the tools you are referring to?"

"I used four: 'meaning units', three-dimensional structures of interview data, analysis of narratives, and narrative analysis. We can start with meaning units."

\section{Meaning Units and Horizontalization}

Damian and Kurtis took notes as I continued: "I learned about meaning units from a phenomenological study I read in Merriam's book. Meaning units highlight shifts in meanings in the texts, breaking these down into units than can be more easily analyzed."

"And how does this help you?" asked Kurtis.

"These meanings can be horizontalized, that is, treated as having the same value, whether they are mentioned once or many times, by one or several collaborators," I explained.

"They can also be reworded to express the meaning more clearly."

"I had not heard that term," he said. 
I smiled. "I know, neither had I before I learned about phenomenology. It's very appropriate for what I am trying to do, because horizontalization highlights comments made by each person that may be lost if we are only looking for what the majority of collaborators said."

"It emphasizes personal experience over that of the group," clarified Damian.

"Right."

\section{Three-Dimensional Structures to Construct Narratives}

"And what about the three-dimensional structures?" asked Damian, looking at the notes he had just taken.

"I learned a method to structure personal narratives in three dimensions, based on Clandinin and Connelly's work. First, I ordered the interview material in chronological order to give it continuity: past, present and future. Second, I classified personal and social interactions. They also call this going inward and outward. And third, I placed the dialogues in a situation or space."

"Sounds pretty clear," said Damian, looking at what he had just written. "And what about the remaining analysis tools?"

\section{Analysis of Narratives and Narrative Analysis}

"According to Polkinghorne's work about narrative inquiry, there are two: analysis of narratives and narrative analysis."

"You are just playing with words to confuse us!" said Damian.

"Bear with me," I replied, laughing. "They are quite different. In the analysis of narratives, I gather stories, find commonalities, and write descriptions that hold across the stories or characters. In narrative analysis, I gather descriptions of events and configure them by means of a plot into a story."

"Got it," Damian said. "In analysis of narratives, you take stories and look for common elements; in narrative analysis, you take individual elements and make them into stories."

"Polkinghorne could not have said it better himself?" I exclaimed.

We all laughed. Kurtis glanced at Damian and looked at me. "So what kind of analysis did you do?"

"I did mostly analysis of narratives but also some narrative analysis. We can talk about at what stages I did each one, when we review the Data Analysis Process Flow Chart," I said, as I pulled a copy of the chart for each one. 
Data Analysis Process*

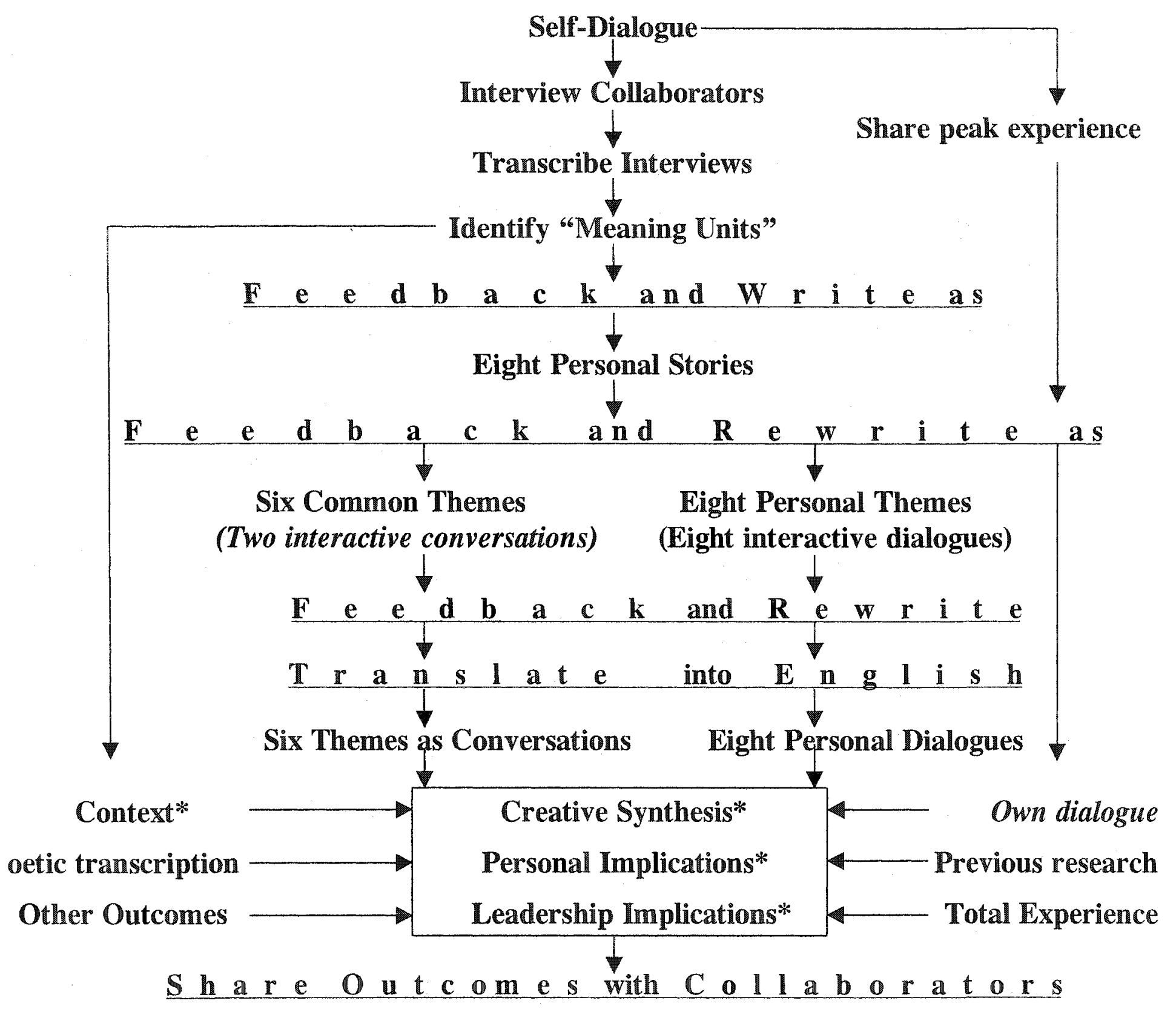




\section{Data Analysis Process}

"Is this a new methodology?" asked Damian, seemingly uneasy after glancing at the chart.

"Not really," I said calmly. "Remember we talked about having to "invent a phenomenological process' because there are no set methods? Well, I did not really invent one but combined Moustakas' and Merriam's suggested analysis processes and applied narrative analysis techniques from Clandinin and Connelly, and Polkinghorne."

"This looks like a pretty busy chart," said Kurtis.

"Yes, but it is not complicated. I'll walk you through it."

I drew an imaginary rectangle with my finger on the middle of the chart. "The core of the process is in this area." I then used both hands and moved my index fingers down the edges of the page. "There are two contributory inputs: the context and my own dialogue based on what I called a peak experience with participation." I then drew an imaginary circle at the bottom of the page. "These are the outcomes of the study."

I paused. Kurtis and Damian kept looking at the chart, as if waiting for me to continue.

\section{$\underline{\text { Self-Dialogue }}$}

"I'll follow the flow of the process with you now." I said, turning my copy of the chart to face both of them so they could follow it with me. "It is much easier to understand the flow of the process if we look at the chart as I speak."

Kurtis and Damian looked at the chart intently.

"The analysis process begins with what Moustakas calls a self-dialogue."

Damian looked at me. "You dialogue with yourself?"

I smiled. "I did this early in the process. It is actually a written reflection of my experience with participation in decision making. It was guided by questions as those I prepared for my collaborators. Its purpose was to delve into my own lived experience and use this knowledge to interact with my collaborators with increased awareness of my experience. I finished this before I went to Mondragón."

"I see."

\section{From Interviews to First Cycle of Feedback}

I pointed to the chart. "Once in Mondragón, I interviewed my eight collaborators, four men and four women, transcribed our interviews and did my first narrative analysis." 
"Really?"

"Yes," I said. "I did the first narrative analysis when I transcribed the audio-taped texts from our interviews and eliminated comments not relevant to my topic. I identified the meaning units from the transcribed data and presented them to my collaborators for their first feedback cycle."

"It makes sense," said Kurtis. "And how did the feedback of the transcripts go?"

"Quite well. Three collaborators enriched the written transcriptions by adding material in the second interview, and all but one person changed something, even if it was just clarifying one paragraph."

\section{"Good."}

"It was really exciting to see the openness and interest of my collaborators," I said. "One of them and I met for a longer period the second time because she had gone through a process of introspection after our dialogue and wanted to discuss her feelings about it."

"Great!" exclaimed Damian.

"And then?" asked Kurtis.

"As suggested by Moustakas, I tried to stay with one collaborator at a time until we met for the second time for the review of the transcripts. When I had finished half of the interviews, I paused and took a break to assess how my research work was going."

"Go on," said Damian.

\section{Verifying Research Objectives and Methodology}

"During this break, I reviewed the objectives of my research study and my methodology. My objectives were to keep the voice of each person at the center of the research, to keep the general reader involved, to present data in a 'reader-friendly' way while respecting the original material, and to include my own participation throughout the study."

I paused. "The methodology I had used so far fulfilled some of these objectives but not all of them. It asked for two 'exemplary portraits', or typical stories representing the responses from my eight collaborators, and a group summary of what the majority had agreed on. This approach was not appropriate to keep my individual stories alive."

"So what did you do?" asked Kurtis.

"I modified, in fact, augmented the scope of the methodology to fulfill my objectives." 
"In what way?"

\section{Writing Personal Stories}

"Instead of two exemplary portraits, I wrote eight personal stories based on the interviews, to highlight the diversity of experiences and responses to my questions. These stories were based on the original dialogues, after the first cycle of feedback. I structured the material according to Clandinin and Connelly's three-dimensional structural approach to put the stories together. The key to writing the personal stories in such a way that they could be analyzed was to follow a consistent method, restructuring the stories but adhering rigorously to the original taped material."

"You had a second cycle of narrative analysis to write this stories, I assume," said Damian.

"Yes, as I structured the stories in three dimensions, I sought only the meaning units that fit this scheme."

"And what objective did you fulfill by writing the eight personal stories?" asked Kurtis.

"I kept the voice of each collaborator at the center of the research, respected the original material, and provided texts to fulfill the rest of the objectives. I'll talk about this next."

"Were these like life stories or biographies?" asked Damian.

"I see them as partial life stories, because they show pieces of my collaborators' lives, as they relate to participation. I rewrote them as first-person-singular stories, for example writing "I, Lorea, was born...." This way, each collaborator would be intimately involved and sense if my representation of our interviews reflected what they felt and thought."

"I can see how saying "I began to participate..." is more powerful than "People usually start to participate..." or "Participation began..." said Kurtis.

"Precisely."

"And you could write these personal stories even though your original interviews were informal and unstructured?" asked Kurtis.

"Yes. Not all stories were perfectly symmetrical but this was not important because the purpose of the personal stories was to record the experiences of my collaborators at the level they felt comfortable sharing them."

\section{Avoiding Interpretation of the Texts}

"David," Damian said, "I understand that you intend to expose your reader to your dialogues with your collaborators, respecting the original texts as much as possible." 
"That's right," I said, wondering what his question would be. "That is one of the major outcomes in my book. I intend to save the reader a trip to Mondragón," I added, smiling. "He or she can read my collaborators' stories directly."

Damian looked at me. "Different from my dissertation, and probably Kurtis', which is available to the reader only as our interpretation of the data, yours is trying to avoid interpreting the story. Can you tell us how you did this?"

I looked at Damian and Kurtis for a moment while I gathered my thoughts. "I consciously tried to minimize my interpretation of the material," I said. "However, yours is a good point. I am aware, as pointed out by Mishler, that some interpretation is inevitable."

"Why is that?" asked Kurtis.

"Mishler says that we make stories, not find them," I replied. "I think this is very accurate. We retell what our collaborators tell us through our re-descriptions, coauthoring the story with them. We construct the story and the meaning."

"So, can you say that you really are not interpreting the original dialogues?" asked Damian.

"I can only say that this is one of the reasons I asked my collaborators to review the texts at several stages. They were able to rectify, ratify, delete or add to what they had said anytime, from the original dialogues up to the final version. If I interpreted something that did not ring true to them, they could change it. And some did!"

"Do you think that was enough?" asked Kurtis.

"I endeavored to avoid an interpretation of the dialogues but probably the most accurate statement would be what Mishler writes: my collaborators and I co-authored, coconstructed, co-created the dialogues and their meanings."

"Fair enough," he said.

\section{Personal Stories Become Group Conversations and Personal Dialogues}

"I can see that you have the second feedback cycle after you wrote the personal stories so the personal stories were ready and available to the reader," said Damian.

"That was my original idea," I said, "and I could have just considered these stories to be my outcomes for the study, translate them into English and consider the research field and analysis work completed."

"And why didn't you do it?" he asked. 
"Because of what you asked me earlier: this step in the process did not yet fulfill all my objectives."

"Can you elaborate?"

"I had a dilemma when I rewrote my collaborators' personal stories. They contained some themes unique to each collaborator and some that were common, albeit with diverse views, to several of them. I had three choices to represent the data: ignore this commonality and let the reader sort out the diversity of views; segregate the common themes and write about them reflecting the view of the majority; or segregate these themes and find a way to keep the individual voices alive."

"So what did you do?" asked Kurtis.

"Only the third choice fulfilled my objectives: segregate these themes and find a way to keep the individual voices alive. I struggled for some time to find a way to accomplish this. After reviewing the available tools of narrative non-fiction, I thought of a solution: What if I recreated a group setting, in which my collaborators could talk to each other, and to me, with their own words, extracted from the personal stories?"

"How did this solution help your objectives?"

"In three ways. First, the collaborators' voices were maintained. Second, the exact words were transferred from each personal story into a group conversation. Third, the reader could 'hear' the voice of each collaborator, compare and contrast their responses, and form his or her own view."

\section{Recreating Group Conversations}

"Can you explain how you put together these group conversations?" asked Damian.

"Yes, For the group conversations, I placed several collaborators in a recreated setting interacting with others and me about common themes -- those which had come up in the interviews and they had talked about."

"Common themes or common responses?" asked Kurtis.

"The purpose of my phenomenological study is to 'hear' the voice of each collaborator. This is why I refer only to common themes, which including diverse responses. A reader can find common responses, that is, those that most collaborators agreed upon, as Other Outcomes at the end of this chapter. It's interesting to identify these common responses but they blur the impact of the individual voices, so they appear in a separate section."

"Extracting these diverse responses from the personal stories sounds difficult," Damian said. 
"Not really. Once I had structured the stories in terms of continuity, interactions and situation, as Clandinin and Connelly suggest, it was not too complicated."

"I sense there was a third analysis of narratives to decide on the common themes."

"Indeed."

"Are you highlighting commonalities or differences?" asked Kurtis

"Neither, I only seek to identify the common themes. As Polkinghorne writes, group narratives may vary from complete consensus to no agreement at all. The reader will find consensus at times, but will also be able to 'hear' diverse arguments and dissenting voices. This is how this study is different."

"So you deviated from your original data analysis process again here?" he asked.

"Not really. I still used the method I had planned to use, from Merriam's example of analyzing phenomenological texts at the individual, group and comprehensive levels. My breakdown of personal dialogues and group dialogues coincided with it, but I took the extra step of maintaining each voice alive, instead of a summary of the group's."

Kurtis and Damian just looked at me. "What recreated settings did you use?" Kurtis asked.

"I used a set of chiquiteos in which we met as a group."

"Oh, yes, I remember the chiquiteos," said Kurtis, as he turned to Damian with a spark in his eyes. "A chiquiteo is like 'cruising' from bar to bar. The difference is that in Mondragón this is done right after work, and everyone is included--men, women and children. Groups of friends order small glasses of wine (or beer) and socialize in the bar. After a while, these groups move to another bar and ask for another small glass of wine, and so on."

"Well said," I concluded.

"So, what objectives did you fulfill by taking this detour from your personal stories?" asked Kurtis.

"I made it easier for the reader to contrast the diverse responses about common themes, thus keeping him involved and giving him or her some material to reflect upon."

\section{Rewriting Personal Stories as Personal Dialogues}

"And what did you do with the remaining text in the personal stories?" asked Damian.

"The personal stories, after extracting common themes, contained what was personal and 
unique in each of my collaborators. It did not, however, include our interactions and the accompanying dynamics of our original dialogues. Also, the eight stories had been structured exactly the same way for analysis, but I thought were tedious to read each one in chronological order."

"So what did you do?" Kurtis asked.

"I converted the stories into interactive dialogues between us, always respecting the original material and restructuring it in such a way that the unique themes from each collaborator appeared at the beginning of their stories."

"So this was still part of the third stage of narrative analysis," said Damian, "in which you highlighted certain themes and restructured the rest."

"Yes, and this was more difficult than the previous ones." I replied. "The personal stories had texts with each collaborator's part of our conversation but excluding mine. To share our dialogues with the reader, I converted these stories into interactive dialogues, with both our voices."

"Why did you write them as dialogues? You already had the personal stories written, you just had to add some of your comments," said Kurtis.

I shifted on my chair. "Because keeping these personal stories in prose form and superimposing my comments would have been very cumbersome and would have eliminated my part of the dialogue and the dynamics of our interactions. A dialogical format resembled our original dialogues but included exclusively relevant material: the meaning units. The personal dialogues were more concrete and fluid."

"More 'reader-friendly'?" asked Damian, mockingly using my words.

"Yes, and more comprehensive. Just as I had encouraged my collaborators to add to our original dialogues and personal stories when I asked for their feedback, this time $I$ added some text to include my voice with short stories, experiences, questions and comments, as called for in heuristic studies."

"Is this why you sent the narratives back to your collaborators? Because you had added some material?" Damian asked, pointing to the third feedback cycle on the chart.

"It was one of the reasons, but I didn't expect much feedback because I only included comments to enrich a point or to add some texture. Another reason was that I wanted my collaborators to 'hear' their voices in the group dialogues to give them an idea of what their colleagues had said, and to make sure they agreed that their voices be presented in a group setting."

"And what reactions did you have?" asked Kurtis. 
"Very positive. They liked the interactions and told me the conversations seemed very natural."

Damian turned a few pages back in his notes, looking as if he had something left to say.

"How did you segregate the common from the unique themes?" he asked, frowning. "I mean, physically, what was your procedure to classify and transfer these data?"

Ilooked at Damian and smiled. "I first decided on the common themes by reviewing the individual personal stories. When I had classified the narratives in three dimensions, I had written titles above each meaning unit in capital letters, directly on the text shown on the computer screen. I classified these as 'unique' and 'group' meaning units, using different colors on the computer screen. I transferred colored meaning units to each one of the identified common themes and kept unique themes for the personal dialogues."

"Got it," he said.

"So the objective you fulfilled by writing these personal dialogues was to participate in the study by interacting with your collaborators, one at a time," said Kurtis.

"Yes, but also to keep the reader involved as he or she will have eight personal dialogues and six conversations about common themes, with everyone's voice, including my own, to read directly."

"Sounds good," he added.

"In addition, by this time, I decided to contribute also by including entries from my journal as reflections for the reader to ponder. I discontinued writing my journal and started including my musings after each event directly on the text."

"A lot of self-disclosure, huh?" said Kurtis.

I smiled and nodded. "I suppose you can say that, I received the same from my collaborators."

Damian looked at the flow chart. "It looks like we are at the end of your analytical process. How do you feel about your process? And what was next?"

"I'm satisfied that the texts reflect what my collaborators said during the interviews, enhanced by three feedback cycles in which my collaborators could add, modify or delete anything. It was a long process made easy because of the enthusiasm and willingness of my collaborators to participate in it. My next step was to translate the texts from Spanish to English."

"How did it go with your English translations?" asked Kurtis. 
"Really good, although I had to wait a little longer than I expected to complete the work."

"Why was that?"

"Because I continued having feedback from my collaborators. One of them rewrote her personal story during the December holidays to include new insights and make them more explicit. Another shared his story as I had written it with colleagues and modified it based on their feedback. I included both of their revisions."

"This is amazing!" exclaimed Kurtis. "But when did you stop adding material?"

\section{"Ownership" of the Research Texts}

"I see the texts as belonging to my collaborators as much as to me," I replied, "so I welcome their feedback. Different from other research methods, I do not consider I own the texts. At best, as mentioned in Patti Lather's paper, I consider myself a 'majority shareholder'. As I see it, the modified texts get us closer to the lived experience of participation. This is my purpose, so I am happy we continue enhancing the story. However, I think we are finished adding material..."

"For now..." said Kurtis, incredulously.

"Yes, for now," I repeated, smiling. "I have now translated all final dialogues from Spanish to English so we'll add nothing new. Any further feedback, and I think there will be some, will be made after my collaborators read the book."

\section{Sharing My "Peak" Participatory Experience}

We were quiet for a minute. I looked at the chart to check what else needed clarification. "I'd like to describe the two contributing inputs on the edges of the page," I said, running my index fingers of both hands along the arrows pointing down."

I paused again. "The sharing of my peak participatory experience, renamed only after my collaborators identified it as such..."

"How did they know that it was a peak experience?" asked Kurtis.

"My original questionnaire intended for my collaborators to tell me about one peak experience they had had, but I quickly found out that, for a person that participates all the time, it is difficult to identify a peak experience. In contrast, my self-dialogue expressed one experience I had, selected among three experiences I had written about in my selfdialogue. My collaborators immediately said when they heard it: "Yours was a peak experience, which is more intense because you do not participate every day'."

"It makes sense." 
"I shared my self-dialogue about one intense participatory experience with my colleagues at work in the mid-eighties. I placed my collaborators and I in a simulated final luncheon in which they reacted to my account of the experience. As in the group chiquiteo conversations, I had discussed my self-dialogue in private with each collaborator and I transferred their exact responses to the conversation after the luncheon."

\section{Outcomes Based on Dialogues with My Collaborators}

"And what did you end up with?" asked Damian.

"I had a total of fifteen outcomes based on the interactive interviews. Six interactive conversations about common themes in two chiquiteo gatherings; eight interactive dialogues, one for each collaborator, based on their personal stories and unique experiences; and one final conversation about my self-dialogue. Each dialogue and my corresponding reflections afterwards stand on their own, as if they were short stories. These are included in Part I, Chapters 6 through 10."

\section{Context of the Study as a Contributor to the Final Outcomes}

"And what about the context?" asked Damian, pointing to the left arrow on the chart.

"The context will be mostly derived from our interviews. It will provide grounding and texture to what my collaborators consider relevant to share with me. In addition, I will also provide some references about available literature in the Notes and Sources and in the Bibliography, in case the reader is interested to know more about the Mondragón story or about participation at the workplace."

"And will you also have a literature review?" asked Kurtis.

"Since phenomenology focuses on learning from lived experience, what I'll provide is a relevant context, as I just described, instead of a traditional literature review."

"But the literature review is an integral part of a research study," said Damian.

"You are right, if you refer to other qualitative methodologies," I replied. "But phenomenological studies intend to explore lived experience, which is unique. The literature review would not contribute to understand this personal experience."

"Okay. So tell us more about the context you'll provide."

"The context is a helpful input to frame the individual experiences, written as stories." I said. "It also contributes directly to the final outcomes of the study, The context uses the dialogic format in a very exciting way. You can read these stories expressed as dialogues in Chapters 3 and 4 in Part I."

Kurtis and Damian just looked at me. "But how can you write context as a dialogue?" 
asked Damian.

"That's right. Did you interview someone about the context?" added Kurtis.

"No," I replied smiling. "Here is where I will use readings from the literature, my previous research and observations. I will take facts, with their respective references, and gave them 'life' through my voice and that of the three characters I created."

"You have to tell me more," he said. "Is this the tool you talked about earlier, creating characters to dialogue with you in parts of the story?"

"Exactly," I replied. "But let me tell you about the context first. It is about the principles of Mondragón and the role of Arizmendiarrieta, the founding priest. The principles are well documented and Arizmendiarrieta's life can be found in numerous stories written about him by people who knew him. His journal is also a good source."

"And will you convert these sources into dialogues," said Damian.

"Yes. It's more difficult than the personal dialogues with my collaborators but it is a worthwhile effort," I said. "I'll research the materials for the context, write them as narrative prose, and document their reference sources. Then I'll convert the narrative into dialogues among the characters I will create and myself, situated in various places in Mondragón."

"So, instead of narrating a story, we'll 'hear' your voices making comments or asking questions," said Kurtis.

I nodded.

"And who are the characters you will 'dialogue with'?" asked Damian.

"Sarah and Bill, a young couple visiting Mondragón; Padre Antonio, a priest visiting the local church; and myself.

"And how did you select these characters?" asked Kurtis.

"I created them to resemble people I have met," I said. "This helped me visualize how they would speak and act. I included questions or comments others have had regarding the contents of my book. It made the conversations seem real, at least to me."

I paused for a moment. "The key in these dialogues is not the characters but the contents. The characters are like actors in a play, a vehicle to articulate the context as a series of dialogues."

"I get it," said Damian. Kurtis nodded. 
"Did you create any other characters in your book?"

"Yes, I borrowed a story that Lorea told me about an English professor that had visited Mondragón recently and had questioned the participatory approach to making decisions. Since Rosario had also talked about this issue, I created Stewart and, again, used exact words from Lorea and Rosario to interact with him and me. My words move the story along, facilitate the conversation, and offer an anecdote from my own experience."

"I see."

I added: "Concepts with an asterisk in the Data Analysis Process Chart indicate that a created character has helped me tell a story. Concepts in italics indicate a recreated location with individual responses placed in a group setting."

We paused for a moment as we looked at the Data Analysis Process Chart. "And what about the other inputs for your final outcomes?" asked Kurtis.

"I also consulted previous research including my pilot study from year 2000 and the poetic transcription I wrote at that time, based on the responses of the study participants during the interviews. In addition, I am using input from other outcomes to help me synthesize the final outcomes and find implications. Finally, I will reflect upon the total experience from the beginning of the process two years ago until now."

\section{Other Outcomes and Sharing Final Outcomes with My Collaborators}

"What can you tell us about Other Outcomes?" asked Damian.

"These are based on common responses from several of my collaborators and observations I made that could be applied to most of my collaborators. You can read them in Chapter 11 in Part II."

"And the synthesis and implications?" asked Kurtis, pointing to the chart.

"They are the final outcomes of this book based on the group and personal dialogues, research, observations and reflections. These outcomes are my interpretation of the study and they are described in Chapters 11 and 12 in Part II."

"Okay. Is there anything else to add?" he asked.

"Just to tell you that I will be going back to Mondragón next June to share my outcomes with my collaborators. I am really looking forward to their reactions."

"Great, David," said Damian, as he looked at his watch. "I've got an appointment..."

"You are right, it is late," Kurtis said, looking at his own watch. 
"Time to go," I said. "How about if I call you when I am ready to continue? We have to talk more about my methodology."

"Fine," I said, as we got up from the table. We walked out and left the restaurant. We shook hands at the parking lot and left. 


\section{CHAPTER 15}

\section{SIGNIFICANCE OF THE STUDY, DOCUMENTING SOURCES, LIMITATIONS AND DELIMITATIONS, TRUSTWORTHINESS}

Today is February 7, 2004. I anticipate this will be a short meeting. We have not met for a long time so I have been calling Damian and Kurtis to stay in contact and to set this meeting. Damian called to advise me that he would be late. Kurtis arrived on time. We sat at the table and ordered an iced tea.

\section{Significance of the Study}

"So, how do you feel about your dissertation, David?" asks Kurtis.

I paused for a moment before answering him. "I am really happy with it, but have one concern. One of the reasons I am writing a dissertation as a book in a 'reader-friendly' format is to facilitate the absorption of a research study about a counter-cultural topic."

"You mean accepting that we should be taking part in the decisions that affect us?"

"Yes, I hope readers will be stimulated by reading the book to work towards getting involved in decision making."

"They probably will be."

"You know as well as I do that becoming aware of what participation could be like will become a threat to the way we think, work and live. Once the readers awaken to what is possible, assuming they accept the challenge, they will have to make major changes."

"I understand your concern but your book is primarily a dissertation," Kurtis said. "I know you are writing this dissertation as a book to reach the general reader but I don't see why you should be so concerned with the readers' reactions. Your basic responsibility is to present a research study as a contribution to the field of research in participation in decision making."

"How do you think I am contributing to the field of research?" I asked, curious to know his perception of the relevance of my topic.

"I think you are adding a new dimension to the myriad of writings about participation, empowerment, decision making, leadership, et cetera. This is a significant contribution."

"Probably," I said, "but I would like my book to be also significant to readers beyond the academic circles."

"I think it will be. Most readers who are trying to improve their own or their organization's environment, motivation or performance are looking for solutions by 
changing policies, processes or procedures, as I did myself before we talked about your book."

"We need systems in place too," I said.

"Yes," Kurtis replied, "but you are reminding us that we need to focus on the person. This is how your book is significant to all your readers. You are adding one important piece to that whole picture by emphasizing that nothing can be done if $\mathrm{I}$, as a person, do not think it is important to do things differently. You bring to our attention that participating in deciding what is important to us is one very important aspect of our lives that we may not even be aware of."

We were silent for a moment. "Also,' Kurtis continued, "you have provided a series of dialogues with experienced participators that your readers would not have access to if you had not spent ten weeks in Mondragón last year and if your collaborators and you had not spent countless hours trying to share your experiences in writing."

"And how is that relevant?"

"If we want to live a more meaningful life, it is worthwhile to explore what role our participation in the decisions that affect us plays in it. You provide us a series of narratives that help us reflect upon the potential significance of becoming involved in the decision making process."

"Now you are beginning to sound like me!" I said, smiling.

"I know, and I think that thoughtful readers will find resonance with your book too."

"There is one aspect we have not talked about. From the beginning, I also hoped to contribute to the perception my Mondragón collaborators have of participation. They'll be able to read their own words and what others in the cooperatives think and feel. It would be great if they find these readings helpful."

"Good," said Kurtis. "You also contribute that way with your book..."

I could see Damian approaching us. He apologized for being late and said he had a lot of questions for me. He sat down, also ordered an iced tea and we ordered our meal.

Kurtis looked at Damian: "David and I have been talking about the significance of his book and the contribution to the field. I told him I thought his perspective focused on the person helps to gain a fuller perspective of participation. What do you think?"

"Have you discussed the contribution to the field of phenomenological research by designing a methodology that can be used by others?" asked Damian.

"Well," I said, "Mine is just a modification of others I read about." 
"Yes, but others may look at yours the same way. They may adopt or adapt your methodology but you still have contributed by providing a point of departure to design theirs."

"Good point," said Kurtis.

"I like your encouraging outlook," I added.

The meal arrived quickly and we shared the usual stories about Christmas vacation, our families, how difficult it had been to go back to work afterwards, and how the New Year resolutions had evaporated by the beginning of February.

Kurtis and I ordered a cup of coffee while Damian preferred to have a refill of his iced tea. Although we had been in contact by phone and e-mail, we had not discussed my book for several months. I had briefed both on the status of my book and they had come prepared to talk about it. I pulled my notes out of my pocket and so did Kurtis and Damian.

\section{Documenting Sources}

Kurtis looked at his notes. "David, I have been wondering about your sources. You are writing your story as a series of dialogues but you are using a lot of research material, both to design your methodology and to tell the story of Mondragón. How are you going to document your sources?"

"I have written my book as a story with dialogues that make it easier to read," I said. "Thus, $I$ will not use superscripts or other reference symbols in the text, which would interrupt the flow. My book is intended to read like a novel, not a research work. Of course, the methodology is also interesting and that is why I have described it in this section as part of this book."

"And how do you let the reader know where to find reference sources?" asked Damian.

"Reference sources will be abbreviated and prefaced by a few key words in a Notes and Sources section at the end of each Part of the book. I will also include a Bibliography at the end, which will provide more complete information about the reference sources."

"Did you design this system of citing references yourself?" asked Kurtis.

"No, not at all. I spent quite a bit of time looking for narrative non-fiction books that would serve as models. I found three fairly recent books: Flow by Mihaly Csikszentmihalyi, Den of Thieves by James Stewart, and All the Shah's Men by Stephen Kinzer. These books read like novels but required extensive reference sources and notes because of their detailed descriptions and explosive topics. The first one, written in 1990, is about the experience of flow, which I'll refer to in Chapter 11. The second one, written 
in 1991, is about the scandals in Wall Street in the late 1980s. The third one, written in 2003, documents the American coup in Iran in the 1950s.

"Interesting!" he exclaimed.

"I concluded that if Csikszentmihalyi, a renowned psychologist; Stewart, a Pulitzer Price winner; and Kinzer, a well-traveled New York Times correspondent and previous bureau chief of the Berlin and Istanbul offices, could use these reference formats, I could try it too."

"Okay, I understand."

\section{Delimitations and Limitations of the Study}

"We can go to the next question," said Damian. "Can you tell us about the delimitations of your study?"

"Fine," I replied, placing my right elbow on the table and resting my chin on my hand. I looked at Damian. "My book has some delimitations. Although the purpose of my book is to delve into the meaning of participation for the reader, you and me, its texts are based on the experience of eight people who have extensive and intense experience participating."

"And most people don't have that experience," he said.

I nodded. "Also, these eight people live in the Basque region of Spain and work in a cooperative environment which promotes participation."

"And most people don't," added Kurtis.

I nodded again. "These are the main ones."

"And the limitations are...?" asked Damian.

"Okay. I am following a non-traditional method of analysis."

"Which may provoke many questions..." he added.

I nodded.

"Fine. What else?" he continued.

"The texts are translated from English to Spanish."

"Okay." 
"By the way you have described your work, you have a lot of thick descriptions," said Damian, "which, by definition, include a lot of descriptive data. Hopefully this reduces the impact of the translation limitation."

"Yes. The dialogues in the book are mostly thick descriptions, describing detailed interactions and including abundant data. My choice to show all dialogues as thick descriptions instead of a summary based on the interpretation of these dialogues was to involve the reader in the whole research process, as Patton suggests, but the descriptions are still there."

Damian kept silent and looked at me, waiting.

"And," I added, "some may disapprove of my becoming intimately involved in the gathering of the material for the book. There is some mystique about supposed objectivity."

"Yes, we already talked about that," said Kurtis. "It's hard to tell how many people see it as we do: objectivity, especially in research, does not exist."

I nodded. "Also, there is a limitation because my dissertation is presented in the format of $a$ book that uses non-academic vocabulary to make it accessible to the reader and it stimulates the reader to get involved."

"Why is that a limitation?" asked Damian.

Kurtis got ahead of me. "Because David's book will be more like a European movie, and some readers may prefer a Hollywood ending..." He laughed.

"You mean Hollywood movies have all loose ends neatly tied up at the end?" asked Damian, frowning while he looked at me.

"Something like that," I said. "I have a creative synthesis and a chapter about implications but I have no neat final chapter with digested conclusions. That's for each reader to come up with, after some reflection."

"I think that's fine," said Kurtis.

\section{Trustworthiness}

Damian looked at his notes and then at me. "I need to bring up the issue of validity. What can you tell us about it?"

"Looking for a question I can't answer?"

"Well...?" he retorted. 
"It is a good point," I said, speaking more seriously. "In phenomenology, the term trustworthiness is used, but it is similar to validity."

"Fine, trustworthiness then..." said Damian.

"Right. I endeavored to built trustworthiness in my book mostly with the multiple cycles of feedback of the narratives by my collaborators."

"I did the same with my dissertation, but I called it member checking," he said. "The people I interviewed checked my transcripts."

"It's the same thing," I replied.

"Yes, but your collaborators read the texts at three different stages," added Kurtis. "This goes beyond member checking."

"You're probably right," I replied. "The last cycle of feedback included the final narratives. Perspectives change with time and, as we discussed earlier, some of my collaborators modified their texts, so I feel that their feedback about the final dialogues represented their evolving thought and increased the trustworthiness of the narratives."

"How about triangulation?" he asked. "You know, relating at least three techniques or sources of data, for example?"

"There is triangulation in the common experiences of my collaborators, which can be construed by the reader when reviewing the chiquiteo narratives. There is also triangulation in the common responses I described earlier in Chapter 11. However, I do not consider triangulation as a major source of trustworthiness for my book."

"Why not?" asked Kurtis.

"Because mine is a phenomenological study, concerned with the meaning of experiences instead of the generalization of the outcomes or the advancement of theories. I think triangulation is not always applicable to narratives or phenomenology, in which the purpose is to explore the singular experience of the collaborators, not the aggregate one."

"Can you review this for us?"

"My objective, and the reason why I have gone through great pains to include as much of the original texts as possible, is for the reader to find resonance with the voice of any of my collaborators. It is about learning from unique individual experiences."

Kurtis rephrased my words: "You intend the reader to be able to identify him or herself with some of the experiences of your individual collaborators."

I nodded. 
"And how about your method of analysis, you had to design your own," said Damian.

'I reached beyond Worthen's approach in Merriam's book and Moustakas' method for heuristic phenomenological studies to make it more comprehensive."

"Would you say that your methodology is as trustworthy as that suggested by Merrian Moustakas?" asked Damian.

"I believe it is more complete. Instead of two sample exemplary portraits, I wrote all eight personal stories. Instead of a group summary, I created interactive conversations including all individual voices. Instead of using my self-dialogue only as a point of personal reference for the interviews, I shared it with my collaborators. All this resulted in keeping all personal voices present throughout the process and in a fruitful interaction about our common experiences with participation."

"Any other sources of trustworthiness?" asked Kurtis.

"The analyses of all dialogues followed a consistent approach and were structured in a chronological order in the three dimensions suggested by Clandinin and Connelly. I followed this method rigorously with each personal dialogue."

"This should be enough, I guess." said Damian.

"Lather mentions a non-traditional measure that is more appropriate for phenomenological and narrative analyses," I said. "Face validity."

"What does that mean?" he asked.

"The narratives must provide a 'click of recognition' or 'yes, of course' reaction from my collaborators. This is similar to member-checks but it is more demanding because it is applied to the outcomes, not the intermediate steps of the study. I will meet this criterion of trustworthiness if my collaborators agree that the outcomes of my study make sense.

"Good," said Kurtis.

"Another one. I've had experience with participation, and the lack of it, for 27 years. I've studied Mondragón for nine years; have visited it nine times; and stayed in Mondragón for ten weeks last year to gather materials for this book. I am confident I have had enough experience with participation and contact with the culture of Mondragón to write this book."

Damian looked at his notes. "What you are referring to is called prolonged engagement and persistent observation by researchers," he read, "as I am sure you remember?"

"I had the term on the tip of my tongue!" I exclaimed, jokingly. "How do you know what 
it's called?"

"Kurtis and I discussed it before we met today and I took some notes," Damian said, laughing. "We thought it was important to challenge you on the issues of validity."

"I hope you are satisfied..."I said.

"Any other?" asked Kurtis.

"I have a few more comments," I said. "Authors I have read lately critique the undue importance that has been placed on trustworthiness based on techniques that do not recognize (tacit) subjective knowledge, as that which arises from experience."

"For example?"

"There is an emerging measure of trustworthiness that I'd like to share with you because it made me think about the way I wrote my dissertation as a book: catalytic validity. It represents the degree to which participants (including readers of the book in my case) are motivated to transform reality after reading the book. Paulo Freire calls it "conscientization"."

"Tell us more," said Damian, frowning.

I read from my notes: "Catalytic validity recognizes that the research done to write the book alters reality and channels its impact to a gain in self-understanding and selfdetermination."

"I assume the readers will be able to assess this measure of validity," said Kurtis.

"I certainly hope the book will help readers to gain self-understanding and motivate them to change their reality regarding participation in decision making."

"We do too," he added.

"I mention this measure of trustworthiness," I continued, "because I find it very interesting that academics are devising measures such as this to evaluate the impact research has on people's lives."

I paused. "This is encouraging because I wrote this dissertation as a book so that general readers will be motivated to read it, reflect on it, and hopefully make some changes in their lives."

"And how does catalytic validity help?" asked Kurtis.

"I would presume that catalytic validity is meant to be assessed by having academics and 
general readers reviewing research studies. If such is the case, my objective to write this dissertation in narrative form for the general readers is affirmed."

"I think it follows," said Kurtis, "that if catalytic validity becomes a standard measure of trustworthiness, researchers will feel the responsibility to write for general readers."

"Good point," said Damian.

"I understand that the first responsibility of an author is to write in such a manner that others will want to read his or her work." I said. "What would happen if researchers had the same requirement?"

"Good question, David," said Damian. "I hope your work poses it to future researchers."

I looked at my watch. "Hey, how about if we stop now?" I suggested. "It's getting late and I know you have things to do."

"You are right, David," said Damian. Kurtis nodded in agreement.

We had been in the restaurant for a long time so we left promptly and said goodbye at the parking lot. We agreed to meet again on Saturday, April 17, 2004 to talk about my interpretation of the study. The contents of this meeting are in Chapter 11 in Part II.

Some final comments for you, as I reread this research and methodology section on June 30, 2004. As you know, I have written this dissertation as a book for general readers like you. Throughout the process of writing it, I often wondered if I would be able to reconcile the requirements of writing a dissertation with the freedom of writing a book. Would this be a non-fiction book that is too constrained by the methodology used to write a dissertation? Or, would it be a dissertation that deviates too far from accepted research methodology in order to make it accessible to the general reader?

After I went back to Mondragón earlier this month, I spent a few days in Barcelona. I went to an unusual, fascinating art exhibit at the Miro museum titled "La bellesa del fracás/ el fracás de la bellesa," [The beauty of failure / the failure of beauty] about utopian art in the 19th and 20th centuries. During the visit, I recalled comments from three people who had read parts of my dissertation and had referred to it as being "art."

These comments made me uneasy because they reminded me of the question about writing the dissertation as a book. And then, as usually happens with such troubling questions, I found a glimpse of a possible answer in the most unexpected place. I read an article in the Spanish El País newspaper from Roberta Smith, written in the New York Times of May 27, 2004, referring to the function of art. I immediately connected it with the exhibit I had just seen. Paraphrasing Smith's words: 
Art is a fusion of ambiguities and multiple interpretations.

The function of art is to provoke in the mind uncomfortable thoughts. It is a place to experiment with themes that have no solution, to practice the magic of abstract flexibility that can move us to act in real life

Is this book a dissertation? Describing the research design and methodology in this part of the book confirms that it fulfills the requirements of a dissertation. Preliminary feedback for the book also shows that it is easier to read than a research study written in a traditional prose style.

One question remains: is this book also "art"? And does is fulfill the "function" of art, as expressed by Smith? Rereading her words, the book reveals ambiguities and allows for multiple interpretations. It also exposes you and me to the issues related to the meaning of participation, a theme that may appear, to those of us who live and work in autocratic organizational cultures, to have no solution. This gives us food for thought. Could the arguments and questions in this book provoke thoughts that are, using Smith's expression, uncomfortable enough to move us to act in a different way in real life? 


\section{NOTES AND SOURCES FOR PART III}

Chapter 13. Research Method and Data Collection (Pages 219-226)

Ethnography defined: Creswell, pp. 58-61, 181-186;

Grounded theory defined: Creswell, pp. 55-58, 178-181.

Phenomenology

--defined: Creswell, pp. 51-55, 175-178.

--origins from philosophy: Patton, p. 69.

--reaching understanding from within us: Van Manen, p. 9

Heisenberg principle: Monks [on-line].

Heuristic inquiry: Moustakas $(1990,1994)$

--description: Patton, p. 71.

--purposeful sample: Glesne, pp. 28-30; Patton, p. 169.

--experienced participants required: Patton, p. 171; Creswell, pp. 112-113

--number of participants: Patton, pp. 183-186.

--criterion sampling: Creswell, pp. 118-119; Patton, p. 171.

Mondragon councils: Whyte \& Whyte, pp. 37-41; Morrison (1991), p. 18.

Gaining access: Creswell, pp. 115-117; Glesne, pp. 39-41

Snowball sampling: Creswell, p. 119; Glesne, p. 29; Patton, p. 176.

Sources of data: Creswell, p. 121.

Sharing equally during interactions: Moustakas (1990), pp. 46-47.

Dialogic introspections: Tesch, p. 29.

Dialogue and discussion: Senge, pp. 238-249.

General interview guide and conversational approach: Patton, pp. 280-282.

Self-dialogue in Heuristic Research: Moustakas (1990), p. 16.

No method to analyze phenomenological data; (Gadamer, 1975 and Rorty, 1979, as cited in Van Manen, 1990, pp. 29-30).

Guiding principles: Moustakas (1990), pp 51-52 
Chapter 14. Representation and Analysis of the Data and Context (Pages 229-251)

Narratives seen in many ways: Polkinghorne (1995), p. 7; Merriam, p. 287.

Stories as sources of understanding: Merriam, p. 286.

Stories as lived experience: Ricoeur (1986/1991) cited in Polkinghorne (1988).

Stories representing life events: Polkinghorne (1995), p. 7. A story is a more accessible term than an emplotted narrative.

Narratives used in organizations: Durrance as cited in Merriam, p. 286.

Narratives used in medicine: Bruner, pp. 105-106.

Narratives as meaning-making devices: Merriam, p. 286.

Collaborators telling stories in interviews: Polkinghorne (1988), p. 163.

Language of collaboration: Polkinghorne (1988), p. 164.

Stories have beginnings and endings: Merriam, p. 286.

Plots: Polkinghorne (1995), p. 7.

Narrative analysis: Polkinghorne (1995), pp. 11-16.

Meaning units: Merriam (2002), p. 123; Creswell, p. 150.

Narrative inquiry in a three-dimensional space: past, present and future (continuity); personal and social (interactions) and place (situation). Clandinin \& Connelly, p. 50.

Horizontalization: Creswell, pp. 55, 147.

Rewording texts: Moustakas, p. 51-52; Creswell, p. 150.

Texts about narratives: See section about this subject in Bibliography.

Phenomenological method to analyze texts: Merriam, pp. 124-126.

Group narratives reaching consensus or not: Polkinghorne (1988), p. 166.

Chiquiteo: Whyte and Whyte, p. 34

\section{Chapter 15. Significance of the Study, Documenting Sources, Limitations and}

Delimitations, Trustworthiness (Pages 252-264)

Interpretation is inevitable: Mishler, as cited in Merriam, p. 287.

Socratic dialogue: Turco, pp. 1-3.

Dialogues modeled after movies: Eisner, p. 6, Coles.

Dialogues modeled after movie Mindwalk (1991), directed by Bernt Capra, based on 
Fritjop Capra's The turning point.

Research is studying the world: Eisner, p. 8.

Poetry to represent data: Richardson, p. 41.

Narrative non-fiction: Rubie, p. 7.

Creative non-fiction: Root and Steinberg, p. xxiii

References about narrative non-fiction: See listing in Bibliography section.

Researcher does not own texts: Tripp (1983) as cited in Lather, p. 264.

Trustworthiness

--Being reconceptualized: Lather, p. 270-272; Eisner, p. 7;

--member checking: Creswell, p. 207-208; Glesne, pp. 32, 152; Lincoln \& Guba, p. 314; Patton, p. 468.

--audit trail: Creswell, p. 208; Lincoln \& Guba, p. 319.

--thick descriptions: Creswell, p. 203; Glesne, p. 22; Patton, pp. 375, 430;

--triangulation: Creswell, 202; Glesne, pp 32, 152; Lincoln \& Guba, p. 305; Patton, pp. 187-189, 464-466.

-method of analysis : Creswell, 208; Moustakas, (1990, 1994); Patton, 461; Worthen, as cited in Merriam, p. 124-126.

--prolonged engagement and persistent observation: Creswell, 201; Glesne, pp. 32-33, Lincoln and Guba, as cited in Glesne, p. 151.

--review of texts by collaborators: Lincoln and Guba, p. 305.

Reconceptualizing validity: Lather, p. 270.

"Yes" experience: Kidder (1982) as cited in Lather, p. 271.

Catalytic validity: Brown \& Tandom, 1978; Reason \& Rowan (1981), p. 240 as cited in Lather, p. 272. 


\section{BIBLIOGRAPHY}

This bibliography has three lists. First are reference sources about the topic of study, in addition to sources about narratives tools, and documentation of notes and sources contained in the next two lists. Next are selected reference sources about writing tools to represent research texts data as narratives. Finally, there are reference models to document notes and reference sources as an alternative to showing superscripts and footnotes in the text.

Reference Sources for Texts, Narrative Representation of Data and Notes and Sources

Adams, F. T. \& Hansen, G. B. (1987). Putting democracy to work. A practical guide for starting and managing worker-owned businesses. San Francisco, CA: BerrettKoehler Publishers.

Alvarez de Mon, S. (1998). La empresa humana y competitiva [The human and competitive enterprise]. Bilbao, España: Ediciones Deusto.

Arguelles, J. D. (2002). Literatura hablada. Veinte escritores frente al lector [Spoken literature. Twenty writers face-to-face with the reader]. Monterrey, Mexico: Ediciones Castillo.

Azurmendi, J. (1992). El hombre cooperativo. Pensamiento de Arizmendiarrieta. [The cooperativist. The thought of Arizmendiarrieta]. Aretxabaleta, España: Otalora.

Bass, B. M. (1990). Bass \& Stogdill's handbook of leadership. Theory, research \& managerial applications. (3rd. Edition). New York: The Free Press.

Bennet, H. Z. (1994) (Ed.). Fritjof Capra in conversation with Michael Toms. Lower Lake, CA: Aslan Publishing.

Bennis, W. (2000). Managing the dream. Reflections on leadership and change. Cambridge, MA: Perseus Publishing.

Bennis, W., Parikh, J., \& Lessem, R. (1994). Beyond leadership. Balancing economics, ethics and ecology. Cambridge, MA: Basil Blackwell Ltd.

Behr, P. \& Witt, A. (2002, July 28). Visionary's dream led to risky business. The Washington Post.

Bradley, K., \& Gelb, A. (1983). Cooperation at work. The Mondragón experience. London: Heinemann Educational Books Limited.

Bredhal, Jr. A. \& Drake, S. L. (1990). Hemingway's Green Hills of Africa as evolutionary narrative. New York: The Edwin Meller Press. 
Bruner, J. (2002). Making stories. Law, literature and life. New York: Farrar, Straus and Giroux.

Buber, M. (1996). (Kaufmann, W., Trans.). I and Thou. New York: Touchstone.

Burns, J. M. (1978), Leadership. New York: Harper Torchbooks.

Callus, A. (2004, March 19). Shell's new cut in reserves jars investors, arouses suspicions. Herald Union Tribune. Pp. C1, C4.

Capra, F. (1982). The turning point. Science, society and the rising culture. New York: Bantam Books.

Capra, F. (1996). The web of life. A new scientific understanding of living systems NewYork: Anchor Books.

Capra, F. \& Steindl-Rast, D. (1991). Belonging to the universe. Explorations on the frontiers of science and spirituality. San Francisco, CA: HarperSanFrancisco

Cheney, G. (1995). Democracy in the workplace. Theory and practice from the perspective of communication. Journal of Applied Communications Research, 23, 167200.

Cheney, G. (1999). Values at work. Employee participation meets market pressure at Mondragon. Ithaca, NY: Cornell University Press

Chiarella, T. (1998). Writing Dialogue. How to create memorable voices and fictional conversations that crackle with wit, tension and nuance. Cincinnati, $\mathrm{OH}$ : Story Press.

Chrislip, D. D., \& Larson, C. E. (1994). Collaborative leadership. How citizens and civic leaders can make a difference. San Francisco, CA: Jossey-Bass Publishers.

Clandinin, D. J. \& Connelly, F. M. (2000). Narrative inquiry: experience and story in qualitative research. San Francisco: Jossey-Bass Publishers.

Coles, R. (1998). Doing documentary work. Oxford, England: Oxford

Covey, S. R. (1989). The 7 habits of highly effective people. New York: Fireside.

Creswell, J. W. (1998). Qualitative inquiry and research design. Choosing among five traditions. Thousand Oaks, CA: Sage Publications, Inc. 
Csikszentmihalyi, M. (1990). Flow. The psychology of optimal experience. New York: Harper and Row, Publishers.

Csikszentmihalyi, M. (2003). Good business. Leadership, flow, and the making of meaning. New York: Viking Penguin.

Dead Poets Society (1989). [Film]. Weir, P., Director. (Available in video format)

De Long, B. (1998). Robber barons of a century ago. Robber barons. University of California at Berkeley, and NBER [On-line] Available:

$\mathrm{http} / /$ econ 161.berkeley.edu/Econ_Articles/carnegie/ delong_moscow paper2.html.

De Mello, A. (1990). Awareness: The perils and opportunities of reality. New York: Image Books.

DeVos, R. (1993). Compassionate Capitalism. People helping people help themselves. New York: Plume.

Denzin, N. K. \& Lincoln, Y. S. (2000). The handbook of qualitative research. Thousand Oaks, Calif: Sage Publications.

Dolby, S. (2002, April 22). Work ethics. San Diego Union Tribune, pp. E1, E4.

Eisner, E. W. (1997). The promise and perils of alternative forms of representation. Educational Researcher. Aug-Sept, 4-10.

Franklin, J. (1986). Writing for story. Craft secrets of dramatic non-fiction by a two-time Pulitzer Prize winner. New York: Plume/Penguin.

Freire, P. (1970). Pedagogy of the oppressed. New York: The Continuum Publishing Corporation.

Fukuyama, F. (1999). The great disruption. Human nature and the reconstitution of the social order. New York: The Free Press.

Gardiner, J. J. (1998). Quiet presence: the holy ground of leadership. Insights on leadership. Service, stewardship, spirit and servant-leadership. (Spears, L. Ed.). New York: John Wiley \& Sons, Inc.

Gates, J. R. (1998). The ownership solution: Towards a shared capitalism for the twenty-first century. Reading, MA: Perseus Books.

Glesne, C. (1999). Becoming qualitative researchers. An introduction (2 ${ }^{\text {nd }}$. Ed.) New York: Addison, Wesley, Longman, Inc. 
Greenwood, D. \& González, J. L. (1992). Industrial democracy as process. Participatory action research in the Fagor cooperative group of Mondragón. Maastrich, Netherlands: Van Gorcum.

Gutkind, L. (1997). The art of creative non-fiction. Writing and selling the literature of reality. New York: John Wiley and Sons, Inc. Hutchinson.

Handy, C. (1994). The empty raincoat. Making sense of the future. Great Britain:

Handy, C. (1997). The hungry spirit. London: Arrow Books Limited.

Handy, C. (2004). The stranded self: How business squeezed the meaning out of work. Compass. A Journal of Leadership. Center for Public Leadership. Harvard University, 1(2), 30-33.

Helgesen, S. (1995). The web of inclusion. A new architecture for building great organizations. New York: Doubleday Dell Publishing Group, Inc.

Herrera, D. (2000). What are the Mondragón values, which value is the most significant, and how relevant is this value to the Mondragón experience? Unpublished pilot study. San Diego, CA: University of San Diego.

Herrera, D (2002). Laborem exercens, "traditional organizations" and the Mondragón model. Work as key to the social question. The great social and economic transformations and the subjective dimension of work. Vatican City: Libreria Editrice Vaticana. 235-254.

Herrera, D. (2004). Mondragón: A for-profit organization that embodies Catholic social thought. Review of Business. St John's University, 25(1), 56-68.

Hesselbein, F., Goldsmith, M., \& Beckhard, R. (Eds.). (1997). Organization of the future. San Francisco: Jossey-Bass Publishers.

Hoose, B. (Ed.). (1998), Christian Ethics. An Introduction. Collegeville, MN: The Liturgical Press.

Hospers, J. (1982). Human conduct. Problems of ethics (2 ${ }^{\text {nd }}$ Ed). New York: Harcourt, Brace Jovanovich, Publishers.

Janis, I. L. (1989). Crucial decisions. Leadership in policymaking and crisis management. New York: The Free Press, A Division of Macmillan, Incorporated.

Kasmir, S. (1996). The myth of Mondragón. Cooperatives, politics and working class life in a Basque town. Albany, NY: SUNY Press. 
Keating, T. (1997). Invitation to love. The way of Christian contemplation. New York: The Continuum Publishing Company.

Kilser, L., Milstead, D. \& Smith, J. (2002, August 3). Qwest's rise and fall. Rocky Mountain News.

King, S. (2000). On writing. A memoir of the craft. New York: Scribner.

Kinzer, S. (2003). All the Shah's men. An American coup and the roots of Middle East terror. Hoboken, N. J.: John Wiley \& Sons, Inc.

Kohan, S. A. (1999). Cómo escribir relatos [How to write stories]. Barcelona: Plaza and Janés Editores.

Korten, D. C. (1999). The post-corporate world. Life after capitalism. San Francisco: Berret-Koehler Publishers, Inc.

Kubis, P. \& Howland, B. (1990). The complete guide to writing fiction and nonfiction and getting it published. (2 ${ }^{\text {nd }}$ ed.). Upper Saddle River, N.J: Prentice Hall.

Kushner, H. S. (2001). Living a life that matters. Resolving the conflict between conscience and success. New York: Alfred A. Knopf.

Larrañaga, J. (1998). Interioridades de una utopía. El cooperativismo de Mondragón. [The inside story of utopia. Cooperativism in Mondragón] Mondragón, España: Azatza, S. L.

Larrañaga, J. M. (2000, November). La participación en la empresa cooperativa. [Participation in a cooperative enterprise]. TU Lankide, 451, 36-37.

Larrañaga, J. M. (2001, May). Es tan vulnerable la democracia! [Democracy is so vulnerable!]. TU Lankide, 457, 34-35.

277

Lather, P. (1986). Research as praxis. Harvard Educational Review. 56(3), 257 -

Leonard, D. (2002, August 12). The Adelphia story. Fortune.

Lincoln, Y. S, \& Guba, E. G. (1985). Naturalistic inquiry. Newbury Park, CA: Sage Publications.

Lipman-Blumen, J. (1999). Connective leadership: Leading in a new era. Keynote address in 1999 Annual Meeting of the International Leadership Association of the James MacGregor Burns Academy of Leadership, October 22-24, 1999. 
MacLeod, G. (1997). From Mondragón to America: Experiments in Community Development. Sydney, Nova Scotia: University College of Cape Breton Press.

Marcos, J. (1999, January). Participación congresual [Participation at the congress]. [Editorial]. TU Lankide, 431, 4.

Marcos, J. (1999, January). Los valores corporativos. [Cooperative values]. TU Lankide, 431, 10.

Marcos, J. (2002, January). Participación: necesidad o virtud? [Participation: need or virtue?] [Editorial] TU Lankide, 464, 3.

Marcos, J. (2002, January). Participación: una cuestión de principios. [Participation, a matter of principle]. TU Lankide, 464, 16-17.

Maremont, M. \& Markon, J. (2002, September 13). Former Tyco executives are charged. Wall Street Journal.

Matthews, R. (1999). Jobs of our own. Building a stake-holder society. Alternatives to the market and the state. Sydney, Australia: Pluto Press.

Maslow, A. (1971). The farther reaches of human nature. New York: Penguin

McClam, E. (2003, December 28). A year of white-collar scandals. San Diego Union Tribune. p. G6.

McInerney, P. K. (1992). Introduction to philosophy. New York: HarperCollins Publishers, Inc

Merriam, S. B., and Associates. (2002). Qualitative research in practice. Examples of discussion and analysis. San Francisco: Jossey-Bass Publishers.

Milking lessons. (2004, January 3). The Economist, pp. 45-46.

Mindwalk. (1991). [Film]. Capra, B., Director. (Available in video format).

Mondragón, forty years of co-operative history. Mondragón, España: Lit Danona, S. Coop.

Mondragón Corporación Cooperativa website. www mondragon moces

Monks, R. A. (1998). The Heisenberg principle. Cranfield Business School [online]. Available: RAGM.com web page. 
Morrison, R. (1991). We build the road as we travel. Mondragon, a cooperative social system. Philadelphia: New Society Publishers.

Morrison, R. (1995). Ecological democracy. Boston: South End Press.

Moustakas, C. (1990). Heuristic research. Design, methodology and applications. Newbury Park, CA: Sage Publications.

Moustakas, C. (1994). Phenomenological research methods. Thousand Oaks: Sage Publications, Inc.

Moxley, R. S. (2002). Leadership as partnership. Focus on leadership. Servant leadership for the $21^{\text {st }}$ century. Spears, L. \& Lawrence, M. (Eds.). New York: John Wiley $\&$ Sons, Inc.

Moyers, B. (1993). Healing and the mind. New York: Doubleday.

Ormaechea, J. M. (1986). El hombre que yo conoci [The man I knew]. Mondragón, España: Fundación Gizabidea.

Ormaechea, J. M. (1993). The Mondragón cooperative experience. Mondragón, España: Lit Danona, S. Coop.

Ormaextea, J. M. (1997). Orígenes y claves del cooperativismo de Mondragón. [Origins and clues of Mondragón cooperativism]. Aretxabaleta, Spain: Lit. Danona, S. Coop.

O'Toole, J. (1995). Leading change. The argument for values-based leadership. San Francisco: Josey-Bass, Inc., Publishers.

Ouchi, W. (1981). Theory Z. How American business can meet the Japanese challenge. Reading, Massachusetts: Addison-Wesley Publishing Company.

Parma splat (2004, January 17). The Economist, pp. 59-62.

Patton, M. Q. (1990). Qualitative evaluation and research methods (2 ${ }^{\text {nd }}$ Ed). Newbury Park, CA: Sage Publications.

Peck, M. S. (1993). A world waiting to be born. Civility rediscovered. New York: Bantam Books.

Pérez de Calleja, A. (1989). Arizmendiarrieta, "El hombre de acción." [Arizmendiarrieta. A man of action]. Mondragón, España: Fundación Gizabidea.

Peters, T. J., \& Waterman Jr., R. H. (1982). In search of excellence. Lessons from American best-run companies. New York: Harper \& Row, Publishers. 
Peyser, M., Naughton, K., Tyre, P., Lipper, T., Gegax, T. T., \& Bergtraum, L. (July 1, 2002). The insiders. Newsweek.

Pierce J. L. \& Newstrom, J. W. (1990). Manager's bookshelf. A mosaic of contemporary views ( $2^{\text {nd }} E d$.). New York: HarperCollins Publishers, Inc.

Pilarczyk, D. F. (1999). Bringing forth justice. Basics for just Christians. Cincinnati, OH: St Anthony Messenger Press.

Politica Empresarial de MCC: 2001-2004 [MCC Corporate Policy: 2001-2004] (1999). Mondragón, Spain: Mondragón Corporación Cooperativa.

Polkinghorne, D. (1988). Narrative knowing and the human sciences. Albany, NY: SUNY Press.

Polkinghorne, D. (1995). Narrative configuration in qualitative analysis. Qualitative Studies in Education, 8(1), 5-23.

Potter, G. W. (undated, after 1993). Organized Crime, The CIA and the Savings and Loan Scandal. Eastern Kentucky University [on line] Available: http//www thirdworldtraveler com/CIA/S\&L Scandal CIA html.

Preservar la esencia [Preserving the essence] (2000, July). [Article from Empresa XX magazine]. TU Lankide, 448, 35.

Ramírez de Okariz Tellería, I. (1997). Arrasate, Our Town. Publisher unknown.

Quinn, D. (1999). Beyond civilization. Humanity's next adventure. New York: Three Rivers Press.

Rabiner, S. \& Fortunato, A. (2002). Thinking like your editor. How to write serious nonfiction - and get it published. New York: Norton \& Company, Inc.

Ray, P. H. \& Anderson, S. R. (2000). The cultural creatives. How 50 million people are changing the world. New York: Harmony Books.

Ray, M. \& Rinzler, A. (Eds.) (1993). The new paradigm in business. Emerging strategies for leadership and organizational change. New York: Jeremy P. Tarcher/Putnam.

Reflections: Don José Maria Arizmendiarrieta. (2000). (C. Herrera et al, Trans.). Otalora. Spain: Gráficas Lizarra.

Retegui, J. (1995). El legado de Don José Maria [The legacy of Don José Maria]. Mondragón, España: Fundación Gizabidea. 
Richardson, L. (1993). Poetics, dramatics and transgressive validity: the case of the skipped line. The Sociological Quarterly, 34(4), 695-710.

Riessman, C. K. (1993). Narrative analysis. Newburg Park, CA: SAGE Publications, Inc.

Ródenas, M. \& Valls, F. (Eds.) (1998). Los cuentos que cuentan [Tales people tell]. Barcelona, Spain: Editorial Anagrama. 2004 .

Rohr, R. (2004). Religious Education Congress, Anaheim, CA, February 13-15,

Root, Jr., R. \& Steinberg, M. (1999). The fourth genre. Contemporary writers of/on creative non-fiction. Needham Heights, MA: Allyn \& Bacon.

Rost, J. C. (1991). Leadership for the twenty-first century. Westport, Connecticut: Praeger Publishers.

Rubie, P. (2003). Telling the story. How to write and sell narrative nonfiction. New York: Harper Collins.

Rubio, J. M. (1990). Don José Maria Arizmendiarrieta, una presencia estimulante [Don José María Arizmendiarrieta. A stimulating presence]. Mondragón, España: Fundación Gizabidea.

Saratxaga, K. (2002, January). La empresa participativa. [The participative enterprise]. TU Lankide, 464, 18-19.

Schein, E. H. (1999). The corporate culture survival guide. Sense and nonsense about cultural change. San Francisco: Jossey-Bass Publishers.

Schumacher, E. F. (1973). Small is beautiful. Economics as if people mattered. New York: Harper \& Row Publishers.

Senge, P. M. (1990). The fifth discipline. The art \& practice of the learning organization. New York: Doubleday.

Senge, P. M. (1995). Robert Greenleaf's legacy: A new foundation for twentyfirst century institutions. Reflections on leadership. How Robert $K$. Greenleaf's theory of servant-leadership influenced today's top management thinkers. (Spears, L. C., Ed.) New York: John Wiley \& Sons, Inc. Journal.

Staples, D. (2002, July 28). A telecom prophet's fall from grace. Edmonton 
Stein, S. (1995). Stein on writing. A master editor of some of the most successful writers of our century shares his craft techniques and strategies. New York: St. Martin's Griffin.

Sternberg, E. (2000). Just business. Business ethics in action. Oxford, Great Britain: Oxford University Press.

Stewart, J. B. (1991). Den of thieves. New York: Simon \& Schuster.

Stewart, J. B. (1998). Follow the story. How to write successful non-fiction. New York: Touchstone.

Sorowiecki, J. (Ed.). (2002). Best business crime. New York: Anchor Books.

Tesch, R. (1984). Phenomenological studies: A critical analysis of their nature and procedures. Paper presented at the AERA Annual Meeting, New

Orleans, LA.

Turco, L. (1989). Dialogue. A Socratic dialogue on the art of writing dialogue in fiction. Cincinnati, OH: Writer's Digest Books.

Van Manen, M. (1990). Researching lived experience. Human science for an action sensitive pedagogy. Ontario, Canada: The State University of New York.

Vázquez, A. (1998). El modelo vasco de transformación empresarial. Retando al futuro [The Basque model of organizational transformation. Challenging the future]. Bilbao, España: Hobest.

Webster's encyclopedic unabridged dictionary of the English language. (1996). New York: Gramercy Books.

Webster's New World Thesaurus. (1974). New York: Warner Books.

Whyte, W. F., Greenwood, Davydd J. \& Lazes, Peter (1989). Participatory Action Research. American Behavioral Scientist, 32 (5), 513-551.

Whyte, W. F. \& Whyte, K. K (1991). Making Mondragón. The growth and dynamics of the worker cooperative complex. Ithaca, New York: ILR Press.

Wood, M. (1995). Elements of Fiction Writing. Description. Cincinnati, OH: Writer's Digest Books.

Wortman, C. B \& Loftus, E. F. (1992). Psychology $\left(4^{\text {th }} E d\right.$.). New York: McGraw-Hill, Inc. 


\section{Reference Sources for Representation of Data as Narratives}

This book contains research data from interviews, context and outcomes represented as narratives. The following sources are selected from the Reference Sources list above as an aid to design and write a narrative methodology.

Narrative Analysis and Style

This book is written as a series of stories based on the analysis of the research data. The following are sources I consulted about narrative analysis and representation.

Bredhal, Jr. A. \& Drake, S. L. (1990). Hemingway's Green Hills of Africa as evolutionary narrative. New York: The Edwin Meller Press.

Clandinin, D. J. \& Connelly, F. M. (2000). Narrative inquiry. Experience and story in qualitative research. San Francisco: Jossey-Bass Publishers.

Polkinghorne, D. (1988). Narrative knowing and the human sciences. Albany, NY: SUNY Press.

Polkinghorne, D. (1995). Narrative configuration in qualitative analysis. Qualitative Studies in Education, 8(1), 5-23

Ródenas, M. \& Valls, F. (Eds.) (1998). Los cuentos que cuentan [Tales people tell]. Barcelona, Spain: Editorial Anagrama.

Riessman, C. K. (1993). Narrative analysis. Newburg Park, CA: SAGE Publications, Inc.

\section{Narrative non-fiction}

This text is written as "narrative non-fiction," utilizing tools from non-fiction authors to write about facts. The following are the references I used to construct the narratives in this book.

Bruner, J. (2002). Making stories. Law, literature and life. New' York: Farrar, Straus and Giroux.

Coles, R. (1998). Doing documentary work. Oxford, England: Oxford

Franklin, J. (1986). Writing for story. Craft secrets of dramatic non-fiction by a two-time Pulitzer Prize winner. New York: Plume/Penguin.

Gutkind, L. (1997). The art of creative non-fiction. Writing and selling the literature of reality. New York: John Wiley and Sons, Inc.

King, S. (2000). On writing. A memoir of the craft. New York: Scribner. 
Kohan, S. A. (1999). Cómo escribir relatos [How to write stories]. Barcelona: Plaza and Janés Editores.

Kubis, P. \& Howland, B. (1990). The complete guide to writing fiction and nonfiction and getting it published. (2 ${ }^{\text {nd }}$ ed.). Upper Saddle River, N.J: Prentice Hall.

Rabiner, S. \& Fortunato, A. (2002). Thinking like your editor. How to write serious nonfiction and get it published. New York: Norton \& Company, Inc.

Root, Jr., R. \& Steinberg, M. (1999). The fourth genre. Contemporary writers of/on creative non-fiction. Needham Heights, MA: Allyn \& Bacon.

Rubie, P. (2003). Telling the story. How to write and sell narrative nonfiction. New York: Harper Collins.

Stewart, J. B. (1998). Follow the story. How to write successful non-fiction. New York: Touchstone.

Wood, M. (1995). Elements of Fiction Writing. Description. Cincinnati, OH: Writer's Digest Books.

\section{Dialogues}

Dialogues in English, including translated texts from the original interviews in Spanish, are an important part of this book. I used them in interactive interviews, group conversations, outcomes and the explanation of the research design and methodology. Models for these dialogues were taken from the following reference sources:

Arguelles, J. D. (2002). Literatura hablada. Veinte escritores frente al lector [Spoken literature. Twenty writers face-to-face with the reader]. Monterrey, Mexico: Ediciones Castillo.

Capra, F. \& Steindl-Rast, D. (1991). Belonging to the universe. Explorations on the frontiers of science and spirituality. San Francisco, CA: HarperSanFrancisco.

Chiarella, T. (1998). Writing Dialogue. How to create memorable voices and fictional conversations that crackle with wit, tension and nuance. Cincinnati, OH: Story Press.

Mindwalk. (1991). [Film]. Capra, B., Director. (Available in video format).

Moyers, B. (1993). Healing and the mind. New York: Doubleday.

Turco, L. (1989). Dialogue. A Socratic dialogue on the art of writing dialogue in fiction. Cincinnati, OH: Writer's Digest Books. 


\section{Reference Models to List Notes and Sources}

The method I used to reference sources is based on the following:

Csikszentmihalyi, M. (1990). Flow. The psychology of optimal experience. New York: Harper and Row, Publishers (241-280).

Kinzer, S. (2003). All the Shah's men. An American coup and the roots of Middle East terror. Hoboken, N. J.: John Wiley \& Sons, Inc. (229-243).

Stewart, J. B. (1991). Den of thieves. New York: Simon \& Schuster (537-561). 


\section{APPENDICES}

\section{Appendix I: Sample Consent Form}

David Herrera is conducting a case analysis at the Mondragón Corporación Cooperativa (MCC) in partial fulfillment for the Degree of Doctor of Education from the University of San Diego. Previous research studies have described MCC's organizational structures and systems that facilitate participation. The purpose of this study is to complement this knowledge by focusing on the personal aspect of participation through the exploration of the significance that the experience of participating in decision making has for $\mathrm{MCC}$ worker-owners.

As a respondent in this study, I understand that I will participate in one individual interview that will last no longer than 60 minutes. There will be a follow-up inquiry that will take no more than 30 minutes. This follow up may be handled through a second interview, an e-mail message, or a telephone conversation. My participation in this study is entirely voluntary and I understand I may refuse to participate or withdraw at any time without penalty. There are no expenses that I must incur associated with this study.

I understand that these interviews will be audio taped and transcribed for analysis and that my identity will remain confidential. I also understand that I will review the narrative describing the contents of my interview and that if I wish I may also review the audio tape, the transcription, or the final report.

There are no other agreements, written or verbal, related to this study beyond that expressed in this consent form. David Herrera has explained the research project to me and answered my questions. I understand that if I have further questions I may contact David Herrera at any time at (858) 453-8662 or by e-mail at davidherrera@softhome.net. I may also contact the dissertation committee chair, Dr. Paula Cordeiro at (619) 260-4282 or by e-mail at cordeiro@sandiego.edu.

I, the undersigned, understand the above explanations, and, on that basis, consent to the voluntary participation in the research.

Signature of Participant

Signature of Researcher
Date and Location

Date and Location 
Appendix II: Sample Questionnaire for Interviews

1. How have you participated in decision making?

2. Can you describe a vivid experience of participation that was meaningful to you?

3. What feelings and thoughts are elicited by your experience of participation?

4. When and how did you learn to participate?

5. How do you remember that learning experience?

6. Did you participate in decision making before you started to work at the MCC cooperatives? Within your family environment? At school? In previous jobs?

7. Have you experienced your participation in different ways throughout your career?

8. How did you experience your participation 10 or 15 years ago and how do you experience it now?

9. If your experience of participating has evolved, is it due to having matured as a person or to having grown in your way of participating?

10. Can you tune into how you feel when you participate now? Can you describe it?

11. What influences your experience: your personal preference or the organization's? Do you participate because you want to or because you feel you have to?

12. Does your experience of participation extend to the rest of your life? In what aspects and how?

13. What else would you like to add about your experience of participation? 